Uma abordagem multinível para a obtenção de Alinhamento Estratégico no Gerenciamento de Processos de Negócio

Felipe Diniz Dallilo 

SERVIÇO DE PÓS-GRADUAÇÃO DO ICMC-USP

Data de Depósito:

Assinatura:

\title{
Uma abordagem para a obtenção de Alinhamento Estratégico no Gerenciamento de Processos de Negócio
}

\author{
Felipe Diniz Dallilo
}

Orientador: Prof. Dr. João Porto de Albuquerque Pereira

Dissertação apresentada ao Instituto de Ciências Matemáticas e de Computação - ICMC-USP, como parte dos requisitos para obtenção do título de Mestre em Ciências - Ciências de Computação e Matemática Computacional. VERSÃO REVISADA

USP - São Carlos

Junho / 2014 
Ficha catalográfica elaborada pela Biblioteca Prof. Achille Bassi e Seção Técnica de Informática, ICMC/USP, com os dados fornecidos pelo(a) autor(a)

\begin{tabular}{|c|c|}
\hline \multirow[t]{3}{*}{ D147a } & $\begin{array}{l}\text { Dallilo, Felipe } \\
\text { Uma abordagem multinível para obtenção de } \\
\text { Alinhamento Estratégico no Gerenciamento de } \\
\text { Processos de Negócio/ Felipe Dallilo; orientador } \\
\text { João Albuquerque. -- São Carlos, } 2014 \text {. } \\
\quad 161 \text { p. }\end{array}$ \\
\hline & $\begin{array}{l}\text { Tese (Doutorado - Programa de Pós-Graduação em } \\
\text { Matemática) -- Instituto de Ciências Matemáticas e } \\
\text { de Computação, Universidade de São Paulo, } 2014 .\end{array}$ \\
\hline & $\begin{array}{l}\text { 1. BPM. 2. Alinhamento Estratégico. } 3 \text {. } \\
\text { Multiníveis. } 4 \text {. BPMN. 5. BMM. I. Albuquerque, João, } \\
\text { orient. II. Título. }\end{array}$ \\
\hline
\end{tabular}




\section{Agradecimentos}

Agradeço primeiramente a Deus por estar sempre comigo, revigorando minhas forças e me ajudando a seguir em frente.

Aos meus pais Jackson e Laide e ao meu irmão Lucas, que durante toda minha vida me iluminaram, incentivaram e ajudaram na realização dos meus objetivos e sonhos. Serei eternamente grato a tudo o que vocês fizeram por mim.

À minha namorada Maisa que esteve presente em todos os momentos alegres e difíceis de nossas vidas, sempre me apoiando com muito amor e companheirismo, não permitindo que eu desista dos meus objetivos e orgulhando-se com as minhas conquistas.

A toda minha família que sempre torceu pelo meu sucesso e pela minha felicidade.

A todos meus amigos que de alguma forma contribuiram na conclusão deste trabalho, em especial, ao meu amigo Adriano Bezerra, prova viva de que a amizade verdadeira não se enfraquece com a distância ao longo dos anos...

Ao meu orientador, o professor Dr. João Porto Albuquerque Pereira, pelo seu empenho, carinho, profissionalismo, ética, paciência e dedicação para comigo durante esses anos nos quais tivemos o prazer de trabalhar juntos.

Por Fim, agradeço ao ICMC-USP pela oportunidade de realização deste trabalho. 

Teoricamente, o Alinhamento Estratégico pode ser obtido com um bom Gerenciamento de Processos de Negócio (BPM na sigla em inglês), porém a relação entre esses temas é, na maioria das vezes, assumida implicitamente e pouco elaborada, tornando-se díficil a visualização e vínculo entre as estratégias e os modelos de processos detalhados, sendo necessário empreender pesquisas na direção de uma união efetiva dos dois temas. O presente trabalho desenvolveu um metamodelo multinível, para ligar os objetivos estratégicos com os processos de negócio da organização através da modelagem de processos de negócio. O trabalho conceitual foi acrescido por uma ferramenta de suporte à modelagem que permite a geração de modelos com base no metamodelo multinível e também a representação dos modelos em diferentes formas de abstração. A abordagem foi aplicada em uma grande multinacional e posteriormente foi conduzida uma avaliação experimental no qual foram realizadas entrevistas com funcionários de diferentes níveis hierárquicos para validar a eficiência e eficácia do trabalho desenvolvido. Como resultado foi possível constatar não apenas a efetividade em alcançar os objetivos propostos como também a facilidade na utilização e compreensão da abordagem em níveis devido a simplicidade na representação dos elementos e seus possíveis relacionamentos. 

Theoretically, the Strategic Alignment can be accomplished with a good Business Process Management, but the relationship between these themes is, most often, implicitly assumed and little developed, making it difficult to visualize and link between the strategies and the models of detailed processes, being necessary to undertake research towards an effective union of the two themes. This study developed a multilevel metamodel for connecting strategic objectives with organizational business processes through modeling of business processes. The conceptual work was increased by a support tool for modeling that allows the generation of models based on multilevel metamodel and also the representation of models in different forms of abstraction. The approach was applied in a large multinational and was subsequently conducted an experimental evaluation in which interviews with employees from different hierarchical levels were performed to validate the efficiency and effectiveness of their work. As a result it was possible to not only the effectiveness in achieving the proposed objectives as well as the ease of use and understanding of the tiered approach because of the simplicity in the representation of the elements and their possible relationships. 

1 Introdução 1

1.1 Objetivos do Trabalho . . . . . . . . . . . . . . . . . . . . 3

1.2 Organização da Dissertação . . . . . . . . . . . . . . . . . . . . . 3

2 Gerenciamento de Processos de Negócio 5

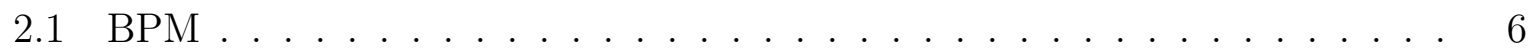

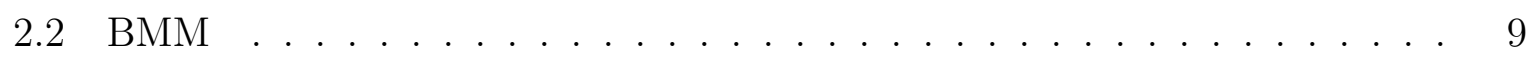

2.2 .1 Fins . . . . . . . . . . . . . . . . . . . . 9

2.2 .2 Meios . . . . . . . . . . . . . . . . . . 10

2.2 .3 Influenciadores . . . . . . . . . . . . . . . . . 11

2.2 .4 Avaliações . . . . . . . . . . . . . . . . . . . . . . . 11

2.2.5 Vocabulário de Negócio . . . . . . . . . . . . . . . . . . . 12

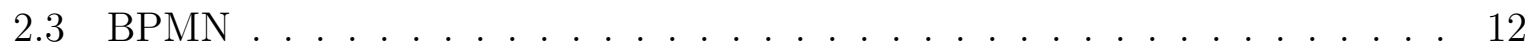

2.3.1 Tipos de Modelagem . . . . . . . . . . . . . . . . 13

2.3.2 Elementos principais . . . . . . . . . . . . . . . . 13

2.3.3 Objetos de Fluxo . . . . . . . . . . . . . . . . . . . 13

2.3.4 Objetos de Conexão . . . . . . . . . . . . . . . . 15

2.3.5 Partições . . . . . . . . . . . . . . . . . . . 15

2.3.6 Artefatos ........................ 16

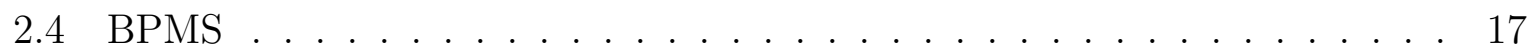

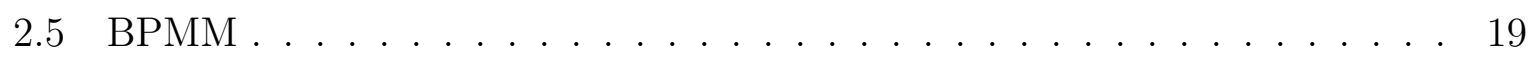

2.6 Ferramentas . . . . . . . . . . . . . . . . . . . . 21

2.6.1 JBPM . . . . . . . . . . . . . . . . . . 22

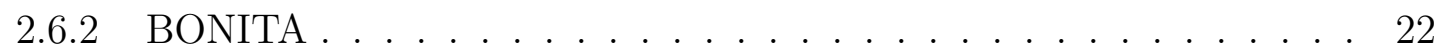

2.6 .3 INTALIO . . . . . . . . . . . . . . . . . . . . . . . . . . . . . . . . . . . 23

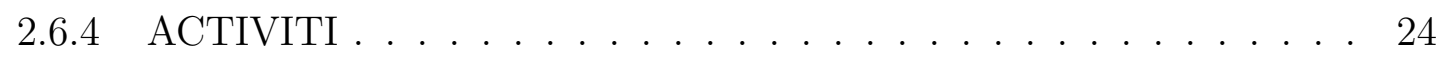

2.7 Considerações Finais . . . . . . . . . . . . . . . . . . . . . . . . 24

3 Alinhamento Estratégico $\quad 27$

3.1 Fundamentos para definição de Estratégias . . . . . . . . . . . . 28

3.2 O Alinhamento Estratégico . . . . . . . . . . . . . . . . . . . . 29

3.2.1 Modelo Henderson e Venkatraman . . . . . . . . . . . . . . . . 29

3.2 .2 Modelo Luftman, Lewis e Odalch . . . . . . . . . . . . . . . 32 
3.3 O Alinhamento Estratégico nos diferentes níveis hierárquicos . . . . . . . . 33

3.4 Abordagens e Ferramentas Multiníveis . . . . . . . . . . . . . 35

3.4 .1 Pensamento em Níveis . . . . . . . . . . . . . . . . . . . . . 35

3.4 .2 Multiníveis e Múltiplas Perspectivas . . . . . . . . . . . . . . . 36

3.4 .3 Aris . . . . . . . . . . . . . . . . 37

3.4 ArchiMate . . . . . . . . . . . . . . . . 38

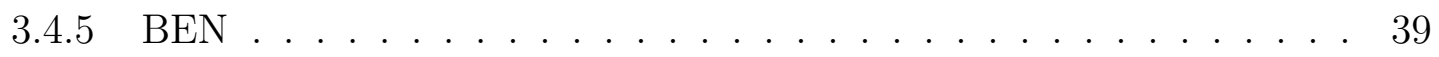

3.5 Comparação entre Trabalhos . . . . . . . . . . . . . . . . . . . . . . . . . . . . . .

3.6 Considerações Finais . . . . . . . . . . . . . . . . . . . . . . . . . . . 42

4 Metamodelo $\quad 45$

4.1 Metamodelo . . . . . . . . . . . . . . . . . . 46

4.2 Primeira Camada . . . . . . . . . . . . . . . . . . 50

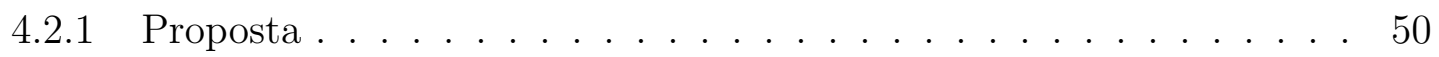

4.3 Segunda Camada . . . . . . . . . . . . . . . . . . . . 52

4.3 .1 Proposta . . . . . . . . . . . . . . . 52

4.4 Terceira Camada . . . . . . . . . . . . . . . . . . 53

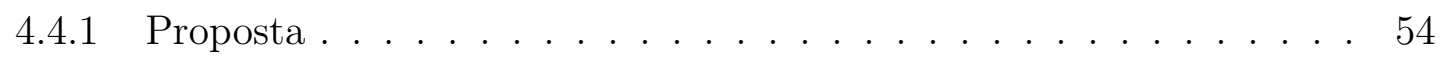

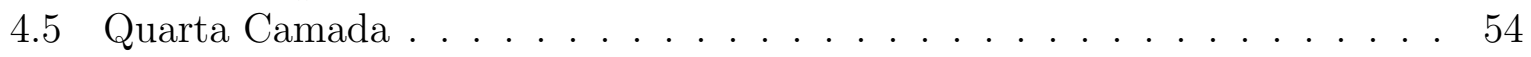

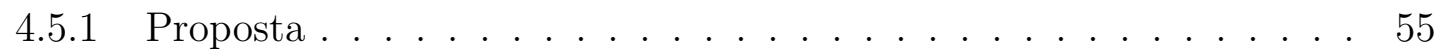

4.6 Prova de Conceito . . . . . . . . . . . . . . . . . . . 55

4.6 .1 Primeiro Nível . . . . . . . . . . . . . . . . . . . 57

4.6 .2 Segundo Nível . . . . . . . . . . . . . . . . . . . . . . . . . . . . . . . . . . . . . . . . . 58

4.6 .3 Terceiro Nível . . . . . . . . . . . . . . . . . . . . . . . . . 59

4.6 .4 Quarto Nível . . . . . . . . . . . . . . . . . . 60

4.7 Comparação entre Abordagens . . . . . . . . . . . . . . . . . 61

4.8 Conclusão . . . . . . . . . . . . . . . . . . . . . . . . . . 63

$\begin{array}{lll}5 & \text { Ferramenta } & 67\end{array}$

5.1 Processo . . . . . . . . . . . . . . . . . . 67

5.1 Prototipagem da abordagem . . . . . . . . . . . . . . 68

5.1 .2 Iterações da abordagem . . . . . . . . . . . . . . . . . . . 69

5.2 Tecnologia . . . . . . . . . . . . . . . . . . . . . . . 69

5.2 .1 GWT ............................. 70

5.2 .2 Hibernate . . . . . . . . . . . . . . . . . . 71

5.3 Ferramenta . . . . . . . . . . . . . . . . . . . . . . . . . . . . . . . . . .

5.3.1 Modelagem em níveis . . . . . . . . . . . . . . . . . 72

5.3.1.1 Primeiro Nível . . . . . . . . . . . . . . . . . . . . . 73

5.3 .1 .2 Segundo Nível . . . . . . . . . . . . . . . . . . . 75

5.3 .1 .3 Terceiro Nível . . . . . . . . . . . . . . . . . . . . . 77

5.3 .1 .4 Quarto Nível . . . . . . . . . . . . . . . . . 79

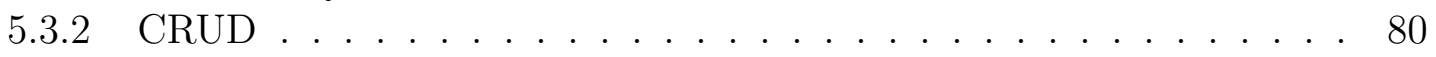

5.3 .2 .1 Cadastrar . . . . . . . . . . . . . . . . . 81

5.3 .2 .2 Abrir ...................... 81

5.3 .2 .3 Excluir . . . . . . . . . . . . . . . . . . . . 82

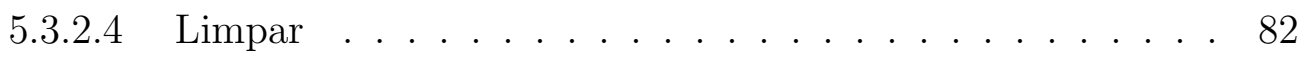

5.4 Desafios de Implementação . . . . . . . . . . . . . . . . . . . . . . . . 82 
5.4 Tecnologia Web . . . . . . . . . . . . . . . . 82

5.4 .2 Arrastar e Soltar . . . . . . . . . . . . . . . . . 83

5.4 .3 Ligação entre elementos . . . . . . . . . . . . . . . . . . . . . 83

5.4 .4 Representação de Fluxo . . . . . . . . . . . . . . . . . . . . 84

5.4.5 GWT e Hibernate .................... . . 84

5.5 Conclusão . . . . . . . . . . . . . . . . . . . . 85

6 Experimento $\quad 87$

6.1 Definição . . . . . . . . . . . . . . . . . . 87

6.1 .1 Objeto de estudo . . . . . . . . . . . . . . . 87

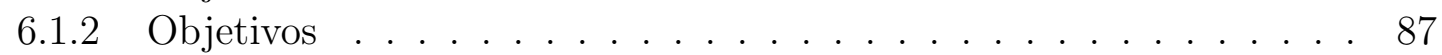

6.1 .3 Foco quantitativo . . . . . . . . . . . . . . . . . 88

6.1 .4 Foco qualitativo . . . . . . . . . . . . . . . . . . . 88

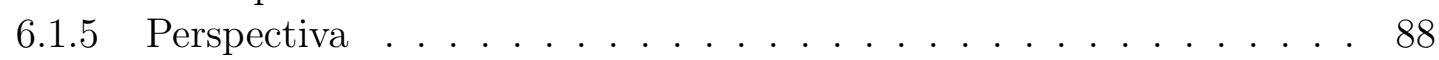

6.1.6 Contexto . . . . . . . . . . . . . . . . . 88

6.2 Planejamento . . . . . . . . . . . . . . . . . . . . . 88

6.2 .1 Definição das Hipoteses . . . . . . . . . . . . . . . . . . . . . . . . 88

6.2 .2 Objetos de Estudo . . . . . . . . . . . . . . . . . . . . . . . 89

6.2 .3 Seleção de Contexto . . . . . . . . . . . . . . . . . . . . . 90

6.2 .4 Projeto do Experimento . . . . . . . . . . . . . . . . . . 90

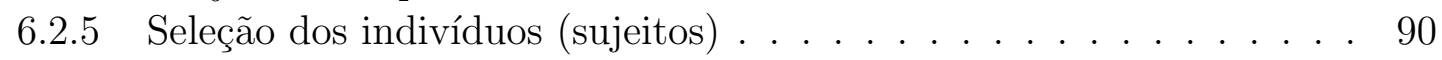

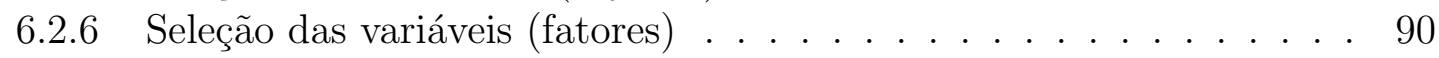

6.2.7 Descrição da instrumentação . . . . . . . . . . . . . . . . . . . . . . . 91

6.2.8 Avaliação da validade . . . . . . . . . . . . . . . . . . . . . . . . 91

6.3 Operação do experimento . . . . . . . . . . . . . . . . . . . 93

6.3.1 Análise e interpretação dos resultados . . . . . . . . . . . . . . . 94

6.3.1.1 Análise e interpretação dos resultados primários ... . 94

6.3.1.2 Análise e interpretação dos resultados secundários ... 94

6.4 Execução . . . . . . . . . . . . . . . . . . . . . . 95

6.5 Análise . . . . . . . . . . . . . . . . . . . . . 95

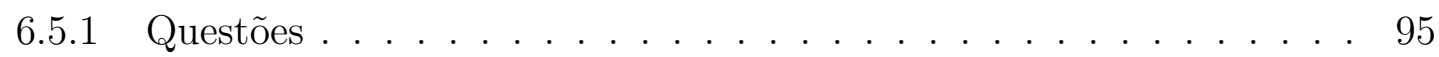

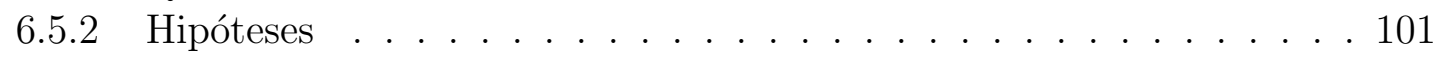

6.6 Conclusão . . . . . . . . . . . . . . . . . . . . . . . . . . 103

7 Conclusão 105

7.1 Sumário dos resultados obtidos . . . . . . . . . . . . . . . . 105

7.2 Contribuições desta dissertação de Mestrado . . . . . . . . . . . . . . . . 106

7.3 Trabalhos Futuros . . . . . . . . . . . . . . 106

$\begin{array}{ll}\text { Referências Bibliográficas } & 116\end{array}$

$\begin{array}{lr}\text { A Revisão Sistemática } & 117\end{array}$

A.1 Sobre à Revisão Sistemática . . . . . . . . . . . . . . . . . . . . 117

A.2 Elaboração da Revisão Sistemática . . . . . . . . . . . . . . . . . . 118

A.3 Planejamento . . . . . . . . . . . . . . . . . . . . 118

A.3.1 Objetivo da RS. . . . . . . . . . . . . . . . 118

A.3.2 Questão de Pesquisa . . . . . . . . . . . . . . 118 
A.3.3 Estratégia de Busca . . . . . . . . . . . . . . . . . . . . . . 119

A.3.4 Critério de Seleção dos Estudos . . . . . . . . . . . . . . . . . . 120

A.3.5 Definição do tipo dos estudos . . . . . . . . . . . . . . . . . . . 121

A.3.6 Procedimentos para seleção dos estudos primários . . . . . . . . . . 121

A.4 Condução da Revisão Sistemática . . . . . . . . . . . . . . . . . . . . . . 122

A.4.1 Buscas realizadas . . . . . . . . . . . . . . . . . . . . 122

A.4.2 Seleção inicial dos estudos primários . . . . . . . . . . . . . . 123

A.4.3 Trabalhos indicados pelos especialistas . . . . . . . . . . . . . 124

A.5 Resultados . . . . . . . . . . . . . . . . . . . . 125

A.6 Conclusão . . . . . . . . . . . . . . . . . . . . . . . . 128

$\begin{array}{lr}\text { B Entrevistas } & 129\end{array}$

B.1 Perguntas . . . . . . . . . . . . . . . . . . . . . . 129

B.2 Respostas . . . . . . . . . . . . . . . . . 131

B.2.1 Participante $1 \ldots \ldots \ldots \ldots \ldots \ldots$

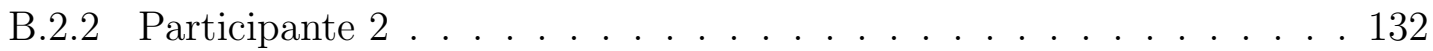

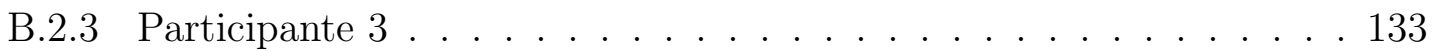

B.2.4 Participante $4 \ldots \ldots \ldots \ldots$. . . . . . . . . . . . . . . . 134

B.2.5 Participante 5 . . . . . . . . . . . . . . . . . 135

B.2.6 Participante $6 \ldots \ldots \ldots \ldots$. . . . . . . . . . . . . . . . . . . . . . . . . . . . . . . 136

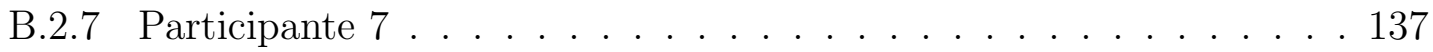

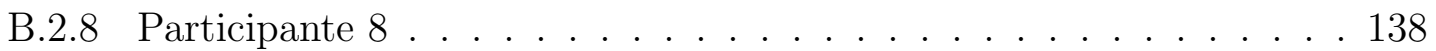

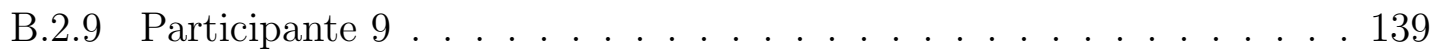

B.2.10 Participante $10 \ldots \ldots$. . . . . . . . . . . . . . . . . . . . . . . . . . . . . . . . . . . .

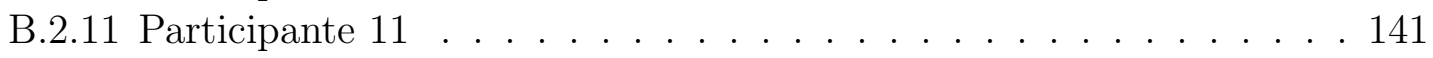

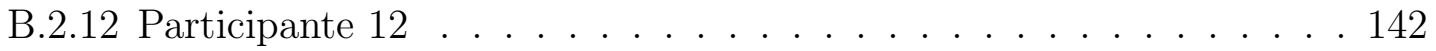

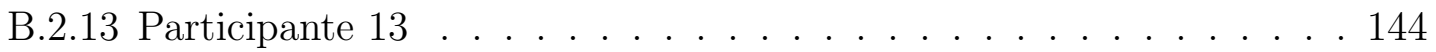

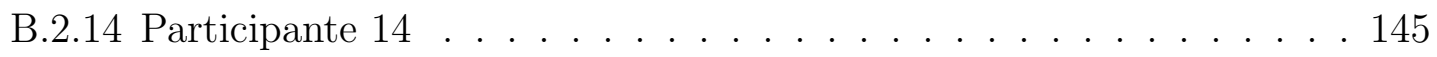

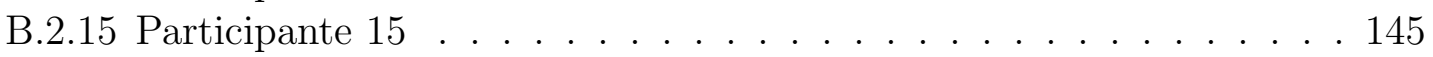

B.2.16 Participante $16 \ldots \ldots \ldots$. . . . . . . . . . . . . . . . . . . . . . . . . . . . . . . . . . . .

B.2.17 Participante 17 . . . . . . . . . . . . . . . . . . . . . . . 147

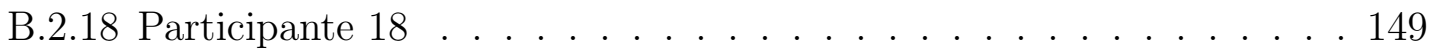

C Modelagem e Codificação 151

C.1 UML . . . . . . . . . . . . . . . . . . . . . . . . . . . . . . 151

C.1.1 Caso de Uso . . . . . . . . . . . . . . . . . . . . . . . . . 151

C.1.2 Diagramas de Classes . . . . . . . . . . . . . . . . . . . . . 152

C.1.3 Diagrama de Sequência . . . . . . . . . . . . . . . . . . . . 154

C.2 DER . . . . . . . . . . . . . . . . . . . . . . . 156

C.3 Codificação . . . . . . . . . . . . . . . . . . . . 157 
2.1 Processos em uma Organização . . . . . . . . . . . . . . . . . . 6

2.2 Fins $(\mathrm{OMG}, 2010) \ldots \ldots \ldots \ldots$

$2.3 \operatorname{Meios}(\mathrm{OMG}, 2010) \ldots \ldots \ldots \ldots \ldots \ldots$

2.4 Avaliação(OMG, 2010) . . . . . . . . . . . . . . . . . . . 12

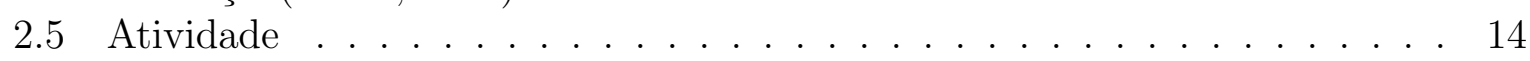

2.6 Evento . . . . . . . . . . . . . . . . . . . . . . 14

2.7 Gateway . . . . . . . . . . . . . . . . . . . . . . 14

2.8 Associação . . . . . . . . . . . . . . . . . . . . . . . . . . . 15

2.9 Fluxo de Sequência . . . . . . . . . . . . . . . . . . . . 15

2.10 Fluxo de Mensagem . . . . . . . . . . . . . . . . . . . . . . . . . . . . . . . . . . 15

2.11 Piscina e Raia . . . . . . . . . . . . . . . . . . . . . . . . . . 16

2.12 Grupo . . . . . . . . . . . . . . . . . . . . 17

2.13 Anotação . . . . . . . . . . . . . . . . . . . . 17

2.14 Objeto de Dados . . . . . . . . . . . . . . . . . . . 17

2.15 BPD . . . . . . . . . . . . . . . . . . . . 18

2.16 BPMM nível $1 \ldots \ldots \ldots \ldots \ldots$

2.17 BPMM nível $2 \ldots \ldots \ldots \ldots$. . . . . . . . . . . . . . . . . . . 20

2.18 BPMM nível $3 \ldots \ldots \ldots \ldots \ldots$

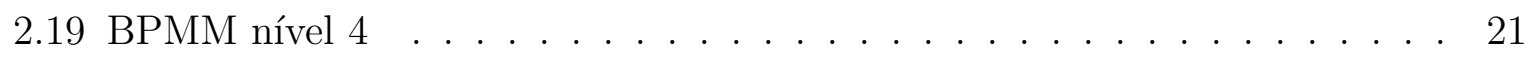

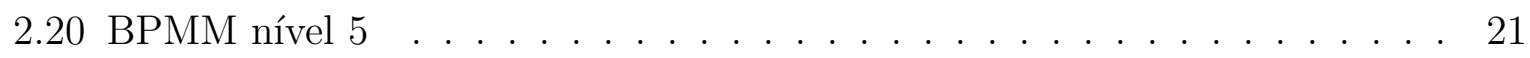

2.21 Representação da Ferramenta JBPM . . . . . . . . . . . . . . . . . . . . . 22

2.22 Representação da Ferramenta Bonita Studio . . . . . . . . . . . . . . . . 23

2.23 Representação da Ferramenta Intalio . . . . . . . . . . . . . . . . . . . . . . . 24

2.24 Representação da Ferramenta Activiti . . . . . . . . . . . . . . . . . 25

3.1 Representação do conceito proposto Henderson e Venkatraman(2003) . . . 31

3.2 Representação do conceito proposto $\operatorname{Luftman}(1993)$. . . . . . . . . . . . . 33

3.3 Representação dos níveis organizacionais(adaptado de Laudon e Laudon, 2007) . . . . . . . . . . . . . . . . . . . . 34

3.4 Representação da Pirâmide baseada no framework multicamadas (Lind e Seigerroth, 2010a) . . . . . . . . . . . . . . . 36

3.5 Framework de Nuffel e Backer (Nuffel e Backer, 2012) . . . . . . . . . . . . 36

3.6 Modelagem EPC na ferramenta Aris $($ Scheer, 2000) . . . . . . . . . . . 37 
3.7 Framework ArchiMate (TheOpenGroup, 2008) . . . . . . . . . . . . . 39

3.8 BEN (Winter, 2011) . . . . . . . . . . . . . . . . . . . . . . 40

4.1 Representação da abordagem . . . . . . . . . . . . . . . . . . . . . . . . . . . . . . . . 47

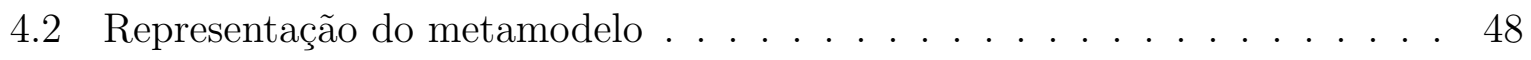

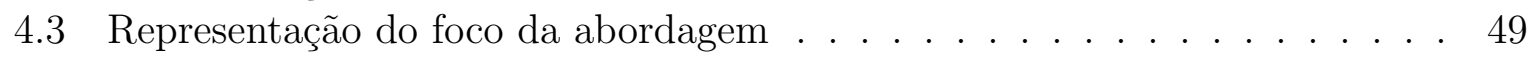

4.4 Representação da primeira camada da abordagem. . . . . . . . . . . . . . . 51

4.5 Representação da primeira camada da abordagem sobre perspectiva de co-

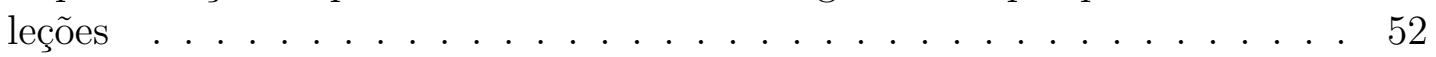

4.6 Exemplo da segunda camada da abordagem . . . . . . . . . . . . . . 53

4.7 Representação da terceira camada da abordagem . . . . . . . . . . . . . 54

4.8 Representação da quarta camada da abordagem . . . . . . . . . . . . . . 55

4.9 Exemplo de modelo na primeira camada da abordagem . . . . . . . . . . 57

4.10 Representação dos Macro Processos e Processos Variantes no primeiro nível

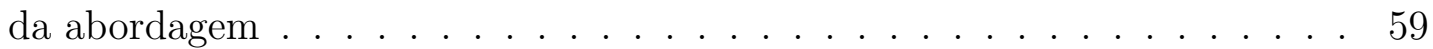

4.11 Representação das Coleções . . . . . . . . . . . . . . . . . . . . . . 59

4.12 Representação da terceira camada da abordagem . . . . . . . . . . . . . . . 60

4.13 Representação da quarta camada da abordagem . . . . . . . . . . . . . . . . 61

4.14 Processo de Suporte ao Call Center . . . . . . . . . . . . . . . . 64

4.15 Processo de desenvolvimento de script . . . . . . . . . . . . . . 65

4.16 Representação da segunda camada da abordagem . . . . . . . . . . . . 66

5.1 Ciclo de vida da Prototipagem (Pressman, 2006) . . . . . . . . . . 68

5.2 Tela Inicial da Ferramenta . . . . . . . . . . . . . . . . . . . . . 73

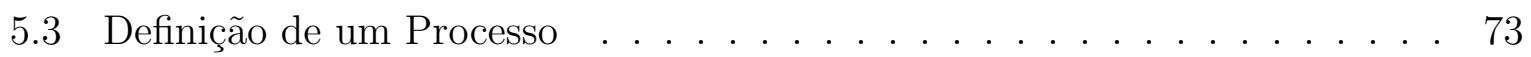

5.4 Definição de um Processo . . . . . . . . . . . . . . . . . . . . . . . . . . . . . . . . . . . . . . . .

5.5 Perspectiva de Coleções . . . . . . . . . . . . . . . . . . . 75

5.6 Segundo Nível . . . . . . . . . . . . . . . . . . . . . . . . . . . . . 76

5.7 Modelagem do Segundo Nível . . . . . . . . . . . . . . . . . . . 77

5.8 Fluxo do Processo no Segundo Nível . . . . . . . . . . . . . . . 77

5.9 Terceiro Nível . . . . . . . . . . . . . . . . . . . . . 78

5.10 Modelagem do Terceiro Nível _ . . . . . . . . . . . . . . . . 78

5.11 Fluxo do Subprocesso no Terceiro Nível . . . . . . . . . . . . . . . . . 79

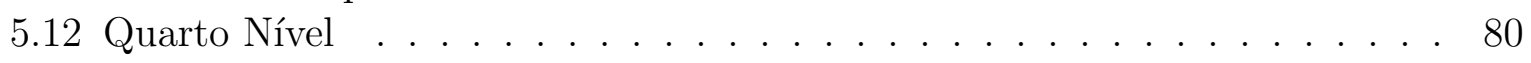

5.13 Fluxo da Atividade no Quarto Nível . . . . . . . . . . . . . . . . . . 80

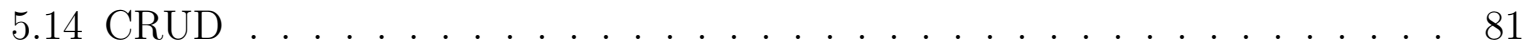

5.15 CRUD . . . . . . . . . . . . . . . . . . . . 81

5.16 Abrir . . . . . . . . . . . . . . . . . . . . . 82

5.17 Excluir . . . . . . . . . . . . . . . . . . . . . . 83

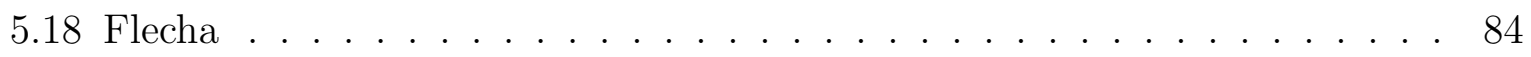

6.1 Formulário de Questões de Experimento . . . . . . . . . . . . . . . . 96

6.2 Tabela de Participantes do Experimento . . . . . . . . . . . . . . . . . . . . . 97

6.3 Respostas Questão $1 \ldots \ldots$. . . . . . . . . . . . . . 97

6.4 Respostas Questão $2 \ldots \ldots$. . . . . . . . . . . . . . . 97

6.5 Respostas Questão $3 \ldots \ldots$. . . . . . . . . . . . . . . . . . . . . . . . . . . . . . . . . 97

6.6 Respostas Questão $4 \ldots \ldots$. . . . . . . . . . . . . . 98 
6.7 Respostas Questão $5 \ldots \ldots$. . . . . . . . . . . . . . . . . . 98

6.8 Todos os BoxPlots . . . . . . . . . . . . . . . . . . . . . . 98

6.9 Média e Mediana das Questões Quantitativas . . . . . . . . . . . . . 99

C.1 Caso de Uso . . . . . . . . . . . . . . . . . . . . . . . . . . 152

C.2 Diagrama de Classe Cliente . . . . . . . . . . . . . . . . . 153

C.3 Diagrama de Classe Servidor . . . . . . . . . . . . . . . . . . . 154

C.4 Diagrama de Sequência - Carregar Diagrama . . . . . . . . . . . . . . . 155

C.5 Diagrama de Sequência - Cadastro . . . . . . . . . . . . . . . 155

C.6 Diagrama de Sequência - Exclusão . . . . . . . . . . . . . . . . . 156

C.7 Diagrama Entidade Relacionamento . . . . . . . . . . . . . . 157

C.8 HTML . . . . . . . . . . . . . . . . . . . . . . . 158

C.9 Empacotamento . . . . . . . . . . . . . . . . . 159

C.10 Fonte Principal . . . . . . . . . . . . . . . . . . . . . 160

C.11 Asynchronous Callback . . . . . . . . . . . . . . . . . . . 160

C.12 Annotation . . . . . . . . . . . . . . . . . . 161 



\section{Lista de Tabelas}

3.1 Comparação entre Trabalhos . . . . . . . . . . . . . . . . . . . . . . 42

4.1 Comparação entre Trabalhos . . . . . . . . . . . . . . . . . . . . . . 62

A.1 Bases Selecionadas . . . . . . . . . . . . . . . . . . . 119

A.2 Trabalhos Duplicados . . . . . . . . . . . . . . . . . . 123

A.3 Trabalhos Selecionados por base . . . . . . . . . . . . . . . . 123

A.4 Trabalhos Selecionados . . . . . . . . . . . . . . . . . . . 124

A.5 Trabalhos Recomendados por Especialistas . . . . . . . . . . . 125 



\title{
Lista de Abreviaturas e Siglas
}

\author{
AE Alinhamento Estratégico \\ ANS Acordo de Nível de Serviço \\ BAM Business Architecture Model \\ BEN Business Engineering Navigator \\ BMM Business Motivation Model \\ BPD Business Process Diagram \\ BPEL Business Process Execution Language \\ BPELWS Business Process Execution Language for Web Services \\ BPM Business Process Management \\ BPMM Business Process Maturity Model \\ BPMN Business Process Modeling Notation \\ BPMS Business Process Management Suite ou System \\ BRG Business Rules Group \\ CMMI Capability Maturity Model Integrated \\ CRUD Create, Read, Update and Delete \\ CSS Cascading Style Sheets \\ DHTML Dynamic HyperText Markup Language \\ DTO Data Transfer Object \\ EPC Event Driven Process Chain \\ GWT Google Web Toolkit \\ HTML HyperText Markup Language \\ JPDL jBPM Process Definition Language \\ JSON Javascript Object Notation \\ KPI Key Performance Indicator \\ LGPL Lesser General Public License \\ MDA Model Driven Architecture \\ OMG Object Management Group \\ ORM Object-Relational Mapping \\ PEN Plano Estratégico de Negócio \\ PETI Plano Estratégico de Tecnologia de Informação \\ RFC Request for Comment \\ RS Revisão Sistemática \\ SAM System Architecture Model \\ SIPOC Suppliers, Inputs, Process, Outputs and Customers \\ SLA Service Level Agreement \\ SOA Service Oriented Architecture \\ SQL Structured Query Language \\ SWOT Strengths, Weaknesses, Opportunities and Threats \\ TI Tecnologia da informação \\ UML Unified Modeling Language \\ XML eXtensible Markup Language
}




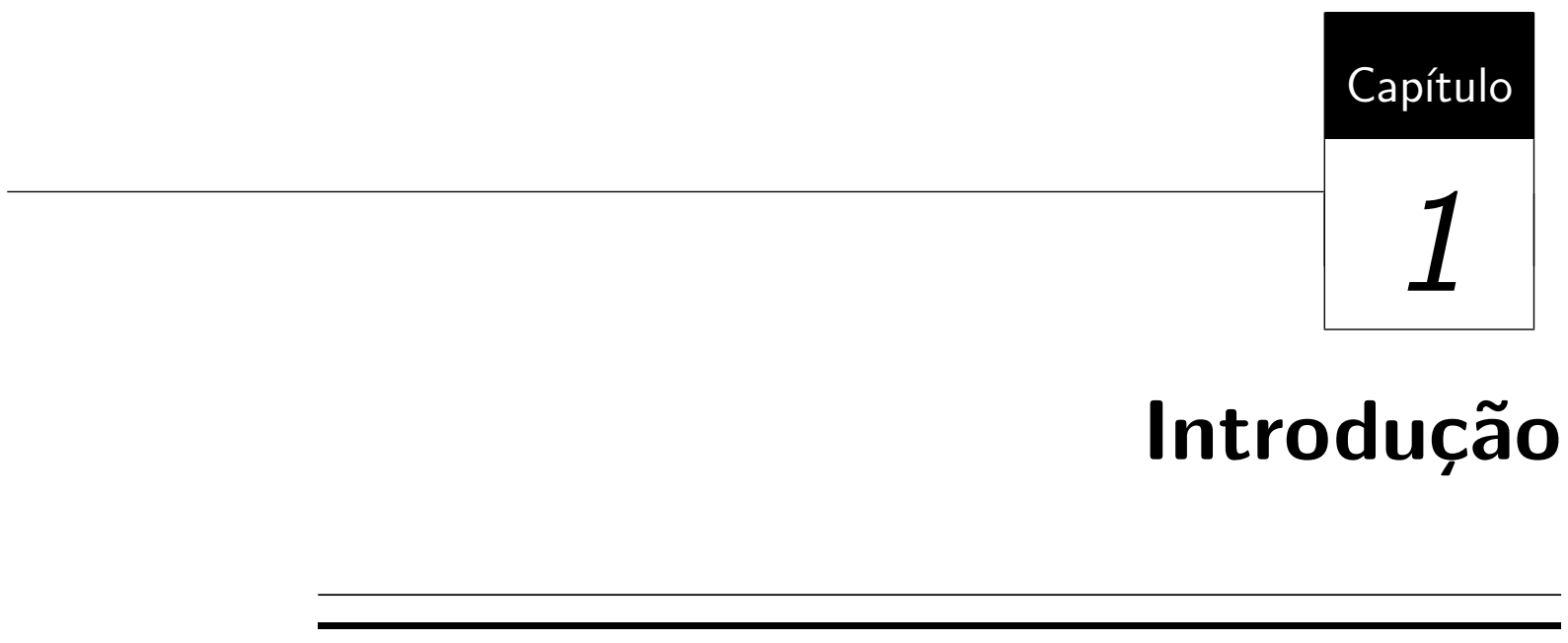

Para que o gerenciamento do negócio seja feito de forma efetiva, as organizações atualmente buscam uma estruturação baseada em processos, pois os mesmos permitem a padronização e a coordenação das atividades e atravessam os limites funcionais ou departamentais para alcançar uma meta de negócio.

Segundo Albuquerque (2009), a principal vantagem de uma abordagem baseada em processos consistiria em sua capacidade de ultrapassar as divisões funcionais e o pensamento fracionado em departamentos, modelando as atividades de uma organização sob a perspectiva do cliente. Dessa forma, esta abordagem corta transversalmente diferentes áreas funcionais e níveis hierárquicos da organização partindo da entrada provida dos fornecedores e chegando ao resultado final a ser entregue.

Nesse contexto, o Gerenciamento de Processos de Negócio (BPM - Business Process Management) é considerado a terceira onda das abordagens baseadas em processos. A primeira onda foi atribuída ao Movimento da Qualidade Total (TQM), desenvolvido a partir da década de 1940 com o objetivo de ajudar as empresas a competir em um ambiente de negócios mais volátil. Este movimento se baseia na abordagem da melhoria contínua dos processos para garantir a qualidade.

A segunda onda consiste na Reengenharia dos Processos de Negócio (RPN), cujo movimento originou-se com a publicação de dois artigos em 1990: o primeiro, de Davenport e Short (1990), argumenta que o uso combinado da TI e o redesenho de processos poderia transformar a organização e melhorar os processos. A segunda publicação, de Michael 
Hammer(1990), abordou a necessidade das empresas de mudarem seus processos de forma radical para ganharem a vantagem do uso dos sistemas de TI. Devido ao grande percentual de projetos que falharam com a utilização do BPR, foi constatado a necessidade de uma nova visão que dê maior ênfase à importância das pessoas e aos aspectos de gestão de mudança na implantação.

Dessa forma, a abordagem BPM surge como uma terceira onda de processos em 1990 realizando uma convergência das abordagens TQM e BPR . Segundo a abordagem BPM, por meio da medição, do monitoramento, do controle e da análise dos processos de negócio uma empresa pode gerar valor consistente aos negócios do cliente com base na melhoria contínua dos processos.

Para que as empresas modelem e gerenciem seus processos efetivamente, as mesmas devem definir processos que sejam eficientes e eficazes em relação aos objetivos organizacionais e às expectativas de seus clientes. Não apenas modelar, também é necessário atender ao que está especificado na modelagem, no entanto, o negócio está em constante evolução, por isso é necessário efetuar mudanças para que as novas estratégias de negócio correspondam às constantes mudanças do ambiente, resultando em mudanças nas estratégias e posteriormente no fluxo dos processos. A agilidade nesta mudança é fundamental para que a organização responda às necessidades do mercado e adquira um diferencial competitivo em relação aos seus concorrentes (Lind e Seigerroth, 2010b).

Paralelamente, a área de TI (Tecnologia da Informação) pode dar suporte ao Negócio e prover a agilidade necessária para efetuar as mudanças entre o planejado nas estratégias definidas e o executado nos processos estabelecidos. Entretanto, muitas vezes ocorre uma lacuna entre o negócio e a TI, pois o negócio precisa compreender o potencial da TI para usufruir de seu suporte e, em contrapartida, a TI precisa entender o negócio para fornecer soluções que proporcionem um auxílio efetivo (Nuffel e Backer, 2012). Processos não alinhados com os interesses e expectativas do negócio resultam em prejuízos operacionais elevados, impossibilidade de automatizações e melhorias contínuas.

O Alinhamento Estratégico tem como finalidade preencher esta lacuna entre a TI e o negócio e vem recebendo nos últimos anos uma crescente atenção por parte das organizações e, em consequência, tem sido alvo de diversas pesquisas (Alibabaei et al., 2009). No entanto, poucas pesquisas se dedicaram a examinar a relação entre o Alinhamento Estratégico e BPM. Os processos de negócio devem evoluir em resposta às mudanças nos objetivos estratégicos, o que resulta em adversidades para a efetiva gestão desses processos. As mudanças estratégicas podem gerar implicações em processos em todos os diferentes níveis de abstração que fazem parte da pirâmide organizacional, na qual no topo está a visão estratégica e que tem em sua base a visão operacional. Dessa forma, é importante procurar pesquisas que estendam as ferramentas e abordagens atuais de BPM de forma 
a oferecer um suporte adequado à evolução dos processos para possibilitar a consistência entre processos de diversos níveis, bem como entre os processos de negócio e os objetivos estratégicos de uma organização. Este é o principal objetivo do presente projeto, ou seja, desenvolver uma ferramenta que permita modelar os processos em seus diferentes níveis, possibilitando a navegação entre eles, com isto, a ferramenta servirá de apoio ao BPM e também incluirá as preocupações do Alinhamento Estratégico.

\subsection{Objetivos do Trabalho}

O objetivo principal deste projeto de mestrado foi desenvolver uma abordagem que garantisse o Alinhamento Estratégico no Gerenciamento de Processos de Negócio. Para alcançá-lo, foram definidos três objetivos específicos:

1. Desenvolver um metamodelo que relacionasse os objetivos estratégicos com os processos de negócio, permitindo abstração e detalhamento das informações, aproveitando de notações atuais sobre o tema abordado.

2. Implementar um protótipo web que suportasse toda o metamodelo proposto de forma a contribuir com a representação da abordagem.

3. Validar empíricamente o metamodelo e protótipo em processos reais de uma grande multinacional.

\subsection{Organização da Dissertação}

Este trabalho está organizado em 7 capítulos e 3 apêndices. Este capítulo introduziu a área de pesquisa apresentando a motivação para a realização deste trabalho. O Capítulo 2 apresenta um estudo sobre o BPM e modelos, notações, padrões de qualidade e ferramentas. No Capítulo 3, é apresentada a fundamentação teórica sobre Alinhamento Estratégico e abordagens multiníveis que visam o AE nos processos de negócio. No Capítulo 4, é apresentada a abordagem proposta, trabalhos relacionados e uma comparação entre este trabalho e outros a eles relacionados, além de um estudo de caso da abordagem proposta. No Capítulo 5, é apresentado o processo de desenvolvimento, tecnologias selecionadas e a ferramenta desenvolvida. No Capítulo 6, é descrito o experimento realizado em uma grande multinacional para validação da abordagem e suporte computacional. O Capítulo 7 apresenta as conclusões e as contribuições deste trabalho no decorrer deste projeto. Por fim, são listadas as referências bibliográficas e os apêndices com a revisão sistemática, entrevista dos participantes do experimento e modelagem e codificação da ferramenta desenvolvida. 



\section{Gerenciamento de Processos de \\ Negócio}

Um processo é a execução de um conjunto de atividades a partir de uma entrada de informação ou insumo, resultando na saída de uma informação, produto ou serviço. Algumas definições similares são vistas na literatura, como, por exemplo: "Processo é um conjunto coerente de ações realizado por um conjunto de papéis colaborativos para atingir uma meta"(Ould e Kiffer, 2005) ou "Processo é um conjunto completo e dinamicamente coordenado de atividades colaborativos e transacionais que entrega valor aos clientes"(Smith et al., 2007).

Além das atividades, um processo possui papéis, pessoas, recursos, interações, metas e saídas. Uma simples definição de cada um dos atributos do processo.

- Papel - É uma responsabilidade atribuída a uma pessoa dentro de um processo.

- Pessoa - Desempenha um papel no processo.

- Recursos - São utilizados pelas pessoas.

- Interações - Os papéis se interagem a fim de um resultado em comum para o processo.

- Metas - O objetivo do processo. Segundo Martyn Ould, existem dois tipos de metas, as metas ponto e estado estável. As metas ponto são atingidas quando o 
processo atinge um objetivo em específico. As metas estado estável são alcançadas ao longo da execução do processo, e representam um ponto ideal em que o processo deve manter.

- Saídas - O resultado da execução do processo.

\subsection{BPM}

A Gestão de Processos de Negócio - mais conhecida pelo termo em inglês Business Process Management (BPM) (Melao e Pidd, 2000; Sinclair e Zairi, 1995; Smith e Fingar, 2003; Weske, 2007) sucedeu iniciativas de Reengenharia de Processos de Negócio (Business Process Reengineering) da década de 1990 (Davenport e Short, 1990; Hammer, 1990), porém com uma abordagem mais holística, com a capacidade de transcender as divisões funcionais e orquestrar as atividades de uma organização de forma a cortar horizontalmente diferentes áreas funcionais em um fluxo fim-a-fim, isto é, que parte dos insumos de fornecedores e chega ao resultado final (produto ou serviço) a ser entregue. A Figura 2.1 ilustra o comportamento dos processos nas diferentes áreas funcionais.

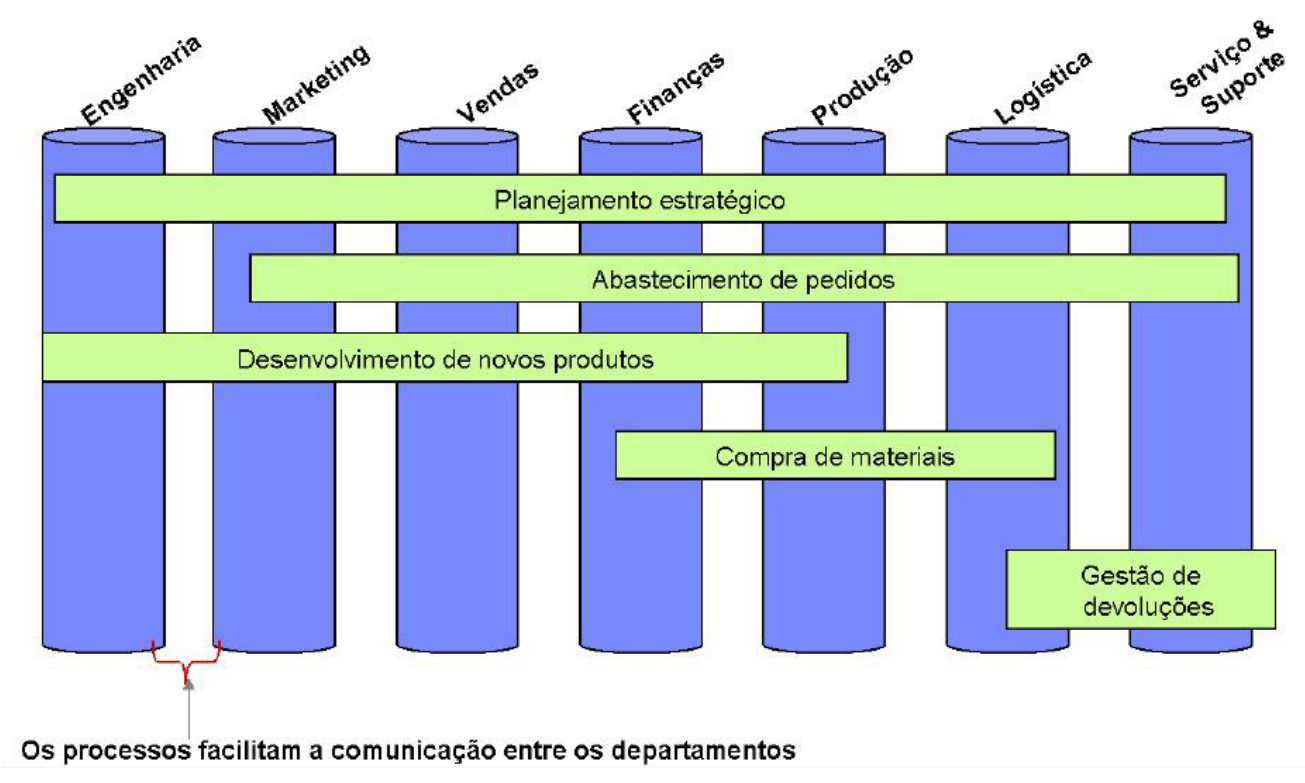

Figura 2.1: Visualização dos Processos entre os Departamentos

A abordagem BPM busca combinar as vantagens de abordagem radicais e incrementais (Melao e Pidd, 2000) modelando processos, mas mantendo a capacidade de mudanças , apoiando-se para tanto na intensa participação da equipe envolvida para a gestão de mudanças.

Segundo Smith \& Fingar, os processos de negócio possuem as seguintes características 
- Grandes e Complexos - Os processo de negócio dependem do suporte das pessoas, que estão presentes em todo o fluxo de fim-a-fim da organização. Este fluxo também envolve os materiais, informações e compromissos do negócio.

- Dinâmicos - Os processos tendem a responder as necessidades dos clientes, podendo mudar de acordo com as necessidades do mercado.

- Distribuídos largamente e personalizados - Os processos podem percorrer toda uma organização e ainda depender de outras organizações para responder de acordo com o esperado. Frequentemente, o processo abrange múltiplos aplicativos e plataformas.

- Longa Duração - uma instância de um processo como "desenvolvimento de um produto"pode ser executada durante meses ou anos.

- Automatizado - Algumas atividades podem usufruir de suporte computacional para agilizar o processo.

- Estratégico e/ou técnico - Os processos de negócio são dependentes dos suportes computacionais e da TI que é necessária para atender as necessidades do negócio.

Como os processos são dependentes das execuções de tarefas e atividades, um dos aspecto fundamentais para o sucesso do BPM, segundo Smith \& Fingar, é a coordenação. Esta característica pode ser complexa, pois os processos contém múltiplos passos , laços e relacionamentos entre indivíduos e com o ambiente externo.

Para qualquer nível organizacional, os processos devem possuir um gatilho ou motivo para o qual o mesmo será chamado e sua resposta será esperada. O processo envolve pessoas com papéis definidos(responsabilidades) e que possuem interações com outros papéis a fim de colaborar para o resultado final do processo, que é atingido com a utilização de seus recursos.

Se uma organização deseja implantar processos, ela deve seguir o ciclo de implatação desses em negócios. O passo inicial deve ser o mapeamento dos processos já existentes na organização e que estão implícitos. A partir deste mapeamento é possível realizar uma análise de como os processos estão atualmente $(A s-I s)$ e efetuar o desenho de como os processos devem ser $(T o-B e)$. Após a modelagem dos processos, é realizado o desenvolvimento dos componentes necessários para o novo processo. Com o processo modelado, é realizada a implantação do novo que irá entrar em operação. Mudanças podem ocorrer posteriormente nos processos em operação (Verner, 2004).

O ciclo de vida dos processos de negócio são divididos pelas etapas: Descoberta, Análise, Desenho, Desenvolvimento, Implantação, Operação e Manutenção (Verner, 2004). 
- Descoberta - O conhecimento dos processos nas organizações são frequentemente tácitos, com isso, não existe uma visão de ponta a ponta no processo. Esta característica é agravada em organizações dívidas por departamentos, pois geralmente o departamento possui uma visão local do processo, dificultando uma visão dele como um todo. A descoberta de processos é responsável por transformar o entendimento deles de negócio atuais de implícitos ou tácitos para explícitos (Verner, 2004). Esta etapa tem como finalidade eliminar este gap, mapeando o processo conforme ele é desempenhado na organização ( modelo $A S-I S$ ).

- Análise - A etapa de Análise segue a partir dos resultados obtidos na etapa de Descoberta. Com o modelo AS-IS levantado, é possível identificar os principais gaps do processo. Na análise também é definida as prioridades de melhoria dos processos analisados, uma vez que normalmente não é possível implantar todas as melhorias simultaneamente.

- Desenho - O desenho do processo é feito a partir dos resultados obtidos na etapa de Análise. Com o levantamento dos gaps é possível definir um modelo de processo ideal para os objetivos da organização (modelo TO-BE). Em BPM é comum a utilização do BPMN nas etapas de descoberta e desenho de processo. O BPMN é explicado na seção 2.2 .

- Desenvolvimento - A etapa de desenvolvimento é aplicada após a modelagem de como o processo é estruturado na organização e como ele deveria ser. Nesta etapa é desenvolvido as tarefas/atividades necessárias para a implantação do novo processo.

- Implantação - A etapa de implantação consiste na adequação das mudanças desenvolvidas no processo existente.

- Operação - A etapa de Operação é constituída da execução do processo na organização.

- Manutenção - A etapa de manutenção corrige eventuais falhas no processo de negócio.

Ao comparar as etapas com as pesquisas realizadas é possível verificar uma necessidade de um ponto de equilíbrio entre a flexibilidade e formalização, que deve ser encontrado para garantir que os processos sejam modelados e definidos de maneira consistente e que possuam a flexibilidade necessária para mudanças nos objetivos estratégicos da organização (Albuquerque, 2009; Becker et al., 2009). Desta forma, o Alinhamento Estratégico deve ser considerado como uma visão fundamental de estudo, já que o mesmo visa preencher a lacuna existente entre o negócio e a TI. 


\subsection{BMM}

O BMM (Business Motivation Model) é um modelo publicado pela BRG (Business Rules Group) em 2000, que tem como finalidade fornecer uma estrutura para gerenciar os planos de negócio. O modelo pode ser utilizado em conjunto com BPM, uma vez que o levantamento feito pelo mesmo serve como base para o gerenciamento dos processos de negócio (OMG, 2010).

A finalidade do BMM é modelar o negócio (de uma forma abstrata) permitindo uma visão simplificada do negócio. A partir desta modelagem é possível com o BPM identificar, analisar e criar ou melhorar os processos de negócio da organização. Também é possível testar os processos antes de implementá-los, verificando se eles satisfazem as necessidades do negócio (levantados pelo BMM).

O BMM fornece um conjunto de conceitos que servem como embasamento para a definição dos elementos de planos de negócios da organização. Os mesmos estão associados a uma metodologia neutra de aplicabilidade, para que não ocorra resultados tendenciosos. A modelagem do negócio definida permite um senso comum entre os clientes, usuários e desenvolvedores do modelo(OMG, 2010).

A especificação do BMM divide o modelo em termos e elementos apresentados abaixo:

- Fins (End)

- Meios (Means)

- Influenciadores (Influencer)

- Avaliações (Assessment)

- Vocabulário de Negócio (Common Business Vocabulary)

Os termos e elementos supracitados são a base para a compreensão das necessidades da organização e serão descritos detalhadamente nas subseções $2.2 .1,2.2 .2,2.2 .3,2.2 .4$ e 2.2 .5 .

\subsubsection{Fins}

O termo Fim é utilizado para representar onde o negócio pretende chegar, sem descrever como isso será feito. Os fins são categorizados como Visão ( Vision) e Resultados Desejados (Desired Result) que é composto por Metas(Goal) e Objetivos(Objective)(OMG, 2010).

- Visão - Descreve o status futuro da organização onde a mesma pretende alcançar (normalmente inalcançado).

Ex: Ser a maior empresa de TI do País 


\section{CAPÍTULO 2. GERENCIAMENTO DE PROCESSOS DE NEGÓCIO}

- Metas - Descreve um status a ser alcançado e sustentando a partir dos Meios. Ex: Desenvolver software com agilidade e qualidade

- Objetivos - Descreve um alvo alcançável, mensurável e limitado por prazo. Ex: Aumentar a produção de software em 20\% até o final de 2012

A Figura 2.2 representa como os fins são organizados.
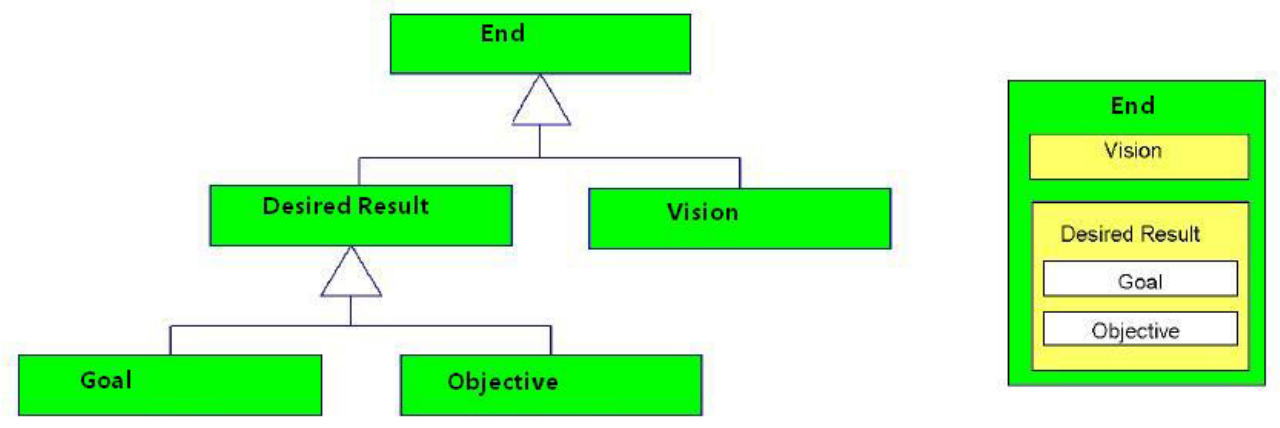

Figura 2.2: Fins(OMG, 2010)

\subsubsection{Meios}

Os meios são os métodos utilizados para alcançar os Fins. Os meios são categorizados em Missão (Mission), Curso de Ação (Course Of Action) e Diretivas (Directive). O Curso de Ação é dividido em Estratégias (Strategy) e Táticas (Tactic) e a Diretiva é composta por Regras de Negócios (Business Rule) e Políticas de Negócios (Business Policy)(OMG, 2010).

- Missão - A missão descreve uma atividade continua em que a empresa realiza para colocar a Visão em prática.

Ex: Fornecer software para todo o País

- Estratégias - A estratégia é uma abordagem estabelecida para alcançar as metas. Ex: Atuar em nível nacional, com funcionários qualificados

- Tática - A tática é um curso da ação que sustenta os objetivos da organização. Ex: Fornecer treinamentos para todos os funcionários da empresa

- Regras de Negócio - A regra de negócio orienta ou influencia o comportamento do negócio para suportar a política de negócio.

Ex: Casos de uso devem ser produzidos de acordo com a especificação. 
- Políticas de Negócio - A política de negócio é uma diretiva com o propósito de governar a organização.

Ex: Todo o software produzido deve ser testado antes da homologação.

A Figura 2.3 representa como os Meios são organizados.
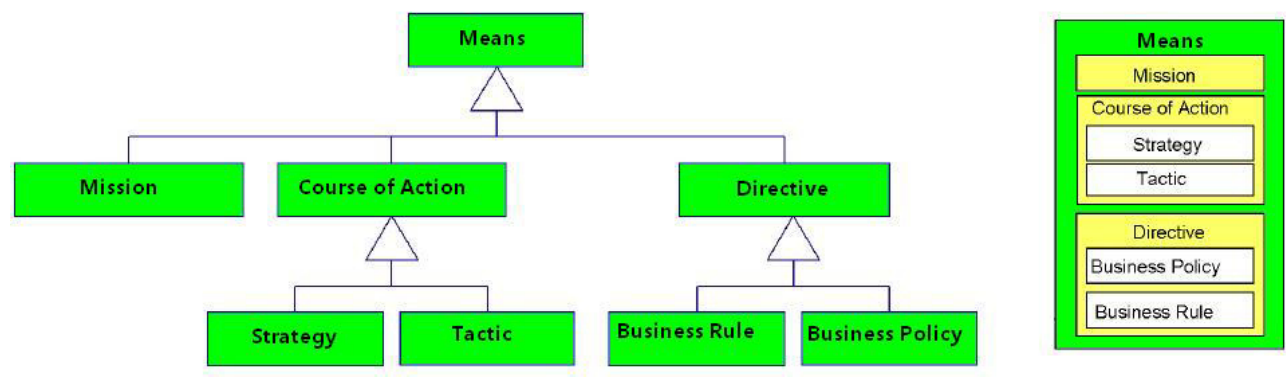

Figura 2.3: $\operatorname{Meios}(\mathrm{OMG}, 2010)$

\subsubsection{Influenciadores}

Um influenciador é algo que produz um efeito ao plano de negócio, podendo impactar a organização de maneira positiva ou negativa. O levantamento dos influenciadores deve ser feita de forma neutra e cabe ao processo de avaliação determinar se o mesmo pode ser benéfico ou maléfico ao negócio. Existem dois tipos de influenciadores, os internos e os externos(OMG, 2010).

- Interno - São considerados Influenciadores Internos os efeitos que são produzidos dentro da organização.

Ex: Hábito, Infraestrutura, Recursos

- Externo - São considerados Influenciadores Externos os efeitos que são produzidos fora da organização.

Ex: Concorrentes, Fornecedores, Tecnologia

\subsubsection{Avaliações}

Como destacado anteriormente, os influenciadores são neutros, eles são classificados positivos ou negativos a perspectiva do negócio no momento da avaliação. A avaliação efetua a classificação do impacto nos termos Fins e Meios. Com à avaliação também são identificados os possíveis impactos potenciais dos influenciadores.

A Figura 2.4 mostra a avaliação dos influenciadores sobre os meios e fins, resultando nos potenciais riscos para a organização. 


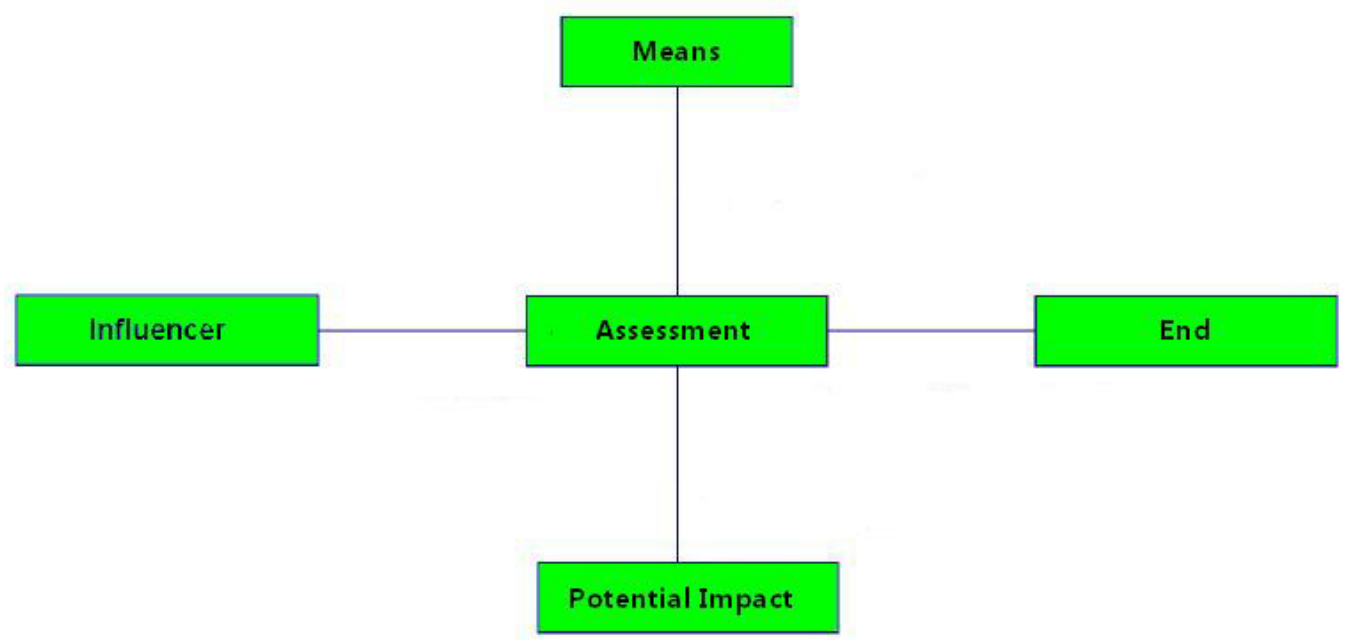

Figura 2.4: Avaliação(OMG, 2010)

\subsubsection{Vocabulário de Negócio}

No BMM, é possível definir um vocabulário dos termos e expressões mais comuns do domínio do negócio para que seja mantida uma padronização das descrições textuais e evitar mal-entendidos entre os membros do projeto. Para efetuar este procedimento, deve ser considerado os termos comuns do domínio de problemas, considerando os termos utilizados para se referir ao negócio(OMG, 2010).

\subsection{BPMN}

Desenvolvido por um grupo de trabalho selecionado para desenvolver uma notação gráfica em 2001, o BPMN ( Business Process Modeling Notation) é uma notação orientada para uso humano, baseado em flow chart e utilizada para representar os processos de negócios por meio dos BPD's( Business Process Diagram). Em maio de 2004 a BPMN 1.0 foi liberado ao público e em Fevereiro de 2006 a notação foi adotada como padrão OMG ( Object Management Group). Atualmente o modelo se encontra na versão 2.0, onde foi acrescentado novos símbolos, diagramas e regras para uso de alguns elementos(OMG, 2011).

A meta principal do BPMN é fornecer uma notação que facilite o alinhamento estratégico na organização, uma vez que é possível com a mesma, representar os objetivos estratégicos e interliga-los com os recursos de TI necessários para apoiar o negócio. Outro objetivo do BPMN é representar as linguagens de execução como o BPEL ( Business Process Execution Language) ou BPELWS ( Business Process Execution Language for Web Services)(OMG, 2011). 


\subsubsection{Tipos de Modelagem}

A notação BPMN possui três níveis de modelagem :

- Nível 1 - Modelagem Descritiva - Mapeamento mais abstrato que os demais níveis, pois possui o foco na representação do negócio. Utiliza os conjuntos básicos do BPMN, omitindo alguns caminhos de exceção.

- Nível 2 - Modelagem Analítica - Utiliza a notação completa para representar de forma precisa o fluxo do processo. Omite detalhes técnicos como especificação de estrutura de dados. O modelo é estendido para a perspectiva de negócio e TI.

- Nível 3 - Modelagem Executável - Apresentado no BPMN 2.0, tem como objetivo capturar os detalhes executáveis em atributos padrões do BPMN e eliminar os modelos de execução governados por código.

Para cada nível de modelagem é utilizado um conjunto de elementos com o intuito de representar o processo de negócio. A seguir será apresentado os elementos principais do $\operatorname{BPMN}(\mathrm{OMG}, 2011)$.

\subsubsection{Elementos principais}

O BPMN define quatro categorias de elementos:

- Objetos de Fluxo ( Flow Objects) - É constituído de Eventos, Atividades e Gateways.

- Objetos de Conexão ( Connecting Objects) - É constituído de Fluxo de Sequencia, Fluxo de mensagem e Associação.

- Partições ( Swimlanes) É constituído de Piscinas e Raias.

- Artefatos ( Artifacts) É constituído de Objeto de Dados, Grupo e Anotação.

Para a apresentação da notação foi utilizado exemplos para auxiliar na definição de cada grupo de elemento com seus respectivos objetos.

\subsubsection{Objetos de Fluxo}

Os objetos de fluxos são utilizados para definir o comportamento dos processos de negócio. Existem três tipos de objetos de fluxos(OMG, 2011): 
- Atividade - São passos lógicos que ocorrem dentro do processo, representa uma ação que é feita dentro de um processo de negócio, consumindo recursos, tempo e gerando custos e resultados que serão repassados para uma próxima tarefa (atividade subatômica ou o nível mais baixo de uma atividade) ou subprocesso (uma atividade composta por diversas atividades interligadas em um fluxo de entrada, atividades e saída). A Figura 2.5 ilustra como é representada uma atividade no diagrama de processo.

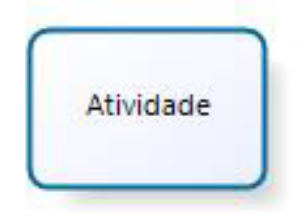

Figura 2.5: Atividade

- Evento - É um gatilho ( Trigger) que é disparado a partir de alguma ação esperada, como por exemplo a chegada de uma mensagem de outro processo. Existem três tipos de evento, de início que indica quando o processo inicia, intermediário que representa algo que ocorre durante a execução do processo e o evento de fim representando o final do processo. A Figura 2.6 mostra um evento de início.

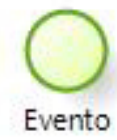

Figura 2.6: Evento

- Gateway - É utilizado para controlar o fluxo de sequência do processo de negócio, age como ponto de divisão e junção de caminhos, decidindo o caminho que será seguido ou criando caminhos paralelos no processo. Existem 4 tipos de gateways, Exclusivo, Inclusivo, Complexo e Paralelo. Para cada tipo existe um comportamento específico. A Figura 2.7 representa um gateway exclusivo(OMG, 2011).

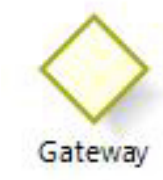

Figura 2.7: Gateway 


\subsubsection{Objetos de Conexão}

Os objetos de conexão são utilizados para interligar os objetos de fluxo, permitindo que a informação percorra as atividades do processo. Existem três objetos de conexão(OMG, 2011):

- Associação - As associações são utilizadas para interligar anotações, objeto de dados e outros artefatos com os objetos de fluxo. A Figura 2.8 mostra como é representado em um diagrama uma associação.

\section{Associaçầo}

Figura 2.8: Associação

- Fluxo de Sequência - É utilizado para interligar as atividades/subprocessos. O fluxo de sequência aponta para o próximo objeto do fluxo, indicando a sequência em que as atividades/subprocessos são realizados dentro do processo de negócio. A Figura 2.9 ilustra o fluxo de sequência.

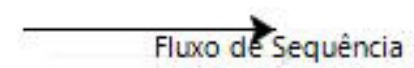

Figura 2.9: Fluxo de Sequência

- Fluxo de Mensagem - É utilizado para representar troca de informações entre piscinas ou processos. A Figura 2.10 ilustra o fluxo de mensagem.

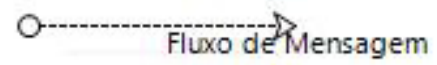

Figura 2.10: Fluxo de Mensagem

\subsubsection{Partições}

As partições são utilizadas para agrupar os elementos de modelagem e são divididas em Piscina e Raia(OMG, 2011).

- Piscina - A piscina representa um papel no negócio, como por exemplo o de um cliente ou fornecedor. Também pode representar uma entidade de negócio, como por exemplo uma empresa terceirizada que dá apoio ao processo específico. 
- Raia - São utilizadas para criar subdivisões dentro das piscinas, especificando papéis internos, departamentos ou sistemas. Com a raia é possível definir qual papel é responsável por executar cada atividade. A Figura 2.11 ilustra uma piscina com duas raias.

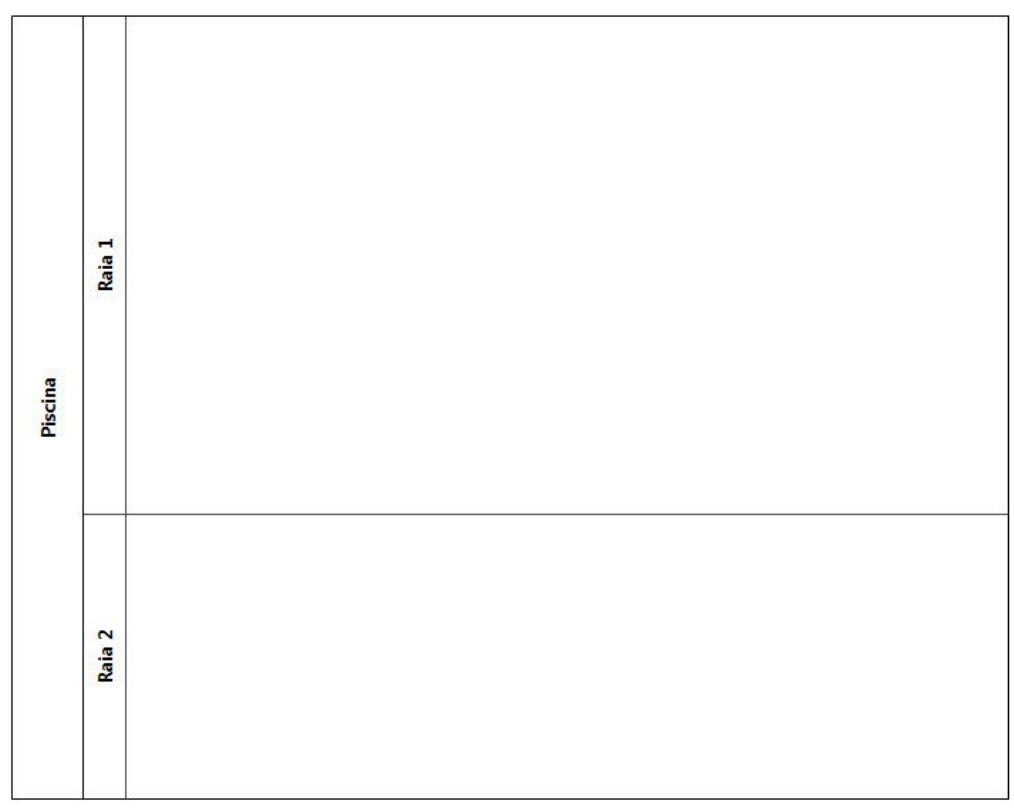

Figura 2.11: Piscina e Raia

\subsubsection{Artefatos}

Os artefatos são utilizados para adicionar informações ao processo de negócio, não possuem nenhum efeito direto sobre o fluxo de sequência ou fluxo de mensagem do processo(OMG, 2011).

- Grupo - Possui a finalidade de agrupamento de atividades para fins de documentação ou destaque. Não altera o fluxo de sequência das atividades dentro do processo. A Figura 2.12 ilustra um grupo.

- Anotação - É utilizado para adicionar informações adicionais ao leitor do BPD. É conectado a outros objetos a partir do objeto de conexão associação. A Figura 2.13 ilustra uma anotação.

- Objeto de Dados - Informa qual atividade produziu (saída de uma atividade) ou necessita (entrada de uma atividade) de informação. Normalmente estão relacionados com objetos de fluxo, no entanto podem ser representados como envio de informação de uma atividade para outra por meio de um fluxo de sequência. A Figura 2.14 representa um objeto de dados. 


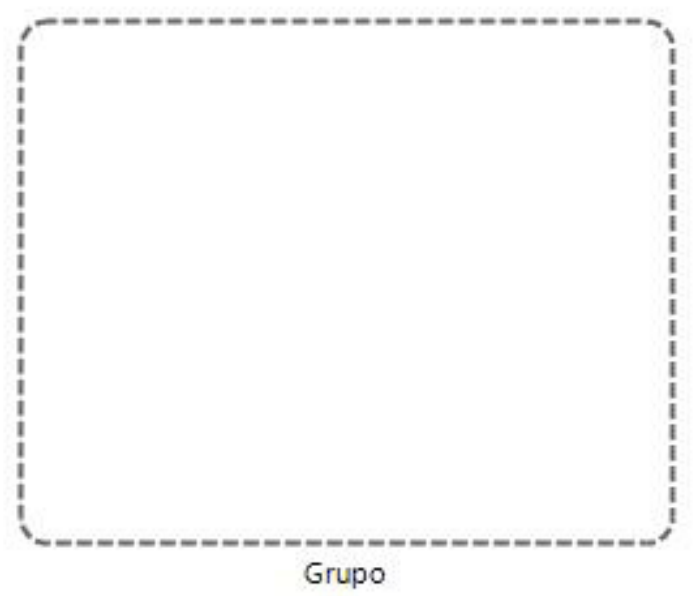

Figura 2.12: Grupo

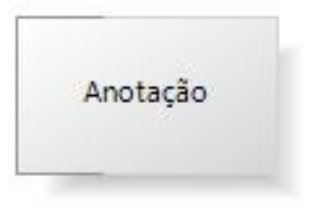

Figura 2.13: Anotação

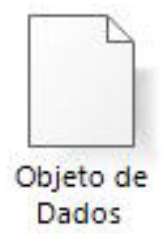

Figura 2.14: Objeto de Dados

A Figura 2.15 apresenta um BPD com algum dos elementos apresentados em toda esta seção.

\subsection{BPMS}

O BPMS pode ser definido como um sistema que automatiza a gestão dos processos de negócio, ressaltando as etapas de monitoração, controle e execução (Karagiannis, 1995).

É uma eficiente ferramenta de gestão, que garante que os processos estão sendo executados de acordo com o que foi modelado, contribuindo para os objetivos da organização. A partir desta perspectiva, é válido ressaltar que um dos benefícios da utilização do BPMS é o fato da execução dos processos serem feitos a partir da modelagem do processo de negócio, consequentemente, a execução ocorre a partir da estratégia, facilitando o alinhamento estratégico. 


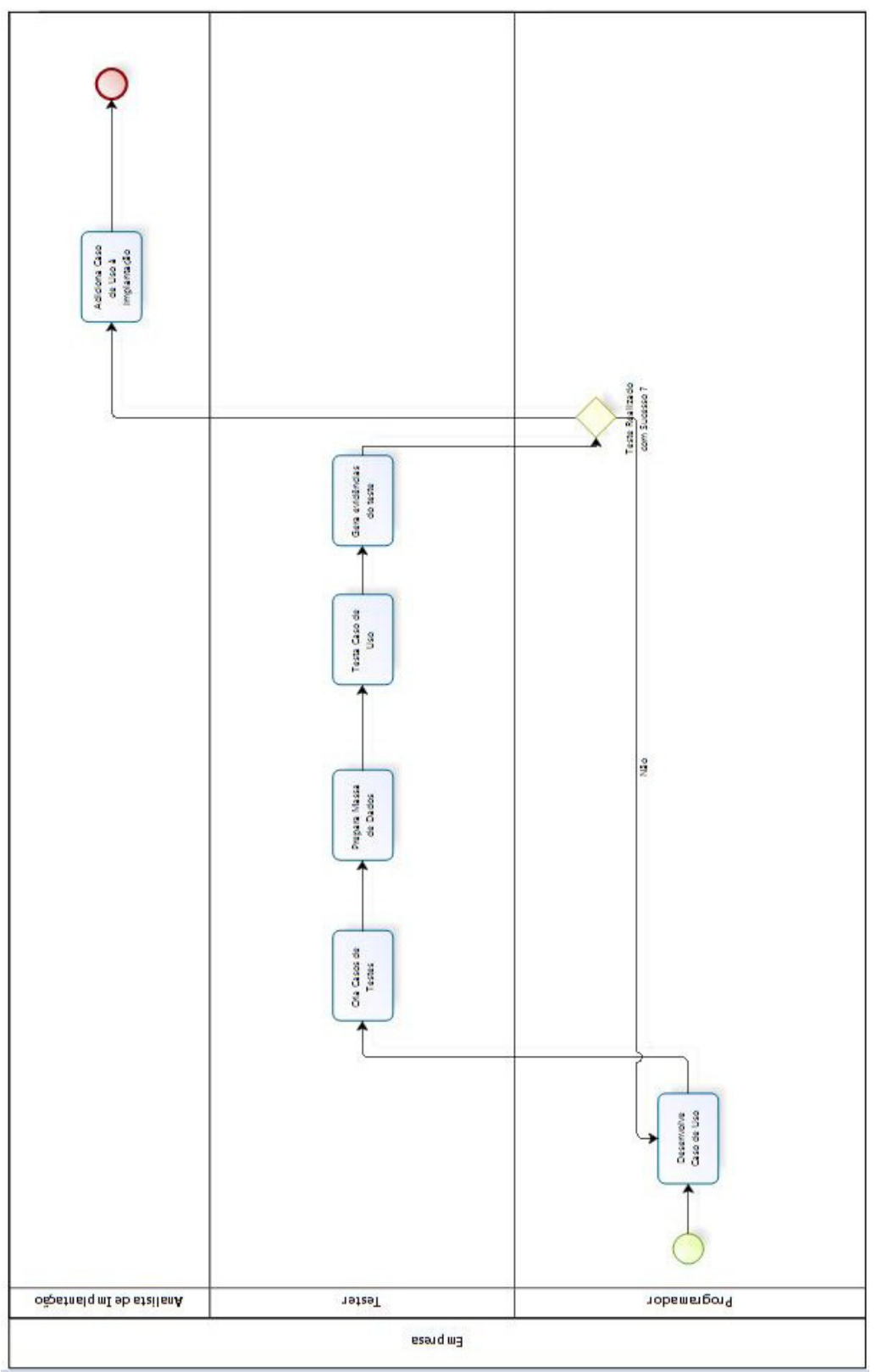

Figura 2.15: A imagem ilustra um BPD

De acordo com o que foi abordado no artigo de Sordi (José Osvaldo De Sordi, 2004), o BPMS deve possuir alguns algoritmos básicos como:

- Visualização do fluxo de trabalho O fluxo de trabalho do processo descreve a sequência de atividade a serem executadas após a conclusão de cada atividade antecessora. Um dos requisitos básicos de uma solução BPMS é a existência de algoritmos que permitam a iteração com o fluxo de trabalho de forma gráfica.

- Visualização dos eventos e suas regras de tratamento Como abordado na seção 2.3, os eventos de negócio abrangem uma grande diversidade de eventos que 
podem acionar um determinado processo de negócio. A partir destes acionamentos, é seguido um fluxo de trabalho estabelecido de acordo com o evento.

- Painel de controle (management cockpit) Com um painel de controle é possível gerenciar o desempenho dos processos de negócio, selecionado diferentes tipos de análise como metas, custos, recursos, atividades, entre outros atributos que indicam a performance do processo.

Outro aspecto a ser considerado é que a solução BPMS não emprega o conceito de substituição de sistemas, em vez disso, a solução BPMS disponibiliza um ambiente de integração de sistemas de informação, permitindo definir o fluxo de execução, regras, eventos entre outras especificações necessárias para garantir à operação e gerenciamento do processo de negócio. Esta característica do BPMS o torna extremamente dinâmico, permitindo mudanças rápidas em todos os níveis dos processos (José Osvaldo De Sordi, 2004).

\subsection{BPMM}

O BPMM (Business Process Maturity Model) é um padrão de maturidade que teve seu início em 2002, e foi submetido a OMG no formato de uma $\mathrm{RFC}$ (Request for Comment) para ser adotado com um padrão de mercado de BPM. A especificação do BPMM foca em 5 aspectos (OMG, 2008):

1. Ser um padrão de maturidade dos processos de negócio.

2. Servir como referencia para avaliação dos processos implantados.

3. Permitir uma padronização de tarefas entre empresas.

4. Avaliar serviços do negócio, dentre eles o fornecimento de TI.

5. Servir como guia de implantação de processos de negócio.

O BPMM pode ser mapeado para o CMMI (Capability Maturity Model Integrated), no entanto, o mesmo é transacional e caracterizado como fluxo de trabalho entre os limites organizacionais, por sua vez, o CMMI possui o foco em projetos.

Igual ao CMMI, o mesmo possui 5 níveis de maturidade. Cada nível representa um grau de maturidade que a organização possui em seus processos de negócio. A seguir será apresentado todos os níveis e suas respectivas caracteristicas(OMG, 2008; Paulk et al., 1995). 
- Nível 1 - Inicial: Os processo de negócio são realizados de maneira ad hoc, sem previsibilidade de resultados, ficando depende da competência dos recursos envolvidos. Com a perda de recursos, pode haver queda na qualidade. Com isso, neste nível, é encontrado problemas gerenciais, pois não há uma visão clara de como é elaborado os processos, apenas se sabe que os requisitos entram e o produto sai. A Figura 2.16 mostra uma representação dos processos BPMM no nível 1.

\section{1 - Inicial}

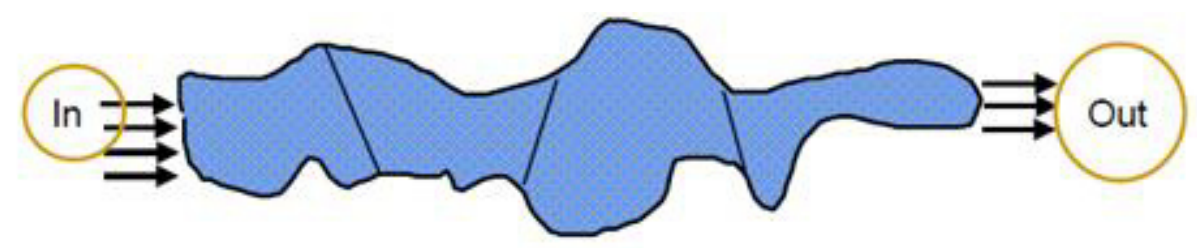

Figura 2.16: Representação do Nível 1 de BPMM (Adaptado de Paulk, 1995)

- Nível 2 - Gerenciado: No nível 2, os métodos de gerenciamento estão mais claros, existe documentação e acompanhamentos. As políticas organizacionais orientam os processos estabelecendo processos de gerenciamento. As práticas bem sucedidas podem ser repetidas em novos processos como lição aprendida. Neste nível já existe um gerenciamento em vigor com cumprimento de custos e prazos do processo. A Figura 2.17 mostra uma representação dos processos BPMM no nível 2.

2 - Gerenciado

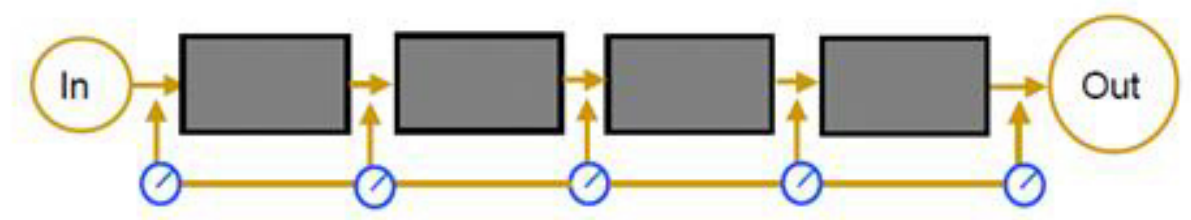

Figura 2.17: Representação do Nível 2 de BPMM (Adaptado de Paulk, 1995)

- Nível 3 - Padronizado: No nível 3, a organização possui os processos bem definidos. Existe uma sintetização dos processos a partir da adoção das melhores praticas identificadas pelos grupos de trabalho, somada a uma preocupação com a padronização dos processos da organização. Apesar dos processos serem padronizados, existe uma diferença entre os processos estabelecidos, para que os mesmos atendam da melhor forma possível os objetivos do negócio. Neste nível é possível identificar o que ocorre dentro dos processos como ilustra a Figura 2.18.

- Nível 4 - Previsível: O processo é gerenciado estatisticamente por meio do fluxo do trabalhos, possibilitando previsões dos resultados e permitindo tomadas de decisões. 
3 - Padronizado

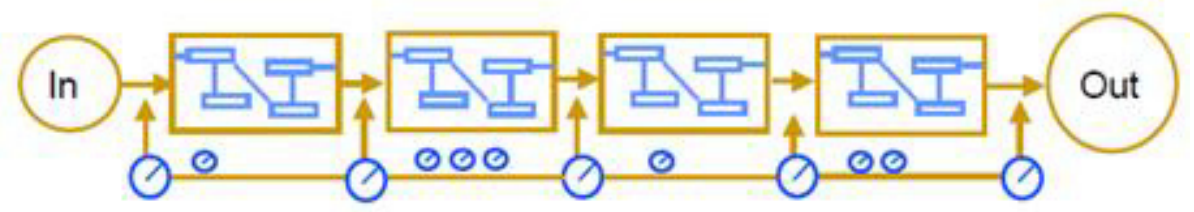

Figura 2.18: Representação do Nível 3 de BPMM (Adaptado de Paulk, 1995)

A Figura 2.19 ilustra as atividades do processo sendo medidas, e essas medidas serão subsídios para possíveis melhorias no processo:

4 - Previsivel

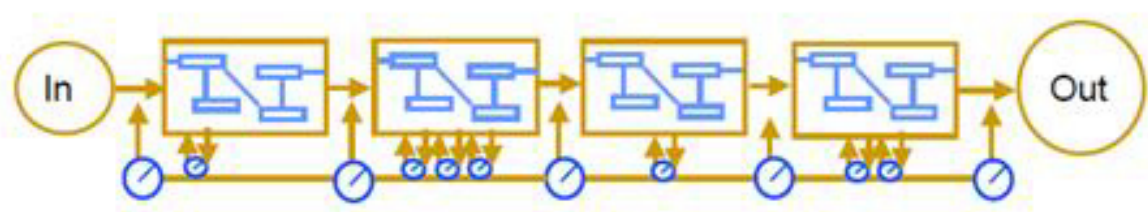

Figura 2.19: Representação do Nível 4 de BPMM (Adaptado de Paulk, 1995)

- Nível 5 - Inovando: Os processos estabelecem inovações para fechar as lacunas (gaps) entre a capacidade atual e os objetivos de negócio. A otimização continua dos processos é uma preocupação constante neste nível. A Figura 2.20 mostra o duas atividades sendo substituídos por uma atividade otimizada:

5 - Inovando

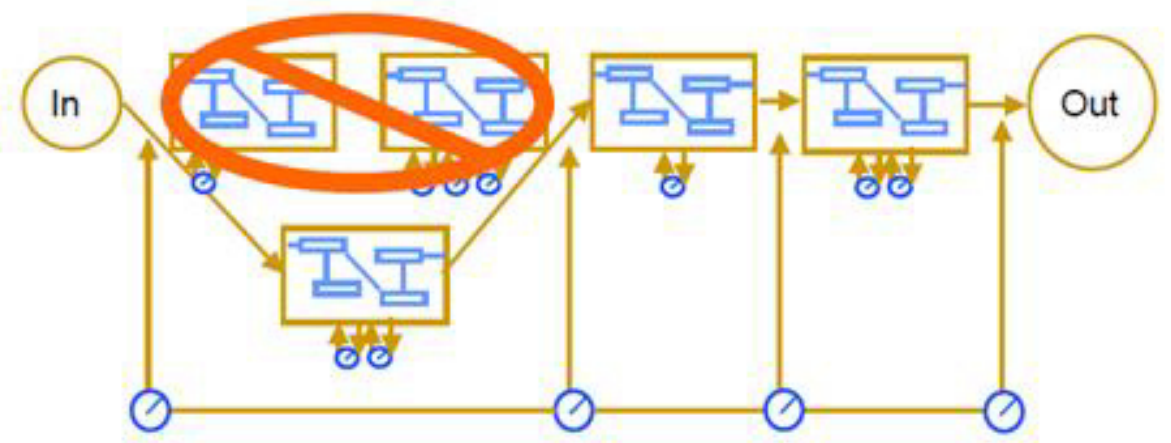

Figura 2.20: Representação do Nível 5 de BPMM (Adaptado de Paulk, 1995)

\subsection{Ferramentas}

Como visto anteriormente, a projeção de um processo de negócio é relativamente complexa e trabalhosa, e seu resultado influência todo o ciclo de desenvolvimento de processos de negócio. Com isso, o auxilio de uma ferramenta facilita o modelador no momento de projetar os processos de negócio. Esta seção tem como finalidade apresentar algumas 
ferramentas de modelagem de código aberto que estão em evidência pelos autores para a implantação de um modelo multiníveis de processos.

\subsubsection{JBPM}

JBPM é uma solução para BPM escrita na linguagem Java, capaz de executar os processos descritos em BPEL ou seus próprios processos que podem ser representados em BPMN ou JPDL. A mesma é distribuída sob a licença LGPL pela JBoss Community. A ferramenta é baseado na Máquina Virtual de Processos para suportar múltiplas linguagens de processo de forma nativa.

Além da modelador de processos de negócio, a ferramenta é responsável pelo gerenciamento das instâncias dos processos, permitindo a persistência do estado das execuções dos processos enquanto estiverem em atividade de espera. A Figura 2.21 ilustra a ferramenta JBPM.

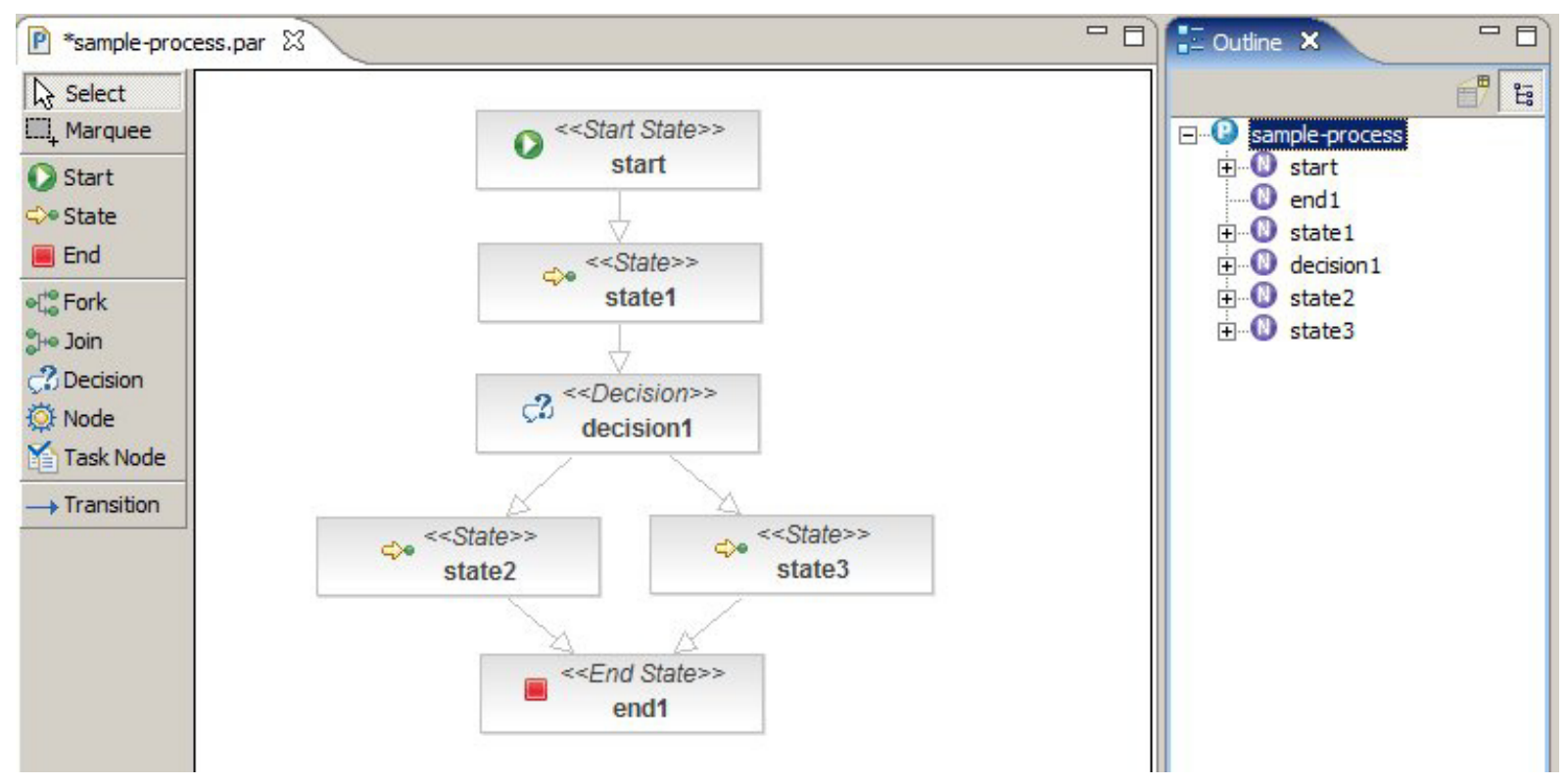

Figura 2.21: Representação da Ferramenta JBPM

\subsubsection{BONITA}

A ferramenta Bonita Open Solution é uma solução de código aberto para BPM implementada na linguagem de programação Java que auxilia na modelagem dos processos.

A ferramenta possui usabilidade simples, somada a várias funcionalidades (incluindo conectores para redes sociais, sharepoint e outros)e visual inovador. No entanto, em testes a mesma mostrou uma performance inferior as demais concorrentes (provavelmente resul- 
tante da quantidade superior de recursos fornecidos). A Figura 2.22 ilustra a ferramenta Bonita.

No site da aplicação é disponibilizado suportes, treinamentos, guias entre outros.

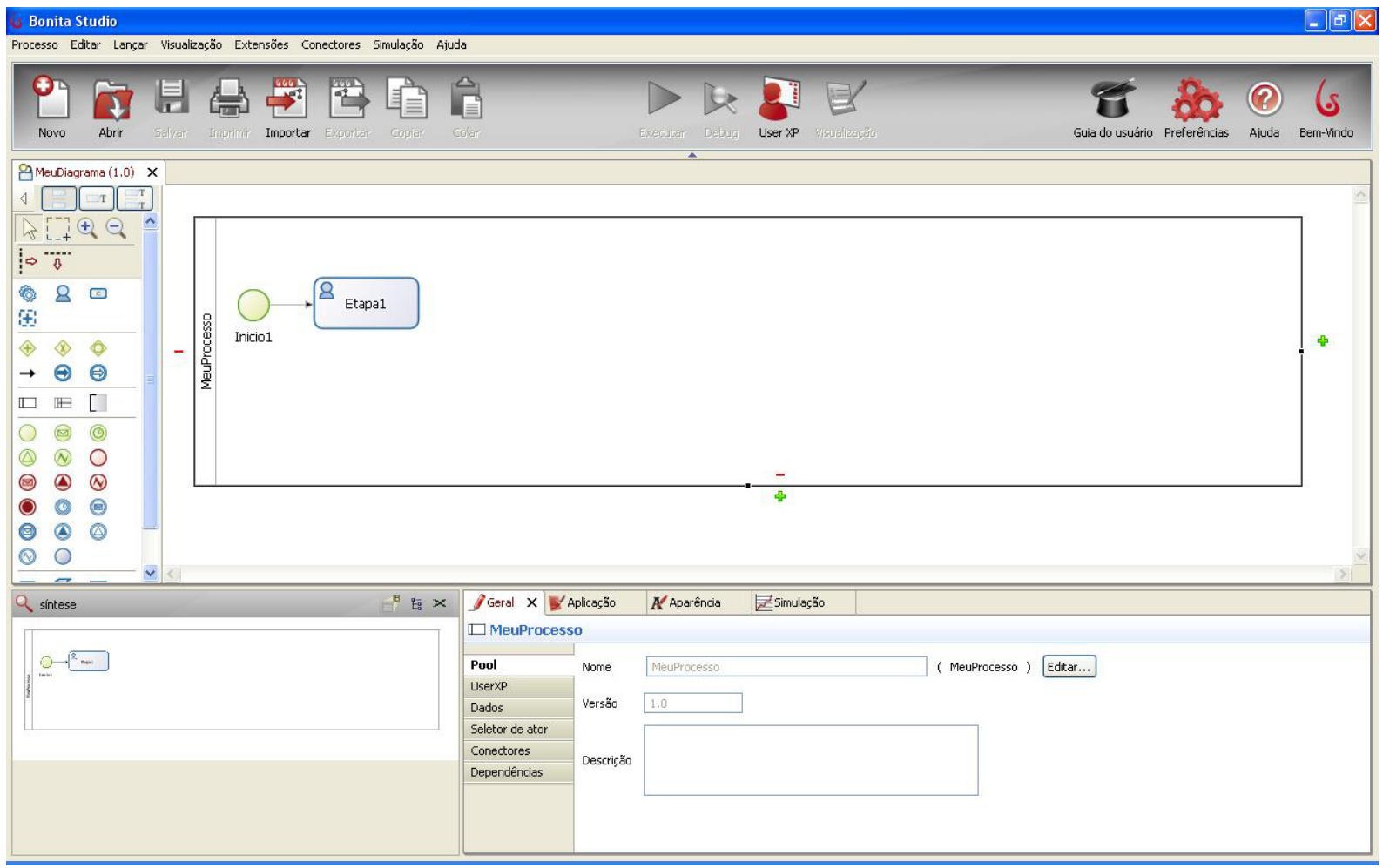

Figura 2.22: Representação da Ferramenta Bonita Studio

\subsubsection{INTALIO}

A ferramenta Intalio é um software de BPM que tem como objetivo apoiar os padrões BPMN, BPEL 2.0 e BPEL4People. A ferramenta foi implementada na linguagem Java e atualmente o software está na versão 5.0. Também fornece apoio a nova especificação da notação BPMN 2.0 integrado agora ao projeto Eclipse(pela Figura 2.23 é possível verificar a similaridade da ferramenta com o Eclipse).

O motor de processos tem o projeto Apache ODE construído a partir dos códigos doados pela Intalio ao Apache Software Foundation.

A ferrament a Intalio é oferecida por meio de duas versões. A versão Intalio Community é totalmente gratuita e apoiada por uma comunidade online, no entanto esta versão não é totalmente código aberto (apenas $80 \%$ do código fonte da aplicação é disponibilizado). A versão Intalio Enterprise é licenciada por meio de assinaturas anuais em uma base de CPU e vem com suporte profissional e de manutenção. 


\section{CAPÍtUlO 2. GERENCIAMENTO DE PROCESSOS DE NEGÓCIO}

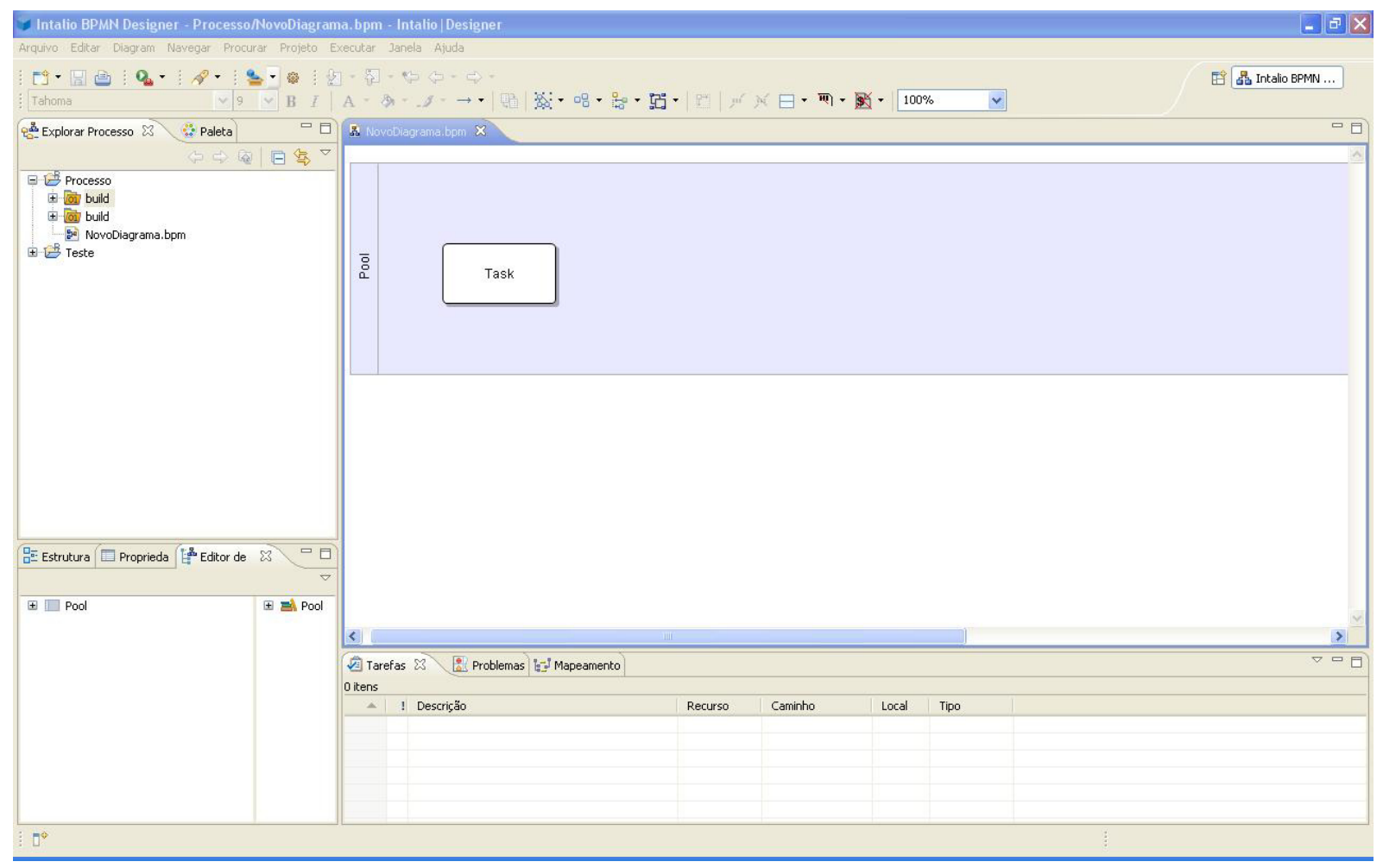

Figura 2.23: Representação da Ferramenta Intalio

\subsubsection{ACTIVITI}

A ferramenta Activiti é um software de BPM que conta com uma plataforma desenvolvida na linguagem Java. O modelador possui compatibilidade com a versão 2.0 do BPMN.

A ferramenta Activiti pode ser executada em um servidor, remotamente ou em nuvem e é integrada ao framework de injeção de dependência Spring. Outra característica da ferramenta é a capacidade de testar as execuções de processo em isolamento em um teste unitário.

O modelador possui suporte para os bancos de dados H2, Oracle, MySQL e PostgreSQL.

\subsection{Considerações Finais}

Neste capítulo foram reunidos os principais conceitos sobre a Gestão dos Processos de Negócio, assim como o modelo de motivação de negócio BMM e notação de processos de negócio BPMN para fornecer embasamento teórico para abordagem que será proposta a partir do capítulo 4. Assim como o BPM, a abordagem também possui como base o Alinhamento Estratégico, com isso, no próximo capítulo serão apresentados seus principais conceitos e as pesquisas que unem o BPM e o AE. 


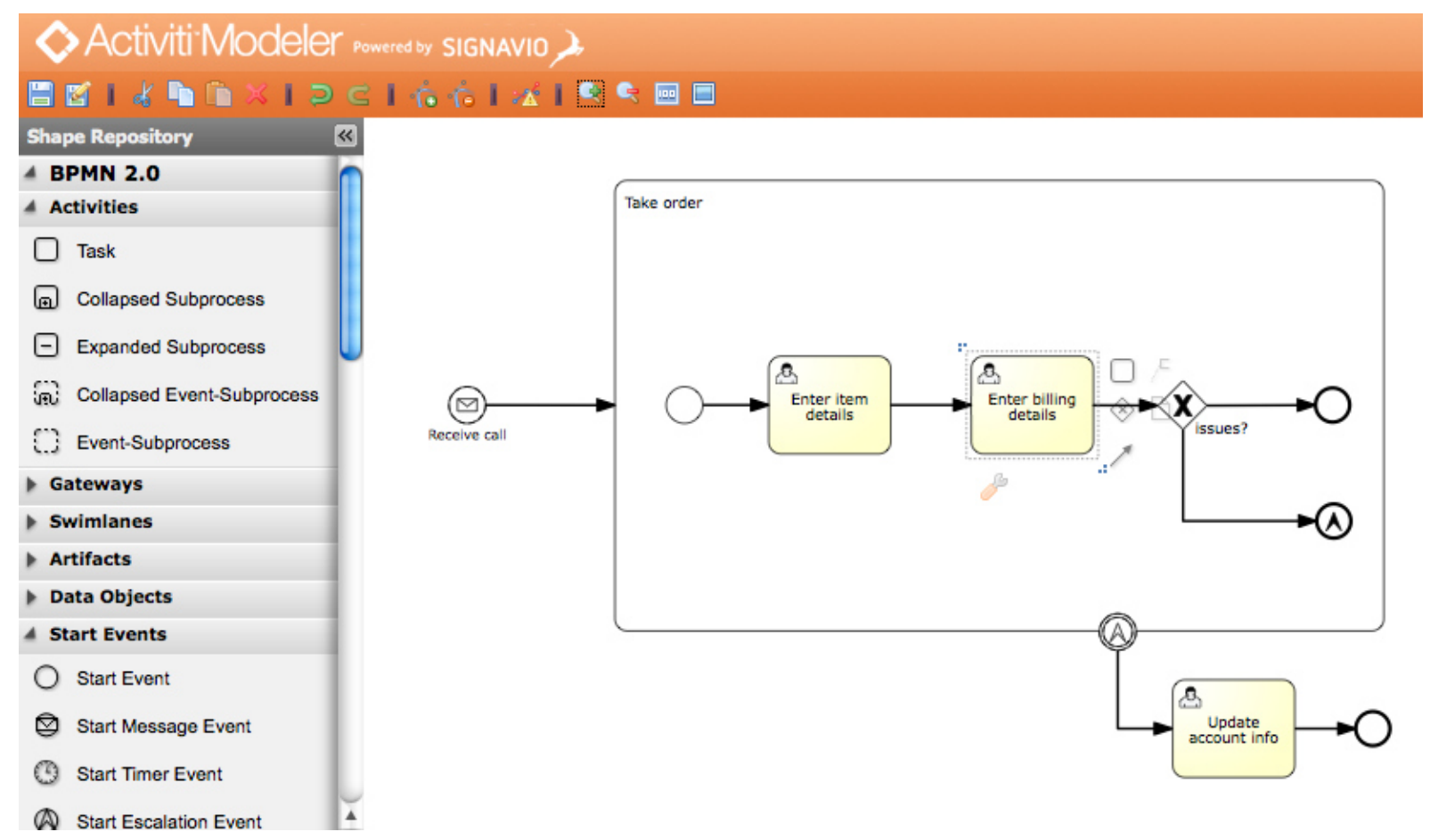

Figura 2.24: Representação da Ferramenta Activiti 



한

\section{Alinhamento Estratégico}

A TI com o passar do tempo evoluiu de suporte administrativo para papel estratégico dentro das organizações. Esta visão estratégica da TI tem sido discutida e enfatizada com diferencial competitivo para as organizações, pois não apenas mantêm as operações de negócio existentes, como também permite que se viabilizem novas estratégias empresariais. No entanto, ainda existem algumas dúvidas sobre os possíveis ganhos de produtividade com à utilização da TI.

Pesquisas mostram que a falta de habilidade das empresas em obter retornos nos investimentos em TI deve se (não totalmente) à falta de alinhamento entre as estratégias de negócio e de TI . No entanto não são ajustes fáceis ou simples de serem obtidos, uma vez que é necessário estabelecer um processo dinâmico e contínuo ao longo do tempo pois nenhuma aplicação de TI, por melhor que seja, não manterá uma vantagem competitiva se utilizada individualmente (Henderson e Venkatraman, 1993). Esta vantagem só poderá ser obtida pela capacidade da organização em explorar a TI de forma contínua (Laurindo et al., 2001). Com isso, o uso eficaz da TI e a integração entre sua estratégia e a estratégia do negócio vão além da perspectiva de ferramenta de produtividade, sendo considerado muitas vezes como um fator crítico de sucesso para a organização.

Antes de abordar o Alinhamento Estratégico, será apresentado os aspectos referentes a estratégia. 


\subsection{Fundamentos para definição de Estratégias}

A Estratégia é uma forma de estabelecer um padrão coeso com os principais objetivos, políticas da organização (Quinn, 1991), esta definição é acrescida com a adição de identificação do segmento de negócio à qual a empresa pertence, o tipo de organização que a mesma almeja, a natureza das contribuições que a mesma proporciona as partes interessadas (Andrews, 1991).

As principais dimensões de uma estratégia são (Nogueira et al., 1998):

- Conter os objetivos, políticas e ações a serem executadas de maior relevância

- Possuir coesão, equilíbrio e foco a partir de conceitos e forças bem estabelecidas;

- Estabelecer uma estrutura flexível à imprevistos, permitindo que a organização consiga atingir aos seus objetivos;

- Quando complexa, uma organização deve possuir uma estrutura hierárquica.

Por sua vez, uma estratégia eficaz apresenta algumas características em comum como por exemplo (Quinn, 1991):

- Possuir objetivos claros e relevantes.

- Promover os recursos da organização, preservando a liberdade de ação e aumentando o comprometimento. Esta característica é ressaltada por Andrews (1991), onde o mesmo afirma que é necessário realizar avaliações dos recursos e competências presentes dentro da empresa.

- Concentrar forças e poder no momento e local crucial.

- Surpreender os competidores.

As características propostas acima podem servir como base comparativa para as novas estratégias a serem definidas. Outra maneira para classificar uma estratégia foi fornecido um quadro de referências para a avaliação de estratégias de negócio. Para isto, a estratégia deve responder a questões referentes aos objetivos, políticas e planos propostos (se são adequados ao negócio) e verificação dos resultados obtidos até o momento (se confirmam os princípios básicos da estratégia) (Rumelt, 1991). 


\subsection{O Alinhamento Estratégico}

O Alinhamento Estratégico visa estabelecer uma união entre a TI e o negócio. Uma definição para negócio corresponde à integração funcional entre o ambiente externo (mercados) e interno (estrutura administrativa e recursos financeiros, tecnológicos e humanos) para desenvolver as competências e maximizar o desempenho organizacional (Henderson e Venkatraman, 1993).

O mesmo não é um evento estático, mas sim um processo contínuo de adaptação e mudança contínua, destacando a importância dos processos de avaliação para a promoção do alinhamento estratégico na organização (Brodbeck e Hoppen, 2003).

Estudos mostram que esta união traz vantagem competitiva para as corporações que conseguem efetuar o alinhamento (Brodbeck e Hoppen, 2003). A questão chave do alinhamento estratégico é a divergência de visões entre o pessoal responsável pelo negócio e as equipes responsáveis pela TI. As equipes voltadas ao negócio devem entender como o sistema se comporta e como o mesmo traz vantagens na execução das tarefas, enquanto a TI deve entender como o negócio funciona para propor soluções que apoiem as tomadas de decisões do negócio.

Apesar de atualmente haver uma popularização sobre a mudança do papel da TI dentro das organizações, antigamente era encontrada resistência por parte dos gerentes que confrontavam com indagações básicas como as apresentadas abaixo (Henderson e Venkatraman, 1993):

- Quais são as implicações da TI nas operações da empresa?

- Quais são as perspectivas para alavancar as capacidades da TI para as operações de negócios?

- Qual é o papel executivo para alavancar a capacidade da TI ? Como deve ser organizada ? deve haver à terceirização da TI?

- Quais são os critérios adequados para avaliar os benefícios?

Estas indagações, apesar de antigas, ainda servem de parâmetros para definir se a TI tem um papel relevante no negócio.

\subsubsection{Modelo Henderson e Venkatraman}

O conceito por Henderson e Venkatraman (1993) de alinhamento estratégico tem como objetivo mitigar as indagações apresentadas anteriormente. O modelo contempla a adequação estratégica, reconhecendo a necessidade de que cada estratégia faça referência aos domínios internos e externos da organização. 
No domínio externo é encontrado a área de negócio em que a empresa atua, tais como os produto e serviços disponibilizados pela empresa s seus atributos estratégicos que diferenciam à de seus concorrentes, incluindo também no domínio as parcerias e alianças. O domínio interno foca na lógica da estrutura administrativa (organização funcional) e a razão específica para o desenho e redesenho dos processos críticos de negócio.

Outra característica do modelo proposto por Henderson e Venkatraman (1993) é o destaque para dois níveis de obtenção de alinhamento estratégico.

O primeiro nível é o de integração funcional, onde o foco está nos planos operacionais de negócio e de TI. Para a sua operacionalização, o plano estratégico de tecnologia de informação (PETI) é formulado seguindo as definições do plano estratégico de negócio (PEN). Este nível é caracterizado pelo foco no nível operacional da organização, que normalmente utiliza a TI como suporte (Brodbeck e Hoppen, 2003; Henderson e Venkatraman, 1993).

O segundo nível mostra a ideia de alinhamento em um nível hierárquico mais elevado, no qual a integração ocorre por meio da adequação estratégica dos objetivos da TI com as estratégias, objetivos e competências do negócio. Neste nível a TI coordena o negócio, PEN e PETI devem estar integrados . Os sistemas de informação estão diretamente relacionadas com as estratégias de negócio, sustentando os objetivos do negócio e identificando novas oportunidades de negócio, baseadas em soluções de TI (Brodbeck e Hoppen, 2003; Henderson e Venkatraman, 1993). A Figura 3.1 ilustra o modelo proposto por Henderson e Venkatraman (1993).

A seguir as definições para cada item do modelo de Henderson e Venkatraman (1993), representado pela Figura 3.1:

- Estratégia de Negócios (Business Strategy) - Determina as decisões que a empresa deseja realizar. Essas decisões podem incluir tipo de produtos, serviços e escopo em que a empresa irá atuar.

- Estratégia de TI (I/T Strategy) - Determina o papel da TI como suporte as necessidades da Estratégia de Negócio.

- Governança de Negócio (Business Governance) - São ações tomadas que representam o que foi definido na estratégia.

- Governança de TI (I/T Governance) - Utilização de mecanismos para a obtenção do suporte necessário da TI.

- Competências distintas (Distinctive Competencies) - Mostram quais são as capacidades necessárias para a organização diferenciar seus produtos e serviços.

- Habilidades $($ Skills $)$ - Envolve a capacidade dos funcionários em atender a estratégia do negócio 


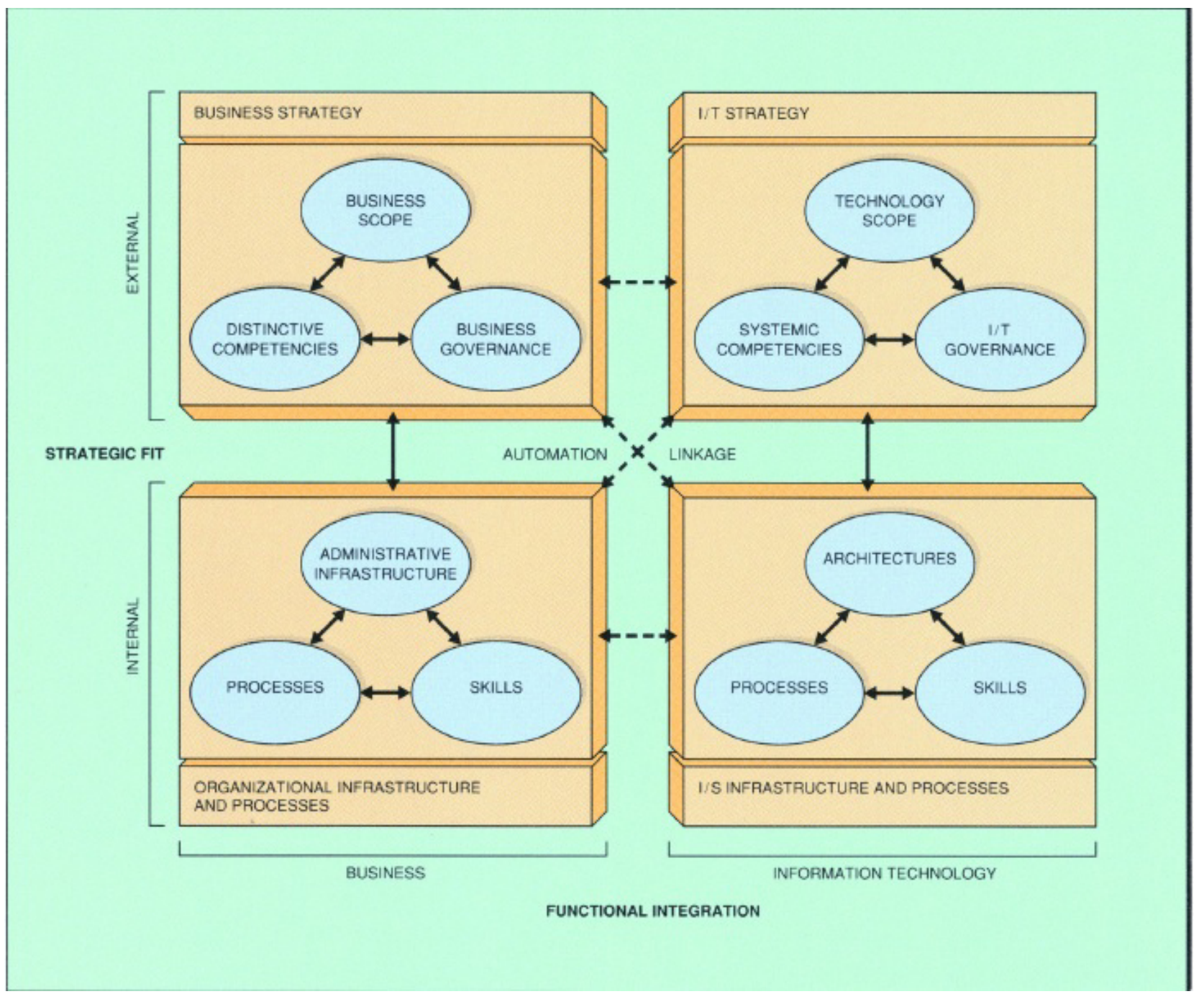

Figura 3.1: Representação do conceito proposto Henderson e Venkatraman(2003)

- Competências sistêmicas (Systemic Competencies) - Mostram quais são as capacidades necessárias de TI para auxiliar a organização a atender determinada estratégia.

- Habilidades TI(I/T Skills ) - Potencial da organização para entregar os Produtos e Serviços de TI

- Processos de negócios(Business Process) - Envolvem as atividades definidas para garantir os resultados esperados pelo negócio.

- Processos de TI $(i / T$ Process $)$ - Envolvem as atividades definidas para garantir o funcionamento das operações de TI.

- Infraestrutura Administrativa (Administrative Infraestructure) - Inclui tomadas de decisões, Definição de níveis de processos e atribuições de papéis e responsabilidades. 
- Arquitetura de TI (I/T Architecture) - Definição da infraestrutura técnica de TI (Hardware, Software. comunicação, arquitetura de dados).

Como destacado anteriormente, o modelo proposto por Henderson e Venkatraman (1993) é baseado na integração funcional entre os processos e as competências da organização, as quais possuem impacto direto sobre os processos de negócio da organização. O impacto ocorre nos ambientes internos e externos da organização, sendo que internamente é feito o ajuste estratégico, unificando as diversas áreas da organização, para alinhar a organização as necessidades do mercado.

\subsubsection{Modelo Luftman, Lewis e Odalch}

O modelo proposto por Henderson e Venkatraman (1993) serviu como apoio para outros modelos como o proposto por Luftman (Luftman et al., 1993). O modelo estabelece quatro perspectivas estratégicas distintas.

O modelo de perspectivas estratégicas incorpora quatro perspectivas de direcionamento do Alinhamento Estratégico. Cada perspectiva é compostas pelos seguintes elementos: uma "Ancora"simbolizando a área que dirige as forças, uma mudança sobre a área problema sendo atacada e o seu Impacto (área afetada pela mudança).

A perspectiva de potencial competitivo reflete como a tecnologia emergente, podendo influenciar ou habilitar novas estratégias de negócio como, por exemplo, novas oportunidades de mercado. A perspectiva mostra a estratégia de TI como a área que são dirigidas as forças, a estratégia de negócio como domínio de ataque e a infraestrutura organizacional como área afetada.

A perspectiva de potencial tecnológico foca no estabelecimento do ajuste estratégico para a TI, onde a mesma é utilizada para habilitar novas estratégias de negócio. A estratégia de negócio é a área que são dirigidas as forças, a estratégia de TI é o domínio de ataque a infraestrutura de TI é a área afetada.

A perspectiva de Nível de serviço é semelhante a perspectiva de potencial competitivo , no entanto, o domínio de ataque é a infraestrutura de TI ao invés da estratégia de negócio. Esta perspectiva permite analisar qual seria o impacto se a TI falhasse.

A perspectiva de execução estratégica que são suportadas pela infraestrutura da organização e da TI e representa as estratégias de negócio como área que são dirigidas as forças e as mesmas fluem pela infraestrutura organizacional (domínio de ataque) até a infraestrutura de TI (área afetada).

Estas perspectivas variam de acordo com o foco e as práticas gerenciais da organização. Com isso, o modelo possibilita o direcionamento de determinados tipos de processos, 
orientando-os a partir do alinhamento estratégico. A Figura 3.2 mostra o modelo de perspectivas estratégicas:
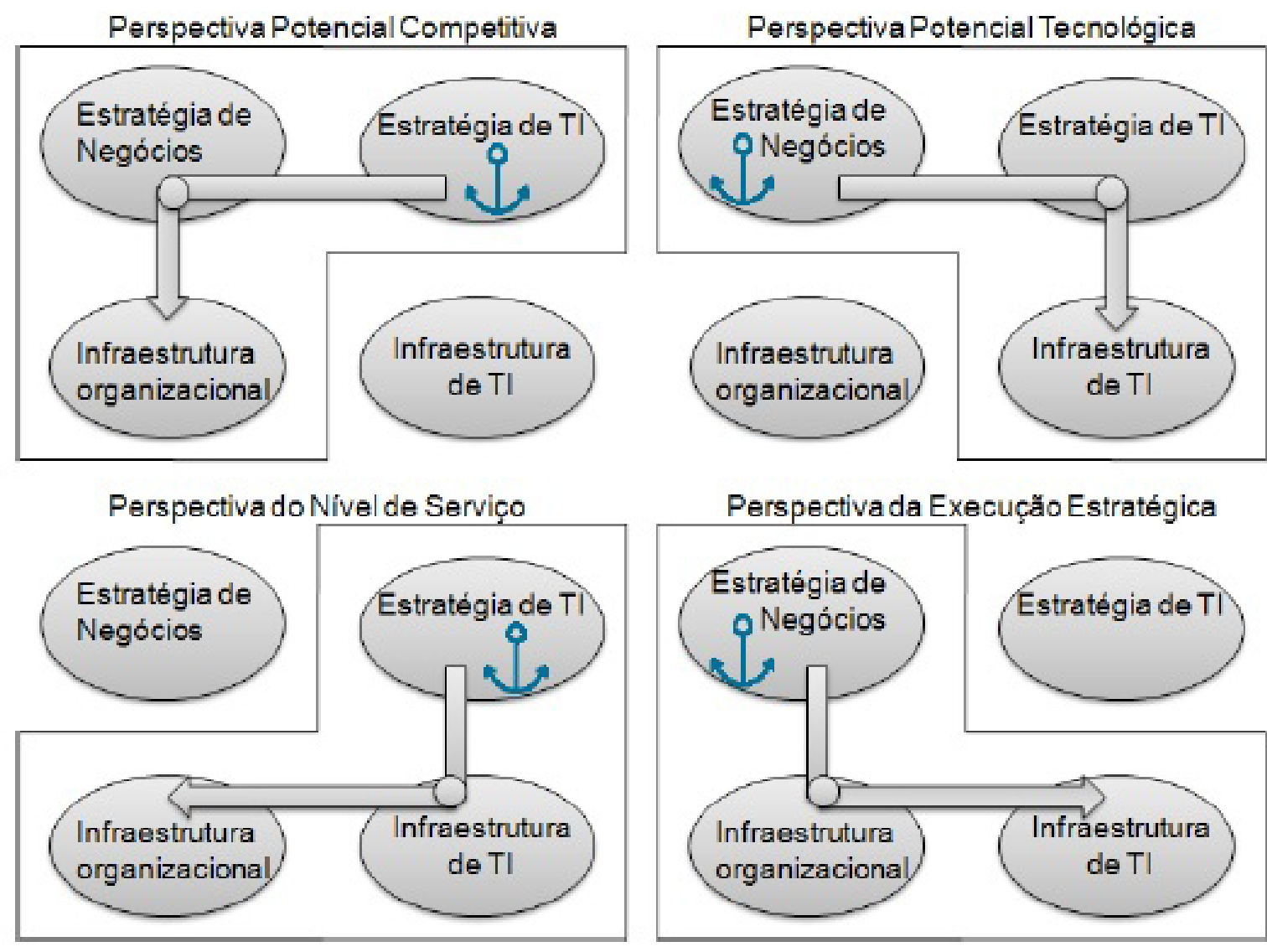

Figura 3.2: Representação do conceito proposto Luftman(1993)

\subsection{O Alinhamento Estratégico nos diferentes níveis hi- erárquicos}

A Figura 3.3 ilustra uma pirâmide que representa uma organização com os seus níveis hierárquicos. Nessa figura, são caracterizados como processos operacionais, processos táticos e processos estratégicos. O nível estratégico consiste dos altos executivos da organização, responsáveis pela definição dos objetivos e planos da empresa, o nível tático, é utilizado para traduzir os objetivos gerais e as estratégias da alta diretoria em objetivos e atividades mais específicos e o nível operacional o processo é de uma menor amplitude, onde o foco é trabalhar junto aos funcionários com o intuito de produzir o que é esperado pelo cliente (Bateman e Snell, 1998) 


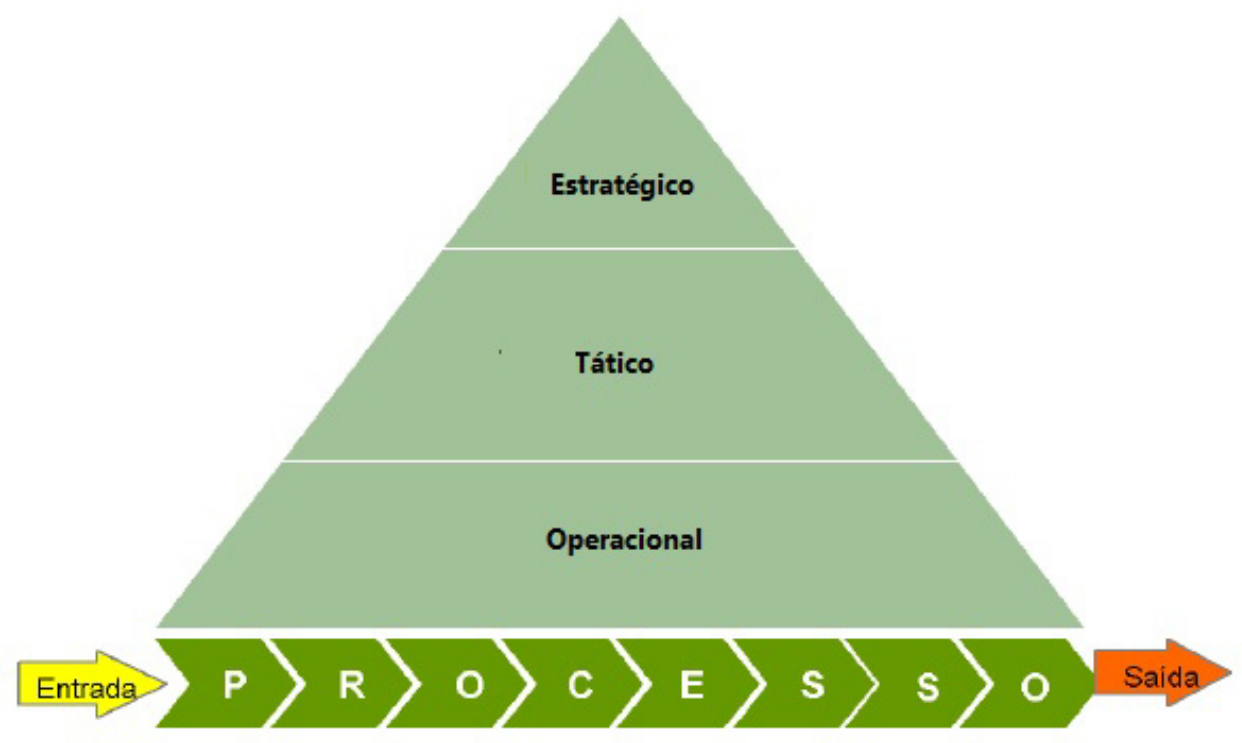

Figura 3.3: Representação dos níveis organizacionais(adaptado de Laudon e Laudon, 2007)

A lacuna entre a TI e o negócio pode ser verificada em condições diferentes para cada nível hierárquico da corporação. No nível operacional o Alinhamento Estratégico ocorre quando a TI fornece suporte a produção do negócio, enquanto para o nível estratégico a TI é utilizada para amparar nas tomadas de decisões. Essas características distintas fazem com que abordagens diferentes sejam tomadas para que seja possível alcançar o Alinhamento Estratégico em todos os níveis organizacionais.

Entretanto, apesar das opiniões favoráveis sobre o impacto positivo do alinhamento estratégico nas organizações, ainda existem algumas barreiras para a adoção da visão processual. Pesquisas mostram que o alinhamento pode ser prejudicado por problemas de comunicação, perda de recursos ou ausência de comprometimento por parte das equipes (Lederer e Sethi, 1996; Reich e Benbasat, 1996) .

Essas falhas no alinhamento podem ser prejudiciais na elaboração dos processos, pois à medida que os requisitos são levantados de maneira incorreta, imprecisa ou existe a omissão de requisitos, e os processos são construídos com base nos atributos falhos, então consequentemente os processos não conseguirão atender as necessidades do negócio.

Uma forma de atender a estas lacunas é realizar a modelagem em nívels, a modelagem pretende atingir a lacuna de atender aos requisitos e alinhar como o processo deve ser feito e os níveis possui a finalidade de representar o processo sobre perspectivas distintas, alinhada aos níveis hierarquicos da organização. 


\subsection{Abordagens e Ferramentas Multiníveis}

A Modelagem de processos facilita discussões mais assertivas entre a TI e as áreas de negócio , apoiando por meio da representação de processos como os mesmos devem ser implementados e executados. Com isso, o processo de modelagem pode ser considerada uma atividade crítica para orientar o alinhamento estratégico.

No entanto, há dificuldades para especificar e medir informações de negócio nas linguagens de modelagem de processos atuais, incluindo BPMN - uma das as notações mais completas e atualmente utilizadas em organizações, uma vez que o foco desta tradicional abordagens é a representação do comportamento funcional e não a representação de informações que descrevem o por quê de realizar determinadas funções.

Com a revisão sistemática, foi possível identificar alguns trabalhos com esta preocupação, propondo soluções voltadas a modelagem em níveis para relacionar as estratégias da organização com os processos de negócio.

\subsubsection{Pensamento em Níveis}

O pensamento em níveis fornece uma perspectiva para visualizar as lacunas entre os processos de negócio e a tecnologia.

No artigo de Lind e Seigerroth (2010) foi realizada uma pesquisa ação sobre o framework multiníveis que permite diferentes níveis de formalismo para mostrar como diferentes conceitos estão relacionados dentro e entre as os diferentes níveis de abstração da organização.

A Figura 3.4 apresentada no artigo, ilustra uma pirâmide que representa um mapa com os níveis gerais da organização. Ao todo são 5 níveis e ao mudar os níveis é possível verificar a transição entre os processos principais e seus atores, os sub processos, as atividades com a performance de seus atores até chegar as Tasks(Tarefas) com os usuários de scripts (na base da pirâmide) (Lind e Seigerroth, 2010a).

Segue abaixo a descrição de cada nível do framework:

- Nível 1 - Este nível possui o foco na Organização como um todo.

- Nível 2 - Este nível representa a relação entre os Processos da organização.

- Nível 3 - Este nível é representado pelo processo e seus subprocessos.

- Nível 4 - Neste nível é mostrado as atividades dentro dos processos e subprocessos.

- Nível 5 - Representa o nível atômico (não pode ser mais detalhado) do diagrama, onde são representadas as tarefas dos processos. 


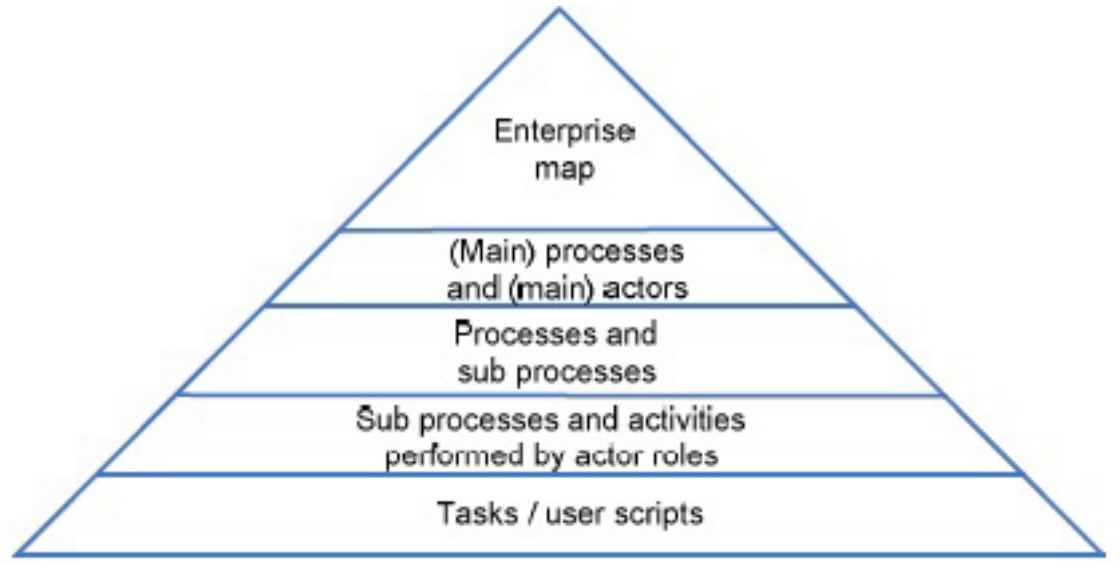

Figura 3.4: Representação da Pirâmide baseada no framework multicamadas (Lind e Seigerroth, 2010a)

Este trabalho é interessante, no entanto, a ausência de suporte computacional impede a mensuração dos ganhos propostos pelo metamodelo. A utilização de modelagens pouco convêncionais também é outro ponto a ser destacado.

\subsubsection{Multiníveis e Múltiplas Perspectivas}

Similar a pesquisa anterior, o trabalho de Nuffel and Backer (Nuffel e Backer, 2012) apresentam um framework que além de permitir uma visão multi camadas, o mesmo também apresenta diferentes visões para cada nível. A Figura 3 apresenta a base do framework de Nuffel e Backer.

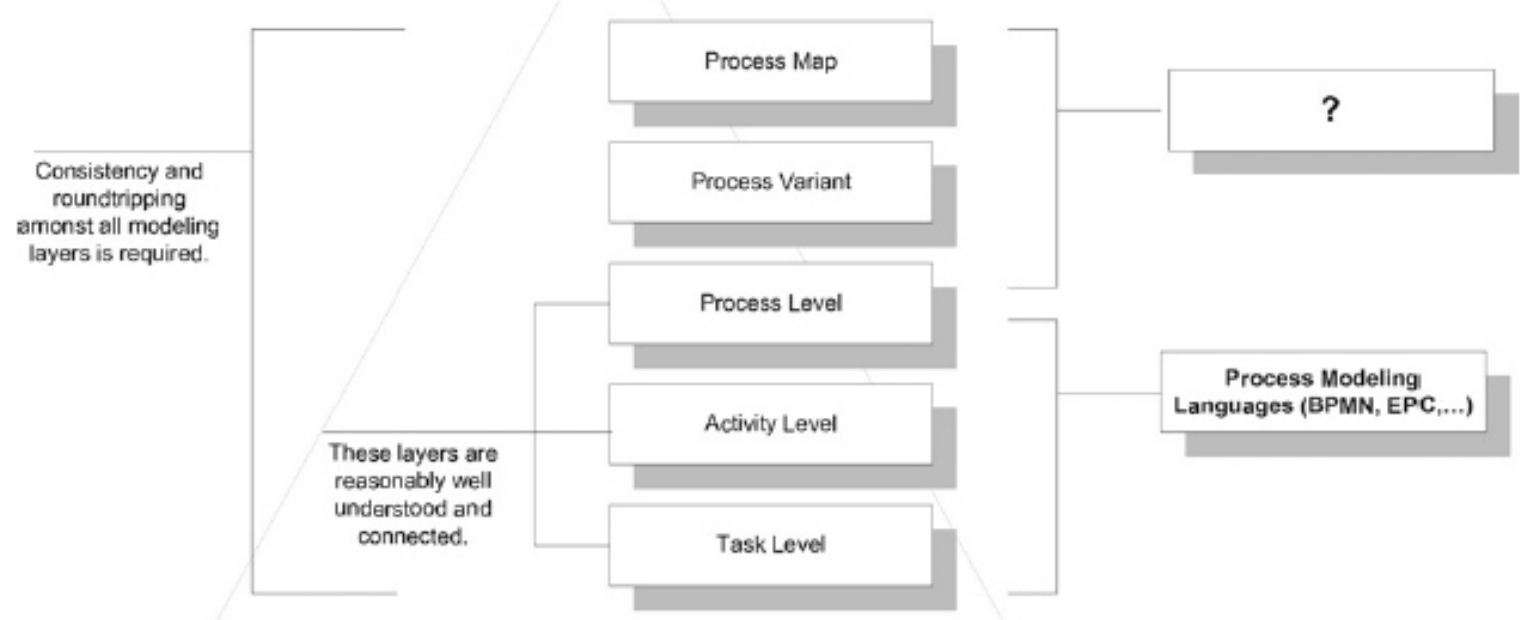

Figura 3.5: Framework de Nuffel e Backer (Nuffel e Backer, 2012)

Outra característica importante do trabalho de Nuffel e Backer é o levantamento do estado da arte das linguagens de modelagem e os modelos de arquiteturas corporativas de 


\section{CAPÍTULO 3. ALINHAMENTO ESTRATÉGICO}

referência assim como o levantamento de trabalhos relevantes sobre metodologias para a modelagem de processos multiníveis.

Assim como o trabalho de Lind, este trabalho também não possui um suporte computacional para facilitar a utilização da abordagem. Ambos os trabalhos serão descritos com maiores detalhes na próxima seção.

\subsubsection{Aris}

A solução Aris(Scheer, 2000) desenvolvida pela Solution AG em 2000, inicialmente para modelagem de processos, hoje conta com diversos tipos de diagramas para a modelagem corporativa. Dentre as soluções e abordagens pesquisadas esta é a mais completa na aréa de modelagem de processos e modelagem em níveis. A solução fornece uma flexibilidade na escolha da linguagem de modelagem, permitindo por exemplo a escolha do BPMN ou EPC para modelagem de Processos e Business model canvas, diagramas de estratégias, diagrama de alocação de estratégia e diagrama SWOT para modelagens de Estratégias. A Figura 3.6 ilustra uma modelagem de processos com EPC na ferramenta ARIS.

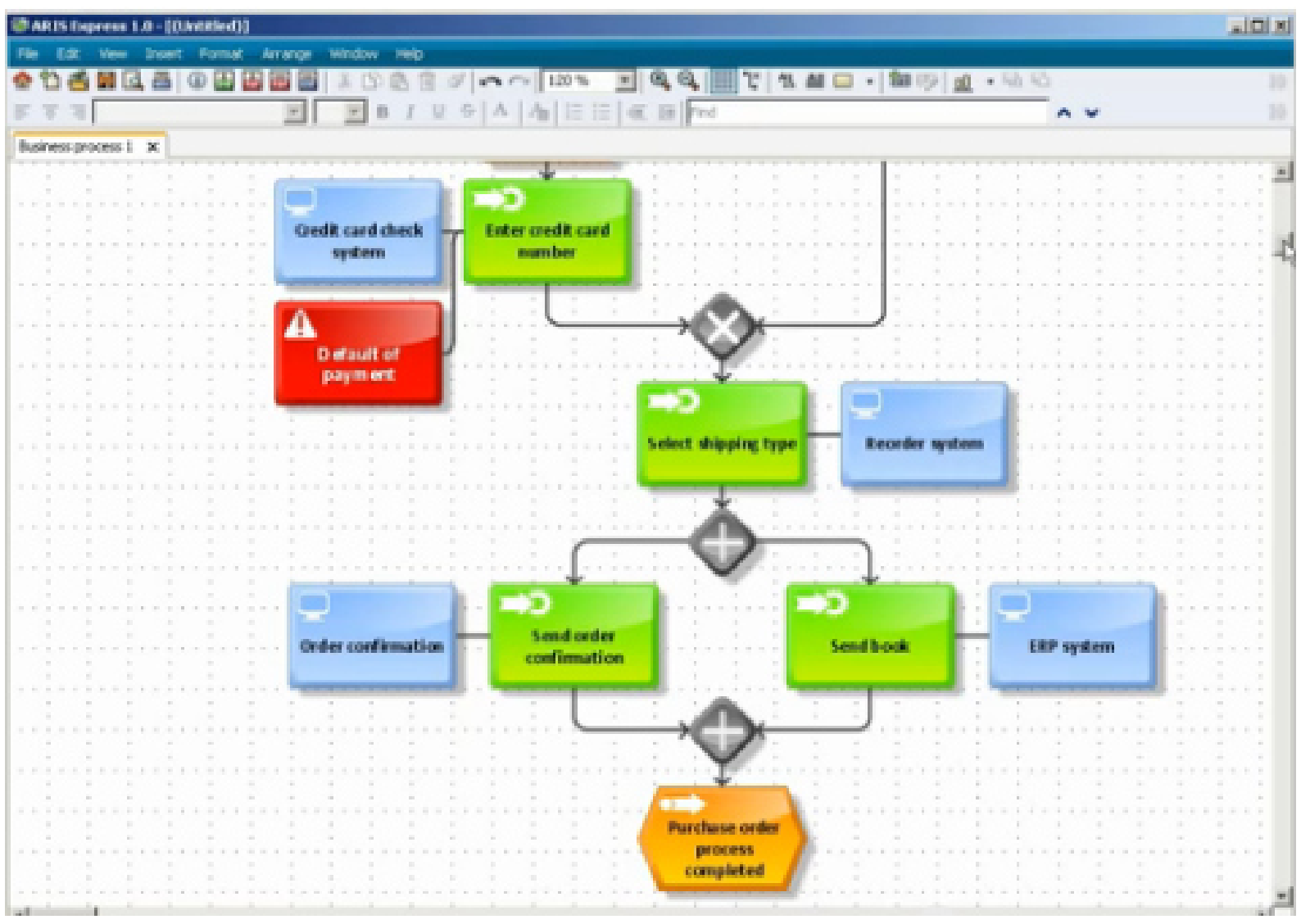

Figura 3.6: Modelagem EPC na ferramenta Aris(Scheer, 2000) 
A ferramenta a partir de um fluxo de processo permite referenciar outros diagramas modelados como por exemplo um diagrama de unidade organizacional, facilitando a abstração de informações.

De forma geral a ferramenta ARIS é completa e está sólida no mercado a muito tempo, no entanto, alguns pontos negativos devem ser destacados.

O primeiro ponto é a aplicação ser desenvolvida em versão desktop, esta arquitetura de sistema dificulta na distribuição de executáveis entre as partes interessadas (tanto na instalação quanto na atualização), pois por mais que a aplicação permita o armazenamento dos diagramas em nuvens e possua um controle de acesso aos diagramas, é necessário que todas as máquinas tenham o software instalado e sincronizados com uma determinada versão, restringindo o acesso aos diagramas da organização.

O segundo ponto é o elevado custo para obter esta solução, o dono da organização precisa investir um valor considerável para obter todos os recursos da ARIS. Existe as versões "express"que são livres para utilização, no entanto, as mesmas não possuem todas os recursos da versão paga.

O terceiro ponto é a falta de integração gráfica entre os diagramas, apesar de haver referências entre eles, não é possível "mesclar"os diagramas ou ter uma perspectiva onde seja possível ver os diagramas trabalhando colaborativamente no mesmo fluxo. Para nossos interesses de pesquisa isto é um ponto a ser considerado pois precisamos ver onde uma determinada estratégia está sendo executada no processo.

O último ponto é o código não ser aberto, isto impede possíveis customizações do projeto para o negócio do cliente.

\subsubsection{ArchiMate}

A linguagem ArchiMate (TheOpenGroup, 2008) desenvolvida pela The Open Group em 2008 é uma linguagem aberta de modelagem para arquitetura empresarial e suportada por diversos desenvolvedores de ferramentas. A mesma é constituida de três níveis principais como pode ser visto na figura 3.7

A primeira camada é a de Negócios, onde é oferecido os produtos e serviços aos clientes externos e desempenhados na organização por meio de processos de negócio. A segunda camada de Aplicação suporta a camada de negócios com serviços de aplicativos que são realizadas por softwares. A terceira camada de Tecnologia oferece serviços de infra-estrutura (por exemplo, processamento, armazenamento e serviços de comunicação) necessários para executar aplicativos , realizados por informática e comunicação de hardware e software do sistema. 
Passive

structure

Behavior

Active

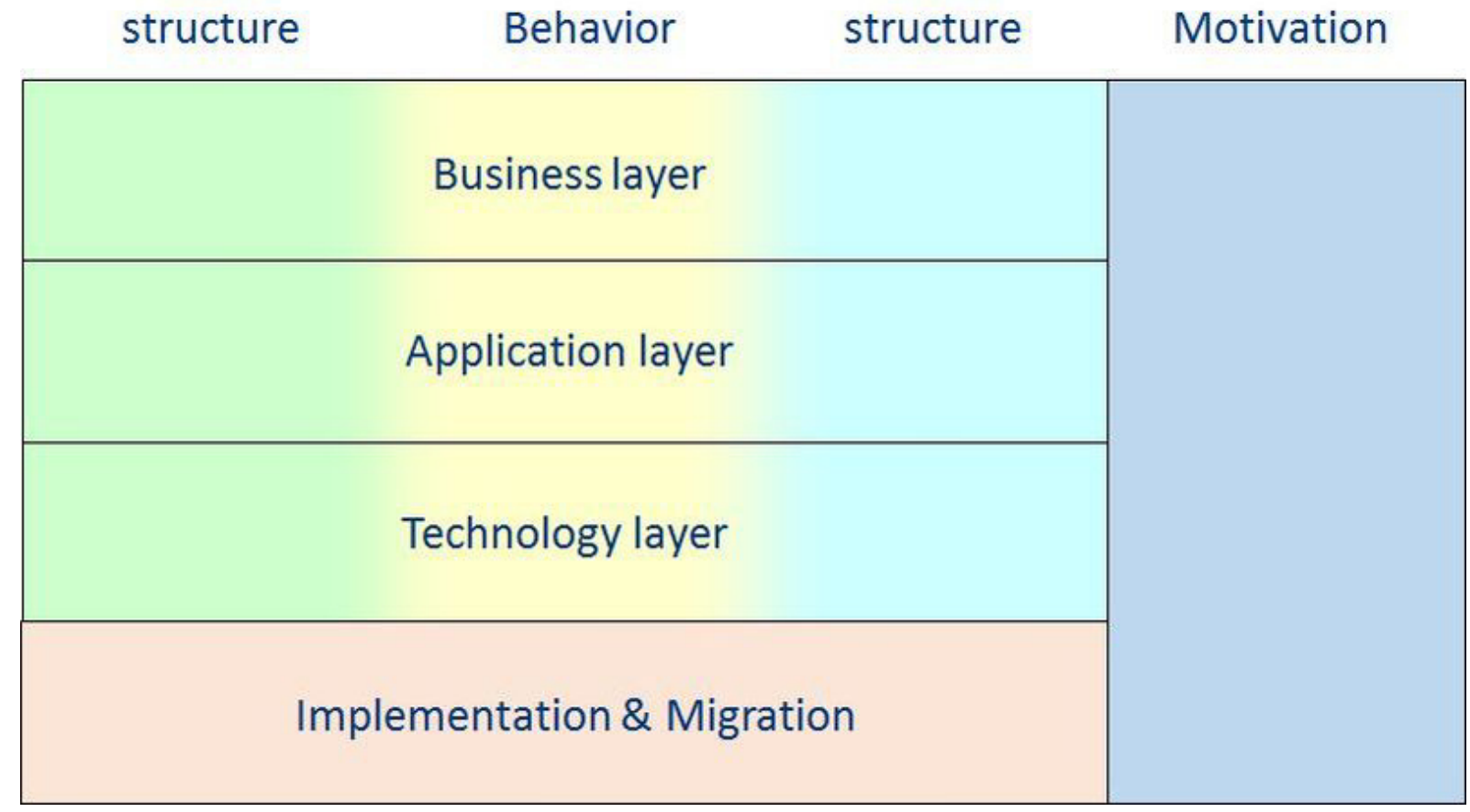

Figura 3.7: Framework ArchiMate (TheOpenGroup, 2008)

Em geral a estrutura dos modelos entre os níveis são semelhantes, os mesmos tipos de conceitos e relações são usados, embora sua exata natureza e granularidade sejam diferentes.

Em questões de modelagem, a Archimate conta com diversos fornecedores como por exemplo o Visio(utilizando plugin), Archi e Archimate Diagram Tool que fornecem APIs para modelar na linguagem.

Assim como a ARIS, foi visto como pontos negativos a ausência de uma ferramenta web para a modelagem e a falta de integração gráfica entre os diagramas que envolvem processos e a ausência de abstrair e detalhar os processos de negócio. Por fim é válido destacar que não é objetivo deste trabalho analisar as vantagens e desvantagens da abordagem de Arquitetura Empresarial e sim a representatividade dos processos de negócio e ligação com as estratégias nas abordagens.

\subsubsection{BEN}

BEN (Business Engineering Navigator ) (Winter, 2011) é uma estrutura que permite a concepção e gestão holística da organização, o mesmo foi desenvolvido pelo instituto de gerenciamento de informação na universidade de St. Gallen na Suiça e tem como base cinco camadas diferentes que representam as arquiteturas empresariais como ilustra a Figura 3.8. 


\section{CAPÍTULO 3. ALINHAMENTO ESTRATÉGICO}

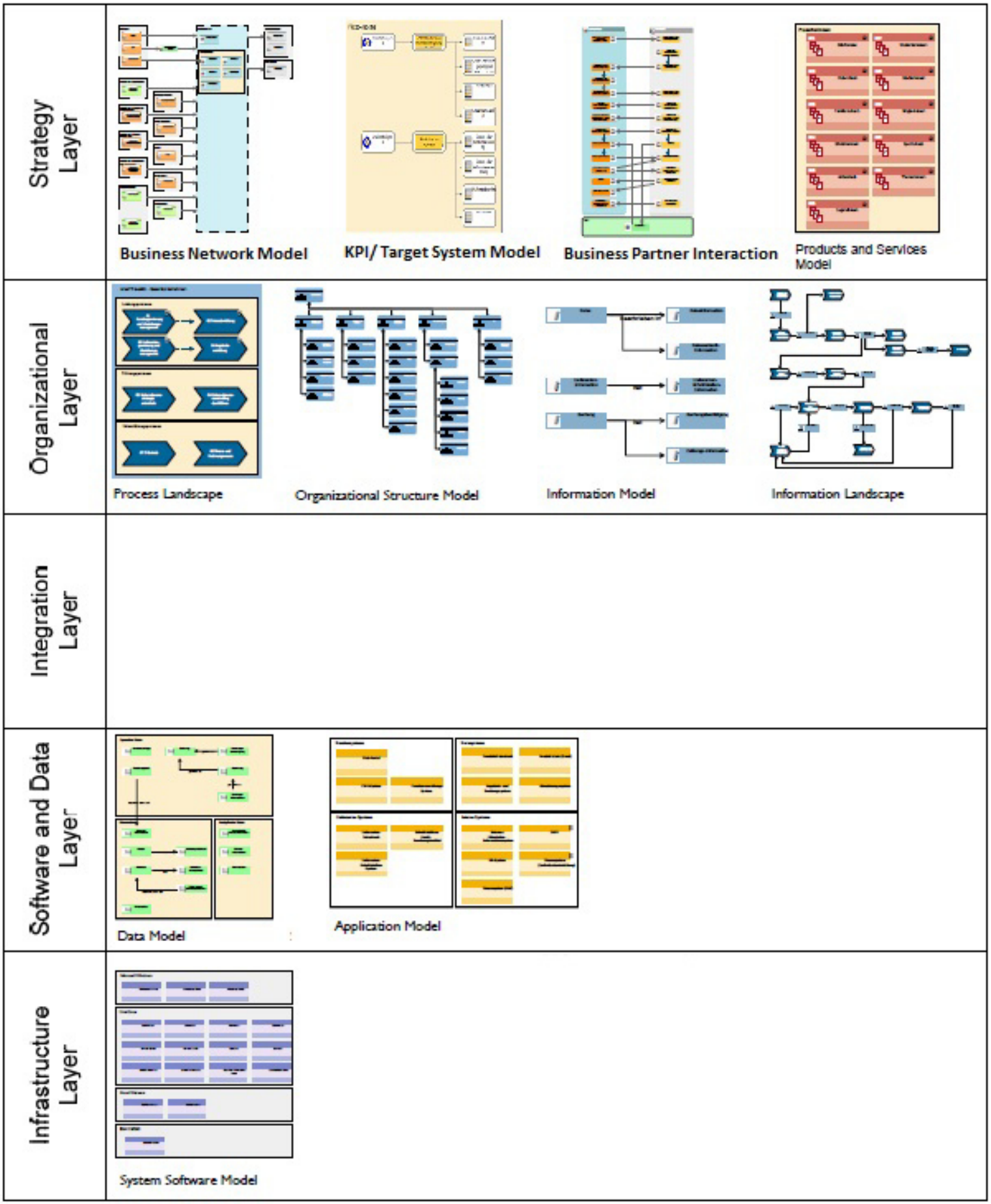

Figura 3.8: BEN (Winter, 2011)

De uma maneira sintetizada, essas camadas representam desde informações estratégicas e as estruturas organizacionais, até a infra-estrutura hardware e software e sua integração. A abordagem também conta com um suporte computacional desktop para a modelagem. 


\subsection{Comparação entre Trabalhos}

As particularidades das abordagens são exploradas abaixo por critérios que permitem a comparação entre os cinco trabalhos apresentados na seção anterior, estão listados a seguir:

(Aris)Aris (Scheer, 2000)

(N\&B)Multiníveis e Múltiplas Perspectivas (Nuffel e Backer, 2012)

(L\&S)Pensamento em Níveis (Lind e Seigerroth, 2010a)

(Archi)Archimate (TheOpenGroup, 2008)

(BEN)BEN (Winter, 2011)

Os critérios para comparação foram definidos de acordo com as lacunas de pesquisas levantadas pelos autores e pelas pesquisas (Lind e Seigerroth, 2010a; Nuffel e Backer, 2012; Scheer, 2000; TheOpenGroup, 2008; Winter, 2011) , acompanhando todos os aspectos, ferramentas e técnicas dessas propostas, chegando ao seguinte conjunto de aspectos:

(a)A abordagem possui ferramenta de suporte para apoiar a definição dos modelos.

(b)A ferramenta permite a modelagem colaborativa entre diversas pessoas no mesmo diagrama. Em uma modelagem em níveis é necessária a presença de participantes de todos os níveis hirárquicos da organização (operacional, tático e estratégico)

(c)A ferramenta permite alterações em seu código fonte (código aberto) para adequar novas abordagens.

(d)A ferramenta possui permite escolher a linguagem desejada para a modelagem, para não limitar os usuários da ferramenta a modelarem em uma linguagem específica.

(e)A ferramenta permite a modelagem na web, uma vez que esta forma de modelagem permite que diversas pessoas acessem os diagramas sem a necessidade de instalação de ferramenta.

(f)A abordagem fornece uma estrutura para representação de Informações de Negócio

(g)A abordagem fornece uma estrutura para associar Informações de Negócio a modelagem dos Processos

(h)A abordagem fornece uma estrutura para associar Informações de Negócio a modelagem das Atividades dos Processos

(i)A abordagem fornece uma estrutura para associar Informações de Negócio a modelagem das Tarefas dos Processos

(j)A abordagem desenvolveu e forneceu um metamodelo em UML.

(l)A abordagem foi aplicada em estudos de casos reais.

(m)A abordagem é recomendada por especialistas ou utilizada em organizações.

(n)A abordagem permite o gerenciamento de coleções de processos, permitindo modelar e visualizar diversos processos da organização. 


\begin{tabular}{cccccc}
\hline & (Aris) & $(\mathrm{N \& B})$ & $(\mathrm{L} \& \mathrm{~S})$ & $($ Archi $)$ & $(\mathrm{BEN})$ \\
\hline (a) & $\mathrm{X}$ & & & $\mathrm{X}$ & $\mathrm{X}$ \\
$(\mathrm{b})$ & $\mathrm{X}$ & & & $\mathrm{X}$ & \\
(c) & & & & $\mathrm{X}$ & \\
$(\mathrm{d})$ & $\mathrm{X}$ & & & $\mathrm{X}$ & \\
$(\mathrm{e})$ & & & & & \\
$(\mathrm{f})$ & $\mathrm{X}$ & & & $\mathrm{X}$ & \\
$(\mathrm{g})$ & & & & & \\
$(\mathrm{h})$ & & & & & \\
$(\mathrm{i})$ & & & & & \\
$(\mathrm{j})$ & & $\mathrm{X}$ & $\mathrm{X}$ & $\mathrm{X}$ & $\mathrm{X}$ \\
$(\mathrm{l})$ & $\mathrm{X}$ & $\mathrm{X}$ & $\mathrm{X}$ & $\mathrm{X}$ & $\mathrm{X}$ \\
(m) & $\mathrm{X}$ & & & $\mathrm{X}$ & $\mathrm{X}$ \\
(n) & $\mathrm{X}$ & & $\mathrm{X}$ & $\mathrm{X}$ & $\mathrm{X}$ \\
\hline
\end{tabular}

Tabela 3.1: Comparação entre Trabalhos

Com os resultados é possível observar que as soluções ARIS, Archimate e BEN possuem suportes computacionais, no entanto, é necessário que o programa desktop esteja instalado e todos os acessos sejam atribuídos para que a modelagem colaborativa seja permitida. Com relação ao Metamodelo, apenas a ARIS não fornece um Metamodelo. Novamente a ARIS, Archimate e BEN representam informações de negócio, no entanto, a relação intrínseca entre as informações de negócio e a modelagem de processos não é representada em um único diagrama.

Com a consolidação foi possível constatar que há uma lacuna de abordagens que permitam a representações dos processos de negócios relacionados com as informações estratégicas em apenas um diagrama. Este relacionamento não pode ser perdido através dos níveis de processos. Por fim, também foi vista a necessidade de um suporte computacional web para facilitar o acesso as diagramas e a colaboração nas modelagens.

\subsection{Considerações Finais}

Neste capítulo foram reunidos os principais conceitos sobre o alinhamento estratégico, apresentando os modelos de Alinhamento Estratégico de Henderson e Venkatraman (1993) e Luftman, Lewis e Odalch(1993). Também foi visto as diferenças do alinhamento estratégico nos diferentes níveis hierárquicos da organização e a necessidade de suportes multiníveis para representar os processos de negócio.

Dentre as abordagens multiníveis foi vista a necessidade de um suporte computacional web que permita modelar os processos em diversos níveis de detalhamento para que seja possível detalhar modelos abstratos quando há necessidade de compreender o todo e 


\section{CAPÍTULO 3. ALINHAMENTO ESTRATÉGICO}

também modelar diagramas completos com execuções de tarefas para que o alinhamento do processo seja feito de forma adequada.

No próximo capítulo será apresentada a abordagem detalhada para atender a essas necessidades. 



Capítulo

\section{Metamodelo}

Atualmente, desenvolver uma nova linguagem de modelagem de processos e modelos de arquiteturas corporativas de referência sem utilizar nenhum outro modelo como base é analogamente comparável à reinvenção da roda, pois houveram inúmeras pesquisas nessas áreas em questão. (Elvesæter et al., 2010; Lind e Seigerroth, 2010a; Sadovykh et al., 2010). Com isso, o objetivo desta pesquisa é unir de forma eficaz os modelos já existentes com o intuito de representar como o alinhamento estratégico pode ser obtido a partir da união e aperfeiçoamento de modelos já existentes, permitindo a partir da modelagem a comparação do que será executado nas tarefas com o que foi planejado.

Para isso, o modelo aqui proposto representa desde os planos do negócio até a sua ligação com os processos de negócio, que por sua vez, podem ser navegados até seu nível atômico. Para isso, têm se como base a abordagem multinível proposta por Lind e Seigerroth (Lind e Seigerroth, 2010a), uma vez que a mesma fornece uma perspectiva para modelagem em níveis partindo do modelo estratégico até o nível atômico dos processos de forma a ter uma representação ora abstrata, ora detalhada dependendo da necessidade e a abordagem multicamadas de Nuffel and Backer (Nuffel e Backer, 2012) que além dos níveis, também fornece múltiplas perspectivas para facilitar a compreensão de possíveis donos de processos entre outras informações. No entanto, divergente das duas abordagens citadas, esta abordagem utiliza como base para as camadas propostas (Lind e Seigerroth, 2010a; Nuffel e Backer, 2012) os modelos do BMM e o BPMN (OMG, 2010, 2011) 
para unir as vantagens dos modelos já difundidos com as vantagens de representações em multiníveis.

A escolha do BMM, fez se necessário unir o primeiro e segundo nível da abordagem de Lind e Seigerroth (Lind e Seigerroth, 2010a) e Nuffel and Backer (Nuffel e Backer, 2012) em apenas um nível(Nível Estratégico) pois o modelo fornece uma perspectiva horizontal, dificultando a divisão do mesmo em dois níveis. Os demais níveis são semelhantes aos propostos nas pesquisas de Lind e Seigerroth (Lind e Seigerroth, 2010a) e Nuffel and Backer (Nuffel e Backer, 2012).

A escolha do BPMN foi devido à alta representatividade que a linguagem de modelagem possui para representar os processos, facilitando a modelagem dos processos em níveis. O BMM por sua vez foi escolhido pois o mesmo além de possuir compatibilidade com o BPMN em seu metamodelo, também fornece uma abordagem de forma livre de aplicação, delegando ao implementador escolher o que utilizar e que informações devem ser acrescentadas, permitindo assim uma adequação com os trabalhos de Lind e Seigerroth (Lind e Seigerroth, 2010a) e Nuffel e Backer (Nuffel e Backer, 2012).

Esta união permite a ligação de elementos de planos de negócios como estratégias e táticas com os modelos de processos de negócio, possibilitando comparar as informações contidas no fluxo do processo com as estratégias e táticas definidas para o processo. Esta forma de representação possibilita que o alto nível hierárquico da organização visualize como suas estratégias e táticas estão sendo atacadas no processo e também quem está executando o processo tem a possibilidade de visualizar o impacto das tarefas sobre o planejamento.

\subsection{Metamodelo}

O metamodelo é composto pela união dos modelos do BMM e BPMN. Com o BMM modelamos informações estratégicas do negócio e com o BPMN conseguimos representar o fluxo dos processos deste negócio. Com a união de ambos conseguimos representar as informações alto nível e suas ligações com o fluxo do processo em um único diagrama de forma unificada, utilizando para isto a representação em níveis que permite que uma informação de alto nível seja ligada as tarefas executadas do processo.

A Figura 4.1 representa como o BMM e o BPMN são implantados nas camadas propostas nos trabalhos de Mikael Lind e Ulf Seigerroth (Lind e Seigerroth, 2010a) e Nuffel e Backer (Nuffel e Backer, 2012).

Na mesma, é possível notar a presença de elementos de alto nível na primeira camada, representados pelos elementos do BMM que possuem ligação direta com os Processos de Negócio. A partir desta ligação é possível representar do segundo ao quarto nível o 

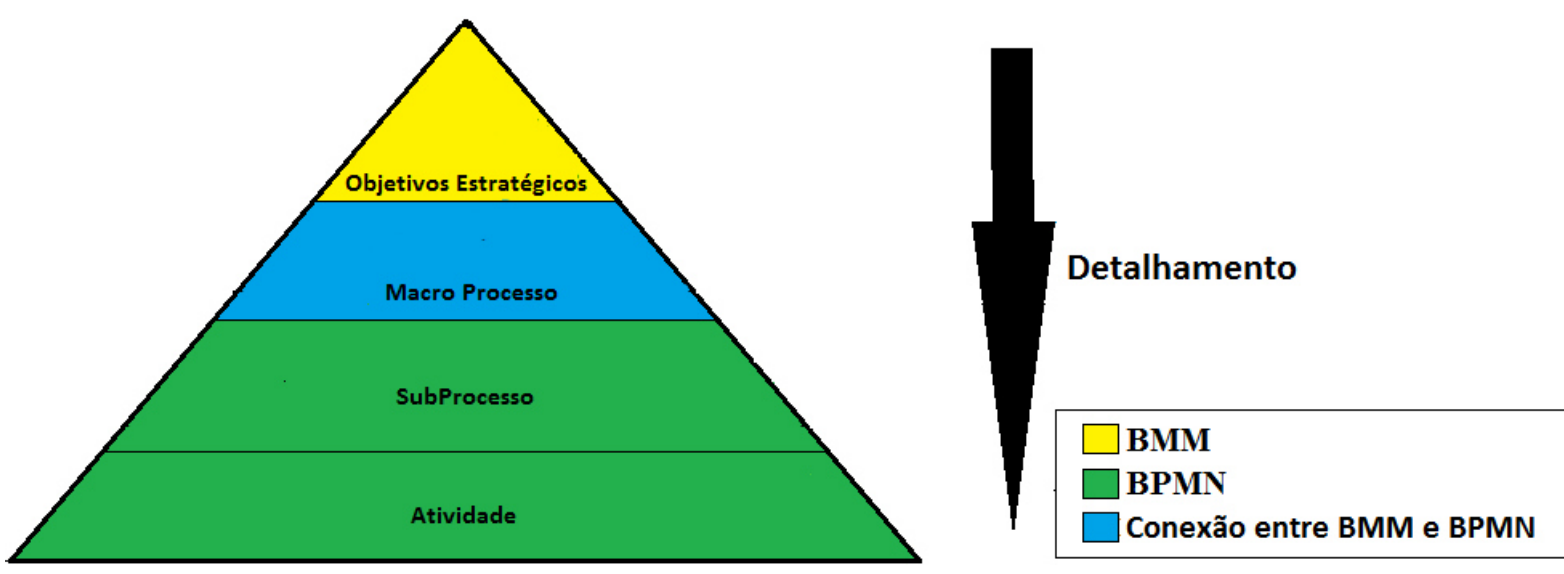

Figura 4.1: Representação da abordagem

fluxo de um processo de negócio com abstrações em níveis de processos para facilitar a compressão do processo Fim a Fim no segundo nível quando é desejado apenas a visão do "caminho feliz"do fluxo processo, agregados a possibilidade de visualizar as características específicas das atividades e tarefas definidas no processo sem perder a ligação com os elementos estratégicos (no terceiro e quarto nível da abordagem). O metamodelo ilustrado na Figura 4.2 representa as possibilidades que a abordagem fornece.

O metamodelo foi dividido em três partes (BMM, Intersecção e BPMN) para facilitar a compreensão do mesmo. Nesta divisão, o nível mais elevado da abordagem é o BMM que por sua vez é representado pelos "Fins", "Meios", "Influenciadores", "Avaliações"(Capítulo 2, Seção BMM).

Os Fins representam de uma maneira geral aonde a organização pretende estar, para isto, elementos alto níveis são definidos como a Visão e os Resultados Desejados pela Organização, estes elementos são abstratos e sustentados pelos "Meios"da Organização. Os elementos definidos no Meio estão relacionados diretamente aos processos de negócio e possuem suma importância na abordagem, uma vez que os processos dependem da forma como esses elementos são criados, compreendidos e aplicados nos processos de negócio. Dentre os elementos estão as Estratégias e Táticas (Curso de Ação) que a organização definem para os processos atingirem os objetivos e metas, Regras de Negócio e Políticas de Negócio que são diretivas a serem seguidas nos processos e a Missão que representa a Visão na prática. O processo também possui a ligação com as unidades organizacionais ou departamentos e por meio deste é feito a ligação com os influenciadores (que podem ser internos ou externos). Os elementos Meios, Influenciadores e Departamentos são avaliados para que algumas ações possam ser tomadas de acordo com o que foi definido.

Entre modelar o processo com o BPMN e ligar os mesmos com os elementos do BMM é possível definir se o processo específico é um Macro Processo ou um Variante de Processo (tradução de Process Variant no inglês original), sendo que a segunda opção é representada por um conjunto de processos contidos em um Macro Processo que possuem o mesmo 


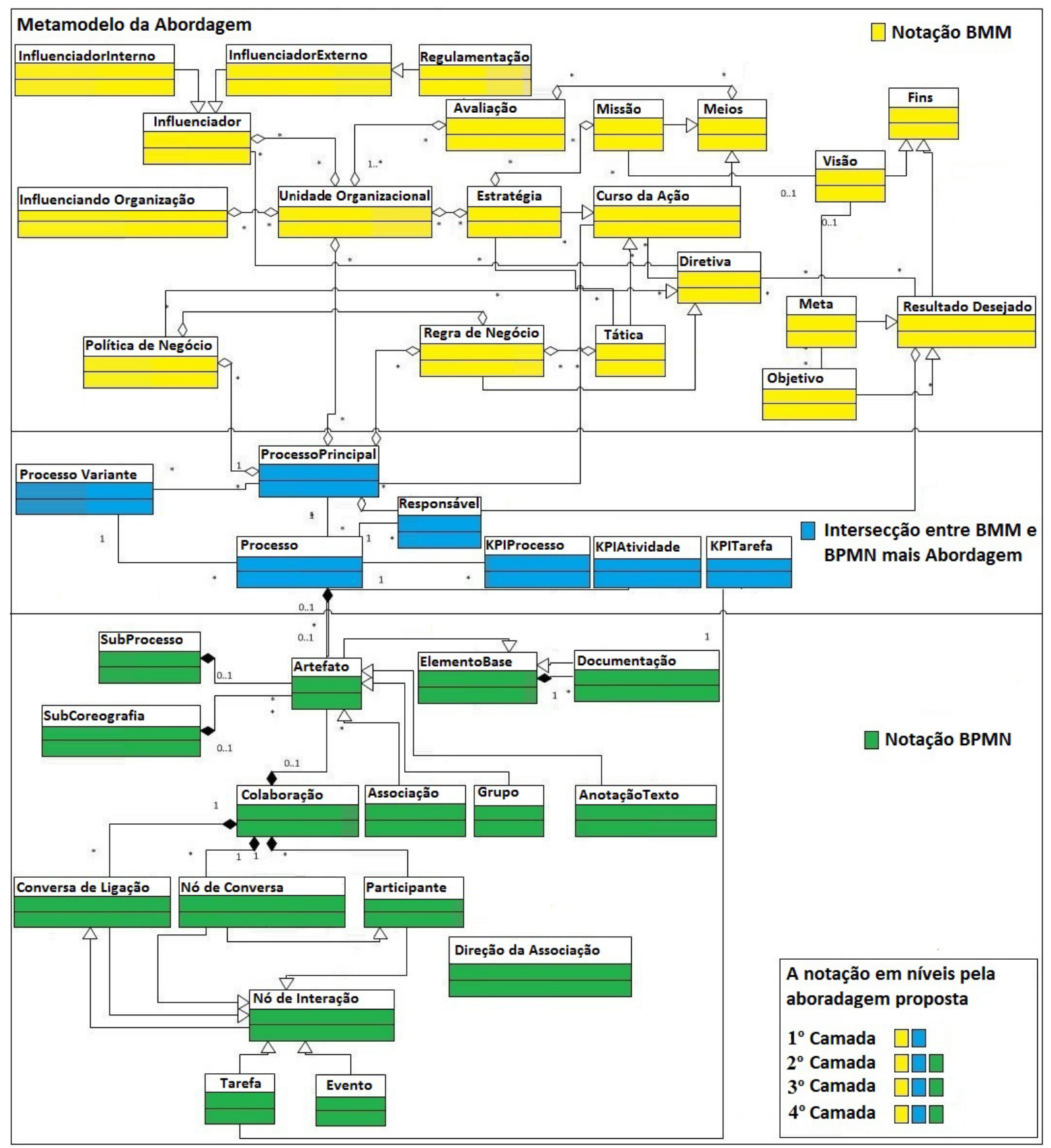

Figura 4.2: Representação do metamodelo

objetivo, esta intersecção permite então a ligação dos elementos estratégicos diretamente com o macroprocesso que será modelado ou com os processos variantes definidos.

Nesta intersecção também foram definidos o KPI de processo, KPI de atividade e KPI de tarefa, levando em consideração que um indicador de desempenho de processo pode ser dividido em alguns indicadores menores que serão ligadas e atacados nas atividades do processo e posteriormente estes indicadores ainda podem ser divididos novamente em indicadores menores para indicar o desempenho das tarefas executadas no nível atômico da abordagem. 
Após definir as informações alto níveis com o BMM é possível definir o fluxo do processo com o BPMN, sendo válido ressaltar que o metamodelo fornece uma perspectiva de relação entre o BMM e o fluxo definido em um processo específico como será descrito com maiores detalhes posteriormente.

Com o metamodelo completo foi necessário realizar algumas adequações como é descrito a seguir.

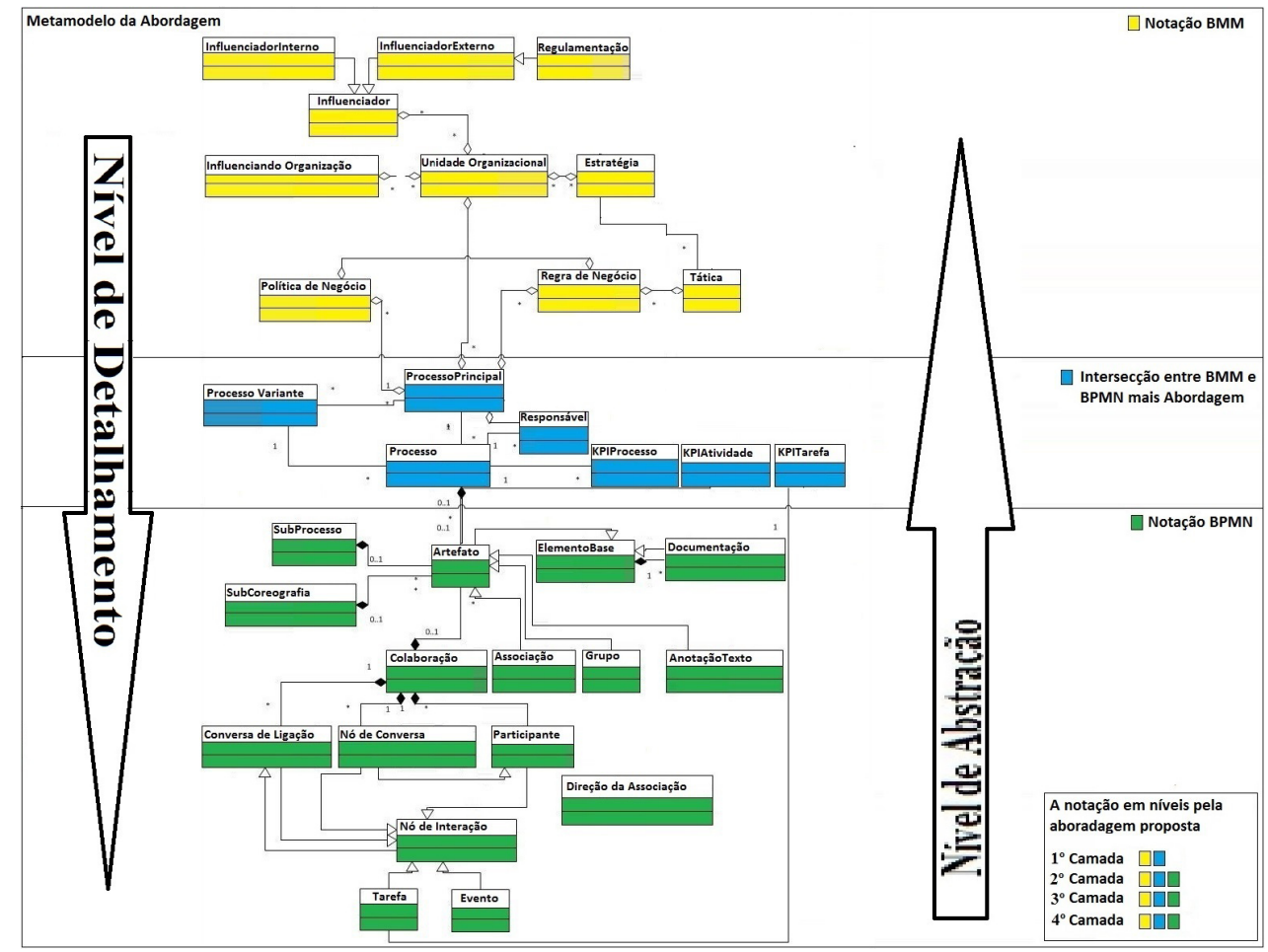

Figura 4.3: Representação do foco da abordagem

A primeira adequação é a retirada dos Fins do BMM, uma vez que todos os elementos dos Fins são executados pelos meios e podem ser descritos dentro das entidades se desejado. É válido ressaltar também que os Fins necessitariam de um nível de abstração superior aos definidos na abordagem. Por fim, a representação do mesmo junto com os meios em apenas um nível poderia causar incoêrencias na abordagem, portanto, optou-se retira-los para futuramente estudar a forma mais adequada de adição (outro nível ou descrição textual dentro dos elementos dos Meios).

A segunda adequação é a inclusão do termo Variante de Processo contido no trabalho de Nuffel e Backer (Nuffel e Backer, 2012), como mencionado anteriormente, o mesmo é utilizado quando existem diversos processos com o mesmo objetivo e podem estar contidos dentro de apenas um Macro Processo, como por exemplo um processo de entrega que pode ser feito por diversos tipos de meios de transporte. Outro ponto importante é a representação do Macro Processo e do Processo variante em uma única camada para permitir o link direto de ambos os tipos de processos com os elementos de BMM. 
A terceira adequação é a criação de uma linguagem de modelagem para o BMM,uma vez que o metamodelo é textual descritivo e não conta com nenhuma iniciativa de modelagem, portanto, todas as representações contidas neste trabalho para o BMM foram criadas com o intuito de facilitar o levantamento do modelo do negócio visualmente e realizar as ligações dessas informações com os modelos de processo em uma única linguagem de modelagem.

A última adequação a ser feita é que as informações contidas nos objetos do metamodelo estão de acordo com os níveis hierárquicos da organização, uma vez que o nível de detalhamento do processo está diretamente relacionado com a execução da tarefa na base da pirâmide proposta pela abordagem e o nível de abstração inversamente proporcional, uma vez que no topo da pirâmide o fluxo do processo não é representado(processo em elemento caixa preta). Com isto, a Figura 4.3 representa de forma adequada todo o metamodelo da abordagem com as respectivas adequações. A seguir será apresentada a divisão em camadas do metamodelo em detalhes.

\subsection{Primeira Camada}

Para iniciar é valido destacar que o primeiro nível da abordagem no estado da arte é representado pelo modelo BMM, o mesmo é similar às arquiteturas organizacionais de referências como o Zachman Framework (Zachman, 1987), TOGAF (Group, 2003), Enterprise Architecture Framework (Lind e Seigerroth, 2010a; Nuffel e Backer, 2012) e ARIS(Scheer, 2000) . Estes modelos ressaltam informações de alto nível que não estão interligados com as modelagens de processos atuais.

\subsubsection{Proposta}

O primeiro nível da abordagem tem como objetivo utilizar-se do BMM para realizar o levantamento das informações de negócio e definir como estas informações são ligadas aos processos de negócio. Este nível é relevante pois fornece uma maneira de acrescentar aos processos de negócio as informações que são de suma importância para o seu desenvolvimento e estão implícitas nas modelagens de processos atuais. Dentre essas informações estão contidas as Regras e Políticas de Negócio do Processo, Unidade Organizacional ou departamentos dos processos facilitando tanto a visualização interdepartamentais dos processos quanto os processos que determinado processo atua, as Estratégias e Táticas definidas para os processos e os Influenciadores Internos e Externos dos departamentos. O processo é representado como caixa preta, omitindo todo o fluxo do processo e delegando esta responsabilidade aos níveis inferiores. A Figura 4.4 ilustra os possíveis relacionamentos que um processo de negócio pode realizar no modelo. 


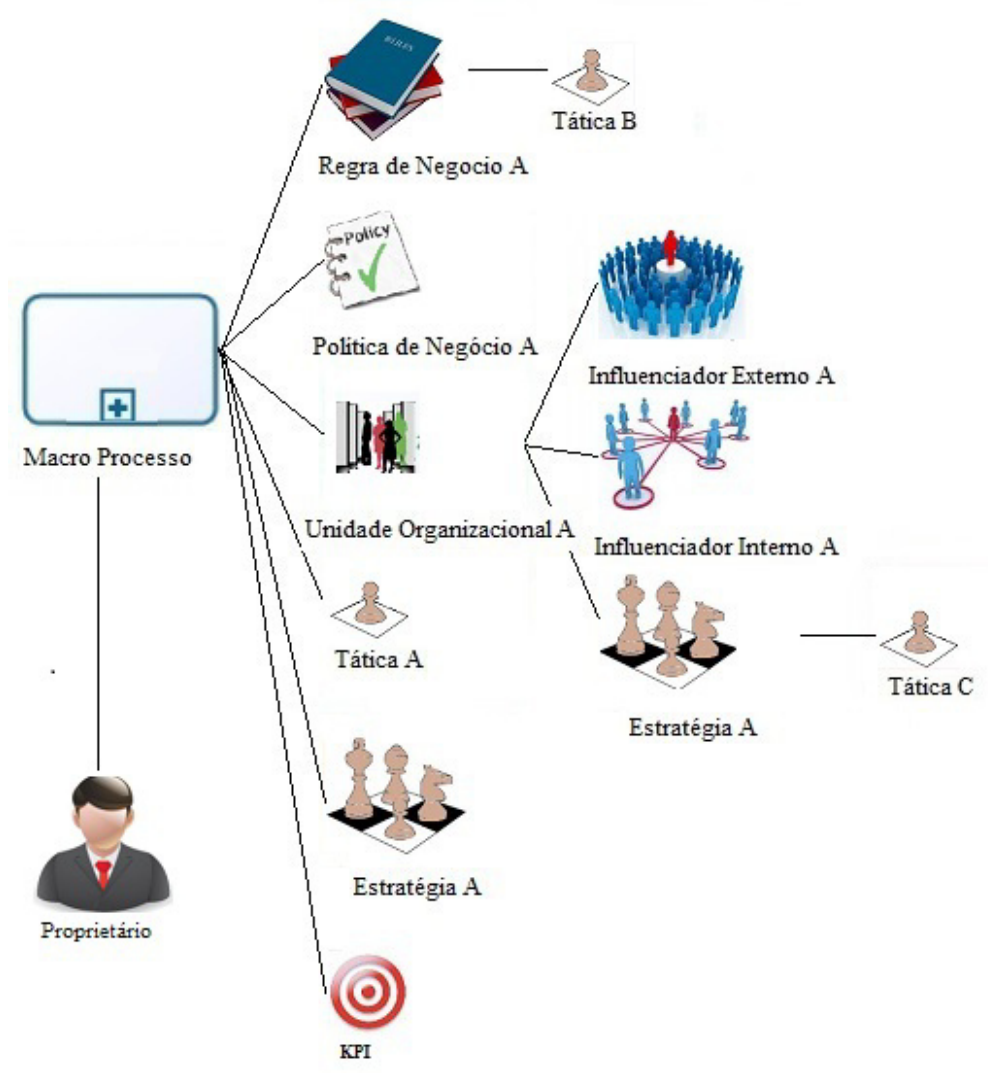

Figura 4.4: Representação da primeira camada da abordagem.

Um Processo pode ter $\mathrm{N}$ relacionamentos com cada elemento e estes elementos podem estar contidos em $\mathrm{N}$ processos, em outras palavras o relacionamento do macroprocesso com os demais elementos do BMM é muitos para muitos. De acordo com a Figura 4.4 é possível visualizar que os elementos unidade organizacional, regra de negócio e estratégia possuem ligações com outros elementos do BMM como por exemplo os influenciadores de um determinado departamento.

Outra característica do primeiro nível é a divisão por demais perspectivas, representando também as coleções dos atributos do BMM, em síntese, ao definir o seu modelo de negócio é possível navegar para perspectiva para visualizar todos os Atributos de um determinado elemento modelado como por exemplo visualizar todos os Processos de Negócio, Táticas, Estratégias, Unidades Organizacionais definidos na Organização. A Figura 4.5 representa outra perspectiva mencionada do primeiro nível, onde é possível visualizar todos os processos de negócio. 

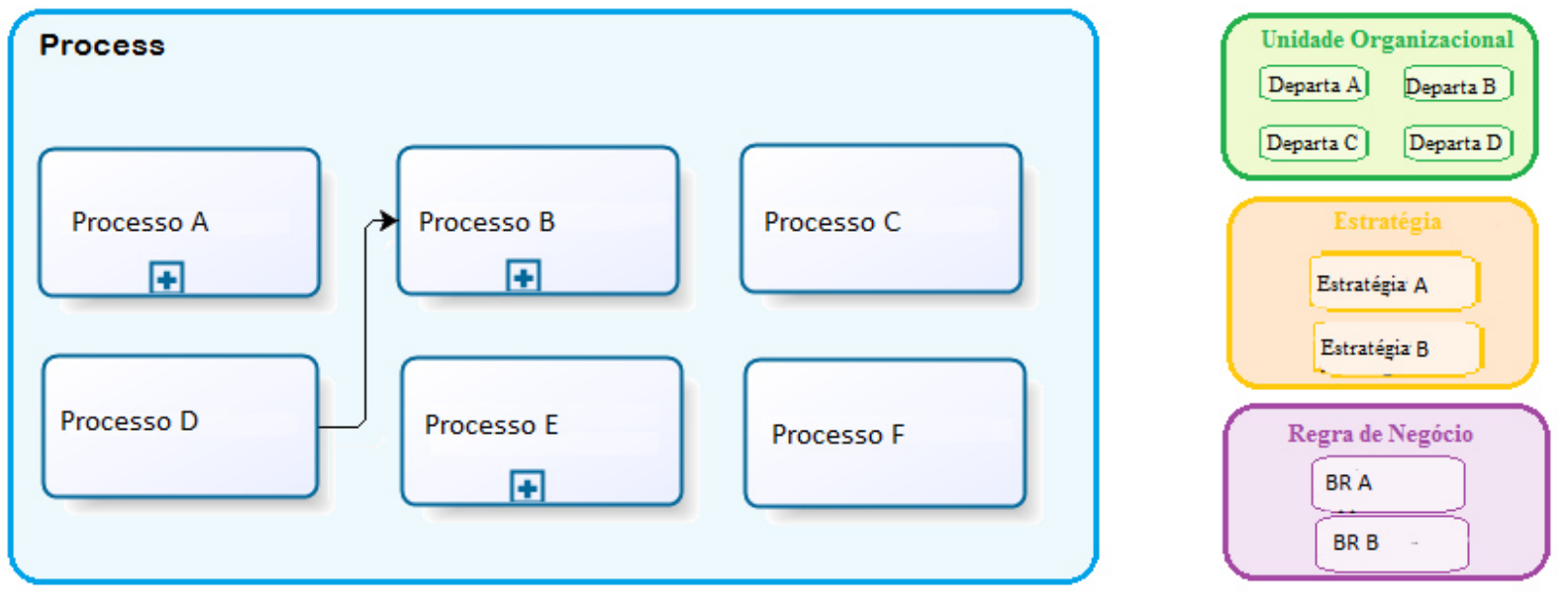

Figura 4.5: Representação da primeira camada da abordagem sobre perspectiva de coleções

\subsection{Segunda Camada}

Após definir o nome do processo e os atributos estratégicos que o mesmo irá conter, é necessário definir o fluxo de trabalho do mesmo. Este nível e os demais níveis inferiores no estado da arte são representados pelas linguagens de modelagem de processo como BPMN, EPC, Petri Nets, SIPOC (Lind e Seigerroth, 2010a; Nuffel e Backer, 2012).

\subsubsection{Proposta}

A segunda camada do metamodelo representa as ligações específicas de determinados atributos do BMM com um processo específico. Neste nível o fluxo do processo de negócio é representado de maneira detalhada com o BPMN, representando o fluxo do processo do início ao fim e os seus relacionamentos com os atributos específicos do BMM.

Outra característica importante é a exigência de uma boa prática de modelagem que se inicia neste nível, pois, este nível tem-se como objetivo mostrar de maneira abstrata o fluxo do processo fim-a-fim sem a necessidade de abordar detalhes de execução deste processo. Para isto, é necessário representar com subprocessos o fluxo e delegar o detalhamento do fluxo para os níveis inferiores.

Portanto, no segundo nível é preferível a simplificação de atividades com a criação de subprocessos, criando assim um fluxo de subprocessos e tarefas que não se enquadram nos subprocessos como ilustrado na Figura 4.6 que representa o fluxo simplificado do processo A e seu relacionamento com o atributos de Regra de Negócio, Política de Negócio, Tática e Estratégia que são ligados ao processo da mesma forma que a modelagem realizada no primeiro nível. A abordagem converte as Unidades Organizacionais definidas no 
primeiro nível em Lanes(Raias) no BPMN e estas Lanes são interligadas aos respectivos influenciadores e estratégias do departamento.

Com o relacionamento das Lanes com os influenciadores e estratégias é possível visualizar como determinado subprocesso é influenciado internamente ou externamente e também quais estratégias aquele departamento possui e se os subprocessos estão definidos de forma adequada.

O processo possui um indicador chave de desempenho definido com unidade de tempo, no exemplo este indicador de execução aponta para 15 dias de execução do processo fim-a-fim, no entanto, este indicador pode ser representado de outras formas, como por exemplo, produtos produzidos por unidade de tempo. Este indicador também pode ser divido para indicar a performance dos subprocessos contidos neste processo.

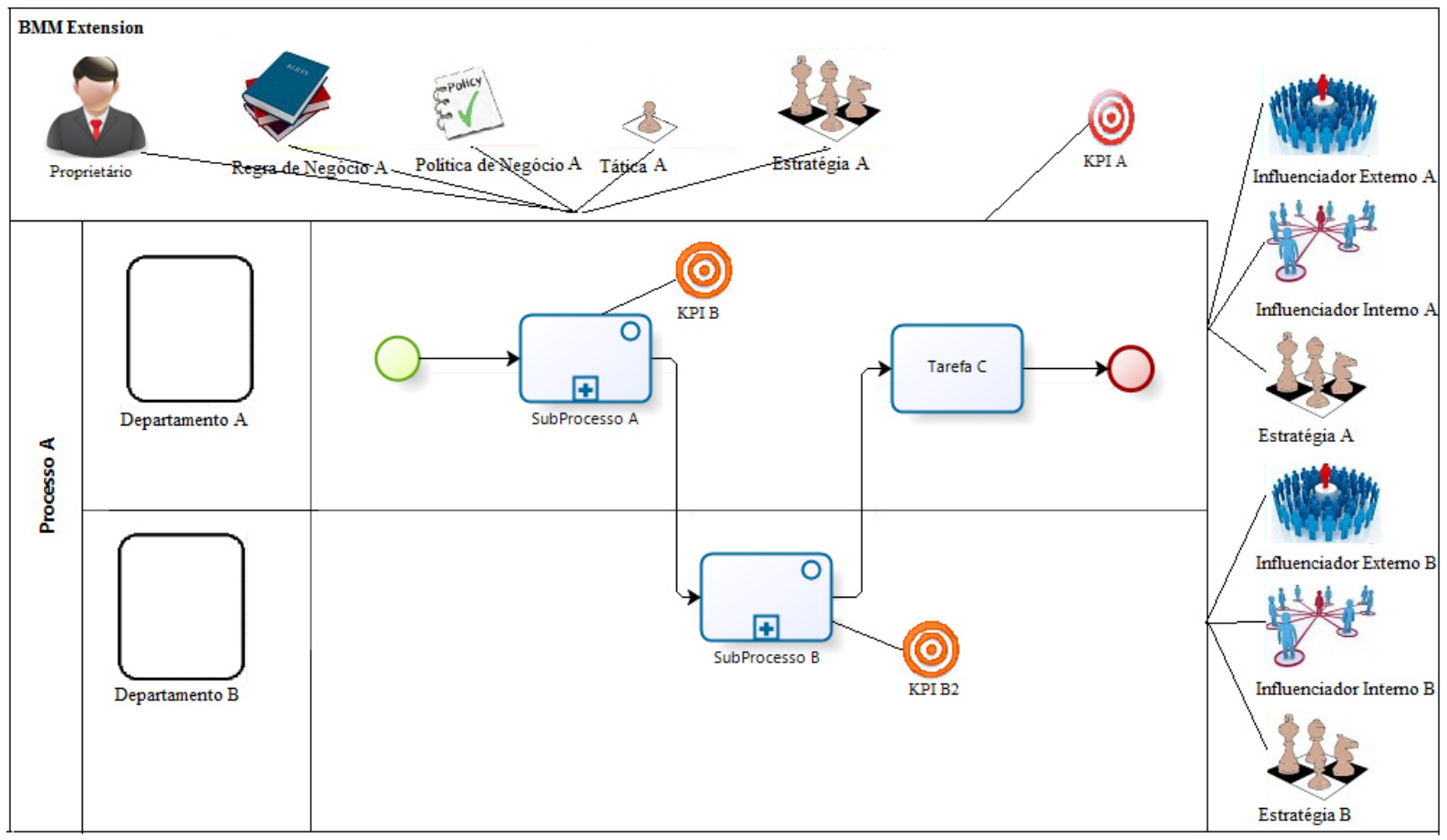

Figura 4.6: Exemplo da segunda camada da abordagem

\subsection{Terceira Camada}

A terceira camada representa a continuação da segmentação do processo em níveis de complexidade, baseando-se no atributos do BPMN. Basicamente este nível aborda o conjunto de atividades e as tarefas que estão contidas no subprocesso.

Um dos benefícios da abordagem pode ser analogamente comparado com a utilização de métodos em uma linguagem de programação, uma vez que é possível compreender o que o método faz apenas lendo seu nome, caso necessite de informações adicionais, é possível 
analisar o método detalhadamente, assim como nos subprocessos, é possível analisar as atividades e tarefas caso seja necessário um nível maior de detalhamento.

\subsubsection{Proposta}

O intuito deste nível é apresentar as atividades e tarefas contidas no subprocessos sem perder as devidas ligações alto nível obtidas pela união entre o BMM e o BPMN. A Figura 4.7 ilustra o fluxo do subprocesso A e seu relacionamento com os elementos do BMM.

Neste nível é omitido os influenciadores e estratégias dos demais departamentos do processo. Esta modularização dos processos de negócio, permitem a divisão e apresentação dos dados de acordo a necessidade, uma vez que detalhes de baixo nível podem complicar a interpretação do fluxo do processo.

Como destacado anteriormentem este nível possui um indicador de desempenho já fragmentado para seu fluxo e novamente é possível dividir este KPI para indicar a performance das atividades contidas neste subprocesso.

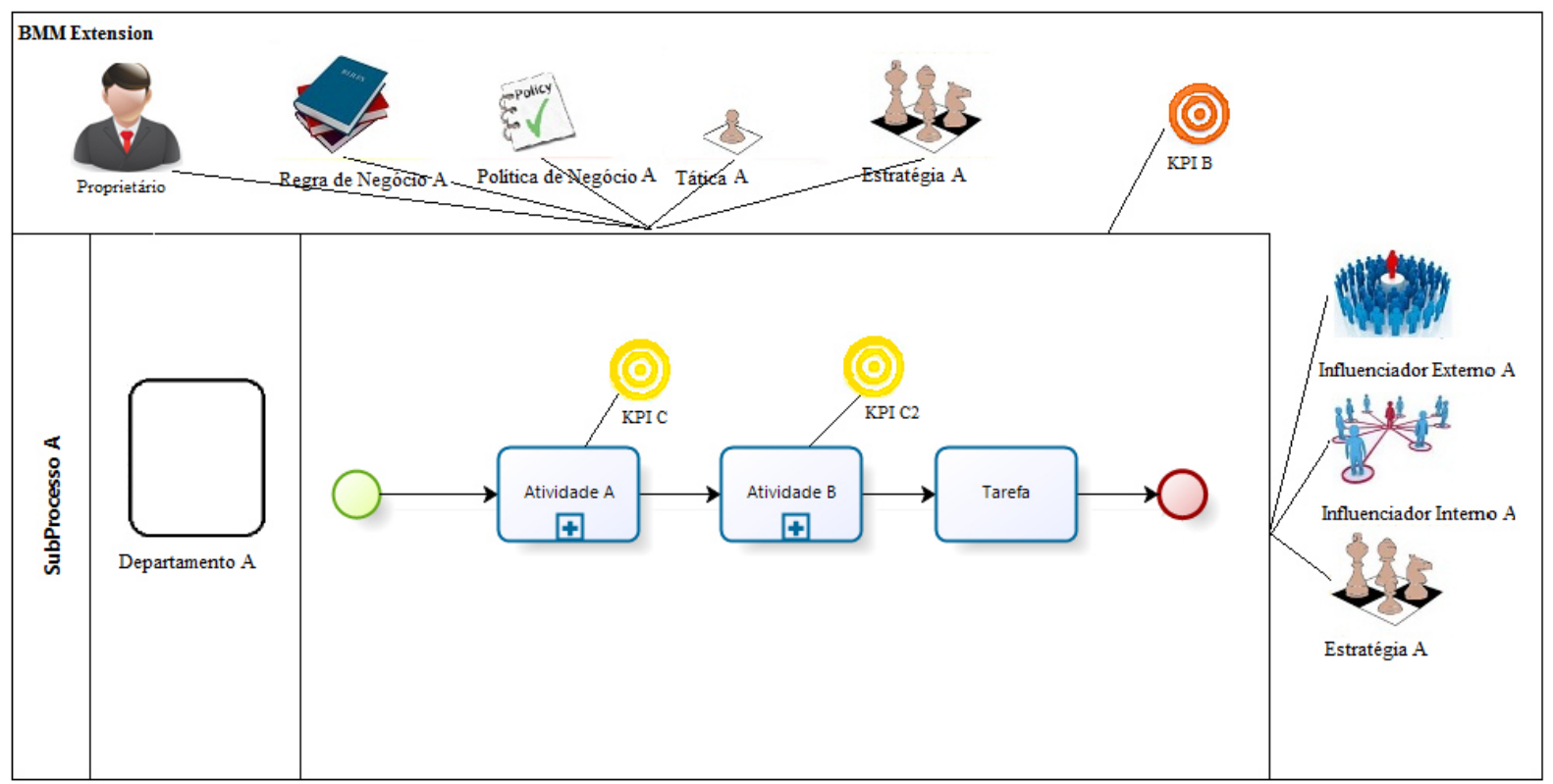

Figura 4.7: Representação da terceira camada da abordagem

\subsection{Quarta Camada}

A quarta camada representa o nível atômico da segmentação do processo em níveis de complexidade. 


\subsubsection{Proposta}

O quarto nível da abordagem representa a execução do processo, no mesmo são definidos os fluxos das tarefas a serem desempenhadas. Assim como ilustrado nos níveis 2 e 3 da abordagem e na Figura 4.8, neste nível também há a ligação com os atributos alto nível do BMM. Como nos níveis anteriores, este nível possui o indicador chave de desempenho vinculado as tarefas e as mesmas devem ser executadas em 1 dia.

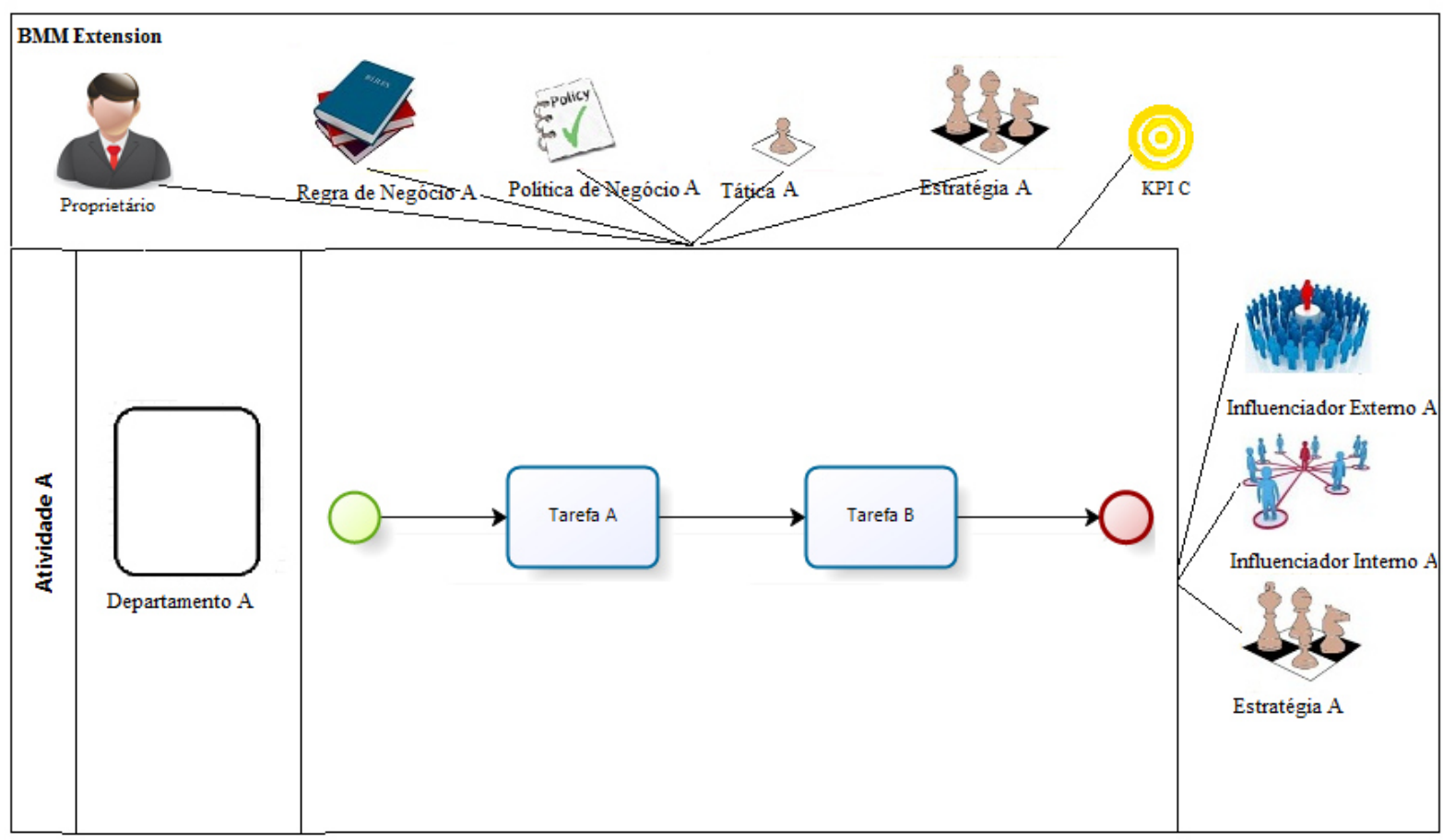

Figura 4.8: Representação da quarta camada da abordagem

\subsection{Prova de Conceito}

Para apresentar de maneira efetiva a abordagem, foram criados exemplos baseados nos processos já existentes de uma grande organização prestadora de serviços de TI que utiliza o BPM como forma efetiva de gerenciamento e BPMN para a modelagem de seus processos. Os elementos de alto níveis dos processos são documentados nas máquinas dos gestores que se queixam pela falta de ferramentas e meios de ligar essas informações aos processos.

O cenário utilizado para a prova de conceito ocorre em um processo de suporte ao call center de um cliente. Este processo é iniciado quando um problema ocorre nos sistemas utilizados pelo call center, que ao se confrontar com esta situação, registra o problema ocorrido em uma ferramenta de atendimento e a equipe de suporte da empresa prestadora de serviço analisa o ocorrido. Existe um Acordo de Nível de Serviço ou SLA ( Service Level 
Agreement) que define o tempo máximo que a prestadora de serviços tem para realizar o atendimento do incidente.

A cada problema que ocorre nos sistemas do call center é criado um incidente que contém informações referentes a uma falha ou inconsistência no sistema que impede o prosseguimento de alguma operação no sistema do cliente. O incidente é a entrada necessária para que o processo de suporte ao call center seja iniciado.

Caso seja um problema já mapeado, a forma convencional de tratamento de um incidente é a correção da inconsistência na base de dados do sistema de acordo com o que está mapeado nos Logs de Problemas pela equipe do Segundo Nível (2N), que se refere às lições aprendidas para cada problema no sistema do Cliente. Caso seja um problema não mapeado, é necessário que o Terceiro Nível (3N) depure o sistema no mesmo cenário do atendente do call center para identificar o motivo pelo qual o sistema não está prosseguindo com a ação desejada e após encontrar o problema, documentar as informações em um Log de problemas que será submetido ao Quarto Nível (4N) para aprovação das informações e alinhamento com o cliente (caso necessário). Os Logs aprovados são utilizados para facilitar o atendimento dos próximos casos no mesmo cenário. A Figura 4.14 representa o As-Is do Processo de Suporte ao Call Center.

Esta variação de tratamentos corretivos faz com que cada inconsitência seja mapeada e categorizada com uma causa (mapeada no Log de Problemas). O volume de incidentes é agrupado por uma causa (motivo pelo qual ocorre aquela inconsistência), se um incidente de determinada causa está com uma volumetria elevada é necessário demandar um esforço para o levantamento de todos os dados incorretos neste cenário para posteriormente realizar a correção em massa do problema que normalmente se resulta em desenvolver um script (conjunto de comandos SQL) que elege os dados incorretos em um determinado cenário e os corrige através de uma execução no banco de dados do cliente.

Com isso, o processo de desenvolvimento de Scripts é realizado dentro do processo de suporte ao call center para mitigar com scripts os incidentes de um cenário específico. A estratégia desde processo é a proatividade em corrigir na raiz os problemas e evitar assim inúmeros incidentes que impactam diretamente a operação do cliente. Por alterar dados de produção de extrema importância, uma vez que essas informações são referentes aos clientes da organização que recebe os serviços, diversas medidas de segurança são tomadas para ter o aval de execução do cliente.

No processo, o analista desenvolve o script, cria o plano de teste para o script desenvolvido e executa o script em uma pequena porcentagem de dados para verificar se o mesmo irá desempenhar a função pelo qual foi criado. Após testar o script é necessário gerar evidência dos testes. Caso o script não esteja de acordo com o especificado ele volta para o desenvolvimento, caso sim, o mesmo é encaminhado para os SMEs (Especialistas) para 
validação do script e dos artefatos e posteriormente enviado para o cliente para aprovação e execução na base de dados. O processo $A S$ IS é apresentado na Figura 4.15.

Um ponto a ser destacado sobre níveis de processos é que apesar de nitidamente o processo de desenvolver script ser um subprocesso do processo de Suporte ao Call Center, o mesmo é considerado e documentado como se fosse um processo. Levando em consideração esta questão, readequamos o processo de Desenvolvimento de Script como um subprocesso do processo de Suporte ao Call Center.

\subsubsection{Primeiro Nível}

Como ilustrado nas imagens 4.14 e 4.15, é possível notar que os processos não possuem níveis e não possuem relacionamentos com informações de alto nível, com isso, a Figura 4.9 ilustra como seria o processo de suporte ao call center se o mesmo estivesse no primeiro nível da abordagem proposta.

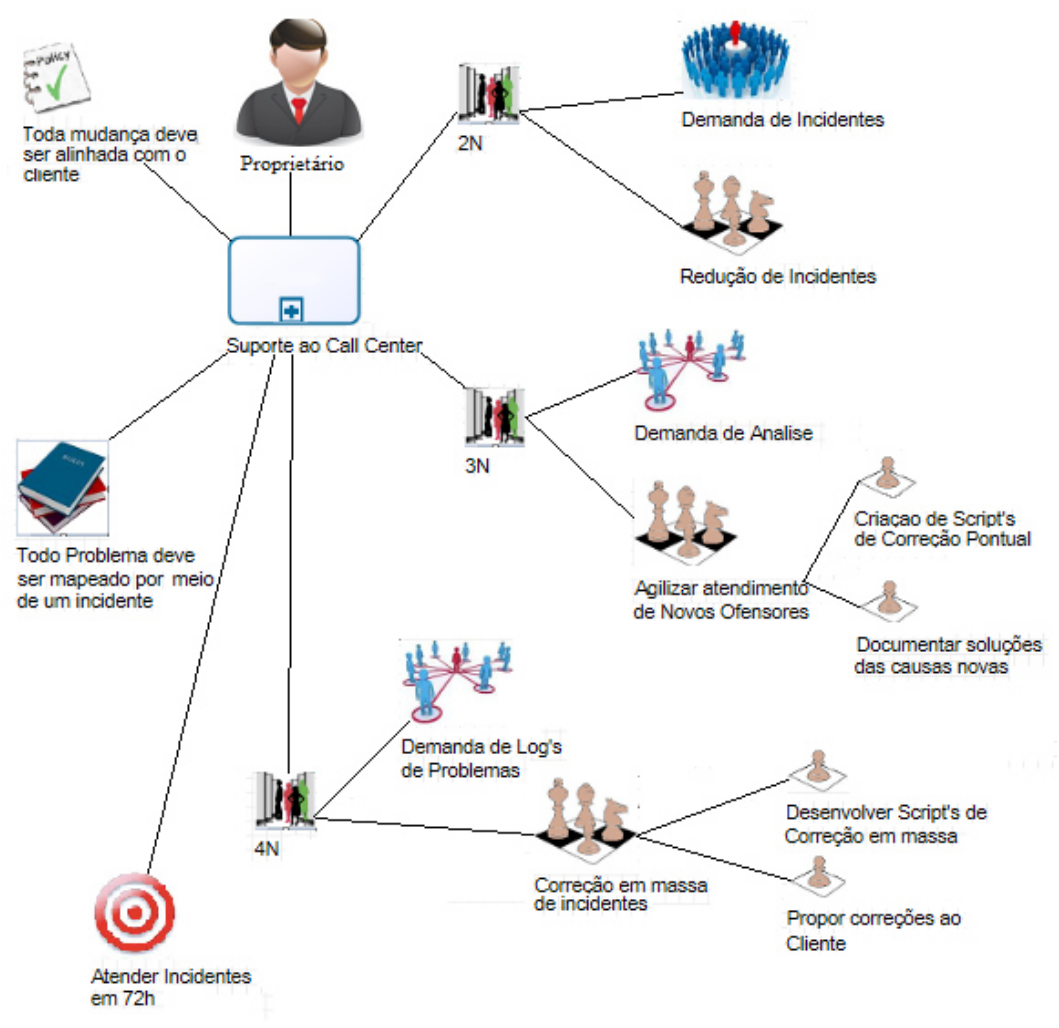

Figura 4.9: Exemplo de modelo na primeira camada da abordagem

Neste nível fica mais claro a compreensão de determinados aspectos que não eram explícitos no modelo padrão:

- O departamento do segundo nível $(2 \mathrm{~N})$ possui como influenciador externo a demanda de incidentes uma vez que os incidentes são criados pelo cliente e o atendimento é 
realizado pela prioridade. O segundo nível possui como estratégia a redução de incidentes.

- O departamento do terceiro nível (3N) possui como influenciador interno a demanda de análises e como estratégia prover formas ágeis de atendimento aos novos tipos de incidentes que estão com uma volumetria elevada. Para atingir esta estratégia, foram definidas duas táticas, uma de criação de scripts que facilitem o atendimento do $2 \mathrm{~N}$ e a documentação das novas causas para orientar o $2 \mathrm{~N}$ como atender as novas causas.

- O departamento do quarto nível $(4 \mathrm{~N})$ possui como influenciador interno a demanda de Logs de Problemas que são basicamente os novos tipos de incidentes identificados pelo terceiro nível e documentado através de um log de problemas para o quarto nível. Como estratégia o quarto nível conta com a criação de scripts para correção em massa, duas táticas foram definidas para suportar a estratégia, criar os scripts de correção em massa e propor soluções no próprio sistema do cliente que regularizam as informações de acordo com a utilização.

- O indicador chave de desempenho deste processo é atender ao incidente em no máximo 72 horas corridas.

- A regra de negócio determina que o processo só iniciado se houver um incidente.

- A política de negócio informa que o cliente deve ser alinhado a qualquer alteração de seus dados.

Como ilustrado na Figura 4.9 o processo de Suporte ao Call Center poderia ser representado como um processo variante assim como os processos de Suporte de Equipamentos e Suporte de Técnicos, todos estariam contidos dentro do macro processo "Suporte ao Cliente". Nesta abordagem seria definido como a Figura 4.10.

Ao alterar a perspectiva para a de gerenciamento de coleções de processos e coleções de artefatos será apresentada a Figura 4.11.

\subsubsection{Segundo Nível}

Como destacado anteriormente, o segundo nível não apenas apresenta o fluxo resumido do processo como também permite a visualização mais específica dos elementos do BMM.

Com os conhecimentos de BPMN é possível notar que o processo de suporte ao call center tem seu fluxo sobre os departamentos do Segundo nível, Terceiro nível e Quarto Nível. Também é possível notar que o segundo nível é responsável pelo atendimento dos incidentes recorrentes, o terceiro nível responsável pela identificação dos novos cenários 


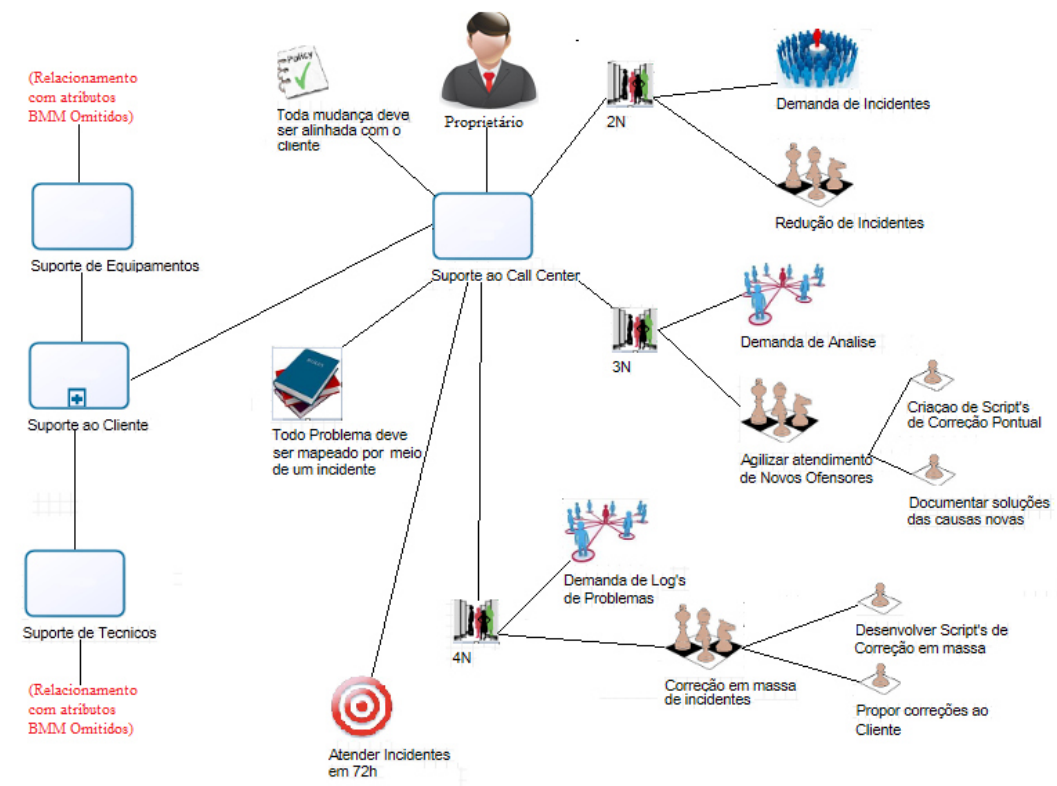

Figura 4.10: Representação dos Macro Processos e Processos Variantes no primeiro nível da abordagem
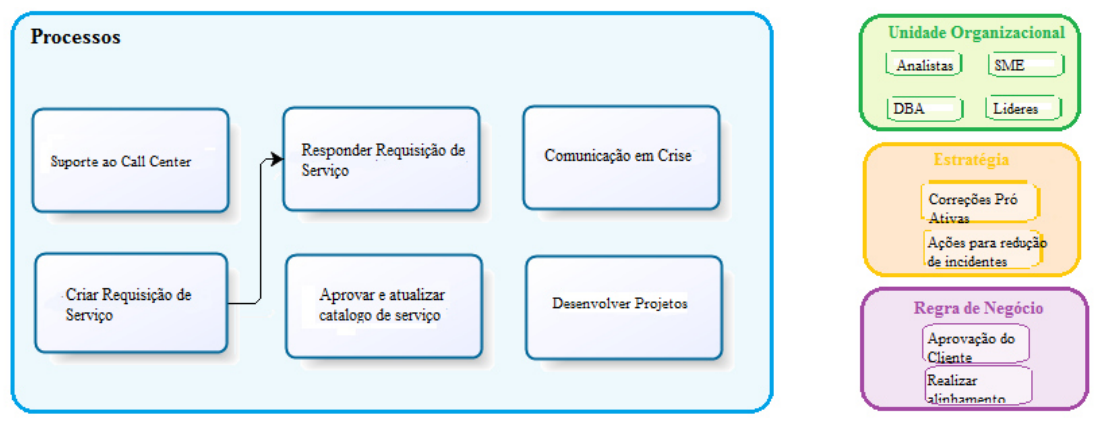

Figura 4.11: Representação das Coleções

e o quarto nível responsável por mitigar o problema na produção do cliente, fornecendo também uma documentação para os demais níveis prosseguir com as atividades.

Contudo, o modelo BPMN não apresentaria as informações de alto níveis do processo, no exemplo apresentado na Figura 4.16 pode ser visto todo o fluxo do processo de suporte ao call center e seu relacionamento com os atributos BMM. Também é possível identificar neste nível a fragmentação do KPI de processo em KPIs de Subprocessos.

\subsubsection{Terceiro Nível}

Dentre os subprocessos e tarefas definidos no processo de suporte ao call center é visto o subprocesso de desenvolvimento de Script que como destacado anteriormente foi readequado a um nível mais coerente. 
Como visto na Figura 4.12 o subprocesso de desenvolvimento de script é feito pelo quarto nível com o intuito de redução dos dados incorretos do cliente e que esta produção de script não é permitida se não houver a aprovação do cliente, justificando o possível relacionamento entre o subprocesso "Validar Script"e a pool caixa preta(Capítulo 2, Seção BPMN) do cliente sem a necessidade de detalhamento da atividade. Também é possível notar que o departamento é influenciado internamente pela demanda de Logs de problemas uma vez que o subprocesso analisado ocorre internamente a equipe do quarto nível e também possui um influenciador externo, uma vez que a execução em base de dados de produção do script criado só pode ser realizada com a aprovação do cliente. Por fim, o subprocesso tem com indicador de desempenho a criação do Script em menos de 40h e suas atividades possuem KPIs novamente fragmentados para gerir seu desempenho.

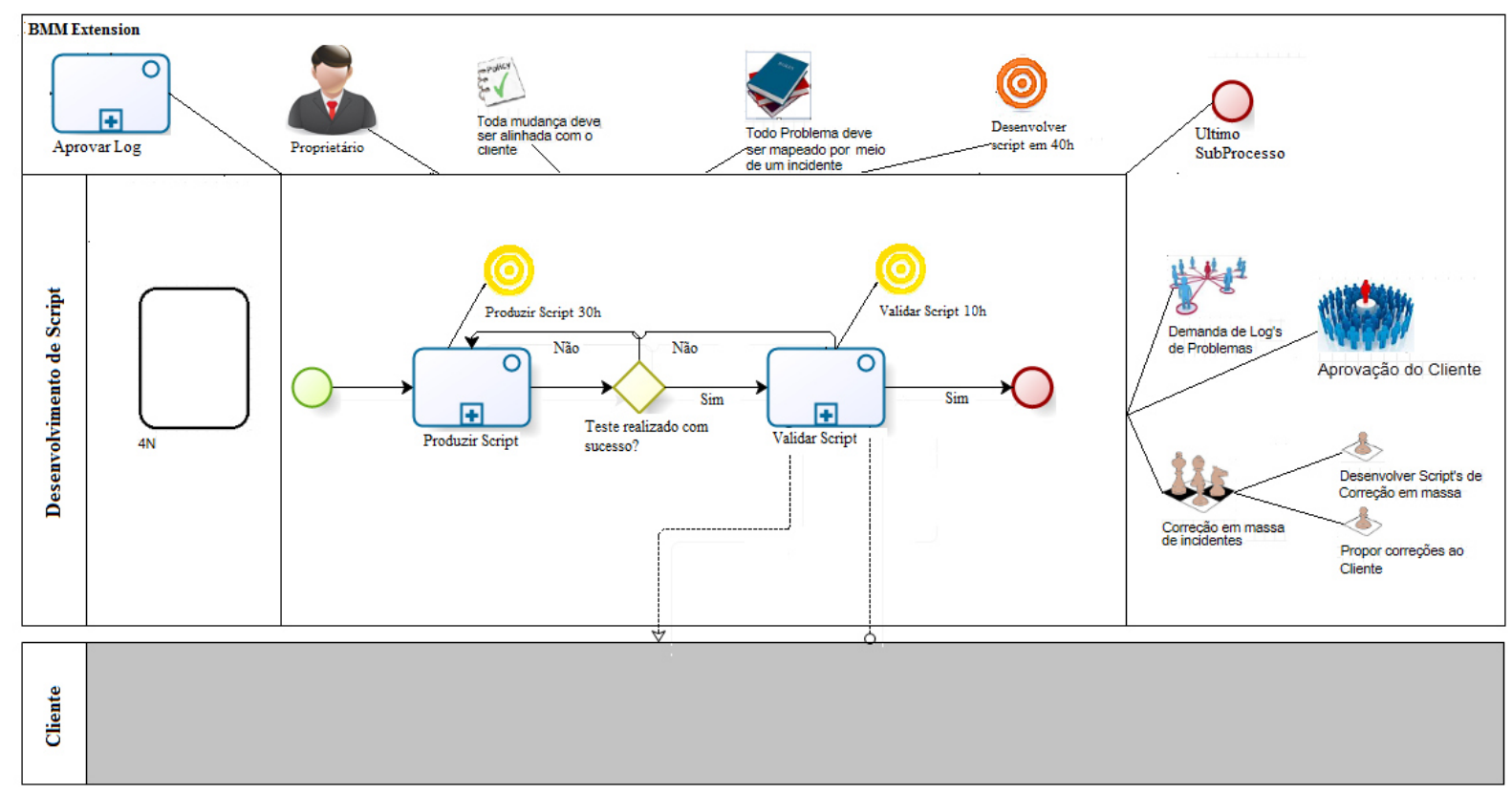

Figura 4.12: Representação da terceira camada da abordagem

\subsubsection{Quarto Nível}

Na atividade "Produzir Script"do processo de desenvolvimento de script existem diversas tarefas definidas. Neste nível de detalhamento já é possível ter uma noção clara de como as tarefas estão sendo desempenhadas e também uma visão refinada dos influenciadores e estratégias deste departamento como é possível notar na Figura 4.12. Também é possível notar um fluxo mais detalhado onde é possível identificar que esta atividade conta com tarefas de desenvolvimento, teste e geração de evidências dos testes realizados, resultando 
na produção de artefatos, script e plano de teste. Esta atividade possui definido um indicador de 3 dias.

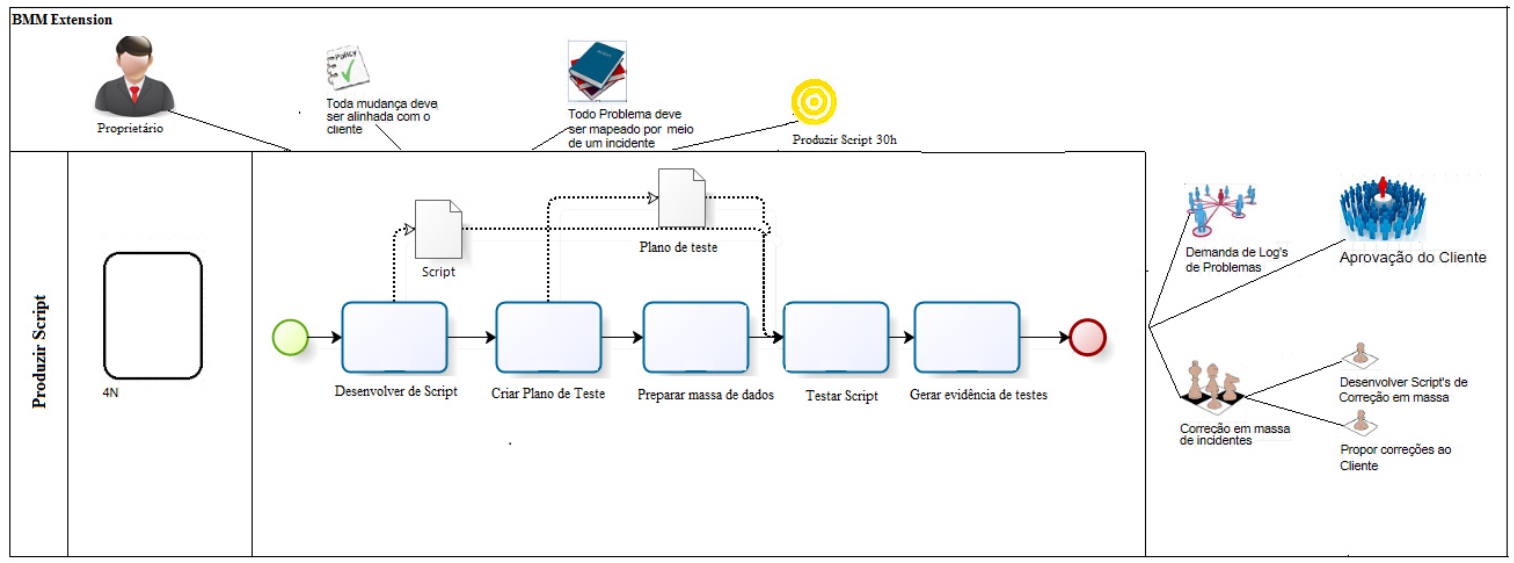

Figura 4.13: Representação da quarta camada da abordagem

\subsection{Comparação entre Abordagens}

Após a definição da abordagem, foi validado junto as cinco abordagens e soluções apresentadas na seção anterior, estão listadas abaixo:

(Aris)Aris (Scheer, 2000)

(N\&B)Multiníveis e Múltiplas Perspectivas (Nuffel e Backer, 2012)

(L\&S)Pensamento em Níveis (Lind e Seigerroth, 2010a)

(Archi)Archimate (TheOpenGroup, 2008)

(BEN)BEN (Winter, 2011)

(Este) Este Trabalho.

Os critérios para comparação foram definidos da mesma forma que a seção 3.5 descreveu, acompanhando todos os aspectos, ferramentas e técnicas dessas propostas, chegando ao conjunto de aspectos listados abaixo:

(a)A abordagem possui ferramenta de suporte para apoiar a definição dos modelos.

(b)A ferramenta permite a modelagem colaborativa entre diversas pessoas no mesmo diagrama. Em uma modelagem em níveis é necessária a presença de participantes de todos os níveis hirárquicos da organização (operacional, tático e estratégico)

(c)A ferramenta permite alterações em seu código fonte (código aberto) para adequar novas abordagens.

(d)A ferramenta permite escolher a linguagem desejada para a modelagem, para não limitar os usuários da ferramenta a modelarem em uma linguagem específica. 
(e)A ferramenta permite a modelagem na web, uma vez que esta forma de modelagem permite que diversas pessoas acessem os diagramas sem a necessidade de instalação de ferramenta.

(f)A abordagem fornece uma estrutura para representação de Informações de Negócio

(g)A abordagem fornece uma estrutura para associar Informações de Negócio a modelagem dos Processos

(h)A abordagem fornece uma estrutura para associar Informações de Negócio a modelagem das Atividades dos Processos

(i)A abordagem fornece uma estrutura para associar Informações de Negócio a modelagem das Tarefas dos Processos

(j)A abordagem desenvolveu e forneceu um metamodelo em UML.

(1)A abordagem foi aplicada em estudos de casos reais.

(m)A abordagem é recomendada por especialistas ou utilizada em organizações.

(n)A abordagem permite o gerenciamento de coleções de processos, permitindo modelar e visualizar diversos processos da organização.

\begin{tabular}{lcccccc}
\hline & (Aris) & (N\&B) & (L\&S $)$ & (Archi) & (BEN) & (Este) \\
\hline (a) & $\mathrm{X}$ & & & $\mathrm{X}$ & $\mathrm{X}$ & $\mathrm{X}$ \\
(b) & $\mathrm{X}$ & & & $\mathrm{X}$ & & $\mathrm{X}$ \\
(c) & & & & $\mathrm{X}$ & & $\mathrm{X}$ \\
(d) & $\mathrm{X}$ & & & $\mathrm{X}$ & & $\mathrm{X}$ \\
(e) & & & & & & $\mathrm{X}$ \\
(f) & $\mathrm{X}$ & & & $\mathrm{X}$ & & $\mathrm{X}$ \\
(g) & & & & & & $\mathrm{X}$ \\
(h) & & & & & & $\mathrm{X}$ \\
(i) & & & & & $\mathrm{X}$ & $\mathrm{X}$ \\
$(\mathrm{j})$ & & $\mathrm{X}$ & $\mathrm{X}$ & $\mathrm{X}$ & $\mathrm{X}$ & $\mathrm{X}$ \\
(l) & $\mathrm{X}$ & $\mathrm{X}$ & $\mathrm{X}$ & $\mathrm{X}$ & $\mathrm{X}$ & $\mathrm{X}$ \\
(m) & $\mathrm{X}$ & & & $\mathrm{X}$ & & \\
(n) & $\mathrm{X}$ & & $\mathrm{X}$ & $\mathrm{X}$ & $\mathrm{X}$ & $\mathrm{X}$ \\
Total & $7 / 13$ & $2 / 13$ & $3 / 13$ & $9 / 13$ & $4 / 13$ & $\mathbf{1 1 / 1 3}$ \\
\hline
\end{tabular}

Tabela 4.1: Comparação entre Trabalhos

Com os resultados é possível observar que apesar da abordagem estar voltada para a relação intrínseca entre as informações de negócio e a modelagem de processos na representação de em um único diagrama para tentar garantir o alinhamento estratégico, a mesma conseguiu também criar uma solução(apresentada no próximo capítulo) que possui as vantagens dos suportes computacionais do mercado e dos metamodelos propostos nas pesquisas. 
É válido destacar que o objetivo da comparação está voltado para validação das abordagens e os critérios que referenciam as ferramentas estão alinhados com as facilidades que a ferramenta provêm para exemplificação e utilização da abordagem. Para avaliação da ferramenta apenas, seria necessária a adição de novos critérios.

\subsection{Conclusão}

Com foi visto anteriormente nos níveis da abordagem, com a navegação é possível notar que as informações estratégicas levantadas pelo BMM não são perdidas em nenhum momento.

É válido também ressaltar que apesar do BPMN possuir notações que representem os subprocessos, atividades e tarefas, o mesmo não possui nada explícito para distinção dos níveis 2, 3 e 4 da abordagem proposta. Com isso, o modelo oferece uma "boa prática de modelagem"onde o mesmo sugere a modularização das camadas para facilitar a compreensão e organização dos diagramas.

Outro ponto a ser destacado é a vantagem fornecida pela abordagem ao prover linguagem de modelagem de negócio que está de acordo com o metamodelo do BMM, facilitando a ligação dos planejamentos com os processos em uma estrutura multiníveis e fornecer uma perspectiva de coleções para gerenciar todos os processos ou demais elementos definidos no BMM.

Todas estas vantagens apresentadas neste capítulo são potencializadas com a inserção de um protótipo que tem como finalidade dar suporte a abordagem proposta. A ferramenta foi responsável pela modelagem da maioria dos diagramas apresentados neste capítulo e será apresentado com detalhes no próximo capítulo. 


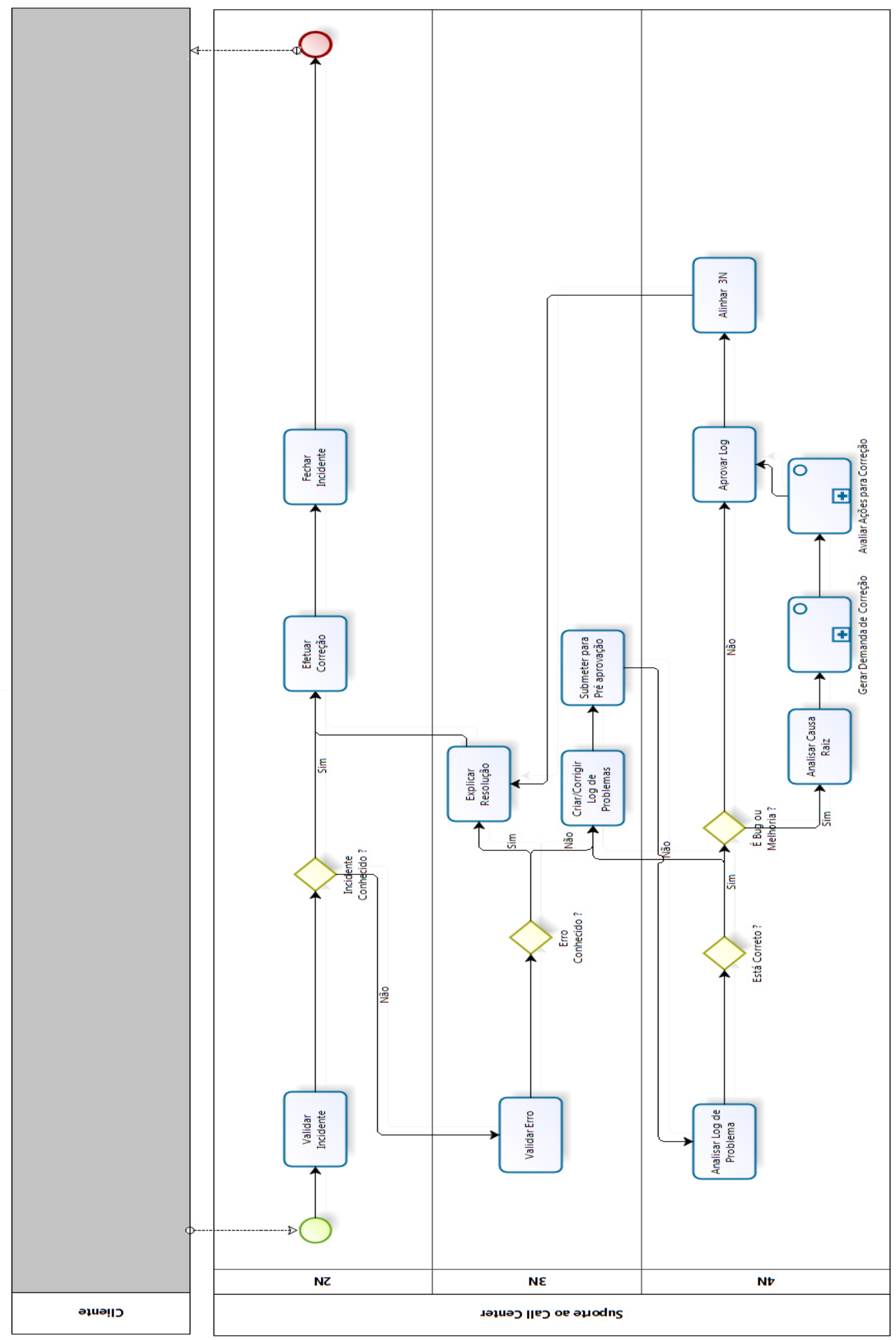

Figura 4.14: Processo de Suporte ao Call Center 


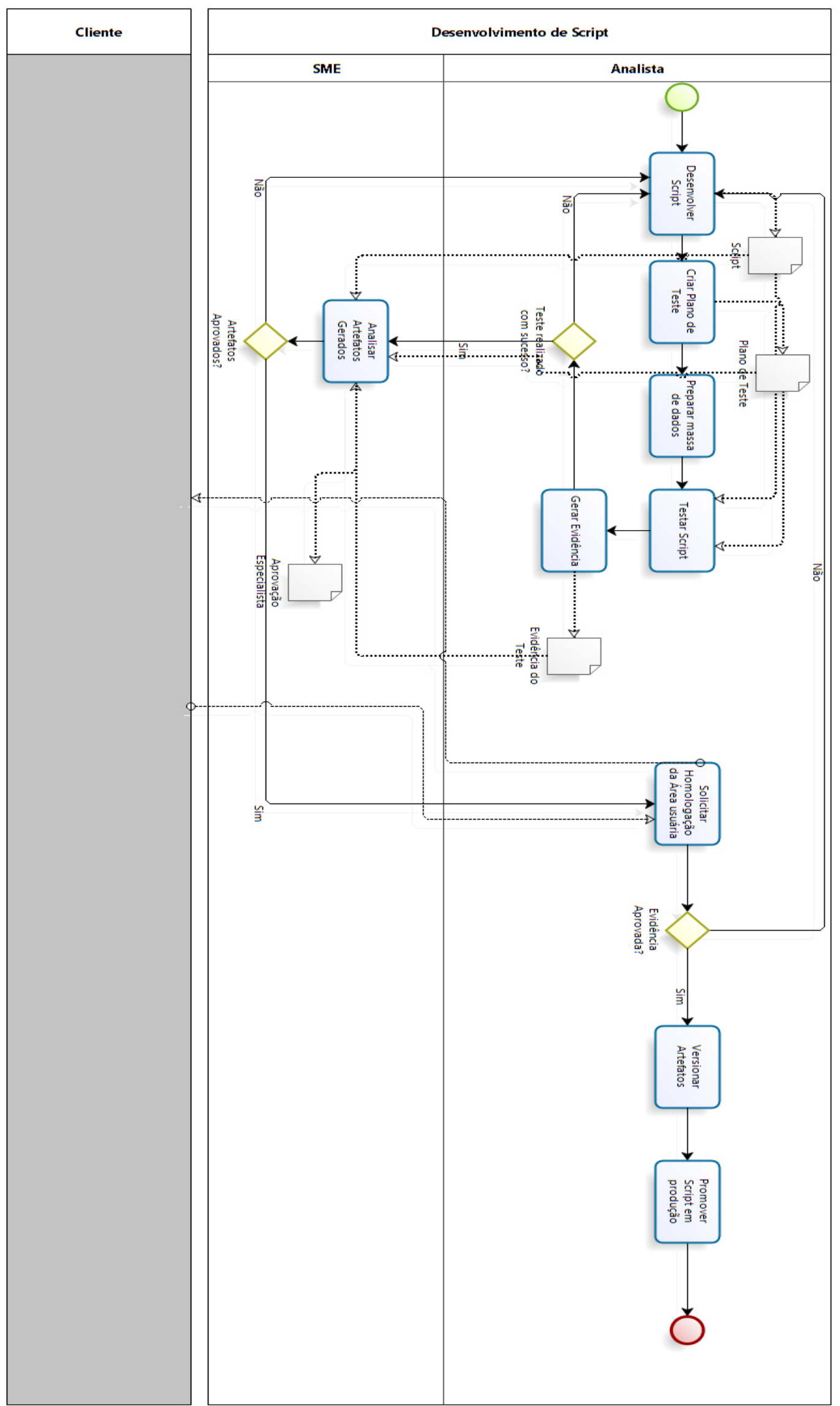

Figura 4.15: Processo de desenvolvimento de script 


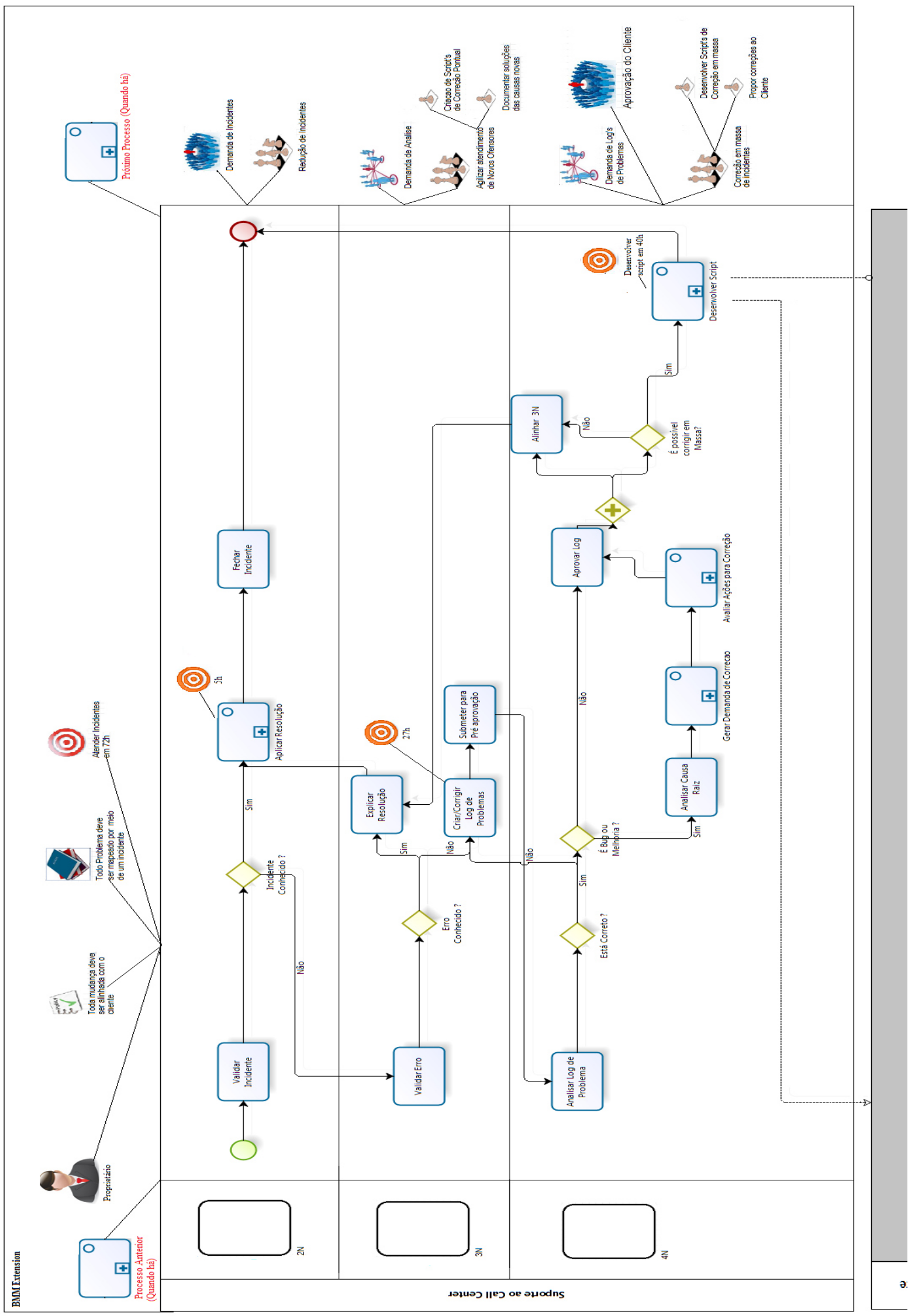

Figura 4.16: Representação da segunda camada da abordagem 


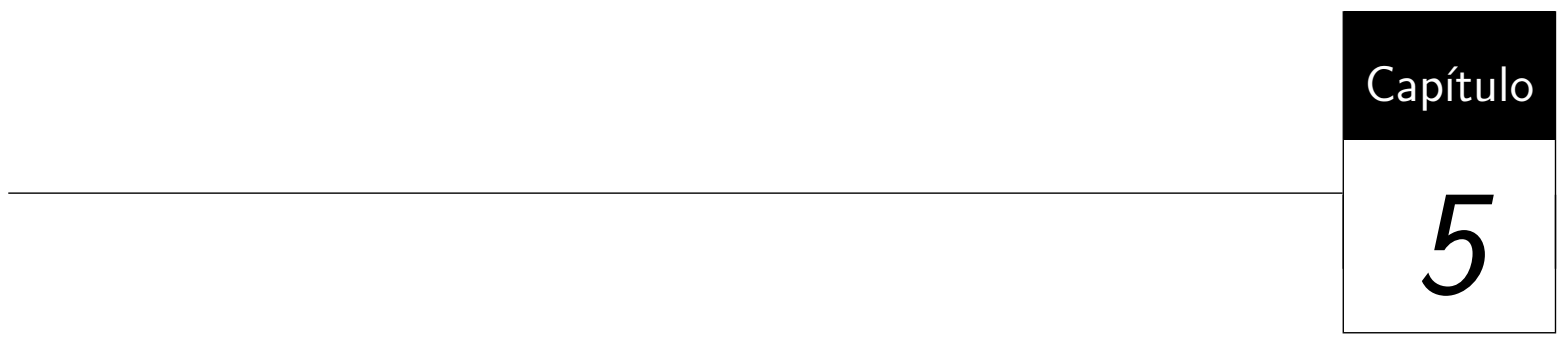

Ferramenta

Segundo Pressman(2006), o software evolui com o tempo, uma vez que seus requisitos por se basearem nas necessidades do negócio, mudam frequentemente, dificultando assim o desenvolvimento de um caminho para o produto final. Este produto, por sua vez, pode estar bem entendido mas os detalhes de suas extensões ainda precisam ser definidos. Para atender estas necessidades, foram propostos modelos de processos de desenvolvimento de software que permitem ao produto uma evolução ao longo do tempo. Estes modelos são conhecidos como modelos evolucionários e são iterativos uma vez que o mesmo permite o desenvolvimento de versões cada vez mais completas de software.

Dentre os modelos evolucionários, o que mais se adequa as necessidades da pesquisa é o modelo de Prototipagem, uma vez que a ferramenta desenvolvida evoluiu em paralelo com a abordagem proposta (apresentada no capítulo anterior), que por sua vez, conta com diversos elementos não convencionais em modeladores.

\subsection{Processo}

De uma forma geral, a prototipagem é processo de desenvolvimento de software que possui como etapas iterativas a comunicação, plano rápido, modelagem, construção do protótipo e a implantação como é ilustrado na Figura 5.1.

O primeiro passo do modelo é a comunicação, no mesmo são definidos os objetivos gerais do software. Após a comunicação é definido o plano rápido, nesta etapa é realizado 


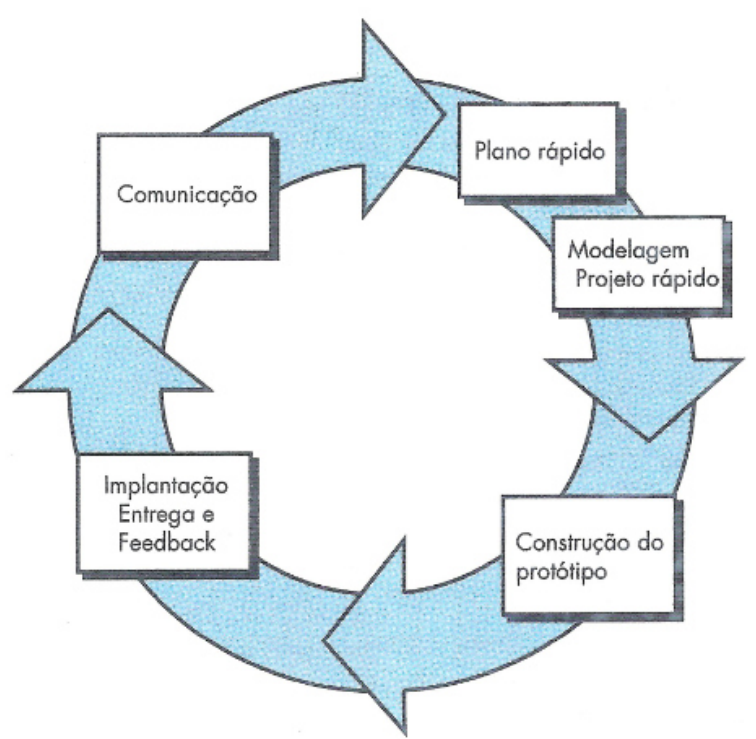

Figura 5.1: Ciclo de vida da Prototipagem (Pressman, 2006)

um planejamento sobre a iteração, assuntos como o layout das telas é discutido nesta etapa. Com o escopo bem definido, é entrada na fase da modelagem rápida do protótipo a ser desenvolvido e posteriormente é feita a implementação do protótipo. Finalmente, com o protótipo desenvolvido é realizada a implantação e coletado os feedbacks para facilitar no embasamento de novas iterações.

\subsubsection{Prototipagem da abordagem}

Na prática, como o projeto foi desenvolvido em um contexto acadêmico e não havia um cliente em específico, foi necessária a adaptação de algumas das fases da prototipagem como informada a seguir:

- Comunicação e Plano rápido Estas duas etapas eram elaboradas entre o mestrando e orientador para a definição e readequação dos objetivos gerais do software e redefinição de layout. Normalmente estas duas etapas eram realizadas em conjunto com a entrega da iteração anterior para ter um aproveitamento dos feedbacks notados no protótipo anterior.

- Modelagem e Implementação A partir dos feedbacks eram feitas as correções no metamodelo da abordagem que posteriormente eram utilizados como base para a modelagem e implementação da ferramenta.

- Implantação e Coleta dos Feedbacks Nesta etapa era apresentado ao orientador acadêmico o protótipo após a iteração. 


\subsubsection{Iterações da abordagem}

Ao todo foram 9 iterações do processo para que a ferramenta pudesse representar de forma adequada um processo de negócio com todos os níveis propostos pela abordagem.

1. Protótipo Web com arrastar e soltar de elemento A primeira iteração foi responsável pela definição da arquitetura do projeto, foi definido a tecnologia e implementado um protótipo web-based com drag and drop dos elementos.

2. Protótipo Web com arrastar e soltar com os elementos do BMM Nesta etapa foi definido onde e como o BMM seria representado na ferramenta e foi implementado o protótipo de acordo com a definição.

3. Protótipo Web com arrastar e soltar com os elementos do BMM e estrutura de Coleções Foi definido e implementada a estrutura para representar as coleções dos elementos BMM.

4. Protótipo Web com arrastar e soltar com os elementos do BMM e estrutura para os 4 níveis Elaborada e desenvolvida uma forma de visualizar os níveis de acordo com a necessidade.

5. Protótipo Web com arrastar e soltar com os elementos do BMM e implementação do Segundo Nível BPMN Definido e implementado o segundo nível da abordagem.

6. Protótipo Web com os 4 níveis Implementado todos os níveis da abordagem.

7. Protótipo Web com comunicação com o Servidor Implementada a estrutura para requisição e resposta do código cliente do modelador com o servidor.

8. Protótipo Web com persistência Definido e implementado o banco de dados e realizado o mapeamento das entidades no modelador para a persistência.

9. Protótipo Web com Crud completo Implementado o Cadastro, Leitura, Atualização e Exclusão dos diagramas no modelador.

No apêndice 3 há um detalhamento sobre as modelagens UML utilizadas e os principais códigos fontes da ferramenta.

\subsection{Tecnologia}

No trabalho de busca de ferramentas de BPMN efetivas foi visto uma certa ausência de ferramentas baseadas na web para modelagem de processos de negócio, as mesmas estão 
em pequena quantidade se comparada as ferramentas desktop disponíveis. Alinhado com isto, também foi notado no estudo dos códigos fontes das ferramentas de código aberto disponíveis que a adequação do metamodelo seria demasiadamente mais complexo do que a criação de uma nova ferramenta, devido a grande quantidade de bibliotecas prontas que deveriam ser alteradas e poderiam resultar em um gasto elevado de tempo de compreensão e implementação.

Com isso, foi pesquisada diversas tecnologias baseadas na web para o desenvolvimento de um protótipo. Dentre as tecnologias vistas podemos citar o JQuery e o ExtJS que apesar de possuírem componentes ricos e que auxiliariam de alguma forma, foram descartados devido a necessidade de dominar inúmeras tecnologias heterogêneas e da natureza do projeto que precisaria em tempo constante trocar informações com o lado Servidor da aplicação.

A maioria das estruturas Ajax disponível atualmente no mercado simplifica o trabalho de desenvolvimento, mas ainda são necessários bons conhecimentos dos recursos tecnológicos. Assim, se houver necessidade de usar o Ajax para melhorar somente a experiência do usuário com o aplicativo, se não o estiver usando também como vantagem estratégica para os negócios, talvez seja insensato investir muito tempo e dinheiro na tecnologia. Após estas considerações, foi visto que o GWT seria a melhor opção para as necessidades do projeto uma vez que os autores já possuiam o domínio da mesma.

Outro ponto a ser discutido segundo Bauer e King (2005) são que os custos de desenvolvimento sem ORM são significativamente mais elevadas na maioria dos casos, devido a uma incompatibilidade entre o paradigma de como os dados são representados em objetos contra bancos de dados relacionais. Muitos desenvolvedores de software e arquitetos estimam que sejam necessários até $30 \%$ a mais de código para lidar com esta preocupação de infra estrutura. O Hibernate aborda diretamente esta lacuna, oferecendo a capacidade de mapear a representação de um modelo de objeto de dados para um modelo de dados relacional e seu esquema de banco de dados correspondente, permitindo também que os beans utilizados no lado cliente do GWT sejam persistidos de maneira adequada.

\subsubsection{GWT}

O GWT propõe uma solução diferente à criação de aplicativos Ajax. Ele usa o Java como uma única linguagem de programação tanto para o lado cliente quanto para o lado servidor da aplicação, fornecendo um compilador que traduz e converte o código Java no lado cliente para Javascript e DHTML. Essa solução simplifica em grande medida os recursos tecnológicos do ponto de vista do programador. É necessário apenas ter conhecimento na linguagem Java. O framework também permite integrar códigos Javascript, por meio de componentes prontos. 
O toolkit da Google traz como umas principais características a compatibilidade com os diferentes browsers da Web que eventualmente não suportam Javascript e DHTML da mesma maneira. Por exemplo, o Microsoft Internet Explorer e o Mozilla Firefox são compatíveis com essas tecnologias, mas com comportamentos um pouco diferentes sendo necessário lidar com isso se o objetivo é executar perfeitamente em qualquer browser.

Uma Aplicação GWT é baseado em comunicação Cliente e Servidor, quando o projeto é criado, ele é dividido em três contextos: Cliente, Servidor e Publico.

O Contexto Cliente contém as classes em Java, com algumas restrições que serão vistas posteriormente, já o contexto do Servidor contém o código Java que será executado no servidor da aplicação e o contexto Publico que contém as páginas HTML, o CSS e as imagens do aplicativo.

O GWT possui um compilador nativo do próprio toolkit, toda a vez que o projeto é executado, ele recompila o código cliente que foi desenvolvido em Java e o transforma em códigos Javascript. Como a linguagem Javascript não é tão extensa e não possui tantas bibliotecas quanto à linguagem Java, existe algumas restrições para os comandos que podem ser executados do lado cliente da aplicação.

A comunicação padrão do cliente GWT com o servidor Java é por meio de JSON ( $J a$ vascript Object Notation) é um formato leve para intercâmbio de dados computacionais. JSON é um subconjunto da notação de objeto de Javascript, mas seu uso não requer Javascript exclusivamente. A simplicidade de JSON tem resultado em seu uso difundido, especialmente como uma alternativa para XML em AJAX. Uma das vantagens reivindicadas de JSON sobre XML como um formato para intercambio de dados neste contexto, é fato de ser muito mais fácil escrever um analisador JSON.

O padrão de comunicação como descrito acima é assíncrona. O cliente faz a chamada ao servidor, e o servidor logo após o processamento faz uma chamada callback ao cliente para retornar dados de seu processo.

Existem algumas bibliotecas próprias para o GWT que tem o intuito desde o acréscimo de inúmeros componentes visuais mais ricos e dinâmicos. Para este projeto foi utilizada as bibliotecas SmartGwt e GWT-dnd.

\subsubsection{Hibernate}

O Hibernate foi desenvolvido em 2001 por Gavin King. Sua missão na época era simplesmente oferecer melhores capacidades de persistência que o EJB2, simplificando as complexidades e permitindo características faltantes. No início de 2003, a equipe de desenvolvimento do Hibernate começou Hibernate 2 que ofereceu muitas melhorias significativas sobre o primeiro lançamento e iria disseminar o Hibernate como o padrão para persistência em Java. (JBoss Community, 2010). 
Ao invés de utilizar o processamento byte code ou geração de código, o Hibernate utiliza reflexão em tempo de execução para determinar as propriedades de uma classe persistente. Os objetos a serem persistidos são definidos em um documento de mapeamento, que possui a descrição dos campos persistentes e associações, bem como quaisquer subclasses ou proxies do objeto persistente. Os documentos de mapeamento são compilados em tempo de inicialização dos aplicativos e proporcionando ao framework informações necessárias para uma classe. (TheServerSide; Nick Heudecker, 2003).

O Hibernate pode ser utilizado em ambientes de forma independente a quantidade de usuários, servindo tanto para aplicações com centenas como para missões críticas que servem a milhares de usuários.

Também é permitido o desenvolvimento de classes persistentes utilizando normalmente os recursos da orientação a objetos como herança, polimorfismo, associação, composição e estruturas do Java collection. Hibernate permite que qualquer estrutura de classes ou de dados a ser persistente. Além disso, ele permite construir procedimentos mais rápidos, uma vez que não apresenta o tempo de compilação de código-fonte ou a geração de byte code ou processamento.

\subsection{Ferramenta}

Como destacado anteriomente, o protótipo foi desenvolvido com o framework GWT e as bibliotecas visuais SmartGwt e GWT-dnd que permitiram todo a funcionalidade e representatividade da modelagem dos processos. O protótipo também teve o acréscimo do framework Hibernate para facilitar a persistência dos processos modelados. Para obter o código fonte da ferramenta é necessário acessar o link: https://lbbmodeler.googlecode.com/svn/lbbmodeler . A Figura 5.2 representa a tela inicial de modelagem do protótipo.

No canto superior esquerdo existem 4 botões que possuem a finalidade de persistir, carregar, deletar e limpar os modelos de processos. Abaixo dos botões há um componente de sanfona que permite a visualização dos níveis conforme a necessidade. No tópico a seguir será apresentado todo o fluxo de modelagem do processo nos 4 níveis.

\subsubsection{Modelagem em níveis}

A ferramenta divide os níveis com o componente de sanfona (Section), com isto é permitido que um nível seja expandido ou não de acordo com a necessidade de quem está modelando o processo. 


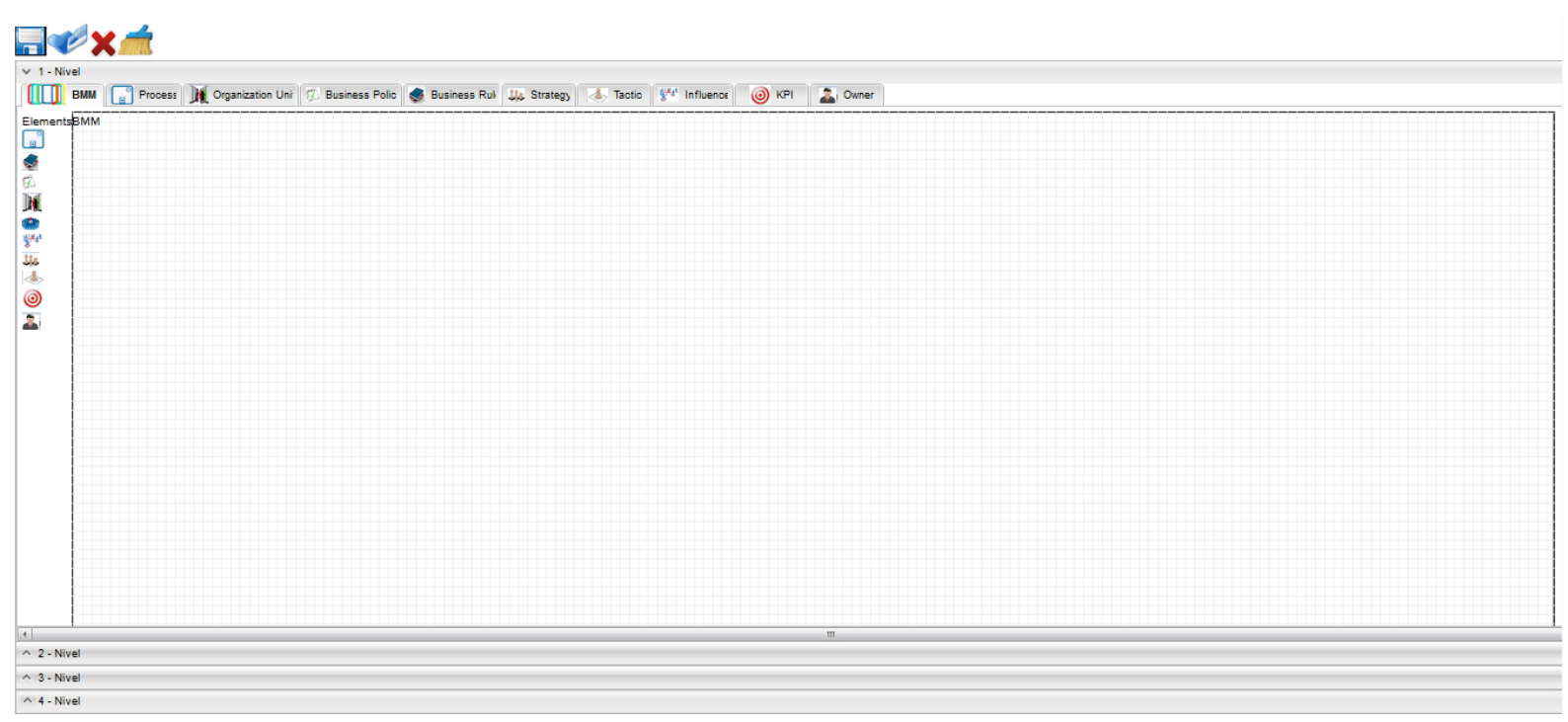

Figura 5.2: Tela Inicial da Ferramenta

\subsubsection{Primeiro Nível}

Em todos os níveis há botões na lateral esquerda para selecionar os elementos de cada nível a ser inserido no diagrama. Para iniciar a modelagem de um processo é necessário selecionar o botão de processo e o elemento surgirá no diagrama como ilustra a parte 1 da Figura 5.4. É válido ressaltar que não existe uma ordem para inserção dos elementos no diagrama, uma vez que os mesmos podem ser ligados e apagados a qualquer momento.

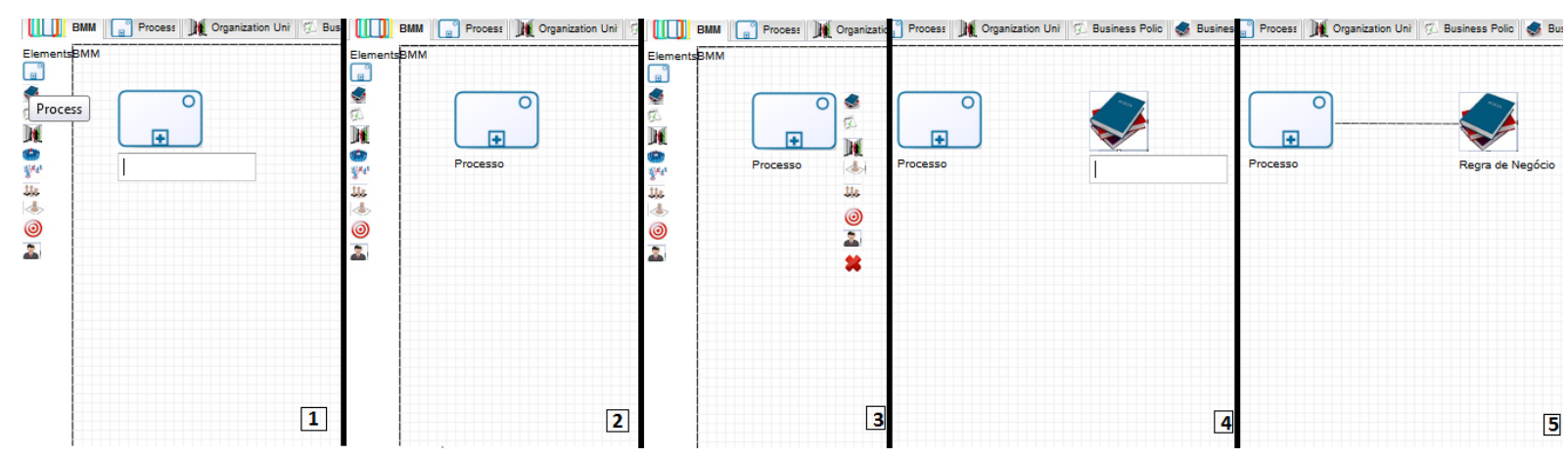

Figura 5.3: Definição de um Processo

Após inserir um processo no primeiro nível, é necessário definir o nome do mesmo e apertar a tecla ENTER. O nome de qualquer elemento pode ser alterado com um duplo clique no nome. Na parte 2 da Figura 5.4 ilustra um processo já definido.

Após definir o nome do elemento, é possível relacionar o mesmo com os demais elementos do BMM, para isto, é necessário clicar no nome do elemento e irá surgir todas as opções de ligações para o elemento selecionado como ilustra a parte 3 da Figura 5.4. Com isto, a ferramenta impede que uma modelagem seja feita de forma incorreta uma vez que a mesma utiliza e valida o metamodelo do BMM antes de fornecer as opções de ligação. 
Após selecionar o elemento desejado como ilustra a parte 4 da Figura 5.4 é necessário definir o nome do mesmo e apertar a Tela ENTER. Com isto, o elemento será ligado automaticamente com o anterior como é apresentado na parte 5 da Figura 5.4.

Desta forma é possível interligar os processos e os elementos do BMM de acordo com o Metamodelo como ilustra a Figura 5.4.

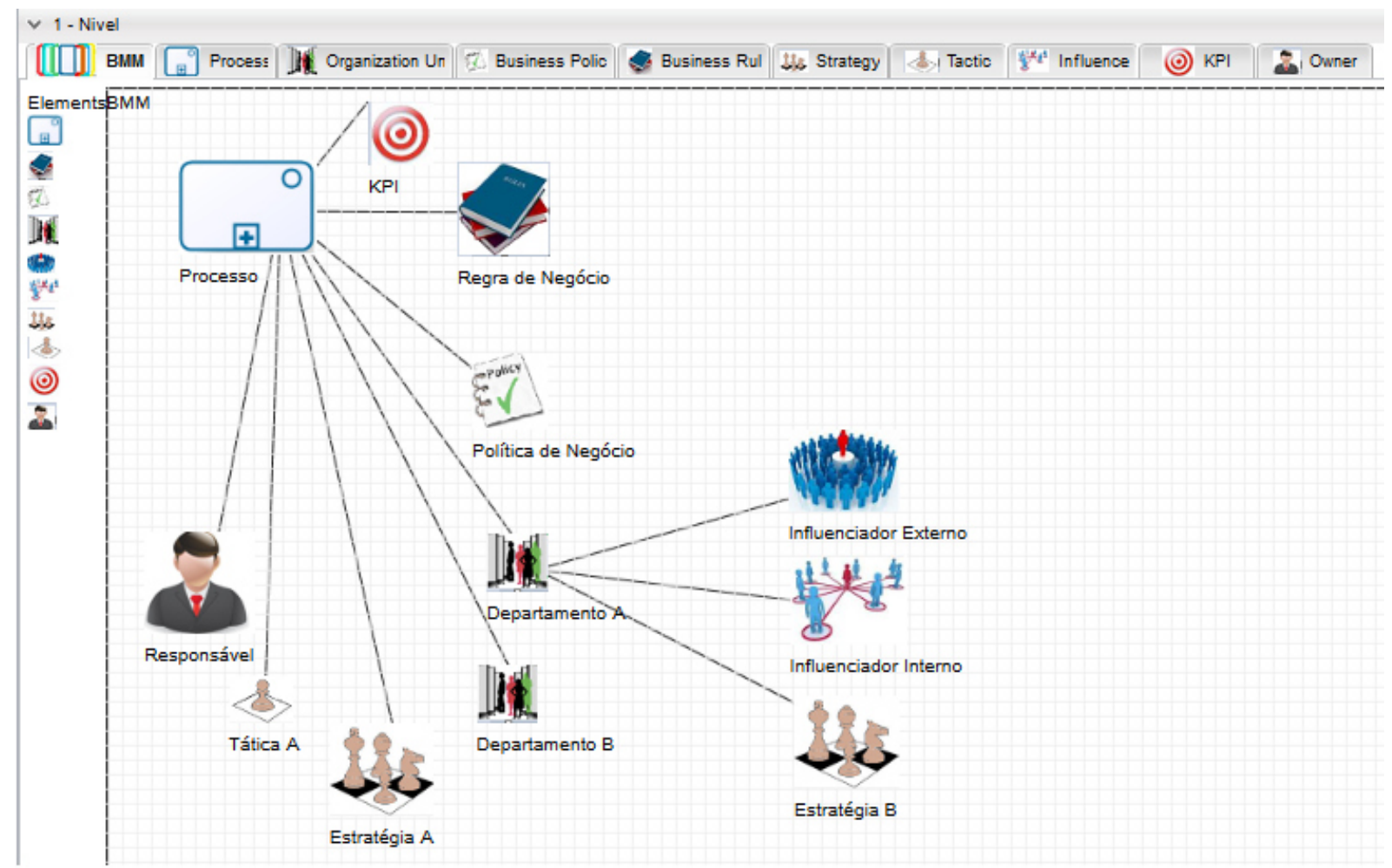

Figura 5.4: Definição de um Processo

A ferramenta provê uma segunda forma de ligar os elementos, ao clicar nas opções BMM de Ligação para o processo (etapa 3 da Figura 5.4 ) aparece o elemento com o campo texto em branco (etapa 4 da Figura 5.4 ), ao digitar o nome desejado e apertar a tecla ENTER a ferramenta procura todos os elementos daquele tipo definido no diagrama com o nome digitado e se o mesmo for encontrado ele realiza a ligação ao invés de definir um novo nome.

Caso algum elemento seja criado de forma incorreta é possível apaga-lo do diagrama selecionando a opção excluir ( ' $\mathrm{X}$ ' em vermelho na etapa 3 da Figura 5.4 ), com isto, além do elemento, todas as ligações deste elemento também serão retiradas do diagrama.

Após definir os elementos no primeiro nível, é possível alterar a perspectiva entre o Diagrama principal BMM e os diagramas que representam as coleções agrupadas pelo tipo do elemento BMM com ilustrado na Figura 5.5. 


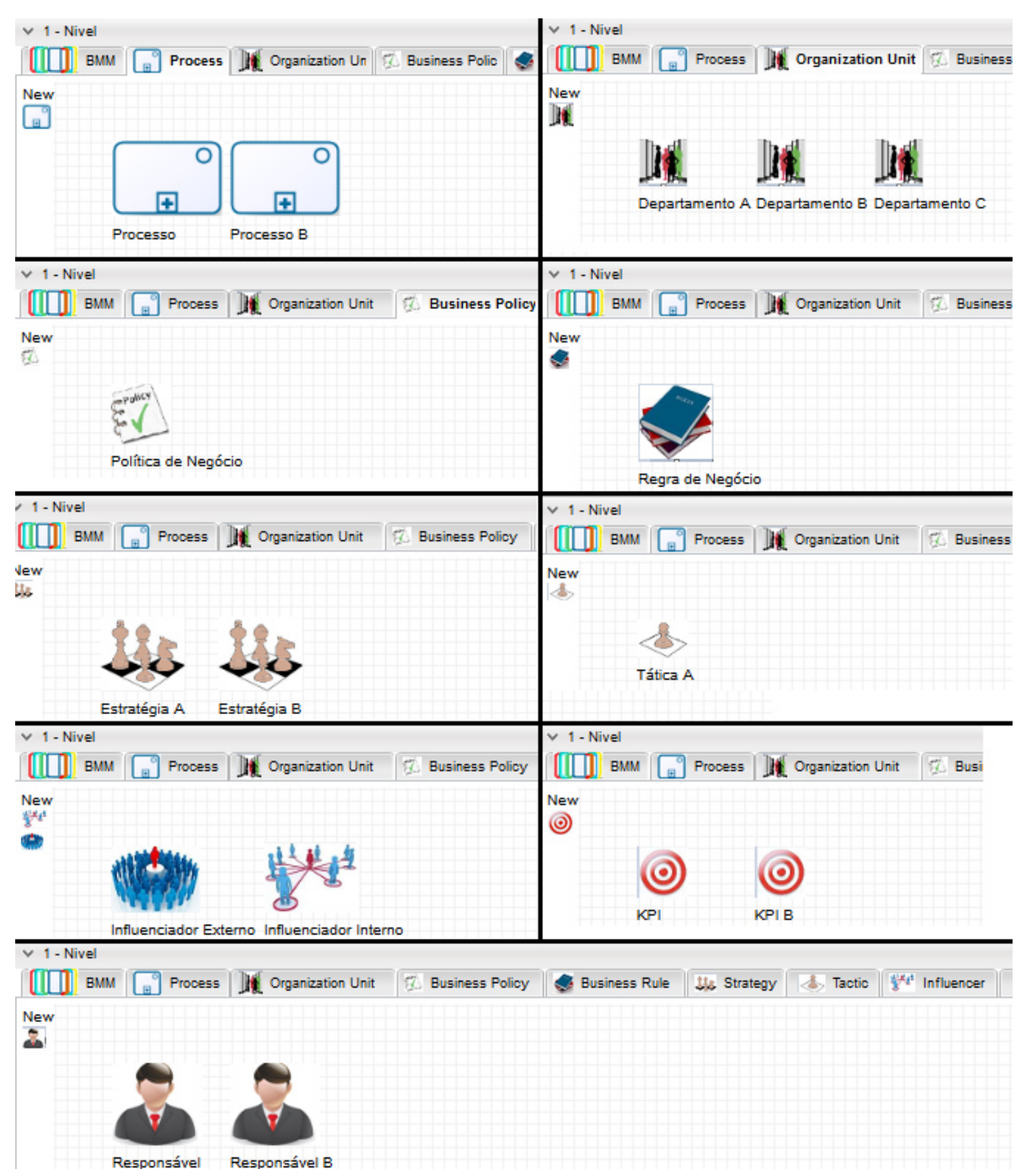

Figura 5.5: Perspectiva de Coleções

\subsubsection{Segundo Nível}

O fluxo a partir do segundo nível é modelado em BPMN, no entanto, por se tratar de um Protótipo, não foi trazido toda a sua notação devido ao pouco tempo e complexidade uma vez que seria necessário adicionar todas as regras da notação para não permitir a modelagem incorreta do fluxo. 
Após definir o processo no primeiro nível como caixa preta e suas ligações com os elementos do BMM, é possível modelar seu fluxo no segundo nível da ferramenta para selecionar o processo a ser modelado o fluxo é necessário clicar com o botão esquerdo do mouse uma única vez sobre o processo no primeiro nível, com isto o componente sanfona irá indicar no segundo nível (entre parênteses) o processo selecionado. A Figura 5.6 mostra o estado inicial de modelagem do segundo nível quando alguns elementos BMM já estão ligados ao processo no primeiro nível.

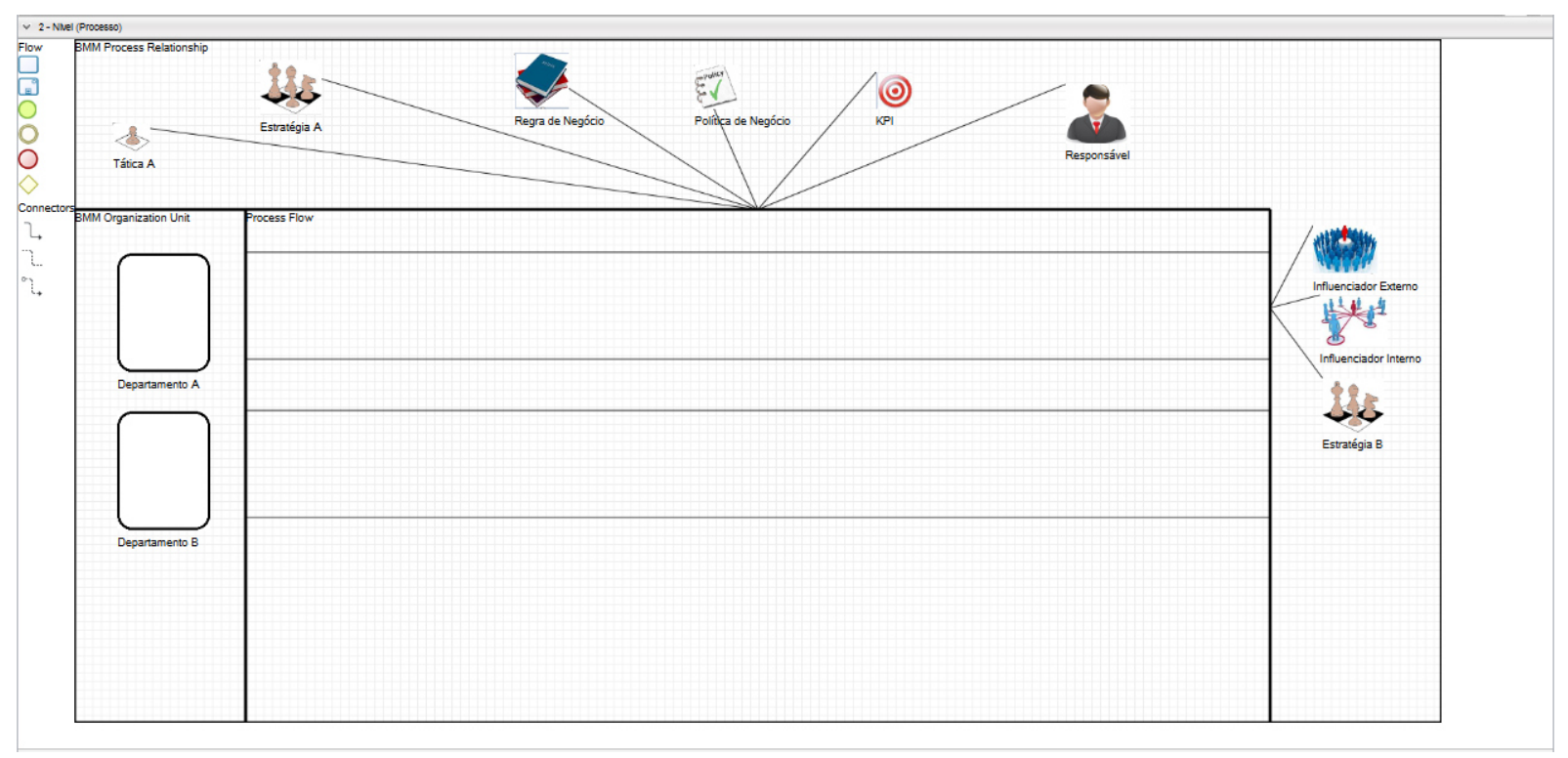

Figura 5.6: Segundo Nível

Pela Figura 5.6 é possível constatar que todos os elementos definidos e associados ao processo no primeiro nível também estão no segundo nível para facilitar a modelagem do fluxo. Também é possível notar que ao definir um departamento no primeiro nível a ferramenta o converte automaticamente para uma Lane no BPMN do segundo nível e relaciona os influenciadores e estratégias do departamento com a Lane no canto direito do diagrama.

A mêcanica de modelagem é idêntica ao primeiro nível, deve ser selecionado um elemento pelo menu ao lado esquerdo e seguir o fluxo de modelagem. A Figura 5.7 apresenta em 3 passos para a modelagem do fluxo do processo.

O primeiro passo escolhido foi definir no começo do diagrama o evento de início no BPMN, posteriormente foi realizado um clique duplo com o botão esquerdo do mouse para a ferramenta fornecer todas as possibilidades de ligação que um evento de início do BPMN possui. Uma tarefa foi selecionada para proceder o evento de início.

Após a modelagem é possível ver na Figura 5.8 como o fluxo completo de um processo seria representado na ferramenta no segundo nível. 
CAPÍTULO 5. FERRAMENTA

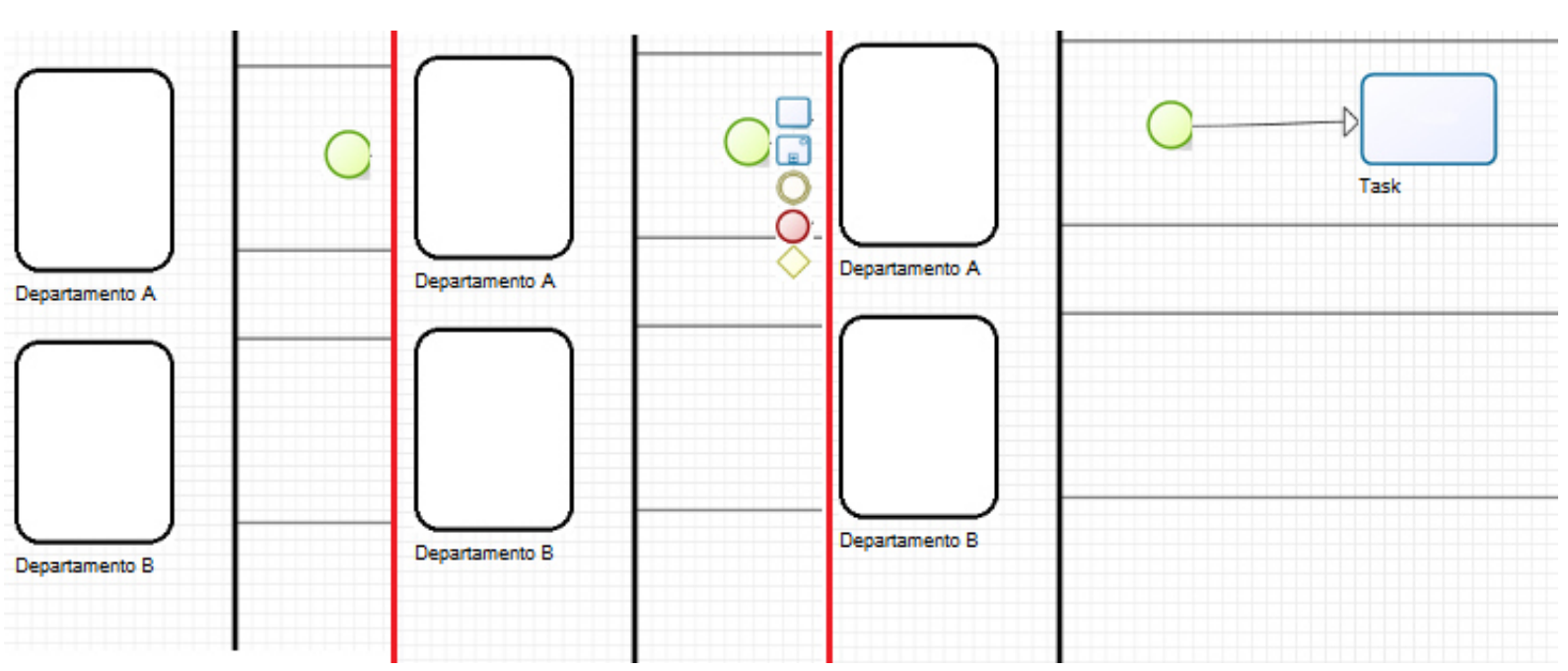

Figura 5.7: Modelagem do Segundo Nível

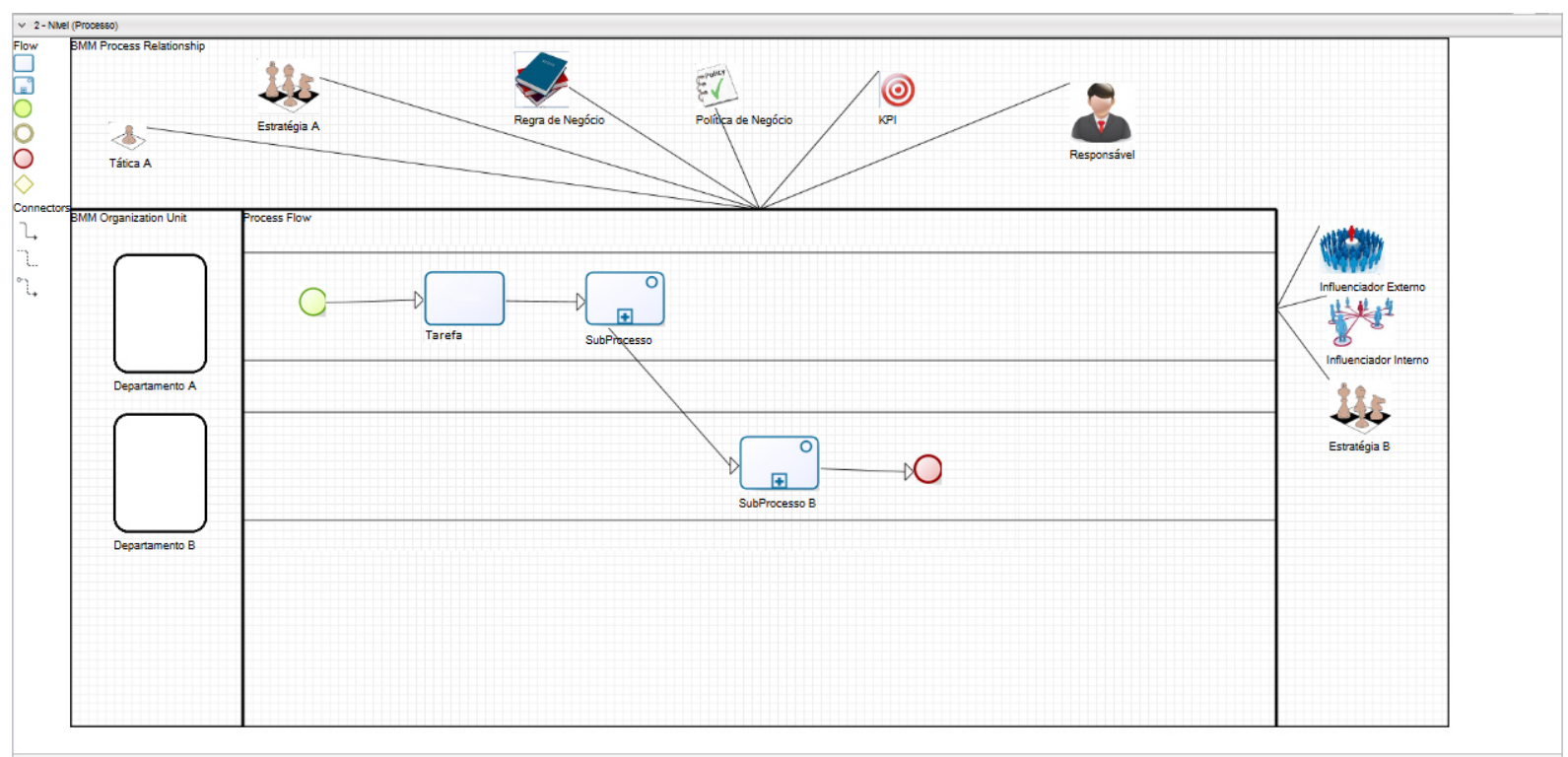

Figura 5.8: Fluxo do Processo no Segundo Nível

Este nível é dependente do processo selecionada no nível anterior, ao selecionar um outro processo no nível superior, este nível irá acompanhar alterando o fluxo do processo.

\subsubsection{Terceiro Nível}

Após definir um subprocesso no segundo nível (também como caixa preta) e suas ligações com os demais elementos do BPMN no fluxo do processo no segundo nível, é possível modelar seu fluxo no terceiro nível da ferramenta. Para selecionar o subprocesso a ser modelado o fluxo é necessário clicar com o botão esquerdo do mouse uma única vez sobre o subprocesso no segundo nível, com isto o componente sanfona irá indicar no terceiro nível (entre parênteses) o subprocesso selecionado. A Figura 5.9 mostra o estado inicial de 
modelagem do terceiro nível quando alguns elementos BMM já estão ligados ao processo no primeiro nível.

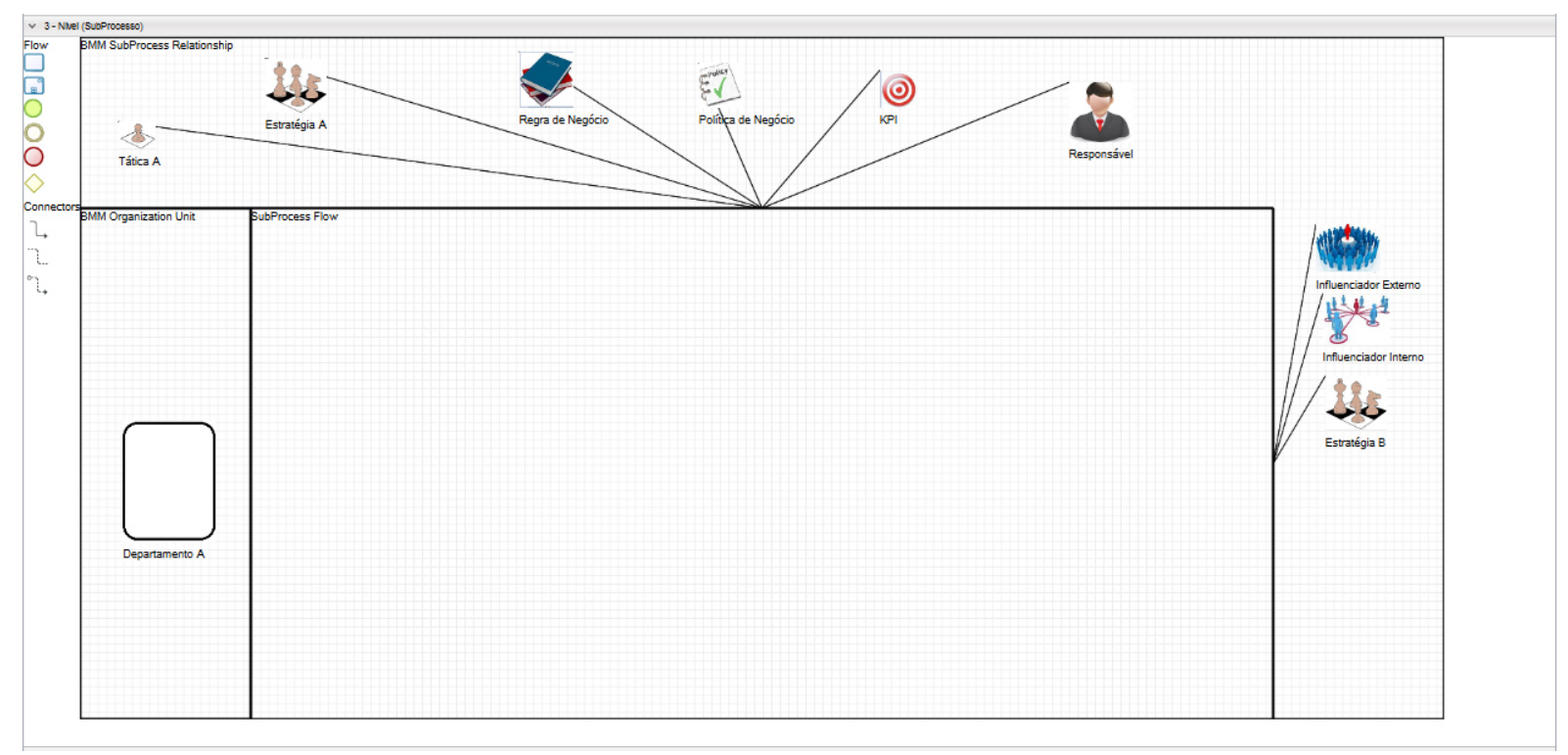

Figura 5.9: Terceiro Nível

Pela Figura 5.9 é possível constatar que todos os elementos definidos e associados ao processo no primeiro nível também estão no terceiro nível para facilitar a modelagem do fluxo. Também é possível notar que o terceiro nível insere apenas o departamento a qual o subprocesso pertence e carrega também apenas os influenciadores e estratégias do departamento que o subprocesso está contido e não todos os departamentos que o processo possui como é mostrado no segundo nível.

A mecânica de modelagem é a mesma dos demais níveis, deve ser selecionado um elemento pelo menu ao lado esquerdo e seguir o fluxo de modelagem. A Figura 5.10 apresenta em 4 passos a modelagem do fluxo do subprocesso.

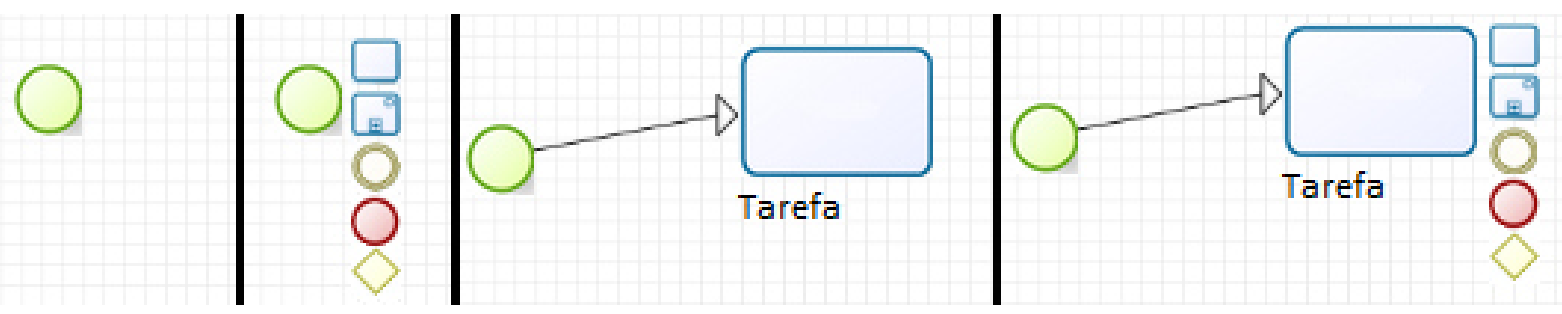

Figura 5.10: Modelagem do Terceiro Nível

O primeiro passo escolhido foi definir no começo do diagrama o evento de início no BPMN, posteriormente foi realizado um clique duplo com o botão esquerdo do mouse para a ferramenta fornecer todas as possibilidades de ligação que um evento de início do BPMN possui. Uma tarefa foi selecionada para proceder o evento de início e na mesma 
foi realizado um clique duplo com o botão esquerdo do mouse para visualizar todas as possibilidades de ligação que a tarefa possui.

Após a modelagem é possível ver na Figura 5.11 como o fluxo completo de um subprocesso seria representado na ferramenta no terceiro nível.

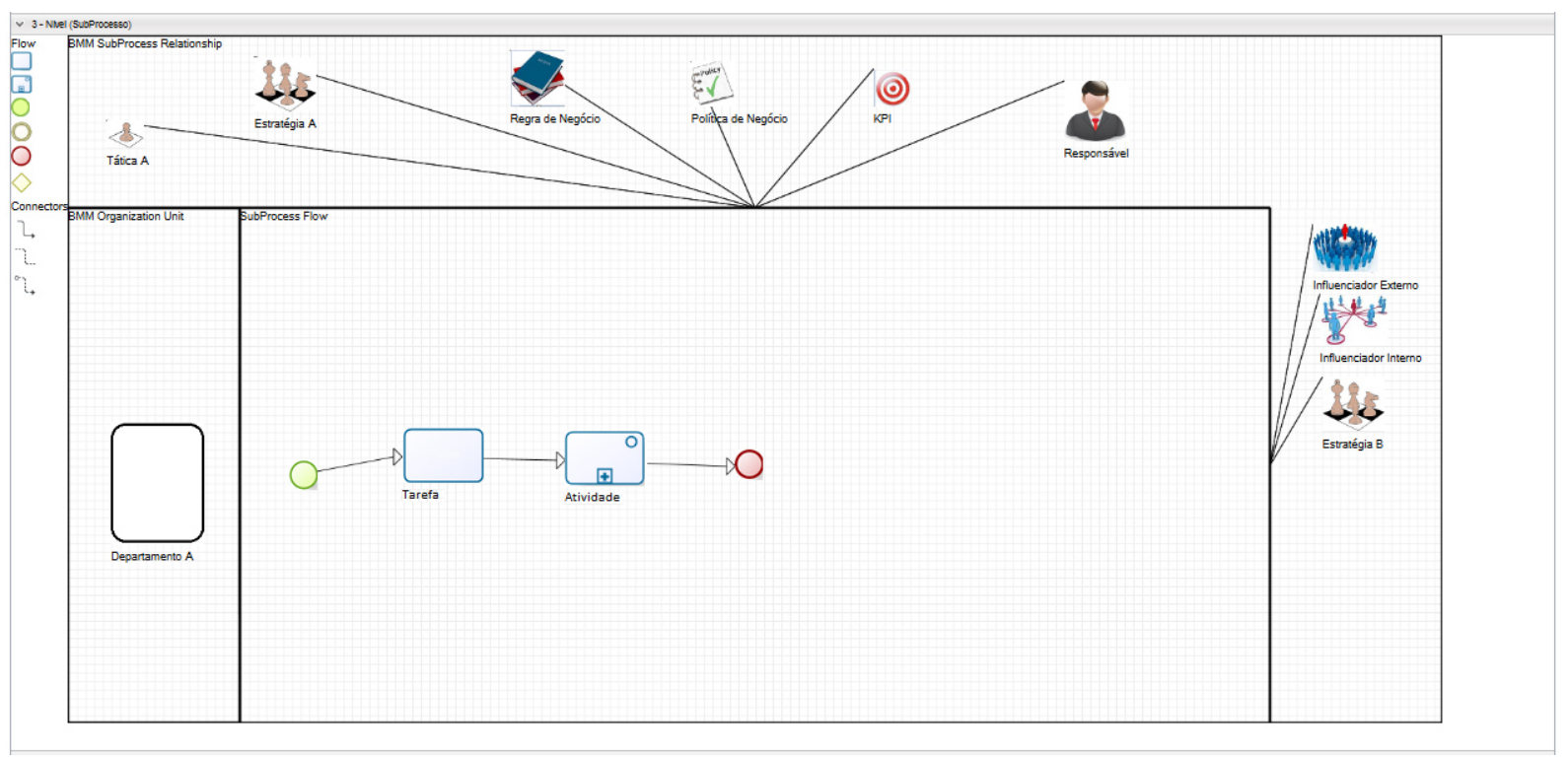

Figura 5.11: Fluxo do Subprocesso no Terceiro Nível

Este nível é dependente do subprocesso selecionada no nível anterior, ao selecionar um outro subprocesso no nível superior, este nível irá acompanhar alterando o fluxo do subprocesso.

\subsubsection{Quarto Nível}

Para finalizar a modelagem em níveis, após definir uma atividade no terceiro nível (também como caixa preta) e suas ligações com os demais elementos do BPMN no fluxo do subprocesso no terceiro nível, é possível modelar seu fluxo no quarto e último nível da ferramenta. Para selecionar a atividade a ser modelado o fluxo é necessário clicar com o botão esquerdo do mouse uma única vez sobre a atividade no terceiro nível, com isto o componente sanfona irá indicar no quarto nível (entre parênteses) a atividade selecionado. A Figura 5.12 mostra o estado inicial de modelagem do quarto nível quando alguns elementos BMM já estão ligados ao processo no primeiro nível.

Pela Figura 5.12 é possível notar que o quarto nível é muito semelhante ao terceiro, no entanto, não há a opção de descer mais um nível, portanto, o fluxo é representado apenas por tarefas. A modelagem deste nível é idêntico aos níveis anteriores como é ilustrado na Figura 5.10.

Após a modelagem é possível ver na Figura 5.13 como o fluxo completo de uma atividade seria representada na ferramenta no quarto nível. 


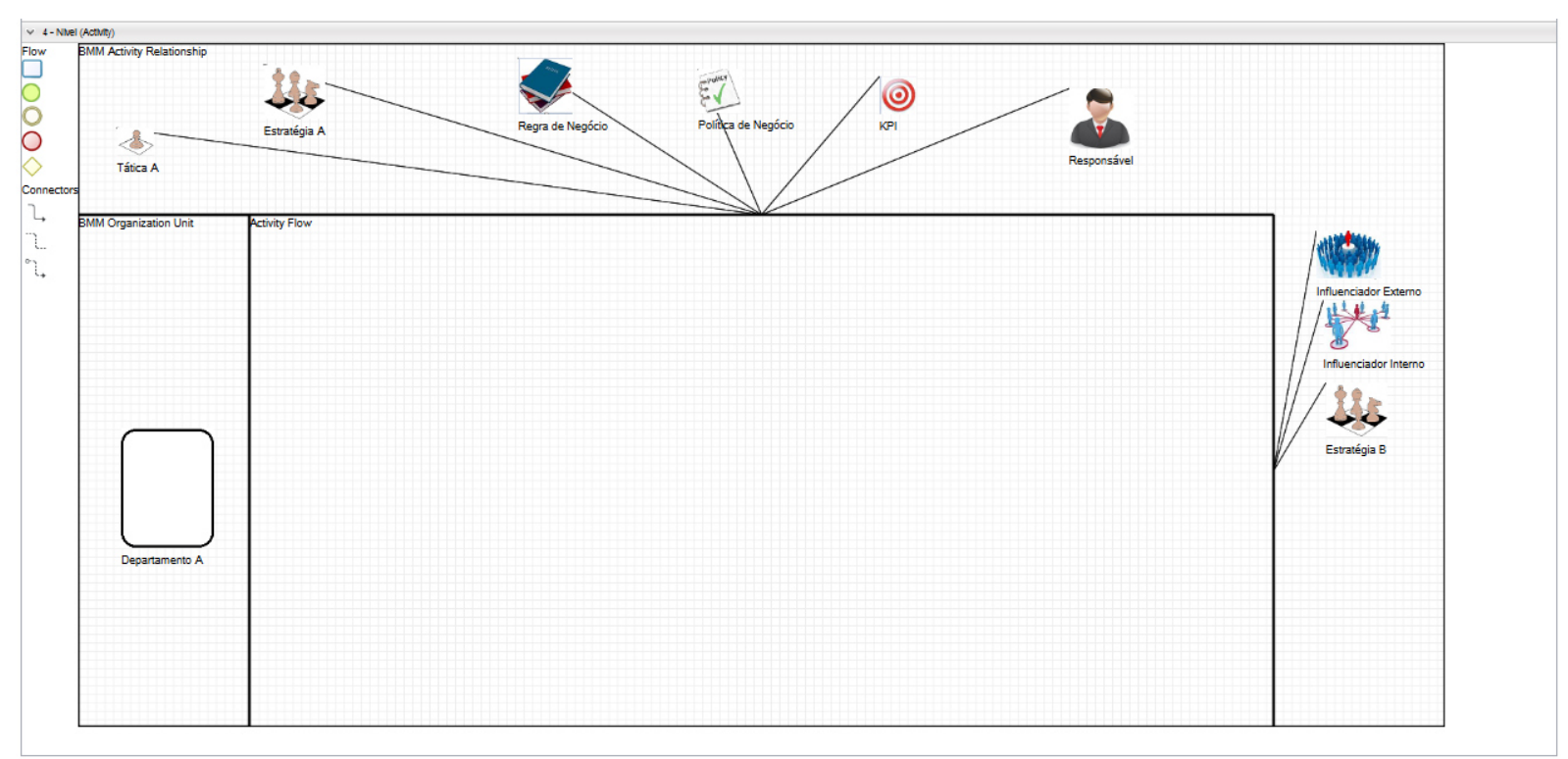

Figura 5.12: Quarto Nível

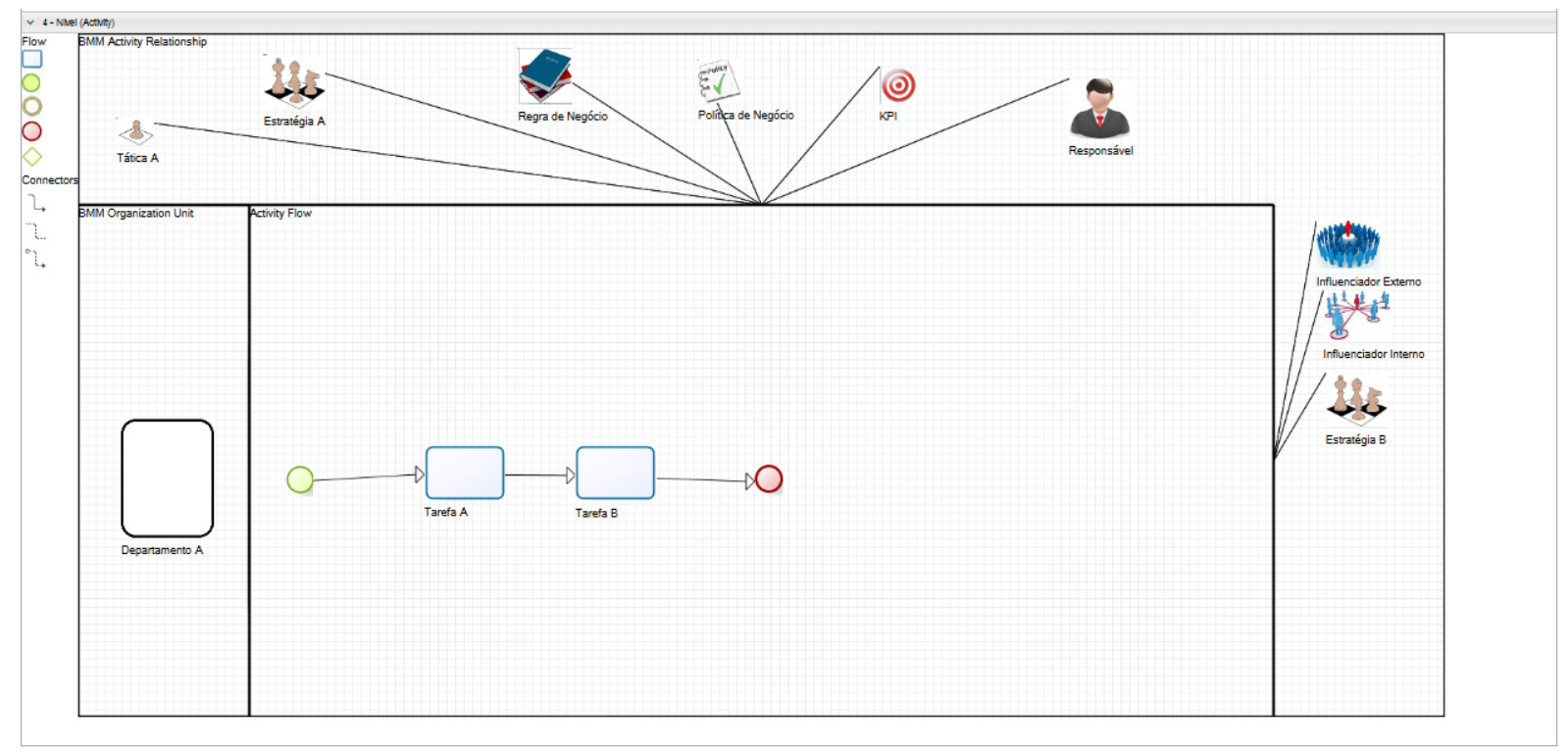

Figura 5.13: Fluxo da Atividade no Quarto Nível

Este nível é dependente da atividade selecionada no nível anterior, ao selecionar uma outra atividade no nível superior, este nível irá acompanhar alterando o fluxo da atividade.

\subsubsection{CRUD}

A ferramenta oferece um CRUD (acrónimo de Create, Read, Update e Delete em língua Inglesa) completo dos diagramas nos 4 níveis para as quatro operações básicas utilizadas em bancos de dados relacionais. A Figura 5.14 apresenta respectivamente os botões de cadastro (inserir e alterar diagrama), abrir, excluir e limpar o diagrama. 


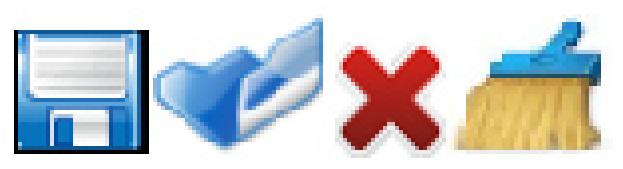

Figura 5.14: CRUD

\subsubsection{Cadastrar}

Após modelar os processos em todos os níveis é possível persistir o diagrama no banco de dados para continuar posteriormente com a modelagem ou apresentar o modelo. Ao clicar no botão de Salvar será apresentado um campo de texto para definir o nome do diagrama como mostra a Figura 5.15.

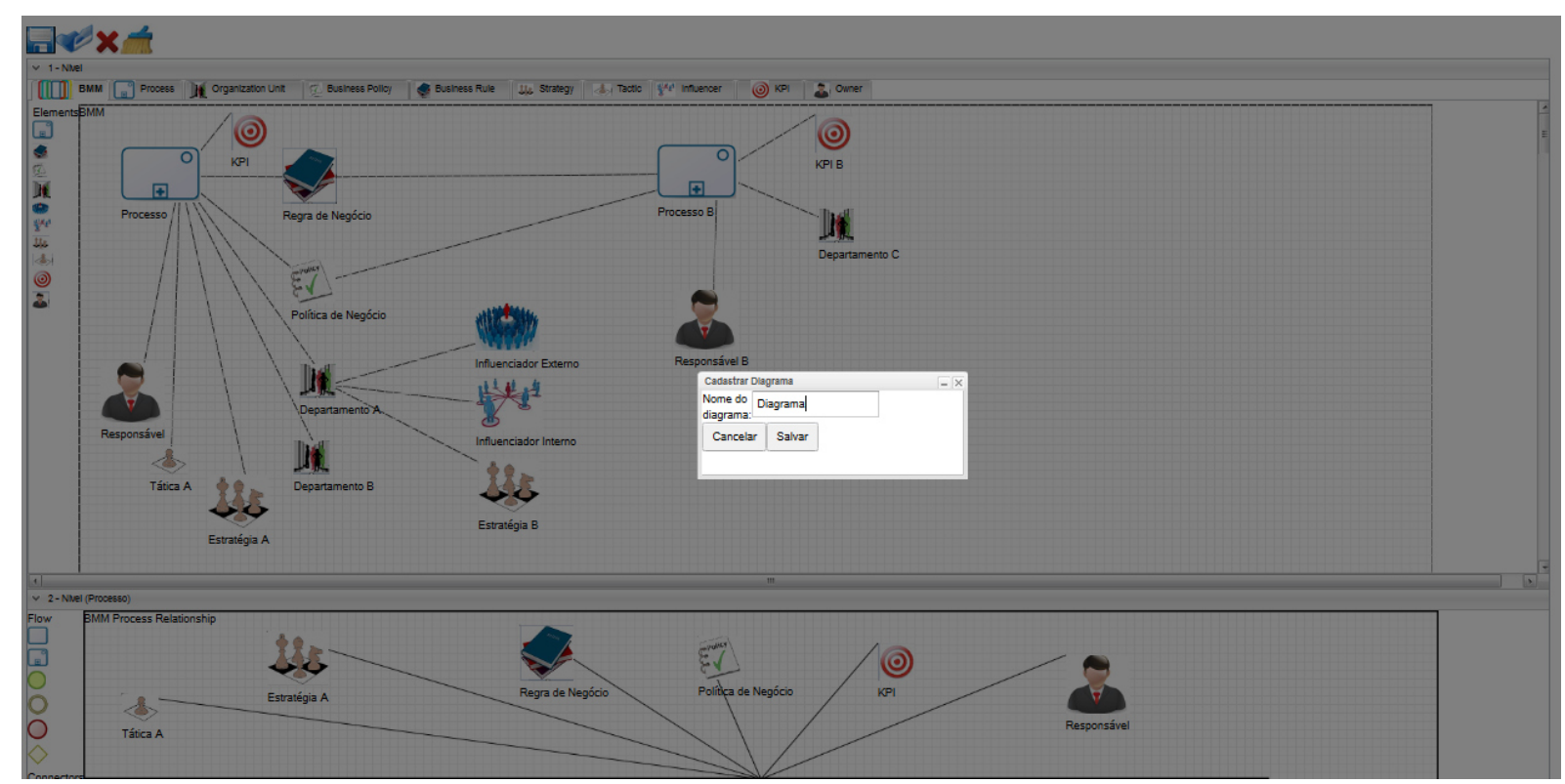

Figura 5.15: CRUD

Após selecionar o nome do diagrama, clicar no botão Salvar para cadastrar o diagrama. Esta funcionalidade insere o diagrama no banco de dados se o mesmo não estiver inserido e o altera caso já esteja cadastrado.

\subsubsection{Abrir}

A ferramenta permite que um diagrama já persistido seja visualizado ou mesmo alterado com esta opção, para isto, clicar no botão Abrir para visualizar todos os diagramas cadastrados e selecionar o diagrama que deseja trabalhar. A Figura 5.16 mostra os diagramas já persistidos que podem ser visualizados. 


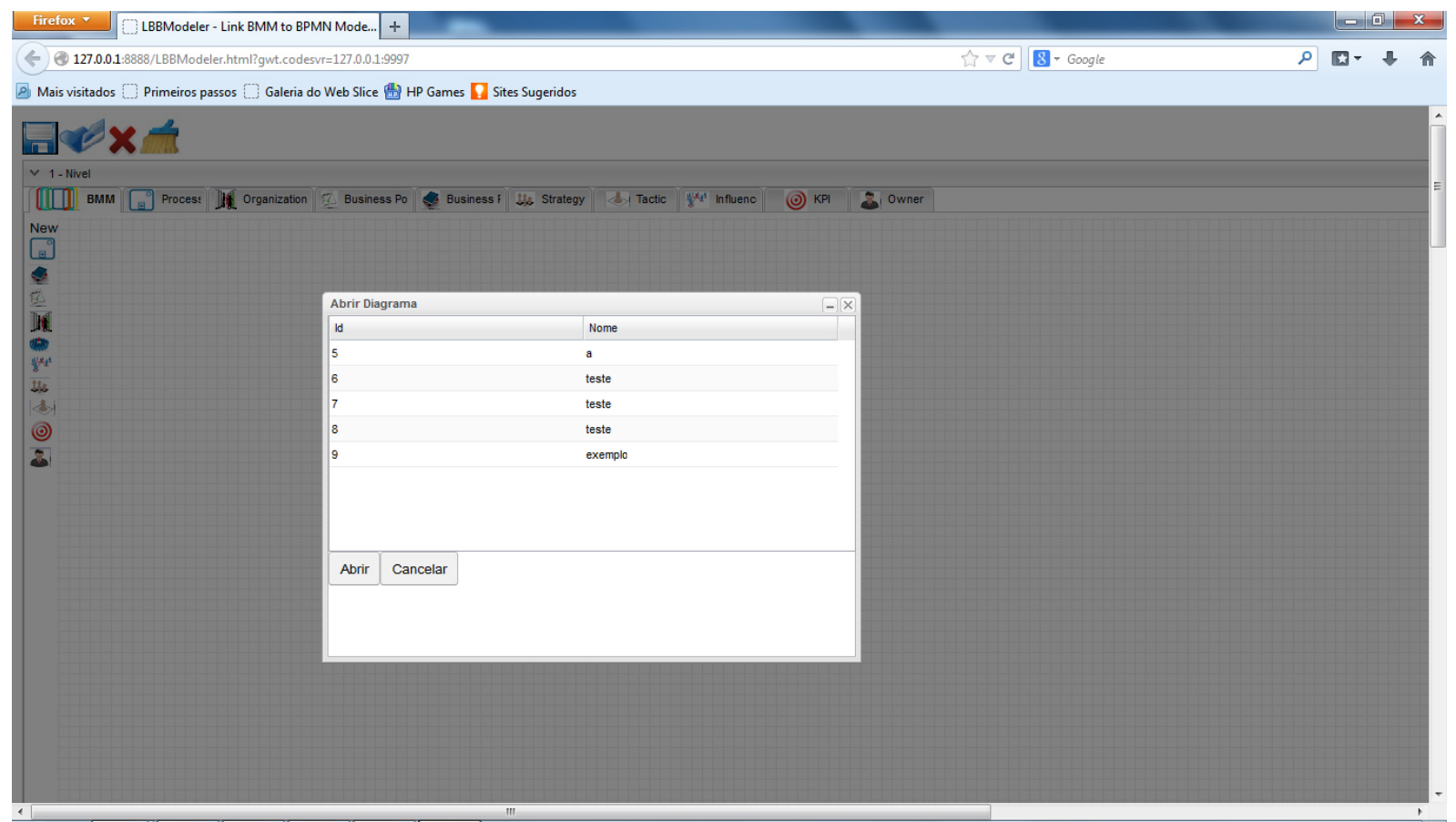

Figura 5.16: Abrir

\subsubsection{Excluir}

É possível excluir qualquer diagrama já criado, para isto, clicar no botão Excluir para visualizar todos os diagramas cadastrados e selecionar o diagrama que deseja excluir. Caso o diagrama escolhido para exclusão estiver sendo modelado, o diagrama será totalmente limpo e todas as informações serão perdidas. A Figura 5.17 ilustra os diagramas que podem ser excluídos.

\subsubsection{Limpar}

Esta opção é utilizada quando é desejado limpar todas as informações do diagrama modelado no momento e começar uma nova modelagem.

\subsection{Desafios de Implementação}

Ao longo da implementação da ferramenta foram encontrados alguns empecilhos que dificultaram consideravelmente a implementação da mesma, resultando em um tempo maior do que o esperado de implementação.

\subsubsection{Tecnologia Web}

A dificuldade inicial de implementação foi desenvolver uma aplicação de modelagem de processos em ambiente web uma vez que haveria a necessidade de realizar a comunicação 


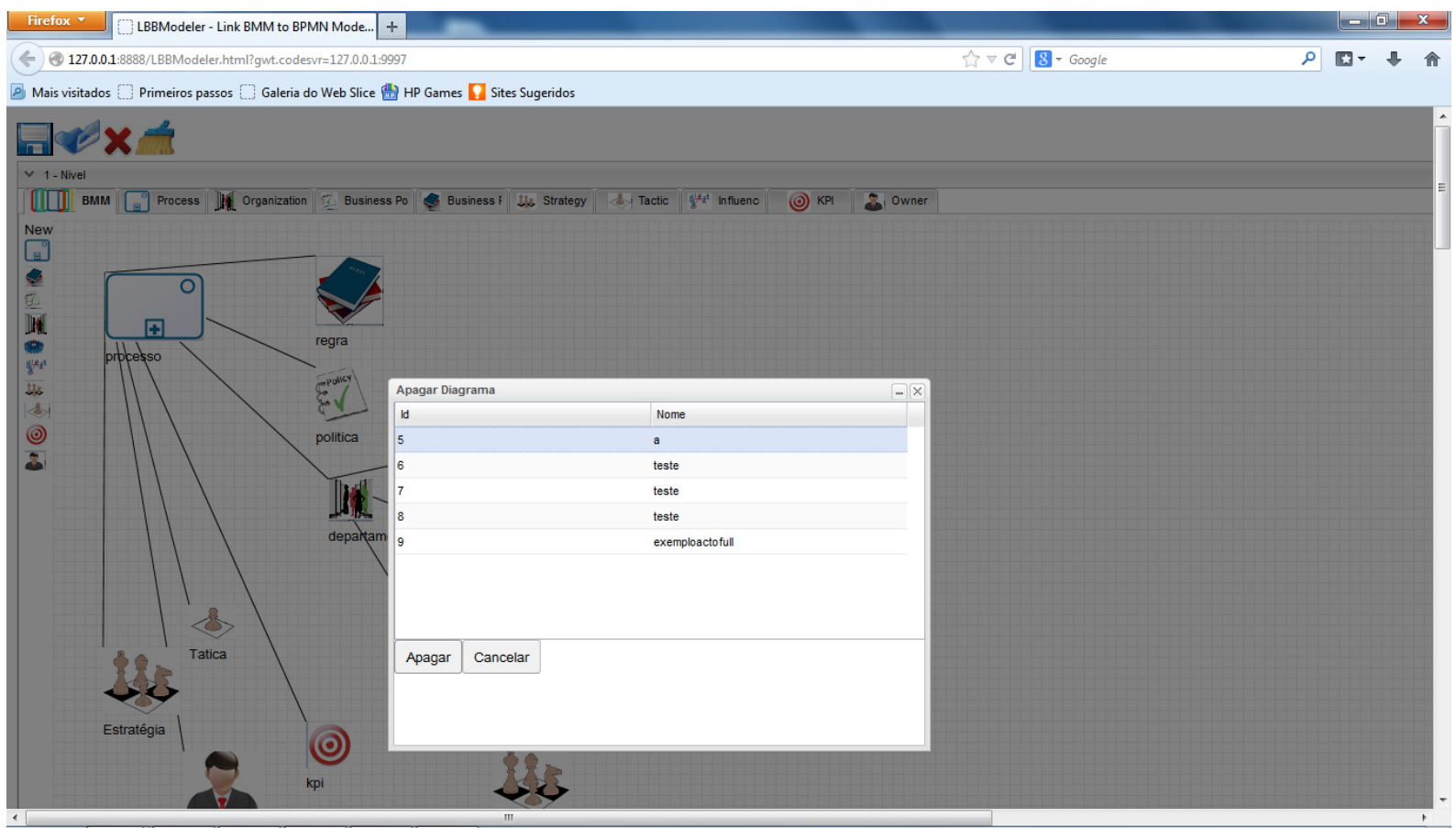

Figura 5.17: Excluir

entre 2 tecnologias (cliente e servidor) a todo o momento, com isto, muito foi estudado sobre as tecnologias que permitiriam esta implementação até entrar no consenso de que o GWT seria a tecnologia ideal uma vez que foi possível definir os beans que seriam utilizados tanto do lado cliente quanto do lado servidor e em ambos os lados a tecnologia Java é a utilizada.

\subsubsection{Arrastar e Soltar}

O ambiente web não foi o único ponto a ser muito pesquisado antes da implementação, a necessidade de um componente que permitiria clicar e arrastar um elemento de um lado a outro do browser e quardar a posição onde foi inserido também foi investigado a fundo e foi visto que poderia ser feito com diversas tecnologias Javascript existentes como o JQuery e o ExtJS no entanto, voltaria a questão de haver 2 tecnologias distintas no mesmo projeto, com isto, antes de iniciar o projeto foi procurado algum plugin que permitisse o clique e arrasta com o GWT e foi encontrada a biblioteca GWT-dnd.

\subsubsection{Ligação entre elementos}

A princípio a biblioteca GWT-dnd fornecia uma opção para ligar um elemento a outro no diagrama, no entanto, quando foi utilizada a fundo, foi visto que esta funcionalidade estava com graves defeitos mapeados pelos desenvolvedores da biblioteca, e que os mesmos não pretendiam prosseguir com a implementação e correção da mesma, causando um sério 
problema na implementação do modelador pois não havia como interligar um elemento em outro no diagrama.

Após muito estudo foi visto uma forma de adaptar a ligação entre os elementos com o componente "Canvas"do GWT. O mesmo tem a finalidade de desenhos a partir de coordenadas, com isto, foi constatado que seria possível ligar a partir deste componente um elemento a outro uma vez que havia todas as coordenadas necessárias.

\subsubsection{Representação de Fluxo}

Apenas a ligação com o componente Canvas não era o suficiente, uma vez que o fluxo dos processos não ficavam claros com riscos entre os elementos. Para o BPMN era necessária a representação por flechas para indicar o fluxo correto do processo. Um algoritmo foi desenvolvido para permitir esta representação no diagrama.

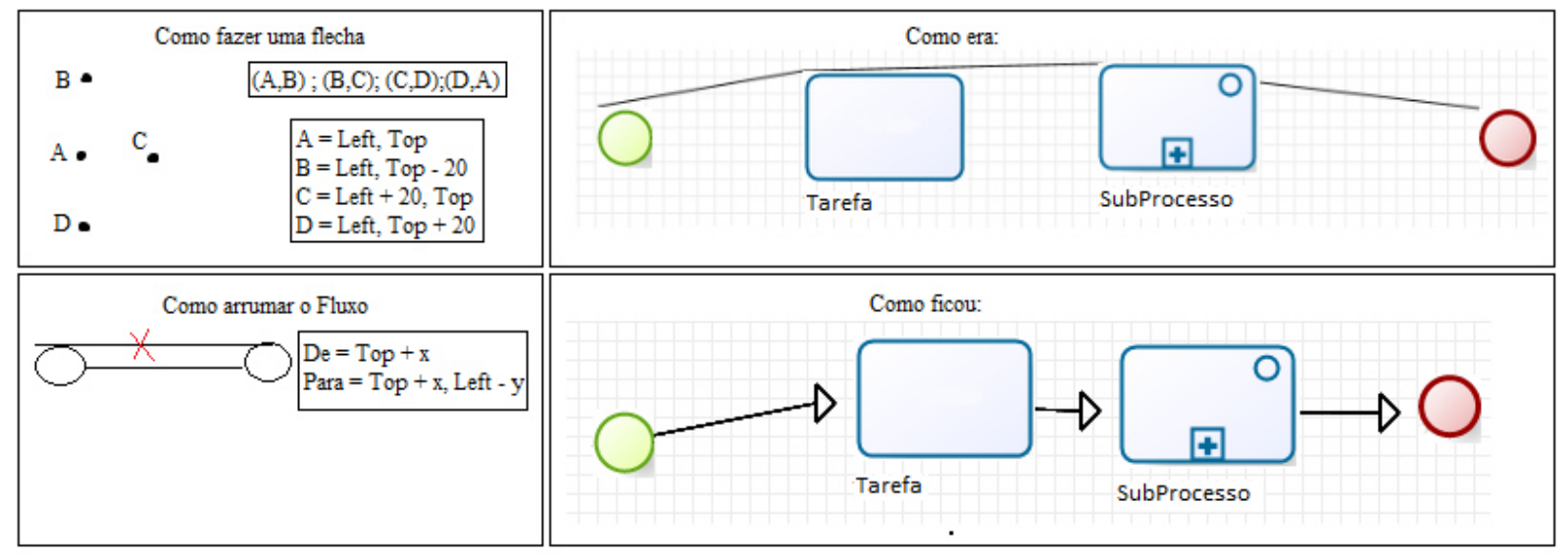

Figura 5.18: Flecha

A Figura 5.18 ilustra como era antes e a solução aplicada para mudar o risco para flecha.

\subsubsection{GWT e Hibernate}

Com o Hibernate é possível mapear com anotação os beans de acordo com as tabelas no banco de dados, no entanto, foi visto que este tipo de mapeamento não funciona no lado cliente do GWT uma vez que o código do mesmo é convertido para javascript pelo framework. Para driblar este problema foi estudado o padrão de projetos DTO (Data Transfer Object) que faz com que seja trabalhado com objetos não mapeados do lado cliente e ao ser enviado para o lado servidor o mesmo é carregado em um bean (idêntico ao objeto do lado cliente, no entanto, com o mapeamento com a tabela do banco de dados). 


\subsection{Conclusão}

Segundo Pressman(2006), a Prototipagem é apenas uma ilustração de onde o software pode chegar. Após a criação do protótipo é necessário remodelar, reprojetar por que o primeiro é apenas uma versão utilizável, no entanto, o software pode ser muito lento, muito grande e muito complicado de ser utilizado.

Com o desenvolvimento deste protótipo e com a aplicação e validação do mesmo no meio empírico (apresentado na próxima seção) foi visto que apesar do mesmo ser efetivo no que foi proposto, ainda há muito a ser feito para o software se transformar em um produto completo na linha de pesquisa em que estamos propondo como é possível notar na parte de trabalhos futuros (Seção 8.3). 



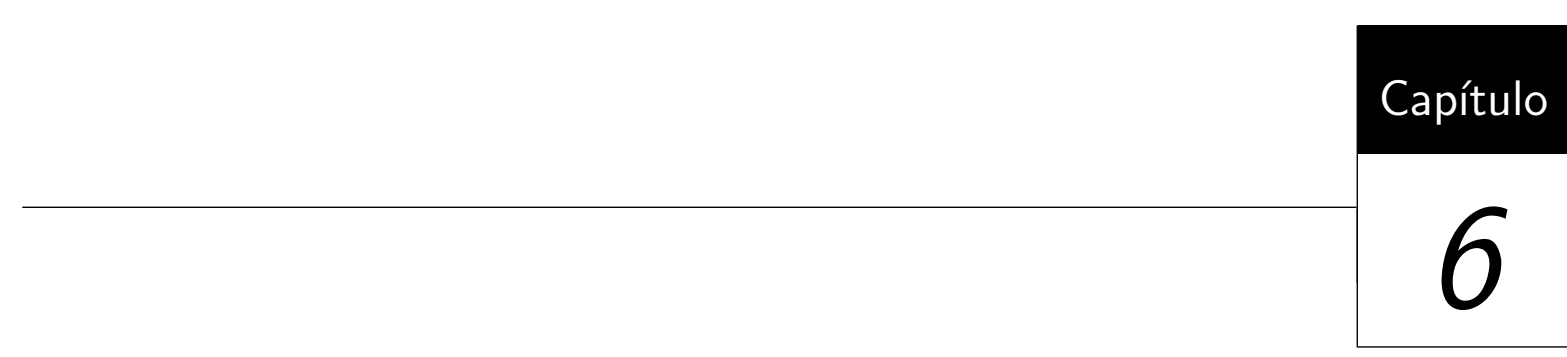

Experimento

Este capítulo tem como finalidade validar por meio do processo de experimentação a efetividade da abordagem e do suporte computacional apresentados anteriormente. Foi elaborado um protocolo de experimentação com base no trabalho proposto por Wohlin(Wohlin, 2000).

\subsection{Definição}

\subsubsection{Objeto de estudo}

Validar a abordagem e o protótipo no contexto corporativo.

\subsubsection{Objetivos}

Avaliar a eficiência e a eficácia da abordagem e do protótipo, considerando a representação e a compreensão das informações contidas nos processos de negócio no contexto corporativo. 


\subsubsection{Foco quantitativo}

O foco quantitativo é mensurar através da escala likert (Likert, 1932) as vantagens, usabilidade e praticidade da abordagem. A escala é do tipo resposta psicométrica utilizada em questionários de respostas fechadas, sendo a escala mais usada em pesquisas de opinião.

\subsubsection{Foco qualitativo}

O foco qualitativo é identificar por meio da experiência dos participantes nos processos se a abordagem proposta possui eficiência e eficácia na representação e compreensão das informações.

\subsubsection{Perspectiva}

Será utilizado, para a pesquisa, o protótipo desenvolvido, para modelar e representar os processos de negócio na abordagem proposta. As informações foram coletadas a partir de processos reais da organização e são importantes na validação do experimento.

\subsubsection{Contexto}

O experimento será realizado dentro de uma empresa multinacional que presta serviço de TI para diversos clientes no mundo todo. Um cliente específico no ramo de Telecomunicação será selecionado onde existe aproximadamente 150 pessoas fornecendo serviços. Estes serviços possuem processos bem definidos e profissionais de TI qualificados que atuam nos níveis estratégicos, táticos e operacionais dos processos. portanto convivem com eles e os gerenciam diariamente.

\subsection{Planejamento}

\subsubsection{Definição das Hipoteses}

\section{Hipoteses Nulas:}

- HN1 - Seja AOEhoc o alinhamento dos objetivos estratégicos com o processo de negócio sem a utilização de uma abordagem e AOEab o alinhamento dos objetivos estratégicos com o processo de negócio utilizando a abordagem proposta onde $\mathrm{AOEhoc}=\mathrm{AOEab}$. Isto significa que o alinhamento dos objetivos estratégicos nos processos providos pela a abordagem será igual a um que não utiliza a abordagem. 
- HN2 - Seja CPhoc o gerenciamento das coleções de processo de negócio sem a utilização de uma abordagem e CPab o gerenciamento das coleções de processo de negócio utilizando a abordagem proposta onde $\mathrm{CPhoc}=\mathrm{CPab}$. Isto significa que o o gerenciamento das coleções de processo de negócio providos pela a abordagem será igual a um que não utiliza a abordagem.

- HN3 - Seja RVhoc as informações obtidas por meio da modelagem do processo de negócio sem a utilização de uma abordagem em níveis e RVab a as informações obtidas através da modelagem dos processo com a utilização de uma abordagem em níveis, onde Rhoc $=$ Rab. Isto significa que as informações obtidas através da modelagem do processo de negócio sem a abordagem igual a obitida de um processo criado com a abordagem.

\section{Hipoteses Alternativas:}

- HA1 - Seja AOEhoc o alinhamento dos objetivos estratégicos com o processo de negócio sem a utilização de uma abordagem e AOEab o alinhamento dos objetivos estratégicos com o processo de negócio utilizando a abordagem proposta na qual AOEhoc $<$ AOEab. Isto significa que o alinhamento dos objetivos estratégicos nos processos providos pela a abordagem será superior a um que não utiliza a abordagem.

- HA2 - Seja CPhoc o gerenciamento das coleções de processo de negócio sem a utilização de uma abordagem e CPab o gerenciamento das coleções de processo de negócio utilizando a abordagem proposta onde CPhoc $<\mathrm{CPab}$. Isto significa que o o gerenciamento das coleções de processo de negócio providos pela a abordagem será superior a um que não utiliza a abordagem.

- HA3 - Seja RVhoc a as informações obtidas através da modelagem do processo de negócio sem a utilização de uma abordagem em níveis e RVab a as informações obtidas através da modelagem do processo de negócio com a utilização de uma abordagem em níveis, na qual Rhoc $<$ Rab. Isto significa que as informações obtidas através da modelagem do processo de negócio sem a abordagem serão menor que a obtida pelo processo criado com a abordagem.

\subsubsection{Objetos de Estudo}

Os objetos de estudo deste experimento são o alinhamento dos objetivos estratégicos com os processos de negócio, o gerenciamento das coleções de processos e a representatividade dos vários níveis. 


\subsubsection{Seleção de Contexto}

Os objetos de estudo serão modelados em fluxos reais da organização para facilitar o entendimento da abordagem por parte dos participantes e impedir o viés, uma vez que os processos e objetivos estratégicos serão levantados de acordo com a forma como é feito na empresa.

Como a organização já possui seus processos mapeados em BPMN, o experimento será conduzido em apenas uma etapa na qual será apresentada a abordagem e um caso real dos processos sobre a perspectiva da abordagem proposta. A avaliação será feita por meio da aplicação de um formulário com questões abertas e fechadas sobre a abordagem e a ferramenta.

\subsubsection{Projeto do Experimento}

Para iniciar o experimento, será necessário realizar um levantamento de todos os interessados em participar dele. Dentre os selecionados, haverá três tipos, pessoas do nível estratégico, tático e operacional. Essas pessoas possuem experiência em gestão, definição de processos e execução dos processos. Os participantes não deverão trocar informações sobre o experimento durante sua execução.

Após a seleção dos participantes (P), preferencialmente 12 participantes ou múltiplos de 3 , haverá os modelos de processo já implementados com BPMN e uma nova modelagem na abordagem proposta.

Os participantes do experimento receberão um treinamento sobre a abordagem na seção. Como o experimento será executado sobre processos reais nos quais todos os participantes já possuem conhecimento, será necessário apenas se preocupar com o alinhamento do que está sendo proposto.

Caso seja identificado algum defeito grave nos processos de cada etapa, serão feita as devidas correções para não inviabilizar ou gerar resultados tendenciosos na pesquisa.

\subsubsection{Seleção dos indivíduos (sujeitos)}

Para que sejam selecionados apenas os participantes que atendão aos requisitos do experimento, as experiências profissionais serão checadas para levantar o nível técnico de cada participante.

\subsubsection{Seleção das variáveis (fatores)}

\section{Variáveis independentes:}

- Metodologia utilizada: A abordagem proposta; 
- Objetos de estudo: A abordagem e o protótipo desenvolvido;

- Critérios de testes: Os artefatos gerados no experimento.

\section{Variáveis dependentes:}

- Métricas e Comentários dos entrevistados com relação ao alinhamento dos objetivos estratégicos com o processo de negócio utilizando a abordagem ;

- Métricas e Comentários dos entrevistados com relação ao gerenciamento das coleções de processo de negócio utilizando a abordagem ;

- Métricas e Comentários dos entrevistados com relação representatividade dos multiníveis da abordagem ;

- Comentários dos entrevistados com relação a praticidade ;

- Comentários dos entrevistados com relação a usabilidade em cenários reais .

\section{Variáveis de contexto:}

- Conhecimento em processos de negócio.

\subsubsection{Descrição da instrumentação}

O material recebido pelos participantes $(\mathrm{P})$ sera composto de:

- Diretrizes para realização do evento;

- Software de apoio para a modelagem dos processos de negócios na abordagens;

- Processo modelado atualmente e na abordagem;

- Formulário para coleta de informações.

\subsubsection{Avaliação da validade}

Validade interna: As ameaças a validade interna do experimento são as seguintes:

- Experiência do funcionário: A falta de experiência ou a divergência de experiências entre os funcionários com relação aos processos de negócio são fatores que podem influenciar o resultado do experimento. No projeto este fator será evitado pela escolha de profissionais com conhecimentos similares na área de gerenciamento de processos de negócio. Também será fornecida uma apresentação para nivelamento dos participantes. 
- Produtividade sobre avaliação: Pessoas tendem a ser mais produtivas quando estão sobre avaliação. Esse fator pode influenciar os resultados, porque os funcionários podem realizar os experimentos pensando que estão sendo avaliados pelos resultados. Para mitigar esta ameaça, o experimento será realizado individualmente entre funcionários da mesma empresa

- O experimentador trabalha na mesma empresa dos participantes: Pessoas tendem a ser induzidas as respostas por medo de opressão devido a presença de alguém de um nível hierarquico superior ou devido a um relacionamento de amizade com o entrevistador. Para mitigar esta ameaça, foi contextualizada a importância dos feedbacks sobre o experimento, principalmente se forem negativos.

- Questões estão induzindo as respostas: As questões podem induzir o entrevistado a concordar com as afirmações para garantir um resultado interessante no experimento. Para mitigar esta ameaça, foi realizado o experimento semi-estruturado para que as informações possam ser coletadas da melhor forma possível

Validade de construção: As ameaças a validade de construção do experimento são as seguintes:

- O experimento não é representativo no contexto no qual foi desenvolvido. Se o experimento não for uma representação do que ocorre na realidade os resultados podem ser invalidados. Neste experimento, apesar dos processos e objetivos serem reais, os mesmos possuirão apenas a finalidade de simular a viabilidade da abordagem proposta perante as abordagens convencionais.

- Expectativas dos participantes ou dos condutores do experimento podem influenciar os resultados. Os participantes podem ter a tendência ou serem influenciados pelos condutores para satisfazer as hipóteses. Neste experimento os participantes não saberão das hipóteses para que este risco seja mitigado.

- Relacionamento entre participantes pode gerar resultados tendenciosos. Devido a todos trabalharem no mesmo local, uma comunicação sobre a abordagem e as respostas pode inviabilizar o experimento com a influência de outras opinões. Para evitar este risco, as entrevistas serão individuais para impedir o contato entre os participantes.

- Inconsistências nos modelos de processos apresentados: O experimento tem como finalidade verificar a efetividade da abordagem proposta perante a abordagem BPMN convencional. Uma inconsistência nos processos pode inviabilizar o experimento, 
portanto a cada etapa serão analisadas e classificadas as dificuldades de compreensão e as devidas correções serão realizadas.

Validade externa: É possível que os resultados do experimento não possam ser generalizados pelos seguintes fatores:

- A população dos participantes não será representativa

- O experimento deverá ser aplicado individualmente para cada funcionário devido a disponibilidade de cada um, podendo afetar os resultados caso haja comunicação entre eles , logo, os mesmos não serão informados dos demais membros participantes

\subsection{Operação do experimento}

- Preparação - O condutor do experimento fará contato com os funcionários da organização para convidá-los a participar voluntariamente do experimento. Após identificar os funcionários em potencial para o experimento será encaminhado os convites individuais para a sua realização.

- Participantes - serão convidados funcionários de uma multinacional que possui seus processos geridos pelo BPM. O objetivo é contactar funcionários com experiência na área de processos e que atuem nos três níveis hierárquicos (operacional, tático e estratégico).

- Projeto do Experimento - Apresentar os processos $A S-I S$ e $T O-B E$ (na abordagem) para os três níveis hierárquicos (operacional, tático e estratégico) para obter diferentes visões e informações sobre a abordagem.

- Execução - A realização do experimento será em apenas uma etapa, no entanto, ela será feita de acordo com a disponibilidade dos participantes.

Nesta etapa será feita uma apresentação sobre a abordagem e será fornecido os modelos atuais dos processos e uma modelagem na abordagem proposta, para o entendimento de ambos e o levantamento de informações pertinentes as vantagens e desvantagens da abordagem proposta.

- Validação dos Dados - As entrevistas serão gravadas, uma vez que os formulários servirão apenas para semi-estruturar as perguntas, este formato de entrevista permitirá maiores informações com perguntas e explicações dos participantes. 


\subsubsection{Análise e interpretação dos resultados}

As respostas serão analisadas com o intuito de validar as hipóteses e levantar possíveis melhorias na abordagem e suporte computacional desenvolvido.

\subsubsection{Análise e interpretação dos resultados primários}

Os processos modelados serão analisados pelos participantes com o entendimento da abordagem e as informações levantadas serão registradas nos formulários. Será verificado se os participantes conseguiram compreender corretamente a abordagem para que se possa coletar de forma efetiva os seus feedbacks.

Os resultados serão analisados pelo autor da abordagem com o auxílio de seu orientador acadêmico. Para todas as hipótese, as análises dos dados serão feitas da forma apresentada a seguir.

\section{Questões fechadas:}

- O participante respondeu uma questão do formulário referente a Hipótese com a qual "Não concordou totalmente": um (1) ponto;

- O participante respondeu uma questão do formulário referente a Hipótese com a qual "Não concordou parcialmente": dois (2) pontos;

- O participante respondeu uma questão do formulário referente a Hipótese e se mostrou "Indiferente": três (3) pontos;

- O participante respondeu uma questão do formulário referente a Hipótese com a qual "Concordou parcialmente": quatro (4) pontos;

- O participante respondeu uma questão do formulário referente a Hipótese com a qual "Concordo totalmente": cinco (5) pontos.

\section{Questões abertas:}

Após a execução, as respostas serão agrupadas e analisadas em conjunto em busca de padrões de feedbacks, gaps e melhorias. As respostas que fugirem do escopo da abordagem serão analisadas posteriormente como entradas para trabalhos futuros.

\subsubsection{Análise e interpretação dos resultados secundários}

Como as entrevistas serão semi-estruturadas e baseadas nos processos nos quais os participantes já possuem especialidade tanto na execução quanto na gestão, será possível coletar melhor os feedbacks de melhoria para a abordagem e protótipo.

Para a coleta de feedbacks será levado em consideração o número de participantes que opinaram sobre determinada melhoria ou mudança e o escopo desta mudança sobre a abordagem e protótipo. 


\subsection{Execução}

As 14 perguntas foram utilizadas como base para a entrevista semi-estruturada realizada no experimento como é apresentado na Figura 6.1. As questões foram divididas em dois formatos, questões de múltiplas escolhas utilizando a escala likert para mensurar quantitativamente as opiniões dos entrevistados e questões abertas para mensurar qualitativamente suas opiniões e permitir uma conversa para recolher feedbacks de melhorias para a abordagem.

O mapeamento das questões por hipóteses também é representado na Figura 6.1. Na mesma é possível identificar as hipóteses e seu desmembramento em itens menores e ver o relacionamento com as perguntas. Esta forma de divisão permite maior detalhamento do escopo do experimento e possibilita melhores respostas e feedbacks.

\subsection{Análise}

O experimento foi executado dentro da organização com 18 funcionários que variam entre os níveis operacional, tático e estratégico como é possível visualizar na Figura 6.2.

As seções eram realizadas individualmente e aplicadas sempre no momento em que o participante possuiam disponibilidade para parar o serviço e focar na abordagem. Em média o tempo entre a contextualização, apresentação da abordagem, apresentação do protótipo, navegação dos processos pela abordagem e a entrevista demorava em torno de 40 minutos. Apesar das entrevistas terem sido gravadas, no apêndice 2 foi redigida todas as respostas dos entrevistados e nas seções a seguir serão apresentas as respostas agrupadas por questões e posteriormente por hipóteses.

\subsubsection{Questões}

1) Você acredita que "Modelar os objetivos estratégicos e relacionar os mesmos com os processos da organização é uma forma útil de gerenciamento"?

A Figura 6.3 destaca que os entrevistados, em geral, acharam útil a possibilidade de modelar os objetivos estratégicos e ligar os mesmos com os processos de negócio.

De forma geral, os entrevistados desconheciam uma abordagem e ferramenta que permitisse modelar objetivos estratégicos e relacionar com os processos. Inclusive foi destacado por alguns participantes do nível hierárquico estratégico a dificuldade atual deles em realizar este relacionamento. 
CAPÍTULO 6. EXPERIMENTO

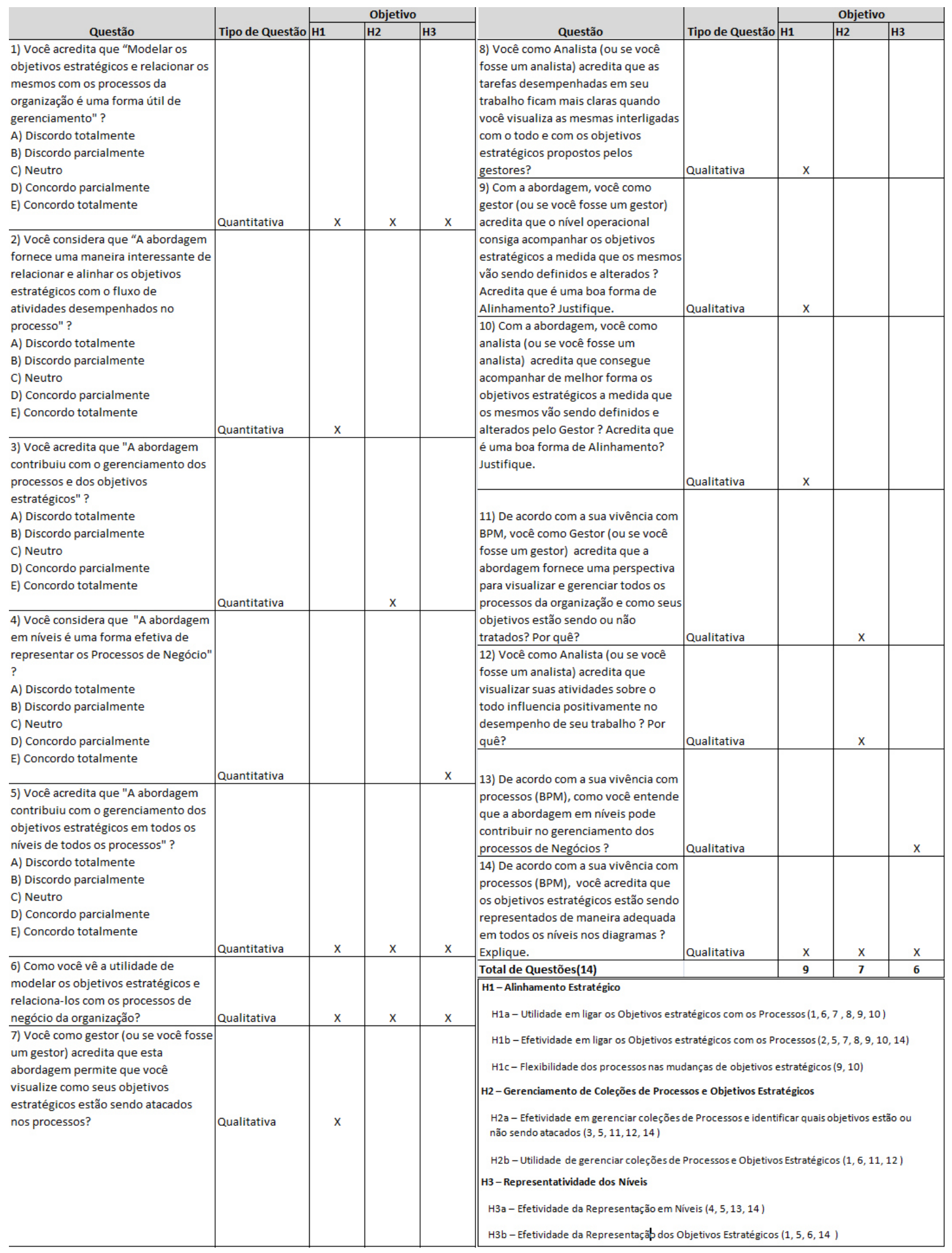

Figura 6.1: Formulário de Questões de Experimento

2) Você considera que "A abordagem fornece uma maneira interessante de relacionar e alinhar os objetivos estratégicos com o fluxo de atividades desempenhados no processo"? 


\begin{tabular}{|c|c|c|c|}
\hline Participante & Nível & Experiência na Empresa & Experiência Total \\
\hline 1 & Operacior & 7 anos & 10 anos \\
\hline 2 & Tático & 10 anos & 16 anos \\
\hline 3 & Operacior & 4 anos & 4 anos \\
\hline 4 & Tático & 7 anos & 7 anos \\
\hline 5 & Operacior & 4 anos & 6 anos \\
\hline 6 & Operacior & 3 anos & 8 anos \\
\hline 7 & Operacior & 3 anos & 3 anos \\
\hline 8 & Estratégic & 7 anos & 10 anos \\
\hline 9 & Estratégic & 8 anos & 12 anos \\
\hline 10 & Estratégic & 8 anos & 10 anos \\
\hline 11 & Operacior & 8 anos & 18 anos \\
\hline 12 & Estratégic & 8 anos & 8 anos \\
\hline 13 & Operacior & 4 anos & 4 anos \\
\hline 14 & Operacior & 4 anos & 7 anos \\
\hline 15 & Operacior & 3 anos & 10 anos \\
\hline 16 & Operacior & 2 anos & 6 anos \\
\hline 17 & Estratégic & 7 anos & 14 anos \\
\hline 18 & Tático & 4 anos & 6 anos \\
\hline
\end{tabular}

Figura 6.2: Tabela de Participantes do Experimento

\begin{tabular}{|l|r|l|r|}
\hline Resposta & Número de Participantes & Pontos & \multicolumn{2}{c|}{ Participantes x Pontos } \\
\hline Concordo Totalmente & 15 & 5 & $15 \times 5=75$ \\
\hline Concordo Parcialmente & 3 & 4 & $3 \times 4=12$ \\
\hline Média & & & \\
\hline Mediana & & & $\mathbf{4 3 3 3}$ \\
\hline
\end{tabular}

Figura 6.3: Respostas Questão 1

A Figura 6.4 destaca que os entrevistados, em sua maioria, acharam a abordagem eficaz em relacionar (por meio de modelagem) os objetivos estratégicos aos processos de negócio.

\begin{tabular}{|c|c|c|c|}
\hline Resposta & Número de Participantes & Pontos & Participantes x Pontos \\
\hline Concordo Totalmente & 17 & & $17 \times 5=85$ \\
\hline Concordo Parcialmente & 1 & & $1 \times 4=4$ \\
\hline Média & & & 4,94 \\
\hline Mediana & & & 5 \\
\hline
\end{tabular}

Figura 6.4: Respostas Questão 2

Alguns entrevistados destacaram a praticidade e representatividade da abordagem.

3) Você acredita que "A abordagem contribuiu com o gerenciamento dos processos e dos objetivos estratégicos"?

A Figura 6.5 mostra que, de uma maneira geral, os participantes concordam que a abordagem contribuiu com o gerenciamento de ambos.

\begin{tabular}{|l|r|l|r|}
\hline Resposta & Número de Participantes & Pontos & \multicolumn{2}{c|}{ Participantes x Pontos } \\
\hline Concordo Totalmente & 13 & $513 \times 5=65$ \\
\hline Concordo Parcialmente & 3 & $43 \times 4=12$ & \\
\hline Neutro & 2 & $32 \times 3=6$ & $\mathbf{4 , 6 1}$ \\
\hline Média & & & $\mathbf{5}$ \\
\hline Mediana & & &
\end{tabular}

Figura 6.5: Respostas Questão 3

Alguns participantes afirmaram não possuir conhecimento suficiente sobre gerenciamento para responder esta pergunta, optando assim pela opção neutro. 
4) Você considera que "A abordagem em níveis é uma forma efetiva de representar os Processos de Negócio"?

A Figura 6.6 mostra que todos os participantes concordaram com a efetividade da representação em níveis.

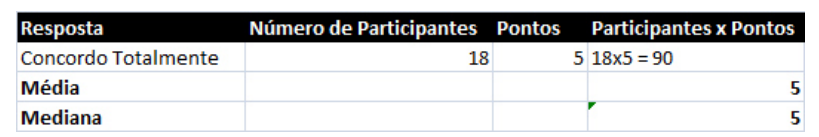

Figura 6.6: Respostas Questão 4

5) Você acredita que "A abordagem contribuiu com o gerenciamento dos objetivos estratégicos em todos os níveis de todos os processos"?

A Figura 6.7 mostra que os participantes em sua maioria concordam que a abordagem conseguiu gerenciar os objetivos estratégicos e fornecer uma ligação com os processos em todos os níveis de abstração.

\begin{tabular}{|l|r|r|r|}
\hline Resposta & Número de Participantes & Pontos Participantes x Pontos \\
\hline Concordo Totalmente & 12 & $512 \times 5=60$ \\
\hline Concordo Parcialmente & 5 & $45 \times 4=20$ \\
\hline Neutro & 1 & $31 \times 3=3$ & $\mathbf{4 , 6 1}$ \\
\hline Média & & & $\mathbf{5}$ \\
\hline Mediana & & & \\
\hline
\end{tabular}

Figura 6.7: Respostas Questão 5

Alguns participantes afirmaram não possuir conhecimento sobre gerenciamento suficiente para responder esta pergunta, optando assim pela opção neutro.

A Figura 6.8 apresenta os boxplots(gráfico de caixa) e a Figura 6.9 apresenta um gráfico com a média e as medianas das 5 questões quantitativas para facilitar a avaliação do dados coletados.

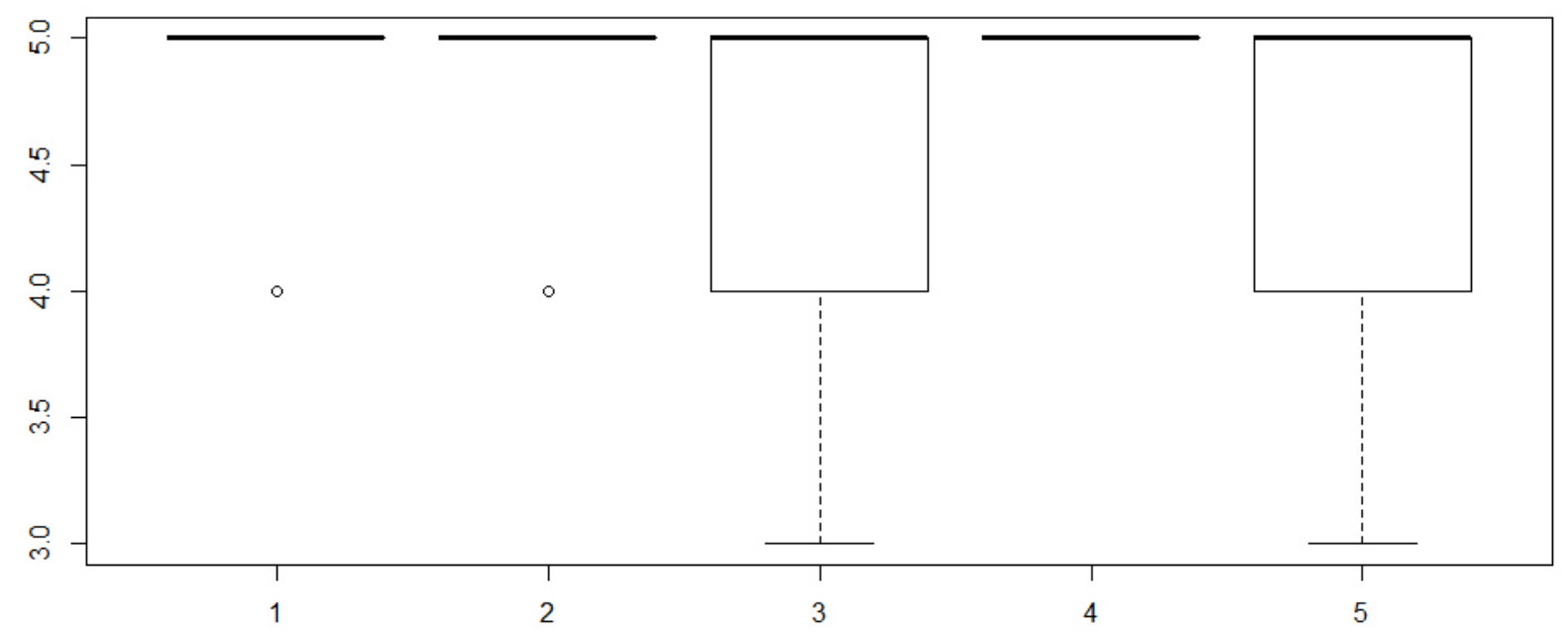

Figura 6.8: Todos os BoxPlots 
Pela Figura 6.8 é possível notar que as questões quantitativas 1 e 2 obtiveram em sua maioria a aceitação total da afirmação e seus outliers, foram as aceitações parciais. Para a questão 3 e 5 houve uma ligeira distribuição entre a total concordância (maioria dos votos) e a concordância parcial, tendo como outliers os participantes que optaram pela opção neutro. Todos os participantes concordaram totalmente com a afirmação da questão 4.

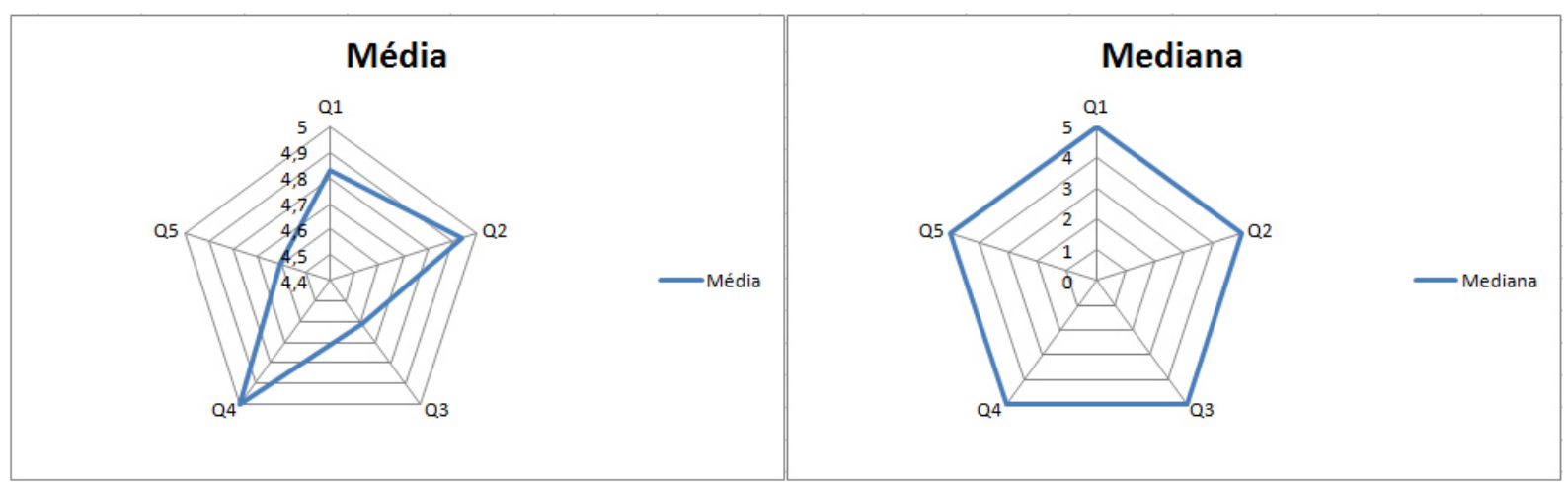

Figura 6.9: Média e Mediana das Questões Quantitativas

A Figura 6.9 comprova quantitativamente a aceitação da abordagem por parte dos participantes. No entanto, as questões qualitativas foram de suma importância na coleta de gaps e melhorias para a abordagem.

6)Como você vê a utilidade de modelar os objetivos estratégicos e relaciona-los com os processos de negócio da organização?

Os participantes (p2, p3,p6, p8, p9, p11, p12, p13, p16, p17) disseram que modelar os objetivos estratégicos é uma forma simples e objetiva de representar onde a organização pretende chegar e o que pode atrapalhar estes objetivos, no entanto, apenas inserir estes indicadores não é o bastante, é fundamental alinhar essas informações com as pessoas que estão envolvidas nos processos com suas atividades e tarefas para que o resultado seja de fato alcançado (p16, p17). Além disto, o fluxo do processo totalmente modelado e ligado aos objetivos estratégicos auxilia na análise do impacto em possíveis tomadas de decisões (p12, p16).

7) Você como gestor (ou se você fosse um gestor) acredita que esta abordagem permite que você visualize como seus objetivos estratégicos estão sendo atacados nos processos?

Segundo os gerentes entrevistados, atualmente, é muito difícil um gerente ter uma visão holística do processo como um todo, muitas vezes ele toma uma decisão e não sabe o quanto aquilo pode impactar no processo e na estratégia dele. A abordagem fornece esta visibilidade aos gerentes por meio dos níveis de abstrações e da ligação entre a estratégia e os processos (p2, p4, p8, p9, p10, p12, p17). 
8) Você como Analista (ou se você fosse um analista) acredita que as tarefas desempenhadas em seu trabalho ficam mais claras quando você visualiza as mesmas interligadas com o todo e com os objetivos estratégicos propostos pelos gestores?

Segundo os analistas (p1, p3, p5, p6, p7, p11, p15), as pessoas executam as tarefas sem saber o porquê de estarem fazendo ou no quê o resultado daquela tarefa irá impactar no prosseguimento do processo. Com a abordagem é fornecido ao analista a compreensão do escopo do seu trabalho sobre o todo dos processos e sobre as estratégias definidas. Isto ajuda tanto na execução, pois permite sugestões de melhorias, umas vez que é possível ligar as tarefas que são executadas com as estratégias definidas, quanto na motivação de quem executa o processo, pois permite que o mesmo tenha uma visão geral da organização, fornecendo uma perspectiva de onde ele pode chegar na organização.

9)Com a abordagem, você como gestor (ou se você fosse um gestor) acredita que o nível operacional consiga acompanhar os objetivos estratégicos a medida que os mesmos vão sendo definidos e alterados ? Acredita que é uma boa forma de Alinhamento? Justifique.

Pela perspectiva dos Gestores (p8, p9, p10, p12, p17) esta é uma forma útil de alinhamento, contanto que houvesse mais um canal de comunicação que assegura-se que os destinatários recebessem as informações de mudança (email manual disparado pelo gerente, email automático disparado pela ferramenta ou micro reunião para alinhamento) e que a mesma sempre estivesse alinhada ou atualizada de acordo com as estratégias e os processos.

10)Com a abordagem, você como analista (ou se você fosse um analista) acredita que consegue acompanhar de melhor forma os objetivos estratégicos a medida que os mesmos vão sendo definidos e alterados pelo Gestor ? Acredita que é uma boa forma de Alinhamento? Justifique.

Pela perspectiva de um Analista (p1, p6, p7, p11, p13, p15), também é necessária uma forma adicional de alinhamento em todas as mudanças dos objetivos estratégicos e dos processos, pois é inviável olhar todos os dias a modelagem dos diagramas em busca de mudanças, com o tempo este tipo de atividade cairia em esquecimento.

11) De acordo com a sua vivência com BPM, você como Gestor (ou se você fosse um gestor) acredita que a abordagem fornece uma perspectiva para visualizar e gerenciar todos os processos da organização e como seus objetivos estão sendo ou não tratados? Por quê?

Segundo os Gestores (p4, p8, p9, p12, p17), com os digramas modelados é possível visualizar os gaps, ver nos processos o que é contra a estratégia, o que da estratégia não se adequa a um determinado processo e base para melhorias nos processos e estratégias. 
12) Você como Analista (ou se você fosse um analista) acredita que visualizar suas atividades sobre o todo influência positivamente no desempenho de seu trabalho ? Por quê?

Uma pequena parte dos entrevistados (p3, p7, p11) acredita que muitos analistas não possuem o mínimo de embasamento nos objetivos da organização, no entanto, desempenham muito bem as suas funções, pois a única coisa que os mesmos devem saber é o que tem que ser feito. Por outro lado, os entrevistados (p1, p2, p4, p5, p6, p8, p9, p10, p12, p13, p14, p15, p16, p17, p18) que possuem uma visão mais abrangente querem trabalhar focados nas estratégias da organização e acreditam que com a abordagem isto é possível. Apenas houve um consenso sobre a praticidade em alinhar as funções aos funcionários recém contratados.

13) De acordo com a sua vivência com processos (BPM), como você entende que a abordagem em níveis pode contribuir no gerenciamento dos processos de Negócios?

Segundo os entrevistados (p2, p3,p6, p8, p9, p11, p12, p13, p16, p17), a abordagem em níveis tem como pressuposto que o entendimento de um diagrama em um único nível (quando muito extenso) é demasiadamente complexo. Com os níveis é possível abstrair o diagrama por complexidade e ter a compreensão do todo e o detalhamento quando necessário. Também foi visto nas entrevistas que o interesse no detalhamento dos processos é proporcional ao nível hierárquico da organização, uma vez que quem define as estratégias dos processos não se preocupa demasiadamente com o fluxo de tarefas, delegando esta perspectiva para quem executa diariamente esta função.

14) De acordo com a sua vivência com processos (BPM), você acredita que os objetivos estratégicos estão sendo representados de maneira adequada em todos os níveis nos diagramas ? Explique.

Segundo os entrevistados, de um modo geral a abordagem facilita a compreensão tanto de quem está em um baixo nível hierárquico quanto de quem está no alto nível, contanto que as manutenções nas estratégias e nos processos sejam realizadas constantemente para que os recursos trabalhem sempre alinhados as necessidades do negócio. Apesar da adaptação do BMM em modelagem facilitar a compreensão das informações, é importante destacar que estes elementos necessitam de detalhes descritivos para serem mais acertivos em suas representações e alinhamentos.

\subsubsection{Hipóteses}

\section{1) Alinhamento Estratégico}

Modelar os objetivos estratégicos é uma forma simples e objetiva de representar onde a organização pretende chegar e o que pode atrapalhar estes objetivos, no entanto, apenas 
inserir estes indicadores não é o bastante, é fundamental alinhar essas informações com as pessoas que estão envolvidas nos processos e com suas atividades e tarefas para que o resultado seja de fato alcançado. Além disto, o fluxo do processo totalmente modelado e ligado aos objetivos estratégicos auxilia na análise do impacto em possíveis tomadas de decisões, pois é muito difícil um gerente ter uma visão holística do processo como um todo, muitas vezes ele toma uma decisão e não sabe o quanto aquilo pode impactar no processo e em sua estratégia. A abordagem fornece esta visibilidade aos gerentes por meio dos níveis de abstrações e da ligação entre a estratégia e os processos.

Por outro lado, a abordagem fornece ao nível operacional à compreensão do escopo do seu trabalho sobre o todo dos processos e sobre as estratégias definidas. Isto ajuda tanto na execução (pois a função está bem definida) quanto na melhoria contínua, uma vez que as tarefas que são executadas estão relacionadas com as estratégias definidas, permitindo a operação fornecer idéias como melhorar suas tarefas diárias para alcançar as estratégias do processo. Também foi visto que há um aumento na motivação de quem executa o processo, pois permite que o mesmo tenha uma visão geral da organização, fornecendo uma perspectiva de onde ele pode chegar em sua carreira.

Pela perspectiva de todos os níveis hierárquicos, esta é uma forma útil de alinhamento, contanto que haja mais um canal de comunicação para assegurar que os destinatários recebam as informações de mudança (email manual disparado pelo gerente, email automático disparado pela ferramenta ou micro reunião para alinhamento) e que a mesma sempre esteja alinhada ou atualizada de acordo com as estratégias e os processos, uma vez que é inviável olhar todos os dias a modelagem dos diagramas em busca de mudanças, com o tempo este tipo de atividade cairia em esquecimento.

Contudo, de uma forma geral a abordagem permite o alinhamento tanto de quem está em um baixo nível hierárquico quanto de quem está no alto nível, contanto que as manutenções nas estratégias e nos processos sejam realizadas constantemente para que os recursos trabalhem sempre alinhados as necessidades do negócio.

\section{Hipótese 1: Aceita}

\section{2) Gerenciamento de Coleções de Processos e Objetivos Estratégicos}

Uma parte dos entrevistados acredita que muitos analistas não possuem o mínimo de embasamento dos objetivos da organização, no entanto, desempenham muito bem as suas funções, pois a única coisa que os mesmos devem saber é o que tem que ser feito. Por outro lado, os entrevistados (mesmo de nível operacional) que possuem uma visão mais abrangente querem trabalhar focados nas estratégias da organização e acreditam que com a abordagem isto é possível.

Com a perspectiva de coleções, foi vista uma facilidade para identificar os processos da organização e suas estratégias, também facilitou na identificação do que não foi criado 
ou não está sendo atacado, no entanto, esta perspectiva é mais interessante para o nível estratégico e para as funcionários que visam crescimento em sua carreira.

\section{Hipótese 2: Aceita}

\section{3) Representatividade dos Níveis}

A abordagem em níveis tem como pressuposto que o entedimento de um diagrama em um único nível (quando muito extenso) é demasiadamente complexo, com os níveis é possível abstrair o diagrama por complexidade e ter a compreensão do todo e do detalhamento quando necessário. Também foi observado, com as entrevistas, que o interesse no detalhamento dos processos é proporcional ao nível hierárquico na organização, uma vez que quem define as estratégias dos processos não se preocupa demasiadamente com o fluxo de tarefas, delegando esta perspectiva para quem executa diariamente esta função.

De um modo geral a abordagem forneceu uma forma simples de representar as informações estratégicas e relacionar aos processos, permitindo a compreensão tanto de quem está em um baixo nível hierárquico quanto de quem está no alto nível. Por fim, apesar da adaptação do BMM em modelagem facilitar na compreensão das informações é importante destacar que estes elementos necessitam de detalhes descritivos para serem mais acertivos em suas representações e alinhamentos.

\section{Hipótese 3: Aceita}

\subsection{Conclusão}

Com o processo de experimentação empírica foi constatado que a abordagem em níveis mostrou-se acertiva em representar e gerenciar os objetivos estratégicos e relacionar com os processos de negócio, efetivando a aceitação da Hipótese 2 e 3 da abordagem. De uma forma geral, este foi o escopo principal do projeto, fornecer um meio de alinhar aos objetivos estratégicos com o fluxo de tarefas desempenhados nos processos de negócio.

É válido destacar que o objetivo principal da experimentação foi validar a abordagem, e para facilitar a representação foi utilizada a ferramenta desenvolvida. Para a validação completa da ferramenta, será necessário a adição de alguns critérios como usabilidade.

Com relação ao Alinhamento, foi visto também a efetividade (comprovando também a aceitação da Hipótese 1), no entanto, foi visto que a abordagem e a ferramenta podem ser melhoradas em alguns aspectos, dentre eles, em seu suporte computacional com avisos automáticos de mudanças nos processos e a possibilidade de detalhar descritivamente os elementos BMM definidos no primeiro nível.

Também foi possível constatar que com o crescimento dos modelos haverá um crescimento proporcional na dificuldade de manter estes modelos atualizados uma vez que 
a ferramenta deve estar com seus processos alinhados com o que está em execução na organização. 


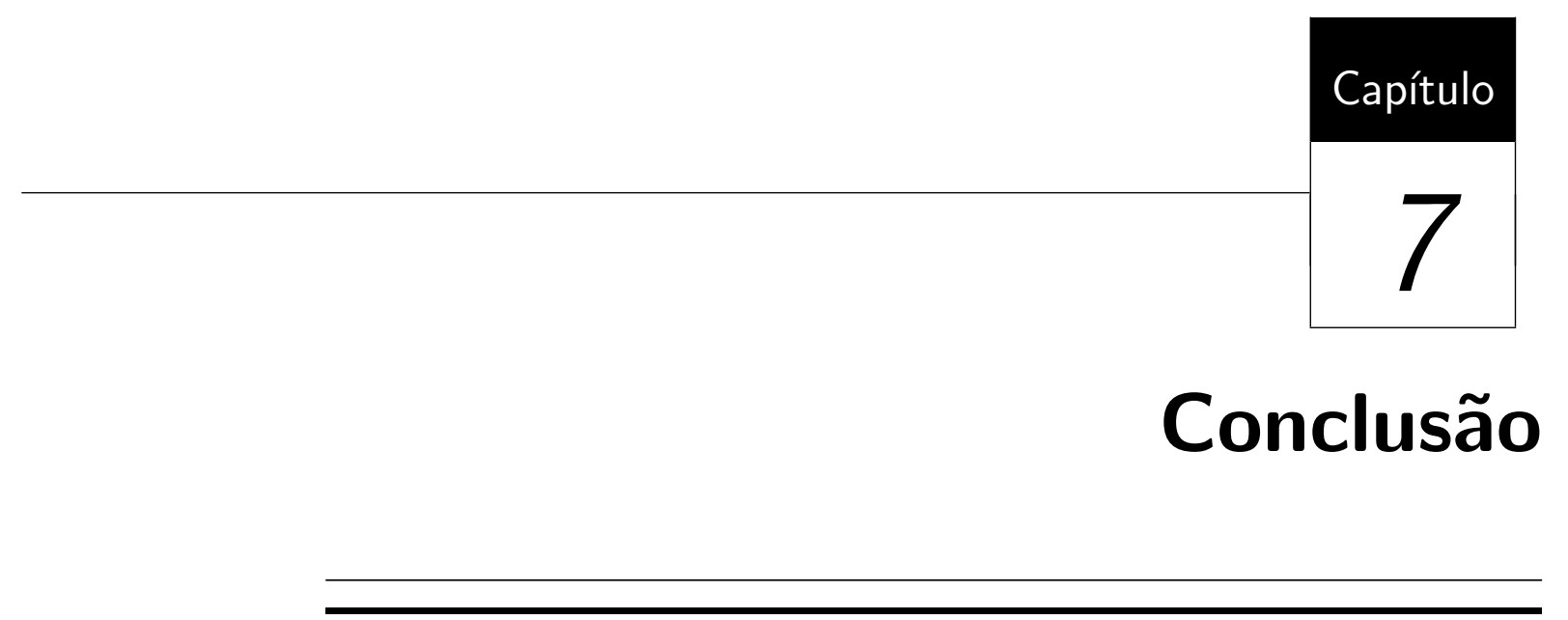

Este capítulo finaliza a dissertação com o que foi feito nesta pesquisa , quais são as maiores contribuições e que pesquisas podem ser feitas no futuro.

\subsection{Sumário dos resultados obtidos}

Esta dissertação apresentou uma revisão bibliográfica sobre gerenciamento de processos de negócios e alinhamento estratégico. Foi observado que há diversas pesquisas para ambos os temas, no entanto, o foco em obter alinhamento estratégico a partir de um efetivo gereciamento de processos de negócio é pouco discutido e não houve um consenso sobre qual a forma mais adequada de ser realizado. Os trabalhos mais relevantes disponíveis até o presente momento sobre o tema foram discutidos nesta dissertação.

O ponto central da pesquisa realizada foi aperfeiçoar as abordagens já existentes que buscavam fornecer alinhamento estratégico a partir da modelagem de processos em níveis, permitindo relacionar os processos com os objetivos estratégicos e detalhar os processos de acordo com as necessidades.

A abordagem contou com o BMM para representar as informações alto níveis pertinentes aos processos e a extendeu para uma linguagem de modelagem.

A linguagem de modelagem foi associada ao BPMN e ambos foram divididos em uma abordagem multinível de 4 camadas que permite a representação dos processos em diferentes níveis de abstração. 
Também foi desenvolvido uma ferramenta baseada na web em Java, totalmente alinhada com a abordagem para mitigar com os gaps de pesquisas levantados, uma vez que as iniciativas de abordagem multiníveis não implementaram suportes computacionais para validar a abordagem.

Para avaliar a abordagem e o suporte computacional foi realizado um estudo de caso e um experimento formal em uma empresa multinacional que conta com seus processos gerenciados pelo BPMN. O estudo de caso remodelou os processos existentes na abordagem e posteriormente estes processos foram apresentados aos funcionários de todos os níveis hierárquicos (operacional, tático e estratégico) dos processos. Uma entrevista individual foi realizada com estes funcionários e foi constatado as vantagens e desvantagens da utilização da abordagem.

\subsection{Contribuições desta dissertação de Mestrado}

A contribuição principal desta dissertação é uma abordagem multinível para obtenção de alinhamento estratégico no gerenciamento de processos de negócio. As partes mais relevantes desta proposta são as seguintes:

1. Revisão Sistemática sobre Alinhamento Estratégico no Gerenciamento de Processos de Negócio;

2. Desenvolvimento de um Metamodelo em níveis para representação das informações estratégicas ,processos de negócio e gerenciamento de coleções;

3. Transformação do BMM em uma linguagem de modelagem, permitindo a união com o BPMN em todos os níveis da abordagem;

4. Desenvolvimento de um suporte computacional web que permite modelar os processos da forma proposta pela abordagem;

5. Estudo de Caso e Experimentação em uma multinacional da área de TI que possui seus processos gerenciados pelo BPM.

Dada todas as contribuições, o trabalho também permite que novas pesquisas sejam continuadas a partir do que foi desenvolvido como ilustra a seção a seguir.

\subsection{Trabalhos Futuros}

Com o término do desenvolvimento da abordagem e a condução do experimento foram observadas algumas questões que podem ser melhoradas na abordagem a ponto da mesma se tornar um bom produto no mercado. 
1. Modulo de Modelagem e Modulo de Navegação

Toda a implementação do protótipo foi realizada, no entanto, foi visto que a ferramenta seria mais acertiva se fornecesse uma estrutura mais "fácil"para a navegação entre os níveis. Para facilitar a navegação entre níveis, está sendo estudada a possibilidade de um modulo apenas de navegação dos processos com funcionalidade de zoom semântico.

2. BPMN completo

O objetivo do protótipo era facilitar a apresentação da abordagem proposta, portanto, não se fez necessária a implementação completa do BPMN no mesmo, contudo, para se tornar mais eficaz ao dia a dia, se faz necessária a implementação das demais opções do BPMN.

3. Possibilidade de escolher outras linguagens de modelagem

A abordagem conta como base o BMM e o BPMN para a modelagem detalhada dos processos, no entanto, existem diversas tecnologias interessantes no mercado que poderiam ser acrescidas no modelador como o Zackman Framework, Togaf e EPC. Futuramente pode ser desenvolvida a possibilidade de escolha da linguagem de modelagem através dos níveis.

4. Modelagem colaborativa

Atualmente, a ferramenta permite que várias pessoas visualizem o mesmo processo ao mesmo tempo, no entanto, elas não possuem o conhecimento de que as demais também estão navegando/alternando, permitindo portanto uma modelagem colaborativa assíncrona (Se dois usuários acessarem o diagrama ao mesmo tempo e realizarem alterações, prevalecerá o último a alterar e nenhuma alteração do primeiro será mantida). Um mecanismo deve ser desenvolvido para a ferramenta informar quais pessoas estão modelando um determinado processo ao mesmo tempo, sincronizando todos os que estão visualizando um determinado diagrama naquele momento.

\section{Segurança}

Deve ser implementado um mecanismo de segurança que defina tipos de usuários e permissões para cada tipo de usuário, garantindo que apenas grupos específicos consigam alterar determinados diagramas.

6. Migração de Ferramenta

Permitir a importação de modelos feitos em outras ferramentas como o Bizagi e Intalio para a modelagem em níveis. 
7. Versionamento de processos

Atualmente a ferramenta realiza a alteração do processo e não registra as informações anteriores. Pode ser estudada a viabilidade/utilidade de versionar os processos a fim de ter uma estrutura comparativa sobre a sua evolução na organização.

8. Persistir modelos "as is" e "to be"

Atualmente a ferramenta armazena o processo e não mostra de forma explícita se o processo está em produção ou se o mesmo é apenas uma melhoria do processo atual. Um mecanismo para armazenar se o processo é "as is"ou "to be"pode ser desenvolvido para facilitar a identificação e permitir a comparação entre os modelos.

9. Adição de informações

Algumas pessoas que participaram do experimento e tiveram contato com a ferramenta sentiram a necessidade de saber mais detalhes sobre os elementos do BMM definidos no diagrama, O BMM possui em sua especificação a possibilidade de adicionar informações em seus elementos de acordo com a necessidade. Futuramente será estudada uma opção para adicionar informações textuais e upload/download de arquivos nos elementos BMM.

10. Mecanismo de busca

Com a modelagem de vários processos , fica difícil encontrar uma determinada atividade ou tarefa dentro dos níveis dos processos ou mesmo determinado aspecto definido dentro de uma Estratégia. Para facilitar a localização, um algoritmo de busca por meio de palavras-chaves pode ser implementado com facilidade.

11. Avisos de mudanças às partes interessadas

Para facilitar o alinhamento estratégico e o fluxo do processo, pode ser implementado uma forma de avisar a todas as partes interessadas quando seus processos e objetivos foram alterados, por exemplo, pode ser criado um email com todos os itens alterados ou ao logar na ferramenta todos os elementos alterados ficam em destaque.

12. Execução de Processos, Indicadores de desempenho e dashboards

Com o processo mapeado, a ferramenta poderia acompanhar os detalhes de execução dos processos e fornecer informações estatísticas para facilitar a gestão dos processos. Alguns mecanismos de referência cruzada também poderiam ser feitos, como, por exemplo, um indicador de perfomance definido com o status atual da execução do processo. 


\section{Referências Bibliográficas}

Albuquerque, J. P. Examinando a relação entre formalização e flexibilidade em modelos de processos de negócio: o caso de uma empresa de manutenção de aeronaves XXXIII Encontro da ANPAD, 2009.

Alibabaei, A.; Bandara, W.; Aghdasi, M. Means of achieving business process management success factors. 2009.

Disponível em http://aisel.aisnet.org/mcis2009/122

Andrews, K. R. The concept of corporate strategy. Prentice-Hall, p. 44-52, 1991.

Ao, Y.; Xiao, X.; Song, B. A unified configurable architecture for human-centric business process management application in smes IEEE, p. 287-292, 2009.

Disponível em http://ieeexplore.ieee.org/xpl/freeabs_all.jsp?arnumber= 5394109

Bannerman, P. L. Capturing business benefits from process improvement ACM Press, p. $1-8,2008$.

Disponível em http://dl .acm.org/citation. cfm?id=1370837.1370839

Bateman, T.; Snell, S. Administração: construindo vantagem competitiva. São Paulo : Atlas, 1998.

Becker, J.; Bergener, K.; Muller, O.; Wienbergen, F. M. Documentation of flexible business processes - a healthcare case study Americas Conference on Information Systems (AMCIS), p. 1-9, 2009.

Beer, M.; Voelpel, S. C.; Leibold, M.; Tekie, E. B. Strategic management as organizational learning developing fit and alignment through a disciplined process. 2005. 
Biolchini, J.; Mian, P. G.; Natali, A. C. C.; Travassos, G. H. Systematic review in software engineering. Engineering, v. 679, n. May, p. 165-176, 2005.

Disponível em http://www.cin.ufpe.br/ ${ }^{\sim}$ in1037/leitura/ systematicReviewSE-COPPE.pdf

Brocke, J. v.; Schmiedel, T. Towards a conceptualisation of bpm-culture: Results from a literature review. 2011.

Disponível em http://aisel.aisnet.org/pacis2011/203

Brodbeck, A. F.; Hoppen, N. Alinhamento estratégico entre os planos de negócio e de tecnologia de informação: um modelo operacional para implementação. Revista de Administração Contemporânea On-line version ISSN 1982-7849, 2003.

Bruin, T.; Rosemann, M. Towards understanding strategic alignment of business process management. 2006.

Disponível em http://aisel.aisnet.org/acis2006/82

Bruin, T. d. Strategies to increase executive commitment to business process management. 2008.

Disponível em http://aisel .aisnet.org/ecis2008/84

Building, R. To standardize or not standardize ?" - understading the effect of business process complexity on business process standardization. 1995.

Ciborra, C. De profundis? deconstructing the concept of strategic alignment. Scandinavian Journal of Information Systems, v. 9, n. 1, p. 67-82, 1997.

Disponível em http://www.cs.aau.dk/SJIS/journal/volumes//volume09/ articles/no1/99_Ciborra_p67-82.pdf

Cleven, A. Exploring patterns of business-it alignment for the purpose of process performance measurement. 2011.

Disponível em http://aisel.aisnet.org/ecis2011/19

Davenport, T.; Short, J. The new industrial engineering: Information technology and business process redesign Sloan Management Review, p. 11-27, 1990.

deBruin, T. Insights into the evolution of bpm in organisations. 2007.

Disponível em http://aisel. aisnet.org/acis2007/43

Decreus, K.; Snoeck, M.; Poels, G. Practical challenges for methods transforming $i^{*}$ goal models into business process models IEEE, p. 15-23, 2009.

Disponível em http://ieeexplore.ieee.org/xpl/freeabs_all.jsp?arnumber= 5328635 
Elvesæter, B.; Panfilenko, D.; Jacobi, S.; Hahn, C. Aligning business and it models in service-oriented architectures using bpmn and soaml ACM Press, p. 61-68, 2010.

Disponível em http://dl .acm.org/citation.cfm?id=1866272.1866281

Finch, K.; Wang, W. Constraint specification for active process models IEEE, p. 7-13, 2009.

Disponível em http://ieeexplore.ieee.org/xpl/freeabs_all.jsp?arnumber= 4782558

Ganesan, E.; Paturi, R. Key performance indicators framework - a method to track business objectives, link business strategy to processes and detail importance of key performance indicators in enterprise business architecture. 2009.

Disponível em http://aisel .aisnet.org/amcis2009/736

Gong, Y.; Janssen, M. Measuring process flexibility and agility ACM Press, p. 173, 2010. Disponível em http://dl .acm.org/citation. cfm?id=1930321.1930358

Grant, G. Reconceptualizing the concept of business and it alignment: from engineering to agriculture. European Journal of Information Systems, v. 19, n. 6, p. 619-624, 2010 .

Disponível em http://www.palgrave-journals.com/doifinder/10.1057/ejis . 2010.50

Grant, G. G. Strategic alignment and enterprise systems implementation: the case of metalco. Journal of Information Technology, v. 18, n. 3, p. 159-175, 2003.

Disponível em http://www.palgrave-journals.com/doifinder/10.1080/ 0268396032000122132

Group, T. O. Togaf version 9 enterprise edition 2003.

Disponível em http://www.opengroup.org/togaf/

Hammer, M. Reengineering work: don't automate, obliterate Harvard Business Review, 1990.

Henderson, J. C.; Venkatraman, N. Strategic alignment: Leveraging information technology for transforming organizations. IBM Systems Journal, v. 32, n. 1, p. 472-484, 1993.

Disponível em http://portal .acm.org/citation.cfm?id=1663581.1663583

José Osvaldo De Sordi, J. C. C. Funcionalidades requeridas às soluções de business process management system (bpms) sob a óptica da gestão do conhecimento. $A C M$ SIGOIS Bulletin, 2004. 
Kapuruge, M.; Han, J.; Colman, A. Controlled flexibility in business processes defined for service compositions IEEE, p. 346-353, 2011.

Disponível em http://ieeexplore.ieee.org/xpl/freeabs_all.jsp?arnumber= 6009280

Karagiannis, D. Bpms. ACM SIGOIS Bulletin, v. 16, n. 1, p. 10-13, 1995.

Disponível em http://dl .acm.org/citation.cfm?id=209891. 209894

Kirkham, T.; Winfield, S.; Raza, M.; Haberecht, T. Business process management and the challenge of dynamic services. Information Society (i-Society), 2011 International Conference on, p. 165-169, 2011.

Disponível em http://ieeexplore.ieee.org/xpl/freeabs_all.jsp?arnumber= 5978530

Kitchenham, B. Procedures for performing systematic reviews. Keele UK Keele University, v. 33, n. TR/SE-0401, p. 28, 2004.

Disponível em http://citeseerx.ist.psu.edu/viewdoc/download?doi=10.1.1. 122 . 3308\&rep=rep1\&type $=$ pdf

Laurindo, F. J. B.; Shimizu, T.; Carvalho, M. M.; Rabechini, R. J. O papel da tecnologia da informação (ti) na estratégia das organizações p. 160-172, 2001.

Lederer, A. L.; Sethi, V. Key prescriptions for strategic is planning. Journal of Management Information Systems, p. 35-62, 1996.

Likert, R. A technique for the measurement of attitudes. 1932.

Lind, M.; Seigerroth, U. Multi-layered process modeling for business and it alignment IEEE, p. 1-10, 2010a.

Disponível em http://ieeexplore.ieee.org/xpl/freeabs_all.jsp?arnumber= 5428543

Lind, M.; Seigerroth, U. Process models as transformation vehicle for strategic alignment. 2010 b.

Disponível em http://aisel.aisnet.org/mcis2010/56

Liu, Y.; Hu, E.; Chen, X. Architecture of information system combining soa and bpm. IEEE, 42-45 p., 2008.

Disponível em http://ieeexplore.ieee.org/xpl/freeabs_all.jsp?arnumber= 4737492

Luftman, J.; Lewis, P.; Oldach, S. Transforming the enterprise: The alignment of business and information technology strategies IBM Systems Journal, p. 198-221, 1993. 
Luftman, J.; Zadeh, H. S. Key information technology and management issues 2010-11: an international study. Journal of Information Technology, v. 26, n. 3, p. 1-12, 2011. Disponível em http://www.palgrave-journals.com/doifinder/10.1057/jit. 2011.3

Melao, N.; Pidd, M. A conceptual framework for understanding business processes and business process modelling Information Systems Journal, p. 105-129, 2000.

Muehlen, M. Z.; Ho, D. T. Service process innovation: A case study of bpmn in practice, v. 0 IEEE, p. 372-372, 2008.

Disponível em http://www. computer.org/portal/web/csdl/doi/10.1109/HICSS. 2008.388

Muenstermann, B.; Eckhardt, A. What drives business process standardization? a case study approach. 2009.

Disponível em http://aisel.aisnet.org/confirm2009/38

Neubauer, T.; Stummer, C. Extending business process management to determine effcient it investments ACM Press, p. 1250, 2007.

Disponível em http://dl.acm.org/citation. cfm?id=1244002.1244272

Nogueira, R.; Moreira, A.; Roberto, A.; Paula, C. O alinhamento estratégico e a construção do futuro: um estudo exploratório p. 103-125, 1998.

Nuffel, V.; Backer, M. D. Multi-abstraction layered business process modeling p. 131-147, 2012.

OMG Specification business process maturity model (bpmm) 2008.

Disponível em http://www.omg.org/spec/BPMM/

OMG Specification business motivation model (bmm) 2010.

Disponível em http://www.omg.org/spec/BMM/

OMG Specification business process model and notation (bpmn) 2011.

Disponível em http://www.omg.org/spec/BPMN/index.htm

Ould, M.; Kiffer, M. Business process management: A rigorous approach 2005.

Paulk, M. C.; Weber, C. V.; Curtis, B.; Chrissis, M. B. The capability maturity model : guidelines for improving the software process 1995.

Pollard, C.; Cater-Steel, A. Justifications, strategies, and critical success factors in successful itil implementations in u.s. and australian companies: An exploratory study. 
Information Systems Management, v. 26, n. 2, p. 164-175, 2009.

Disponível em http://www. informaworld.com/openurl?genre=article\&doi=10. 1080/10580530902797540\&magic=crossref

Pourshahid, A.; Amyot, D.; Peyton, L.; Ghanavati, S.; Chen, P.; Weiss, M.; Forster, A. J. Toward an integrated user requirements notation framework and tool forbusiness process management IEEE, p. 3-15, 2008.

Disponível em http://ieeexplore.ieee.org/xpl/freeabs_all.jsp?arnumber= 4483413

Pressman, R. S. Engenharia de software. 2006.

Quinn, J. B. Strategies for change. Prentice-Hall, p. 04-12, 1991.

Reich, B. H.; Benbasat, I. Measuring the linkage between business and information technology objectives. MIS Quarterly, p. 55-81, 1996.

Rohloff, M. An approach to assess the implementation of business process management in enterprises. 2009 .

Disponível em http://aisel.aisnet.org/ecis2009/69

Rumelt, R. The evaluation of business strategy Prentice-Hall, p. 52-59, 1991.

Sadovykh, A.; Desfray, P.; Elvesaeter, B.; Berre, A.-J.; Landre, E. Enterprise architecture modeling with soaml using bmm and bpmn - mda approach in practice IEEE, p. 79-85, 2010.

Disponível em http://ieeexplore.ieee.org/xpl/freeabs_all.jsp?arnumber= 5783155

Scheer, A. Aris business process modeling 2000.

Shahzad, K.; Zdravkovic, J. A decision-based approach to business process improvement IEEE, p. 810-818, 2010.

Disponível em http://ieeexplore.ieee.org/xpl/freeabs_all.jsp?arnumber= 5641858

Silvius, A. G. Business \& it alignment in theory and practice. 2007.

Sinclair, D.; Zairi, M. Performance measurement as an obstacle to tqm The TQM Magazine, p. 42-45, 1995.

Smith, H.; Fingar, P. Business process management: The third wave 2003. 
Smith, H.; Fingar, P.; Kiffer, M. Business process management: The third wave, fourth anniversary edition 2007.

Sommer, R. A. Linking strategic planning narratives to process-centric business models. 2009.

Strnadl, C. Aligning business and it: The process-driven architecture model IEEE, p. 1048-1051, 2005.

Disponível em http://ieeexplore.ieee.org/xpl/freeabs_all.jsp?arnumber= 1630129

Tallon, P. P. A process-oriented perspective on the alignment of information technology and business strategy. 2007.

Tao, Y.; Wang, J.; Wang, X.; He, D.; Yang, S. Knowledge-based flexible business process management IEEE, p. 1-3, 2006.

Disponível em http://ieeexplore.ieee.org/xpl/freeabs_all.jsp?arnumber= 4142161

Tao, Y.; Zhu, G.; Xu, Z.; Liu, B. A research on bpm system based on process knowledge IEEE, p. 69-75, 2008.

Disponível em http://ieeexplore.ieee.org/xpl/freeabs_all.jsp?arnumber= 4670879

TheOpenGroup Archimate 2008.

Disponível em http://www.archimate.nl/en/home/

Tosic, V.; Bannerman, P. L.; Ebrahimi Nejad, N.; Lu, Q. Extending ws-policy4masc language and miniznmasc middleware with bmm business motivation ACM Press, p. 189, 2011.

Disponível em http://dl.acm.org/citation.cfm?id=1998582.1998622

Verner, L. The challenge of process discovery BPTrends, 2004.

Weske, M. Business process management: Concepts, languages, architecture Springer, 2007.

Winter, R. Business engineering navigator (ben), gestaltung und analyse von geschaftslosungen "business-to-it", universitat st. gallen, muller-friedberg-str. 8, st. gallen, 9000, switzerland Springer, 2011.

Wohlin, C. Experimentationin software engineering KluwerAcademicPublishers, 2000. 
Yogendra, S.; Sengupta, S. Aligning business and technology strategies: a comparison of established and start-up business contexts, v. 1 IEEE, p. 2-7, 2002.

Disponível em http://ieeexplore.ieee.org/xpl/freeabs_all.jsp?arnumber= 1038356

Zachman, J. A framework for information systems architecture p. 276-292, 1987.

ZhenHua, W.; Yousen, H.; ZiYun, D.; Wei, Z. Soa - bpm based information system for promoting agility of third party logistics IEEE, p. 248-252, 2009.

Disponível em http://ieeexplore.ieee.org/xpl/freeabs_all.jsp?arnumber= 5262920 


$\bar{A}$

\section{Revisão Sistemática}

Neste apêndice é mostrado todo o processo da Revisão sistemática, desde o planejamento até os resultados obtidos a partir da mesma. Em suma, existem muitas propostas e casos que mostram como implantar e manter o BPM, no entanto, o foco da Revisão foi levantar trabalhos que continham abordagens para o BPM que refletiam no alinhamento estratégico.

\section{A.1 Sobre à Revisão Sistemática}

Para elaborar um projeto de pesquisa, tem se como primeiro passo o levantamento dos trabalhos e iniciativas relevantes para o tema em que se deseja investigar. Com isso, a Revisão Sistemática vista como a primeira etapa de projeto de pesquisa.

Em comparação com a Revisão convencional da literatura, uma Revisão sistemática requer um esforço superior pois o mesmo efetua uma investigação aprofundada e completa sobre a área de interesse.

A revisão sistemática teve seu início no campo da medicina e pesquisas fizeram com que seu conceito fosse adaptado a outras áreas. Uma dessas pesquisas resultou nas práticas da revisão sistemática para a engenharia de software proposta por (Kitchenham, 2004).

O primeiro passo para a revisão é elaborar a questão de pesquisa, que representa a base da investigação, e que se expressa por meio de conceitos e termos específicos, que facilitam no levantamento das informações relativas à estrutura da pergunta (Biolchini et 
al., 2005). Estes dados são analisados e comparados entre si para ajudar no planejamento da nova pesquisa, evitando uma proposta duplicada ou errada.

\section{A.2 Elaboração da Revisão Sistemática}

Esta revisão tem como fundamento o processo proposto pela Kitchenham (2004) onde o mesma propêm a divisão em 3 fases:

\section{- Planejamento}

- Condução

- Resultados

\section{A.3 Planejamento}

No planejamento da Revisão Sistemática é definido o objetivo e as necessidades de revisão, é especificado a questão de pesquisa, selecionada as fontes de dados e definida as estratégias de busca. Também é definido os critérios de inclusão e exclusão para os trabalhos relevantes.

\section{A.3.1 Objetivo da RS.}

O objetivo desta revisão sistemática é efetuar um levantamento sobre pesquisas que retratam as abordagens para o BPM e seu relacionamento com o Alinhamento Estratégico. As informações coletadas serão a base para a criação de uma abordagem para o BPM que faça a corporação atingir o alinhamento estratégico.

\section{A.3.2 Questão de Pesquisa}

A pesquisa foca em uma questão principal:

\section{Questão: Como obter alinhamento estratégico a partir do BPM ?}

Algumas sub questões foram utilizadas para dar apoio à questão principal da pesquisa:

- Sub - Questão 1: Dentre as abordagens para BPM propostas, como é obtido o alinhamento estratégico? 
- Sub - Questão 2: Dentre as abordagens para BPM, como é proposta a flexibilidade para mudanças?

- Sub - Questão 3: Como os processos se comportam nos diferentes níveis funcionais?

A População, Comparação, Intervenção e Resultados foram descritos abaixo para dar qualidade e amplitude a questão:

- População: Pesquisas que focam na implantação e utilização do BPM

- Intervenção: O alinhamento estratégico e a flexibilidade dos processos

- Comparação: Não aplicável

- Resultados: Metodologias para a implantação e utilização do BPM

\section{A.3.3 Estratégia de Busca}

A string de pesquisa foi definida de forma abstrata para que não tenha restrição dos trabalhos realizados no momento da busca, possibilitando uma busca completa sobre as pesquisas realizadas. Abaixo segue a string geral utilizada:

(('Business Process Management' OR 'BPM') AND 'Strategic Alignment')

No protocolo inicial foi proposto a busca em 7 bases (IEEE Explore, ACM Digital Library, AIS Electronic Library, Web of Knowledge, JSTOR, SCOPUS, INFORMS), no entanto, ao efetuar as buscas nas mesmas, foi visto que 2 bases não contribuiriam de forma significativa (Web of Knowledge, INFORMS ), resultando na desconsideração das mesmas. A tabela A.1 mostra as bases selecionadas e seus respectivos endereços:

\begin{tabular}{ll}
\hline Base & Endereço \\
\hline IEEE Explore & www.ieexplore.ieee.org \\
ACM Digital Library & www.portal.acm.org \\
AIS Electronic Library & www.aisnet.org \\
JSTOR & www.jstor.org \\
SCOPUS & www.scopus.com \\
\hline
\end{tabular}

Tabela A.1: Bases Selecionadas 
Abaixo seguem informações detalhadas sobre cada base, e a string utilizada para cada base, respeitando as particularidades de cada máquina de busca:

\section{IEEE Explore}

Método de pesquisa : máquina de busca na web

String: ('business process management' <or $>$ 'BPM') <or $>$ ('Strategic alignment' < and $>$ ('business process management' <or $>$ 'BPM'))

\section{ACM Digital Library}

Método de pesquisa : máquina de busca na web

String: ('business process management' <or $>$ 'BPM') <or $>$ ('Strategic alignment' <and $>$ ('business process management' <or $>$ 'BPM'))

\section{AIS Electronic Library}

Método de pesquisa : máquina de busca na web

String: ('business process management' <or $>$ 'BPM') <or $>$ ('Strategic alignment' <and $>$ ('business process management' <or $>$ 'BPM'))

\section{JSTOR}

Método de pesquisa : máquina de busca na web

String: ab:(Business Process Management)

\section{SCOPUS}

Método de pesquisa : máquina de busca na web

String: Business Process Management and Strategic Aligment

\section{A.3.4 Critério de Seleção dos Estudos}

Foram estabelecidos os Critérios de Inclusão que tem como objetivo estabelecer as informações que os trabalhos relevantes devem conter para serem aceitos e os Critérios de Exclusão que tem como objetivo classificar os trabalhos não relevantes para a pesquisa.

\section{Inclusão}


Os seguintes critérios de inclusão foram adotados:

I1: Trabalhos que apresentem o BPM correlacionando com o Alinhamento Estratégico

I2: Trabalhos que apresentem o BPM correlacionado com flexibilidade

I3: Trabalhos que mostrem o comportamento dos processos em diferentes níveis hierárquicos

\section{Exclusão}

Os seguintes critérios de exclusão foram adotados:

E1: Trabalhos que não estão no idioma Português ou Inglês.

E2: Trabalhos que abordam o BPM mas não possuem nenhuma correlação com alinhamento estretégico, flexibilidade e comportamento dos processos em diferentes níveis hierárquicos

E3: Trabalho não disponível

E4: Trabalho que aborda o alinhamento estretégico, flexibilidade e comportamento dos processos em diferentes níveis hierárquicos mas não possui nenhuma correlação com o BPM

E5: Trabalho duplicado

\section{A.3.5 Definição do tipo dos estudos}

Como o intuito é futuramente propor uma metodologia, é interessante Estudos experimentais e Estudos de caso. Estudos Qualitativos e Quantitativos vão ter uma importância secundária na pesquisa.

\section{A.3.6 Procedimentos para seleção dos estudos primários}

Estágio 1: Identificar estudos relevantes

Estágio 2: Excluir os estudos com base no título

Estágio 3: Excluir os estudo com base no resumo

Estágio 4: Obter os estudos primários e avalia-los criticamente 


\section{A.4 Condução da Revisão Sistemática}

Na fase de Condução da Revisão Sistemática é executado o planejamento e os trabalhos são retornados pelas buscas e avaliados pelo pesquisador que aplica os critérios de inclusão e exclusão já estabelecidos, analisando os trabalhos que são relevantes ou não para a pesquisa.

\section{A.4.1 Buscas realizadas}

Abaixo informações sobre as datas de buscas, a quantidade de artigos retornados e os trabalhos encontrados em duplicidade em cada base:

\section{IEEE Explore}

Data da busca: 10/11/2011

Resultados String de busca: 277

Resultados Duplicados: 29

\section{ACM Digital Library}

Data da busca: 10/11/2011

Resultados String de busca: 55

Resultados Duplicados: 2

\section{AIS Electronic Library}

Data da busca: 11/11/2011

Resultados String de busca: 119

Resultados Duplicados: 1

\section{JSTOR}

Data da busca: 11/11/2011

Resultados String de busca: 41

Resultados Duplicados: 0

\section{SCOPUS}

Data da busca: 11/11/2011

Resultados String de busca: 211

Resultados Duplicados: 29 
A tabela A.2 mostra os trabalhos que foram encontrados em duplicidade nas bases de dados, como exemplo, pode ser visto que para os trabalhos da IEEE, dois trabalhos voltaram em duplicidade na mesma busca e vinte e sete trabalhos idênticos foram retornados na base JSTOR.

\begin{tabular}{lccccc}
\hline & IEEE & ACM & AIS & JSTOR & SCOPUS \\
\hline IEEE & 2 & 0 & 0 & 0 & 27 \\
ACM & 0 & 1 & 1 & 0 & 0 \\
AIS & 0 & 1 & 0 & 0 & 0 \\
JSTOR & 0 & 0 & 0 & 0 & 0 \\
SCOPUS & 27 & 0 & 0 & 0 & 2 \\
\hline
\end{tabular}

Tabela A.2: Trabalhos Duplicados

\section{A.4.2 Seleção inicial dos estudos primários}

A tabela A.3 mostra a quantidade de trabalhos retornados por Base, o número de trabalhos selecionados após a aplicação dos critérios de inclusão e exclusão e a porcentagem de aceitação por Base de dados.

\begin{tabular}{lccc}
\hline Base & Total & Selecionados & Porcentagem \\
\hline IEEE & 277 & 15 & $5 \%$ \\
ACM & 55 & 5 & $9 \%$ \\
AIS & 119 & 12 & $10 \%$ \\
JSTOR & 41 & 0 & $0 \%$ \\
SCOPUS & 211 & 3 & $2 \%$ \\
\hline
\end{tabular}

Tabela A.3: Trabalhos Selecionados por base

Após o levantamento dos estudos em todas as bases, foi feito um refinamento pelo título, este estágio foi utilizado em poucos casos para evitar a exclusão de trabalhos relevantes para a pesquisa. Na terceira etapa foi verificado os resumos dos artigos, e quando não era possível identificar a partir do resumo, outras informações eram consideradas como a introdução e a conclusão. Por fim todos os artigos da tabela A.4 foram aceitos para serem analisados criticamente. 


\begin{tabular}{|c|c|}
\hline & Trabalhos \\
\hline 1 & Linking strategic planning narratives to process-centric business (Sommer, 2009) \\
\hline 2 & A process-oriented perspective on the alignment of information technology (Tallon, 2007) \\
\hline 3 & Business \& IT alignment in theory and practice (Silvius, 2007) \\
\hline 4 & Strategic management as organizational learning Developing fit... (Beer et al., 2005) \\
\hline 5 & Insights into the Evolution of BPM in Organisations (deBruin, 2007) \\
\hline 6 & Means Of Achieving Business Process Management Success Factors (Alibabaei et al., 2009) \\
\hline 7 & A unified configurable architecture for human-centric BPM ... (Ao et al., 2009) \\
\hline 8 & Capturing business benefits from process improvement (Bannerman, 2008) \\
\hline 9 & Towards A Conceptualisation Of BPM-Culture... (Brocke e Schmiedel, 2011) \\
\hline 10 & Towards Understanding Strategic Alignment of BPM (Bruin e Rosemann, 2006) \\
\hline 11 & Strategies to Increase Executive Commitment to BPM (Bruin, 2008) \\
\hline 12 & To standardize or not to standardize ? (Building, 1995) \\
\hline 13 & Exploring patterns of business-it (Cleven, 2011) \\
\hline 14 & Practical Challenges for Methods Transforming Goal Models into BPM (Decreus et al., 2009) \\
\hline 15 & Aligning business and IT models in service-oriented ... (Elvesæter et al., 2010) \\
\hline 16 & Constraint Specification for Active Process Models (Finch e Wang, 2009) \\
\hline 17 & Key Performance Indicators Framework (Ganesan e Paturi, 2009) \\
\hline 18 & Proceedings of the 4th International Conference ... (Gong e Janssen, 2010) \\
\hline 19 & Controlled Flexibility in BP Defined for Service Compositions (Kapuruge et al., 2011) \\
\hline 20 & Business Process Management and the challenge of dynamic services (Kirkham et al., 2011) \\
\hline 21 & Multi-Layered Process Modeling for Business and IT Alignment (Lind e Seigerroth, 2010a) \\
\hline 22 & Process Models as Transformation Vehicle for strategic alignment (Lind e Seigerroth, 2010b) \\
\hline 23 & Architecture of Information System Combining SOA and BPM (Liu et al., 2008) \\
\hline 24 & What drives business process standardization... (Muenstermann e Eckhardt, 2009) \\
\hline 25 & Extending business process management to determine... (Neubauer e Stummer, 2007) \\
\hline 26 & Toward an Integrated User Requirements Notation ... (Pourshahid et al., 2008) \\
\hline 27 & An approach to assess the implementation of BPM in enterprises (Rohloff, 2009) \\
\hline 28 & Enterprise architecture modeling with SoaML using BMM ... (Sadovykh et al., 2010) \\
\hline 29 & A decision-based approach to business process improvement (Shahzad e Zdravkovic, 2010) \\
\hline 30 & Aligning Business and IT: The Process-Driven Architecture Model (Strnadl, 2005) \\
\hline 31 & Knowledge-based Flexible Business Process Management (Tao et al., 2006) \\
\hline 32 & A research on BPM system based on process knowledge (Tao et al., 2008) \\
\hline 33 & Extending WS-Policy4MASC language and MiniZnMASC ... (Tosic et al., 2011) \\
\hline 34 & Aligning business and technology strategies (Yogendra e Sengupta, 2002) \\
\hline 35 & SOA - BPM based information system for promoting ... (ZhenHua et al., 2009) \\
\hline
\end{tabular}

Tabela A.4: Trabalhos Selecionados

\section{A.4.3 Trabalhos indicados pelos especialistas}

Após a seleção dos artigos relevantes, outros sete artigos foram recomendados pelos especialistas, os quais podem ser vistos na tabela A.5 


\begin{tabular}{ll}
\hline Trabalhos \\
\hline 1 & De profundis? Deconstructing the concept of strategic alignment (Ciborra, 1997) \\
2 & Reconceptualizing the concept of business and IT alignment... (Grant, 2010) \\
3 & Strategic alignment and enterprise systems implementation... (Grant, 2003) \\
4 & Strategic alignment: Leveraging information... (Henderson e Venkatraman, 1993) \\
5 & Key information technology and management issues ... (Luftman e Zadeh, 2011) \\
6 & Service Process Innovation: A Case Study of BPMN in Practice (Muehlen e Ho, 2008) \\
7 & Justifications, Strategies, and Critical Success Factors ... (Pollard e Cater-Steel, 2009) \\
\hline
\end{tabular}

Tabela A.5: Trabalhos Recomendados por Especialistas

\section{A.5 Resultados}

Ao efetuar buscas voltadas ao BPM, foi possível constar que muitas pesquisas foram realizadas para obter o entendimento do BPM, assim como as formas de utiliza-lo e associa-lo com outras técnicas. Em paralelo foi verificado também a importância do alinhamento estratégico como um dos fatores de sucesso no gerenciamento do negócio.

\section{Sub - Questão 1: Dentre as abordagens para BPM propostas, como é ob- tido o alinhamento estratégico?}

O Alinhamento Estratégico é considerado como um dos fatores críticos para alcançar a maturidade no BPM (Alibabaei et al., 2009; Bruin e Rosemann, 2006). Ao efetuar a busca por trabalhos relevantes ao projeto, foram encontrados trabalhos que mostraram várias vertentes para alcançar o alinhamento estratégico como por exemplo o resultado da adoção de meios, técnicas ou abordagens e ações específicas como investimentos em TI (Neubauer e Stummer, 2007) ou metologias para modelagem de processos (Elvesæter et al., 2010; Lind e Seigerroth, 2010a; Sadovykh et al., 2010).

A modelagem de processos é feito na etapa $A S I S$ e $T O B E$ do BPM e são consideradas as mais importantes pois as mesmas representam respectivamente o levantamento de como o negócio é e como ele deveria ser (Lind e Seigerroth, 2010b). O levantamento incorreto de como é o negócio ou a especificação incorreta de como ele deve ser podem impactar nas demais etapas do BPM que dependem da modelagem. Seguindo esta idéia, foi encontrado nos trabalhos de Mikael Lind e Ulf Seigerroth (Lind e Seigerroth, 2010a,b) interesses de pesquisas similares aos levantados nesta revisão com a foco na obtenção de alinhamento estratégico entre negócios e TI em BPM.

Um dos trabalho propostos por Mikael Lind e Ulf Seigerroth (Lind e Seigerroth, 2010a) utiliza o pensamento em camadas para visualizar as lacunas entre os processos de negócio e a tecnologia. No artigo foi feito uma pesquisa ação sobre o modelo multi camadas,permitindo diferentes níveis de formalismo para mostrar como diferentes conceitos 
estão relacionados dentro e entre as os diferentes níveis de abstração da organização. O artigo mostra a imagem de uma pirâmide, representando um mapa geral da organização, e ao mudar os níveis é possível verificar os processos principais e seus atores, os sub processos, as atividades com a performance de seus atores até chegar as Tasks com os usuários de scripts (na base da pirâmide). O modelo também afirma que é possível obter um equilíbrio entre flexibilidade e precisão durante o processo de modelagem pois cobrem diferentes níveis de granularidade. No entanto, um dos pontos a melhorar (segundo os autores) é a integração do modelo com a arquitetura SOA.

Seguindo o pensamento de integração com SOA, dentre os trabalhos selecionados, é possível destacar uma preocupação com o SOAML (Elvesæter et al., 2010; Sadovykh et al., 2010) como um auxiliar para a obtenção do alinhamento estratégico no momento de modelar os processos de negócios pois o mesmo permite que seja feita uma modelagem comum entre a linguagem de negócio e a linguagem de sistema. O SOAML foi desenvolvido pela OMG como uma extensão do UML, permitindo toda a especificação para soluções de sistemas e permite também a conexão com o BMM, modelo utilizado para capturar como as a motivações do negócio.

Em uma pesquisa prática (Sadovykh et al., 2010) foi visto que com a utilização de MDA (Model Driven Architecture) é possível ver o SOAML em níveis BAM (Business Architeture Model) e SAM (System Architeture Model). No entanto também foi visto uma serie de gaps na especificação do SOAML, então foi proposto uma união com MDA, BMM e BPMN (Sadovykh et al., 2010). Em contra partida a utilização de BPMN e SOAML em conjunto podem intensificar a separação do negócio com a TI, pois as modelagens se diferem, dificultando a integração entre modelagens. Para solucionar esta lacuna, foi proposta uma maneira de implementar com SOAML o que normalmente é implementado no BPMN (Elvesæter et al., 2010), unificando as modelagens e permitindo ilustrar o processo da perspectiva de negócio até a perspectiva de TI.

No entanto, foi visto também que este não é o foco dos pesquisadores, sendo que não há muitos trabalhos referentes especificamente ao alinhamento estratégico no BPM ou como ocorre este alinhamento na Gestão de Processos de Negócios.

\section{Sub - Questão 2: Dentre as abordagens para BPM, como é proposta a fle- xibilidade para mudanças?}

Em suma, foi visto que existe uma grande preocupação por parte dos pesquisadores (Kirkham et al., 2011; Liu et al., 2008) em investir na combinação da Arquitetura Orientada a Serviço(SOA na sigla em inglês) e o BPM, pois esta união traz vantagens como as respostas para os problemas tecnológicos, tais como integração e encapsulamento provida 
de SOA, enquanto o BPM emite um revolução na gestão que se concentra na processo de negócio, exigindo que a empresa estabeleçam um sistema de processo claro e eficaz. A união da arquitetura SOA com o BPM traz a agilidade do negócio à empresa e torna a mesma mais competitiva, adaptando rapidamente ao mercado em constante mudança, uma vez que o baixo acoplamento provido da arquitetura orientada a serviço permite mudanças com maior facilidade e agilidade. (Kirkham et al., 2011; Liu et al., 2008).

Além das vantagens providas da união de ambos, o BPM é um conjunto de técnicas e ferramentas para gerenciar os processos de negócio (Baldam et al., 2008; Weske, 2007) e, portanto, de forma mais próxima de seu nível gerencial. Por outro lado, SOA quando abordada em conjunto com o BPM é considerada como um moderno embasamento tecnológico para viabilizar a realização desses processos de negócio de forma eficiente (Georgakopoulos and Papazoglou, 2009; Erl, T. et al., 2009), também é considerado como uma maneira para dar suporte flexibilidade (Kirkham et al., 2011; ZhenHua et al., 2009) e principalmente com o uso de serviços web (Alonso et al., 2004; Papazoglou, 2008), permitindo a realização de processos interorganizacionais. Com isto, a união de BPM e SOA pode facilitar na obtenção do alinhamento estratégico entre as áreas técnicas e as áreas de negócio. Como abordado anteriormente, pesquisadores (Elvesæter et al., 2010) também propoem o alinhamento entre o negócio e a TI a partir do BPMN (Business Process Model and Notation) linguagem utilizada para modelagem de processos (OMG, 2010) e o SoaML (Service oriented architecture Modeling Language) utilizada para modelagem de serviços SOA (Elvesæter et al., 2010; Sadovykh et al., 2010) (OMG, 2009).

De uma forma mais abrangente, pesquisadores buscam a flexibilidade do BPM, agregando o mesmo com outras técnicas e arquiteturas para suportar todo o ciclo de vida do BPM de forma flexível e otimizando a modelagem dos processos (Tao et al., 2006, 2008). Em contrapartida, também é visto que ao necessitar de processos aptos a mudanças rápidas e frequentes pode ser problemático pois o processo pode fugir de suas especificações, comprometendo a qualidade do modelo utilizado para implantar os processos (Finch e Wang, 2009; Gong e Janssen, 2010; Kapuruge et al., 2011).

\section{Sub - Questão 3: Como os processos se comportam nos diferentes níveis funcionais?}

Dos trabalhos selecionados, o único que responde esta pergunta sem fugir do escopo buscado pela revisão é o de Mikael Lind e Ulf Seigerroth (Lind e Seigerroth, 2010a) onde é mostrado um modelo multi camadas proposto pelos autores, permitindo diferentes níveis de formalismo para mostrar como diferentes conceitos estão relacionados dentro e entre 
os diferentes níveis de abstração da organização.

\section{A.6 Conclusão}

Foi apresentada uma revisão sistemática conduzida com o objetivo de encontrar abordagens ou meios de alcançar o alinhamento estratégico a partir do BPM. Dos trabalhos encontrados, alguns podem ser destacados por abordar especificamente o alinhamento estratégico no BPM. Um exemplo de abordagem que apresenta um interesse de pesquisa semelhante ao abordado neste trabalho é o proposto por Mikael Lind e Ulf Seigerroth (Lind e Seigerroth, 2010a), que aborda um pensamento em camadas para a modelagem de processos, permitindo uma visão desde os objetivos estratégicos até a tecnologia da informação, apresentando assim um modelo mais concreto de como o alinhamento estratégico pode ser obtido. No entanto o trabalho ressalta a ausência de suporte para SOA, com isso, seria interessante unir o modelo ao SoaML (Elvesæter et al., 2010; Sadovykh et al., 2010) para garantir todo o alinhamento entre o negócio e a TI. Com relação ao processo de realização da revisão sistemática, foi visto como maior empecilho a ausência de uma ferramenta para armazenar e gerenciar efetivamente as buscas retornadas das máquinas de buscas, uma vez que o processo deve ser feito manualmente. 


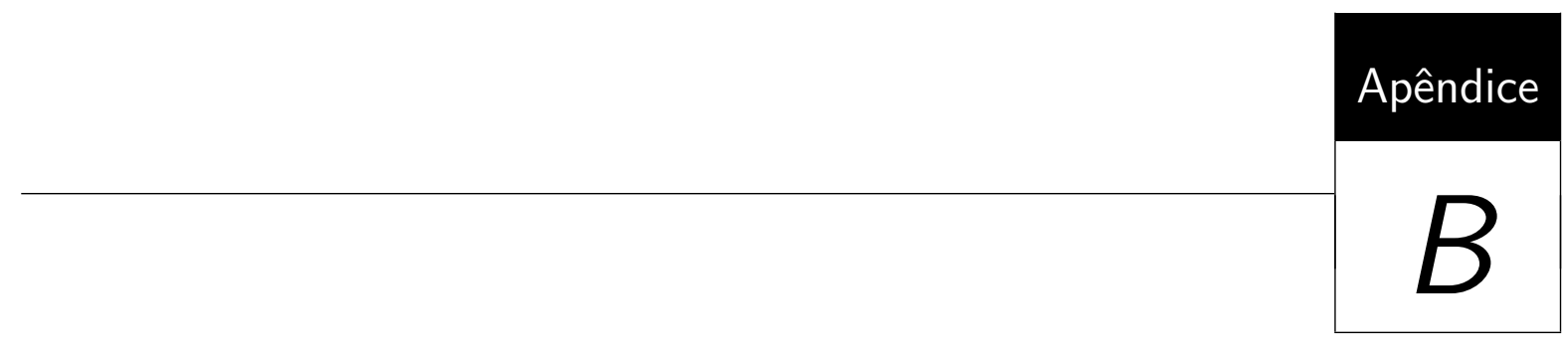

Entrevistas

Neste apêndice é mostrado todas as respostas de todos os entrevistados no processo de Experimentação da abordagem proposta. Este tópico mostra apenas as respostas, os resultados consolidados foram apresentados no capítulo do Experimento.

\section{B.1 Perguntas}

O formulário abaixo foi utilizado como base para a entrevista semi estruturada com os participantes do experimento.

1. Você acredita que "Modelar os objetivos estratégicos e relacionar os mesmos com os processos da organização é uma forma útil de gerenciamento"?

2. Você considera que "A abordagem fornece uma maneira interessante de relacionar e alinhar os objetivos estratégicos com o fluxo de atividades desempenhados no processo"?

3. Você acredita que "A abordagem contribuiu com o gerenciamento dos processos e dos objetivos estratégicos"?

4. Você considera que "A abordagem em níveis é uma forma efetiva de representar os Processos de Negócio"? 
5. Você acredita que "A abordagem contribuiu com o gerenciamento dos objetivos estratégicos em todos os níveis de todos os processos"?

6. Como você vê a utilidade de modelar os objetivos estratégicos e relaciona-los com os processos de negócio da organização?

7. Você como gestor (ou se você fosse um gestor) acredita que esta abordagem permite que você visualize como seus objetivos estratégicos estão sendo atacados nos processos?

8. Você como Analista (ou se você fosse um analista) acredita que as tarefas desempenhadas em seu trabalho ficam mais claras quando você visualiza as mesmas interligadas com o todo e com os objetivos estratégicos propostos pelos gestores?

9. Com a abordagem, você como gestor (ou se você fosse um gestor) acredita que o nível operacional consiga acompanhar os objetivos estratégicos a medida que os mesmos vão sendo definidos e alterados ? Acredita que é uma boa forma de Alinhamento? Justifique.

10. Com a abordagem, você como analista (ou se você fosse um analista) acredita que consegue acompanhar de melhor forma os objetivos estratégicos a medida que os mesmos vão sendo definidos e alterados pelo Gestor ? Acredita que é uma boa forma de Alinhamento? Justifique.

11. De acordo com a sua vivência com BPM, você como Gestor (ou se você fosse um gestor) acredita que a abordagem fornece uma perspectiva para visualizar e gerenciar todos os processos da organização e como seus objetivos estão sendo ou não tratados? Por quê?

12. Você como Analista (ou se você fosse um analista) acredita que visualizar suas atividades sobre o todo influencia positivamente no desempenho de seu trabalho ? Por quê?

13. De acordo com a sua vivência com processos (BPM), como você entende que a abordagem em níveis pode contribuir no gerenciamento dos processos de Negócios?

14. De acordo com a sua vivência com processos (BPM), você acredita que os objetivos estratégicos estão sendo representados de maneira adequada em todos os níveis nos diagramas ? Explique. 


\section{B.2 Respostas}

Foram realizadas 11 entrevistas com pessoas de diversas funções e níveis hierárquicos, as respostas detalhadas são apresentadas a seguir. Por motivo de confidencialidade, seus nomes foram ocultados e foi preservado apenas a função, nível hierárquico e tempo de experiência.

\section{B.2.1 Participante 1}

Nível: Operacional

Tempo de Empresa: 7 anos

Tempo de Experiência: 10 anos

1. Concordo Totalmente

2. Concordo Totalmente

3. Concordo Totalmente

4. Concordo Totalmente

5. Concordo Totalmente

6. As vezes os processos não estão bem definidos, definem os processos e seus fluxos e não entendemos bem o por quê de determinadas ações, com a abordagem consigo entender melhor

7. Ajuda bastante, cada nível tem um tipo de detalhamento, com isso eu consigo visualizar bem de acordo com a minha necessidade

8. Os objetivos ficam mais claros tanto para quem desempenha quanto para quem está desenhando o fluxo

9. Acredito que se todos estivessem seguindo a ferramenta, se isto tivesse bem alinhado eu acredito que sim

10. Se os processos estiverem bem detalhados a ponto de eu desempenhar minhas funções com base no fluxo eu acredito que sim

11. Acredito que sim pois não há um detalhamento deste tipo hoje em dia aqui na empresa 
12. Acredito que seria uma boa base para sabermos o que fazer, embora já saibamos o que fazer, acredito que seria uma boa fonte de busca de informações quando houver dúvidas sobre o fluxo do processo ou sobre os objetivos estratégicos

13. A possibilidade de abstrair e detalhar facilita na busca de algumas informações no fluxo e do entendimento do todo

14. Gostei da abordagem, acho que a possibilidade de abstração e detalhamento alinhado com os objetivos pode ajudar muito no dia a dia

\section{B.2.2 Participante 2}

Nível: Tático

Tempo de Empresa: 10 anos

Tempo de Experiência: 16 anos

1. Concordo Totalmente

2. Concordo Totalmente

3. Neutro

4. Concordo Totalmente

5. Concordo Totalmente

6. A abordagem fornece uma forma clara do que deve ser feito e onde pretende-se chegar tanto para quem executa quanto para quem planeja

7. Acredito que sim, depois de apresentada a abordagem estou começando a pensar que isto deveria ser um requisito obrigatório as empresas

8. Se eu sei o motivo pelo qual eu executo a tarefa, eu executo ela da melhor forma possível pois eu sei o grau de importância que a mesma terá para a organização

9. Acredito que a ferramenta ajuda, mas acho que precisaria de mais algum canal de comunicação para entender as mudanças ou por quê mudou algumas coisas.

10. Se a ferramenta informasse as mudanças e o por quê das mudanças, facilitaria muito mais pois é muito difícil as pessoas acompanharem todo dia o fluxo em busca de mudanças

11. Acredito que sim, só fico um pouco apreensivo com pessoas que exercem muitos papéis e executam muitas tarefas. 
12. Como eu disse anteriormente, acredito que ajuda muito, achei neste aspecto a abordagem formidável

13. Sim, você consegue ter uma visão do todo e consequentemente o que pode ser impactado com as ações realizadas

14. Acredito que sim, apenas como ressalvas, a abordagem é focado Top-Down, talvez alguém muito elevado não consiga ou queira gerenciar o fluxo de tarefas, então precisaria de mais de uma pessoa para gerenciar os níveis. Apesar deste esforço, achei interessante que após os objetivos estratégicos e os fluxos de processos estarem modelados, eles fornecerão informações muito úteis para tomada de decisões. Também como sujestão, acho que se a abordagem virar um produto, a interface de modelagem deveria estar mais rica visualmente, mais formal

\section{B.2.3 Participante 3}

Nível: Operacional

Tempo de Empresa: 4 anos

Tempo de Experiência: 4 anos

1. Concordo Parcialmente

2. Concordo Totalmente

3. Concordo Totalmente

4. Concordo Totalmente

5. Concordo Totalmente

6. Acho que isso hoje é mais que uma utilidade e sim uma necessidade, a ferramenta centraliza as informações e facilita o gerenciamento. A utilidade da abordagem é auto-explicativa, ela por si só mostra a utilidade

7. Sim, inclusive permite que algumas simulações sejam feitas para ver o que a mudança de uma atividade pode impactar no todo

8. Sim, acredito que fica mais claro

9. Acredito que as informações de alto nível são mais focadas aos gestores, quem executa as atividades só precisa saber o que deve ser feito e não o por quê está sendo feito. 
10. Acredito que o mais importante para quem executa é o entendimento do que deve ser feito e o que as outras pessoas fazem. Eu trabalho aqui a um bom tempo e não entendo o fluxo de tarefas desempenhados por outras equipes, com a ferramenta eu conseguiria entender facilmente caso tivesse necessidade

11. Acredito que sim, acho que não tenho experiência para responder com certeza esta questão.

12. Eu acho que existem pessoas e pessoas, muitos recursos hoje na empresa não possuem a mínima noção dos objetivos da mesma, no entanto, desempenham muito bem as suas funções, no entanto, quem tem uma visão mais abrangente e quer trabalhar focado nas estratégias mesmo sendo operacional terá uma boa forma de o faze-lo com a abordagem. O mesmo vale para recursos novos, alguns tirariam muito proveito e outros não tirariam proveitos mas a performance das atividades deles não seria impactada

13. A abordagem em níveis permite encapsular os detalhes e fornecer os mesmos de acordo com as necessidades

14. Com certeza, acredito que tudo está interligado, tenho apenas algumas ressalvas: Para pequenas empresas não há tanta necessidade, se eu fosse aplicar a abordagem, eu precisaria de um pequeno treinamento, Acredito que precisará de mais de uma pessoa para modelar os processos e acho que precisaria fornecer treinamentos para difundir o conhecimento da abordagem nos níveis mais baixos

\section{B.2.4 Participante 4}

Nível: Tático

Tempo de Empresa: 7 anos

Tempo de Experiência: 7 anos

1. Concordo Totalmente

2. Concordo Totalmente

3. Concordo Totalmente

4. Concordo Totalmente

5. Concordo Totalmente

6. Ter o mapeamento total dos processos facilita possíveis necessidades de alteração e ajuda muito no alinhamento do que deve ser feito 
7. Com certeza

8. Acredito que sim, no entanto, hoje aqui na empresa não é muito difundido os processos de negócio, acredito que algumas pessoas não teriam maturidade para o entendimento dos benefícios da abordagem

9. Acredito que para o lado gerencial facilitaria muito

10. Acho que muitas pessoas que executam as tarefas não ligam para os objetivos estratégicos, as mesmas só querem saber o que deve ser feito.

11. Acredito que a abordagem modela de uma forma interessante

12. Venho trabalhando com a minha equipe, trazendo os objetivos estratégicos a eles de forma aberta e em comunicação informal e percebo que o rendimento deles apenas aumenta ao saber o por quê de executar as atividades com excelência, portanto, acredito que a ferramenta ajudaria sim

13. O trabalho com níveis é interessante, pois eu acho que o dono da conta não vai querer saber como as tarefas são executadas, no entanto, acredito que os coordenadores de equipe vão ter a necessidade de saber o por quê e trabalhar sobre o fluxo das tarefas e a abordagem está permitindo isso.

14. O trabalho ficou muito interessante, não tenho nada a complementar

\section{B.2.5 Participante 5}

Nível: Operacional

Tempo de Empresa: 4 anos

Tempo de Experiência: 6 anos

1. Concordo Totalmente

2. Concordo Totalmente

3. Concordo Totalmente

4. Concordo Totalmente

5. Concordo Parcialmente

6. A utilidade é definir os processos de acordo com as estratégias definidas não perdendo o foco 
7. Sim, consegue

8. Com esta visualização em níveis é possível ver as estratégias e saber o que eu posso mudar nas minhas atividades ou mesmo nas atividades anteriores ou posteriores que podem não estar alinhadas com a estratégia definida

9. Acredito que sim, para o lado gerencial é o suficiente.

10. Acredito que sim, no entanto, para quem executa os processos, acho que os elementos BMM poderiam ter mais detalhamentos textuais para facilitar ainda mais o entendimento do que está sendo definido no alto nível

11. Acredito que sim, a abordagem divide bem as informações e permite detalhar bem o fluxo do processo e mesmo informações alto níveis

12. Influencia sim, pois eu vejo aonde os resultados do meu trabalho podem chegar.

13. Você vê especificamente o que você quer no momento em que você precisa. Um mapeamento muito grande te deixa perdido, acaba tirando a atenção do necessário, o mapeamento em níveis ajuda você a focar no que é necessário

14. Sim, consigo modelar e visualizar um processo focado nas estratégias e nos indicares de performances, focando a modelagem e mesmo a execução no que foi definido. Apenas como ressalvas acredito que deveria ser investido mais no detalhamento textual das estratégias e quem está no alto nível entende bem como vai executar, no entanto, quem está no baixo nível fica mais complicado para se situar nos processos, talvez um mecanismo de buscas facilitaria.

\section{B.2.6 Participante 6}

Nível: Operacional

Tempo de Empresa: 3 anos

Tempo de Experiência: 8 anos

1. Concordo Totalmente

2. Concordo Totalmente

3. Concordo Totalmente

4. Concordo Totalmente

5. Concordo Totalmente 
6. Do ponto de vista gerencial é extremamente útil ter todos os seus processos mapeados e ter eles interligados as estratégias. Do ponto de vista operacional eu acho interessante saber o que estão esperando das atividades que eu estou desempenhando

7. Acredito que permite, no entanto, a ferramenta deverá sempre ser alimentada a cada mudança.

8. O analista ter a visão do fluxo de suas tarefas é interessante e acredito que sabendo as estratégias posso propor melhorias no meu fluxo de trabalho.

9. Acredito que sim, É uma boa forma de alinhamento, ainda mais aqui onde temos muitos processos e os mesmos são extensos

10. Acredito que sim

11. Acredito que sim se a ferramenta estiver sempre alinhada com as mudanças

12. Acho que sabendo o produto fim do processo, eu trabalharia melhor para as próximas atividades do processo

13. Fica claro o fluxo de cada nível alinhada com as estratégias

14. Gostei da abordagem, com a minha experiência aqui acredito que ajudaria bastante

\section{B.2.7 Participante 7}

Nível: Operacional

Tempo de Empresa: 3 anos

Tempo de Experiência: 3 anos

1. Concordo Totalmente

2. Concordo Totalmente

3. Neutro

4. Concordo Totalmente

5. Neutro

6. Modelar é uma forma rápida de fornecer a informação e garantir o entendimento do todo.

7. Estou neutro com relação a esta questão, apenas como ressalva, quanto mais detalhado o processo, mais complexo pode ficar. 
8. Acredito que fica mais claro o entendimento.

9. Acredito que sim, no entanto, modelar todo o fluxo é complexo

10. Acredito que sim, no entanto, para atender as necessidades do cliente, as vezes precisamos seguir um fluxo divergente do fluxo atual. Isto pode virar uma entrada para uma nova melhoria em nossos processos.

11. Não tenho o que dizer nesta questão

12. A principio estou indiferente pois acho que isso não organizaria o meu serviço

13. Definir melhor as tarefas e organizar elas de uma melhor forma

14. Inicialmente antes de conhecer melhor a abordagem acredito que a mesma está mais voltada para o nível gerencial, pois não vejo muita utilidade para as pessoas que desempenham as atividades uma vez que elas já sabem as tarefas que elas precisam desempenhar. No entanto, vendo minha atividade sobre o todo, as estratégias e os influenciadores do meu departamento, acredito que facilite melhor a compreensão tanto de quem está em baixo nível quanto de quem está no alto nível. Em contrapartida, a abordagem poderia detalhar mais a estratégia, pois desta forma tenho a impressão que a ferramenta está mais focada em citar a estratégia do que gerenciar

\section{B.2.8 Participante 8}

Nível: Estratégico

Tempo de Empresa: 7 anos

Tempo de Experiência: 10 anos

1. Concordo Totalmente

2. Concordo Totalmente

3. Concordo Totalmente

4. Concordo Totalmente

5. Concordo Totalmente

6. A facilidade e simplicidade da representação e da identificação das informações tanto de alto níveis quanto dos processos. Principalmente se comparado com ferramentas mais estáticas de modelagem de processos 
7. Sim, Com a modelagem eu consigo acompanhar e gerenciar os meus processos de forma simples e efetiva

8. Sim, é mais claro se o analista conseguir se localizar no fluxo de atividades e tarefas do processo

9. Estariam bem alinhados, no entanto acho que ainda assim precisaria de uma comunicação formal. Um email fornecido pela ferramenta por exemplo.

10. Com a comunicação o analista acompanharia melhor a ferramenta

11. Concordo, acredito que o objetivo da ferramenta é este, precisaria apenas de mais experiências com a ferramenta

12. Acredito que sim, acredito que a sua abordagem é muito interessante com base nas ferramentas de modelagem de processos que eu conheço

13. A abordagem em níveis é sensacional, ter a visão abstrata e o detalhamento quando necessário tornam-se essenciais.

14. Acredito que sim, gostei da abordagem e gostei também da perspectiva de coleções

\section{B.2.9 Participante 9}

Nível: Estratégico

Tempo de Empresa: 8 anos

Tempo de Experiência: 12 anos

1. Concordo Parcialmente

2. Concordo Totalmente

3. Concordo Parcialmente

4. Concordo Totalmente

5. Concordo Totalmente

6. Primeira vez que eu vejo algo assim, uma ligação tão simples entre os objetivos estratégicos com os processos, com isso, eu consigo saber nas necessidades de mudanças o que eu posso impactar diretamente

7. Acredito que sim 
8. Com certeza, isso é algo que temos mais dificuldades hoje em dia pois as pessoas executam as tarefas sem saber o por que está fazendo, no entanto, as pessoas entendem de forma diferente, portanto, haveria a necessidade de criar alguma forma de disseminar o conhecimento sobre a abordagem para toda a organização

9. Acredito que trabalhar com versionamento de processos e visualizar como ele era a algumas iterações anteriores seria interessante para este propósito.

10. Eu não vi na ferramenta ela diferenciar quando você adiciona ou altera alguma informação, mostrando que algo mudou.

11. Acredito que sim, com o mapeamento eu consigo dar foco no processo para atingir aquele objetivo, acredito que com a ferramenta seriamos mais efetivos em o que devemos atacar

12. Acredito que sim, tanto afetaria o trabalho quanto daria uma perspectiva de crescimento em sua carreira uma vez que ele poderia propor melhorias e mudanças

13. Com a abordagem em níveis eu consigo tirar muito detalhes quando eu não preciso de detalhes e consigo recuperá-los quando necessário

14. Acredito que sim, apenas como ressalvas, acredito que a abordagem é mais focado em processos alinhados a estratégias do que as estratégias, pois as mesmas necessitam de mais informações. Também é válido destacar que é uma forma útil de gerenciar, no entanto, o gerenciamento vai além da modelagem e sim como este processo será executado e muitas vezes o especialista pode encontrar formas mais eficazes de realizar a atividade que podem ou não ser mapeadas dependendo da situação

\section{B.2.10 Participante 10}

Nível: Estratégico

Tempo de Empresa: 8 anos

Tempo de Experiência: 10 anos

1. Concordo Totalmente

2. Concordo Parcialmente

3. Concordo Parcialmente

4. Concordo Totalmente

5. Concordo Parcialmente 
6. Acredito que toda a documentação de processos é importante. Processos eles se perdem com o tempo quando eles não são documentados. Quando há muitos processos e os mesmos não estão centralizados em algum lugar, eles acabam não sendo padronizados e com isto, há perda de recursos, tempo e esforços desnecessários.

7. Acredito que sim

8. Além de ficar mais claro, ele consegue entender no todo onde as funções dele começa e termina, definido o escopo de cada pessoa. Acredito também que isto ajuda na motivação de quem executa o processo e permite também que o mesmo tenha uma visão de onde ele quer chegar na organização pois ele tem uma visão dos demais processos

9. Acredito que este canal de comunicação é importante

10. Na nossa organização temos um nível de estudo padronizado, no entanto, talvez em algumas outras organizações, as camadas mais baixas não consigam compreender a efetividade da abordagem

11. Acredito que os objetivos ficam bem claros, no entanto, a adição de todos pode deixar o modelo muito complexo, portanto, talvez o foco apenas nos mais importantes faça-se necessário

12. Acredito que sim, quando fica claro o por quê da empresa precisar disto e o porquê de eu fazer isto para atingir um determinado objetivo faz com que eu trabalhe da melhor forma possível

13. Sim, Também acredito que desta forma você consegue inclusive uma administração melhor dos próprios recursos pois você pode ter gestores abaixo de você e com essa visão mais ampla eu consigo me organizar melhor, definido quais processos são mais críticos onde eu posso triagular recursos, onde deve ser investido mais dinheiro, facilitando muito.

14. Sim, no entanto, acredito que as estratégias e os processos necessitarão de manutenções constantes e muito precisas para que os recursos trabalhem sempre alinhados as necessidades do negócio. Achei a abordagem mais focada nos processos tentando atender os objetivos estratégicos do que no gerenciamento dos objetivos estratégicos, para isto, precisaria adicionar mais informações nesses elementos

\section{B.2.11 Participante 11}

Nível: Operacional 
Tempo de Empresa: 8 anos

Tempo de Experiência: 18 anos

1. Concordo Totalmente

2. Concordo Totalmente

3. Concordo Parcialmente

4. Concordo Totalmente

5. Concordo Totalmente

6. Acredito que a maior vantagem é a mesma ser colaborativa por ser web ela permite que todas as pessoas (independente do seu nível hierárquico) modelem e trabalhem no mesmo processos gerando um alinhamento do conhecimento entre todos, além dos modelos serem bem representativos, facilitando a compreensão

7. Acredito que sim

8. Acredito que sim, hoje temos uma dificuldade muito grande em mostrar o quanto uma tarefa mau desempenhada pode afetar o todo.

9. Acredito que sim

10. Sim, no entanto, senti falta de algum mecanismo avisando as mudanças para facilitar o entendimento do que foi alterado.

11. Acredito que tecnologia e metodologia tem para isto

12. As equipes se interagem entre elas, um bom ou mal trabalho influencia muito as demais equipes.

13. Trabalha em níveis ajuda muito, hoje temos aqui uma dificuldade muito grande em dividir em níveis e trazer detalhamento nos fluxos conforme as necessidades

14. A abordagem e a ferramentas estão muito boas, apenas a questão de avisar as mudanças que seria interessante implementar

\section{B.2.12 Participante 12}

Nível: Estratégico

Tempo de Empresa: 8 anos

Tempo de Experiência: 8 anos 
1. Concordo Parcialmente

2. Concordo Totalmente

3. Concordo Totalmente

4. Concordo Totalmente

5. Concordo Totalmente

6. A abordagem é interessante pois não é todo mundo que tem a visão do negócio. Muitos recursos trabalham aqui sem ter a visão das estratégias e do impacto que suas tarefas podem causar. Com essa visão você consegue ligar as estratégias com as atividades e alinhar melhor o por quê. Acredito inclusive que isto ajude bastante na motivação do analista

7. Sim, ajuda a ligar e ajuda também quem está definido a estratégia saber quem realmente está desenvolvendo a tarefa responsável pelos resultados esperados

8. No dia a dia não clarificaria pois as atividades já deveriam estar bem definidas, agora clarifica quando ele vê o quanto as atividades dele pode impactar perante as estratégias definidas. Por saber onde ele se encaixa, talvez isto traga mais motivação e permita que ele desempenhe melhor sua função

9. Sim, o nível operacional acompanha, no entanto, acredito que deva haver uma comunicação muito forte para evidênciar isto.

10. Se houver uma comunicação forte sobre isto, acredito que sim.

11. Sim, ele ajuda a desenhar e ajuda a visualizar os gaps, ver nos processos o que é contra a estratégia e o que é da estratégia que não da para encaixar nos processos

12. Acredito que pode motivar sim por ver a parte dele num todo.

13. Ter a visão do todo facilita a visualização do que ele pode impactar nas demais equipes, no entanto, modelar diagramas deste tamanho e dividi-los em níveis pode ser mais complexo do que aparenta.

14. Gostei da abordagem, acredito que é uma boa forma para gerenciar a estratégia e ver como ela será desempenhadas nos processos ,no entanto, não sei se facilitaria gerenciar os recursos nas atividades do dia a dia. 


\section{B.2.13 Participante 13}

Nível: Operacional

Tempo de Empresa: 4 anos

Tempo de Experiência: 4 anos

1. Concordo Totalmente

2. Concordo Totalmente

3. Concordo Totalmente

4. Concordo Totalmente

5. Concordo Totalmente

6. Da para especificar todos os processos, facilita muito na hora de definir novas informações e analisar todos os processos pois os mesmos estão centralizados no mesmo lugar.

7. Sim, pois os processos estão bem especificados.

8. Sim, ajuda bastante a saber o por quê de estarmos realizando determinadas tarefas nos processos quando possuímos o entendimento das estratégias

9. Acredito que para um gerente é mais fácil realizar as alterações, ele só deve se preocupar com a comunicação

10. Para um analista, é necessário um treinamento para alinhar e facilitar o entendimento de como seguir os processos.

11. Um gerente alto nível consegue acompanhar os níveis mais baixos, exemplo, consegue visualizar se os gerentes abaixo conseguem trabalhar colaborativamente

12. Acredito que sim, pois conseguimos visualizar o por quê e o para quê de estarmos desempenhando determinadas atividades, também conseguimos visualizar os indicares de desempenho que facilitam na avaliação de como estou trabalhando.

13. Achei bem interessante pois quando um diagrama é muito grande fica difícil ter todo o entendimento do assunto, no entanto com a abordagem eu posso abstrair o diagrama por complexidade e ter um melhor entendimento

14. Pelo que eu vivênciei da abordagem, acho que a mesma está bem completa e não tenho nada a adicionar 


\section{B.2.14 Participante 14}

Nível: Operacional

Tempo de Empresa: 4 anos

Tempo de Experiência: 7 anos

1. Concordo Totalmente

2. Concordo Totalmente

3. Concordo Totalmente

4. Concordo Totalmente

5. Concordo Totalmente

6. Fornece visibilidade no momento da tomada de decisão

7. Sim, totalmente. São bons parâmetros para a melhoria contínua dos processos

8. Sim, é fácil para eu me situar e saber a minha parte sobre o todo

9. Sim, pela ferramenta ser web, qualquer pessoa pode acessar a qualquer momento e saber o que está acontecendo nos processos

10. Bastaria apenas avisar que houve mudanças

11. Acredito que sim, talvez adicionar alguns indicadores para facilitar a visualização de se o mesmo está sendo atendido ou não

12. Sim, a abordagem traz uma sinergia maior entre o gestor e o executor do processo, permitindo um canal de comunicação para melhorias

13. Eu achei excelente a representatividade dos níveis.

14. Visualmente está muito interessante, A abordagem top down, acho que não tenho feedbacks, gostei muito da abordagem, é muito melhor do que modelar em outras ferramentas e ter que colocar todos os arquivos em um repositório.

\section{B.2.15 Participante 15}

Nível: Operacional

Tempo de Empresa: 3 anos

Tempo de Experiência: 10 anos 
1. Concordo Totalmente

2. Concordo Totalmente

3. Concordo Totalmente

4. Concordo Totalmente

5. Concordo Totalmente

6. Tudo o que está bem documentado, bem modelado facilita na comunicação, permite que exemplifique melhor o que se espera de cada recurso.

7. Acredito que a abordagem permite isto.

8. Sim, facilita para todas as partes, incluindo novos funcionários

9. Como gestor, acho que deveria avisar por sistema ou uma micro reunião

10. Algum mecanismo de aviso ou reunião de alinhamento facilitaria

11. Estando bem modelado estará bem entendido, no entanto, isto não garante que as pessoas seguirão totalmente o que foi modelado

12. Com certeza pois desta forma os recursos deixam de trabalhar as cegas e entendem o que é esperado. Também poderia propor melhorias com entendimento do todo.

13. É uma forma bem interessante de estudar as coisas. Pois dependendo do nível hierárquico não há a necessidade de saber detalhes de execução dos processos.

14. Gostei da abordagem, apenas como observação, eu senti a necessidade de mais campos descritivos para adicionar informações com mais detalhes.

\section{B.2.16 Participante 16}

Nível: Operacional

Tempo de Empresa: 2 anos

Tempo de Experiência: 6 anos

1. Concordo totalmente

2. Concordo totalmente

3. Concordo totalmente

4. Concordo totalmente 
5. Concordo parcialmente

6. Facilita o planejamento da organização. Quando ocorre o alinhamento dos objetivos do cliente junto ao processo de negocio, tem se um nível de internação maior, o que minimiza perdas e aumenta o retorno do investimento.

7. A abordagem permite ao gestor ou responsável por fiscalizar, a possibilidade de acompanhar cada processo desde o seu nível atômico, o que acarreta em maior controle, uma vez que pode se alinhar o cumprimento de cada processo com os objetivos de cada etapa.

8. Sim, concordo. Quando se tem uma visão geral do negocio como um todo, pode se mensurar melhor os riscos e gerir melhor o que cada mudança em um dado departamento ou equipe, pode acarretar em processos de outras equipes. Pode se correr riscos calculados.

9. Acredito que sim, dado que assemelha se a um modelo incremental, onde o gestor ou pode alinhar as estratégias de negocio concomitantemente a equipe de desenvolvimento, minimizando os riscos.

10. Sim, uma vez que a abordagem define claramente o que deve ser feito a cada etapa, e como as mudanças afetam o projeto como um todo, pode ser considerada uma forma segura e de fácil acompanhamento por parte dos analistas.

11. Sim, pois mostra pelo diagrama, a organização de todos os processos envolvidos no sistema, bem como seu status o que permite ao gestor acompanhar a evolução e cumprimento de objetivos inerentes a organização.

12. Sim, como dito anteriormente, quando se tem uma visão sobre o todo e de como cada parte interage com outras, pode se mitigar riscos e realizar um melhor trabalho onde o mesmo envolve a participação de diversos departamentos.

13. Abordagem em níveis permite subdividir os conjuntos de processo de maneira inteligente, de forma a selecionar tarefas especificas a pessoas com habilidades especificas

14. Sim, gostei a da forma de representação, achei bem simples e direta

\section{B.2.17 Participante 17}

Nível: Estratégico

Tempo de Empresa: 7 anos

Tempo de Experiência: 14 anos 
1. Concordo Totalmente

2. Concordo Totalmente

3. Concordo Totalmente

4. Concordo Totalmente

5. Concordo Parcialmente

6. Os processos devem estar totalmente interligados a estratégias, no entanto o que manda é a execução. Você define uma estratégia e as vezes precisa de vários processos para atingir, com a abordagem fica tudo completamente ligado. Você tem que se preocupar em documentar tudo e transmitir ao time.

7. Hoje é muito difícil um gerente ter uma visão holística do todo, muitas vezes ele toma uma decisão e não sabe o quanto aquilo pode impactar no modelo e na estratégia dele. Com a abordagem eu acredito que ela dê visibilidade ao gerente para estas tomadas de decisões.

8. Olhando pela perspectiva do analista, eu não sei dizer se faz diferença para ele ter o entendimento de um todo. Não sei se ele se interessaria no escopo de outras equipes que não se relacionam com a dele (apesar de eu achar importante). Talvez ele ver o todo tire o foco dele pois ele pode não ter a experiência de entender o todo, No entanto, ele ver o dele e o da equipe dele é totalmente importante

9. Pensando em custos, seria difícil conseguir recursos hoje para manter esta ferramenta, no entanto, se a mesma fosse mantida e atualizada constantemente eu acharia útil esta forma de alinhamento

10. Acredito que acompanharia

11. Sim, com o link com o BPM, seguindo todos os parâmetros eu acredito que sim

12. Creio que sim, no entanto, acho que teríamos que investir mais em treinamento para que o analista entenda mais sobre processo e acompanhar a evolução dos processos. Também acho interessante emails chegando avisando o analista quando o processo foi alterado pois o analista em si não vai ficar entrando na ferramenta e olhando quando o processo foi alterado

13. Você não consegue ter uma visão em um nível de tudo, você tem que acabar criando uma visão simplificada e posteriormente detalhar o que mais interessa. Também é fundamental que as pessoas saibam em que níveis elas estão. 
14. Resumidamente eu acho que a adição de informações como metas, tempos para atingir essas metas dentro dos elementos é fundamental para o gerenciamento das estratégias sobre os processos

\section{B.2.18 Participante 18}

Nível: Tático

Tempo de Empresa: 4 anos

Tempo de Experiência: 6 anos

1. Concordo totalmente

2. Concordo totalmente

3. Concordo totalmente

4. Concordo totalmente

5. Concordo parcialmente

6. A utilidade deste tipo de modelagem ocorre pelo fato de ser permitido o link do que foi planejado com o que está em execução

7. Sim, além de definir, eu posso com a abordagem, acompanhar o fluxo do processo para saber se o mesmo está condizente.

8. Sim, sabendo os objetivos estratégicos, eu sei em quais tarefas eu devo focar e entregar mais qualidade

9. Acredito que sim, no entanto, acredito que ficaria mais confortável se pudesse alinhar de outra forma também para reforçar.

10. Acredito que com o tempo eu pararia de olhar o diagrama pois eu possuiria um conhecimento do todo. Se alguma coisa ou alguém me avisasse que há mudanças me ajudaria mais

11. Sim, acredito que sim.

12. Sim, ao me deparar com o todo e com os objetivos definidos para o processo, eu sei o que esperar das tarefas anteriores, o que esperam da execução das minhas tarefas e sei o que as próximas pessoas que executam as demais tarefas esperam do meu trabalho. 
13. Ela fornece uma visão resumida do todo e quando desejado posso encontrar maiores detalhes, facilitando a visão geral do processo e permitindo o enriquecimento do mesmo com muitas informações sem perder este entendimento

14. Acredito que a modelagem está interessante, acredito que a adição de informações textuais contribuiriam ainda mais com o projeto 


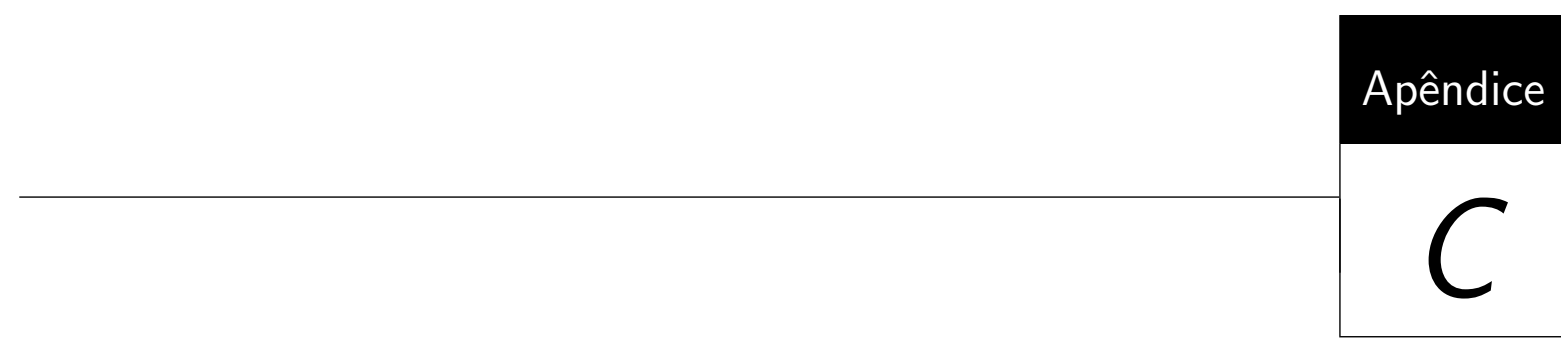

Modelagem e Codificação

Este apêndice possui a finalidade de apresentar os diagramas modelados em UML para a implementação do protótipo e apresentação de trechos chaves de codificação da ferramenta.

\section{C.1 UML}

A Unified Modeling Language (UML) é uma linguagem de modelagem que possui a finalidade de especificar, documentar, estruturar e ilustrar a lógica de desenvolvimento de um software orientado a objetos através de diagramas padronizados permitindo a visualização dos produtos.

\section{C.1.1 Caso de Uso}

Um Diagrama de Caso de Uso mostra os atores (usuários do sistema), casos de uso (cenários) e seus relacionamentos. No contexto do projeto é possível visualizar através da Figura C.1 que a ferramenta possui um caso de uso para o cadastro de diagramas e este cenário utiliza a consulta de diagramas para identificar se é um diagrama novo ou uma alteração. O cenário de busca é utilizando também no momento de carregar um diagrama e na exclusão. O cenário limpar diagrama é utilizado quando há a necessidade de iniciar um novo diagrama, este cenário pode ser utilizado no cenário de exclusão quando o diagrama selecionado pelo usuário é o mesmo que está sendo modelado 


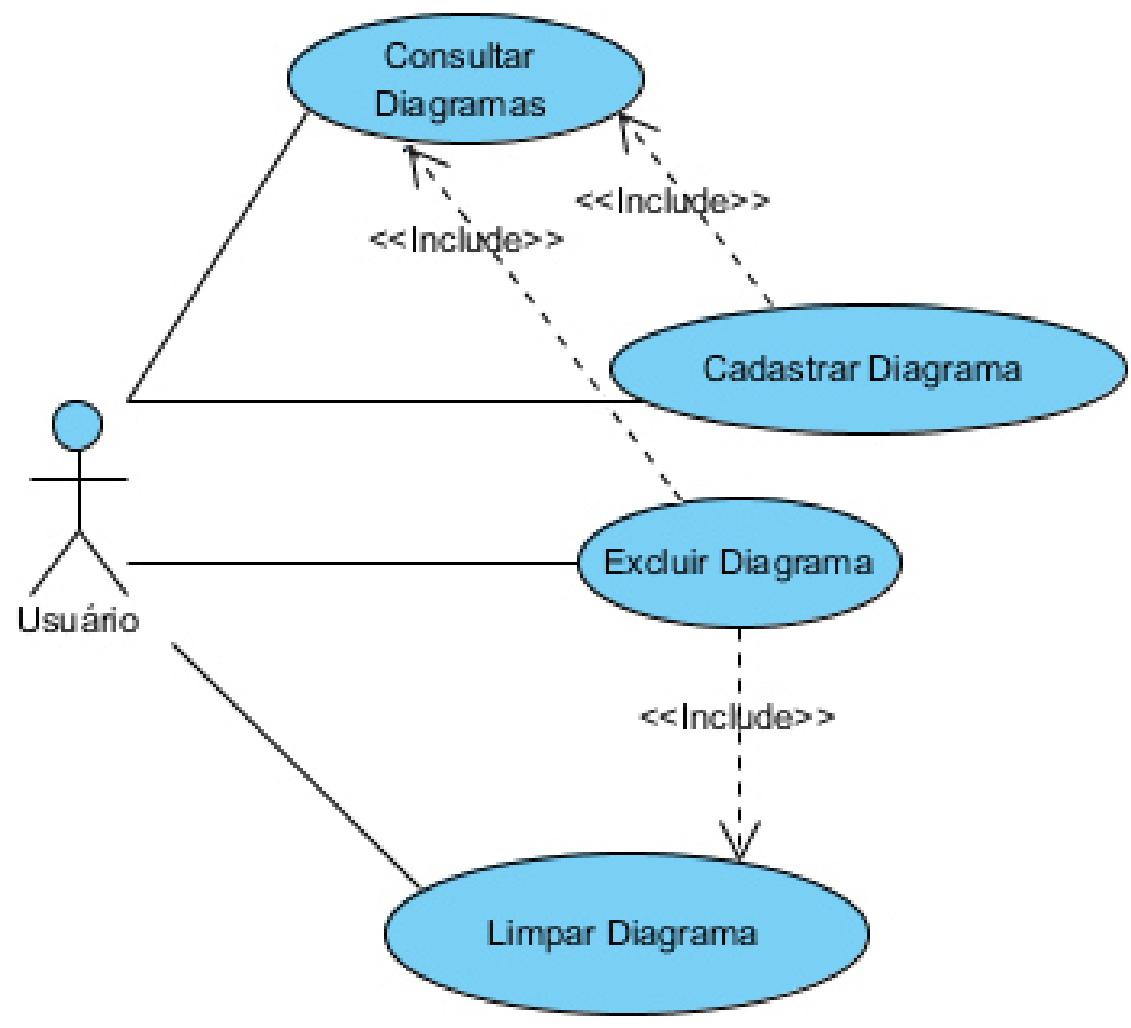

Figura C.1: Caso de Uso

\section{C.1.2 Diagramas de Classes}

O Diagrama de Classe possui a finalidade de apresentar as classes e seus relacionamentos no projeto.

Basicamente, haviam 2 tipos de objetos, os Beans que são classes Java utilizadas para adicionar propriedades (normalmente alinhada com uma tabela no banco de dados) e os DTOs (Data Transfer Objects) classes utilizadas para a transferência de dados entre o cliente e o Servidor.

A implementação de DTOs é obrigatória quando é utilizado Beans mapeados com anotações em um projeto GWT, uma vez que framework converter todo o código cliente em Javascript e ao tentar converter as anotações o mesmo dispara um erro pois não há como substituir por algum componente ou propriedade Javascript.

Para facilitar a compreensão, foi dividido as classes em 2 diagramas (Cliente e Servidor). Na Figura C.2 é apresentado o diagrama de classes no lado cliente da aplicação.

A classe DiagramaDTO que representa um novo diagrama no lado cliente da aplicação e possui $\mathrm{N}$ instâncias da classe BMMDTO que é utilizada para representar um elemento BMM. A classe DiagramaDTO também possui N instâncias da classe ConnectorBMM que é responsável pela ligação entre os elementos BMM, a mesma possui duas instâncias 


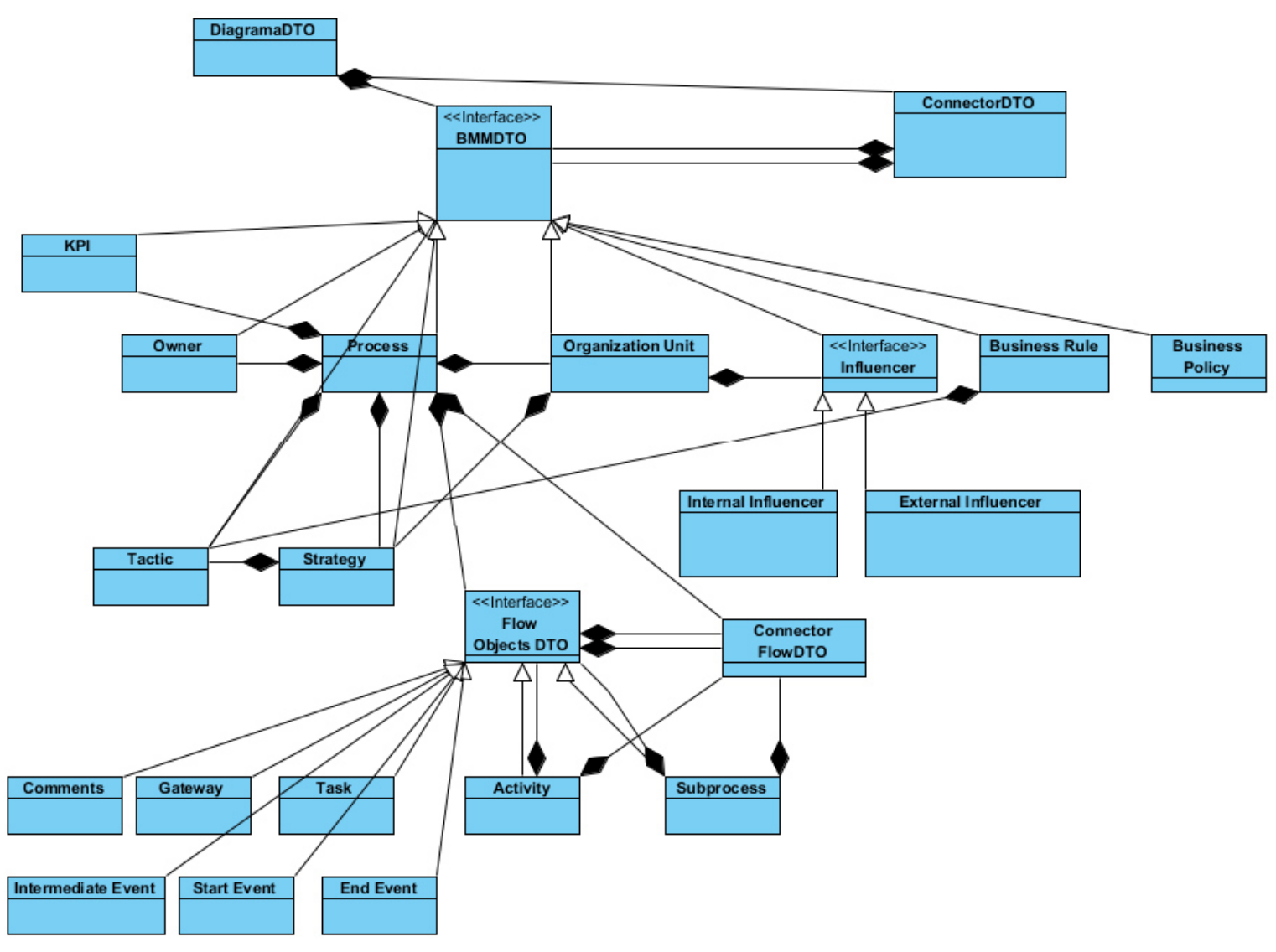

Figura C.2: Diagrama de Classe Cliente

da classe BMMDTO que indicam o elemento dê e para no diagrama. Todos os elementos BMM herdam a classe BMMDTO e entre eles há o relacionamento contido no Metamodelo.

A classe Process é analogamente comparável a classe DiagramaDTO, a mesma possui $\mathrm{N}$ instâncias da classe FlowObject (Comparada com a BMMDTO, no entanto, tem a finalidade de representar os elementos de fluxo do BPMN) e N instâncias da classe ConnectorFlow(Comparada a classe ConnectorBMM)que possui a finalidade de interligar os objetos de fluxo.

Através da recursividade das tabelas BMMDTO e ConnectorBMM é feito os níveis 2, 3 e 4 da abordagem.

Após o usuário realizar a modelagem de todo o diagrama, é submetido ao lado servidor a classe DiagramaDTO. A Figura C.3 apresenta o diagrama de classes no lado servidor da aplicação.

No mesmo é possível identificar que as classes DTOs são convertidas para os Beans mapeados com as tabelas no banco de dados. Como o mapeamento é feito para os 4 níveis, a recursividade do FlowObjectDTO e ConnectorFlowDTO são convertidas para os 3 Beans que representa os níveis 2, 3 e 4 da abordagem. Foi escolhida esta forma 


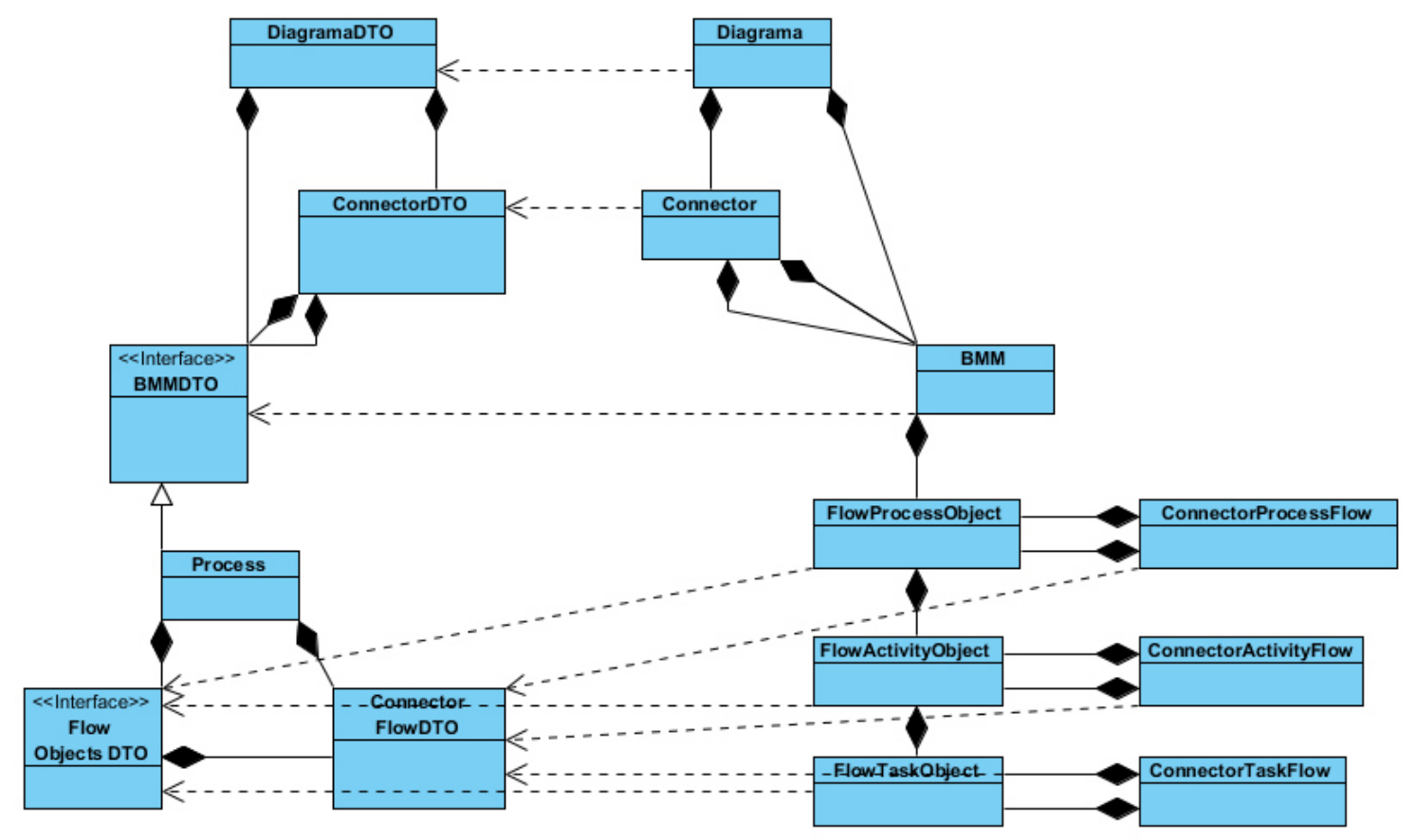

Figura C.3: Diagrama de Classe Servidor

de representar ao invés da recursividade (também deste lado) devido a possibilidade de crescimento e maiores detalhamentos nos níveis.

\section{C.1.3 Diagrama de Sequência}

Diagrama de Sequência mostra objetos e uma sequência das chamadas do método feitas para outros objetos.

O diagrama de sequência de carregar (apresentado na Figura C.4)é iniciado com o usuário solicitando o módulo do diagrama, esta solicitação é atendida pela camada de apresentação da aplicação. O usuário solicita a ferramenta todos os diagramas cadastrados, esta solicitação atravessa as camadas de apresentação, negócio e persistência, onde será feita a busca no banco e retornada ao usuário.

Após devolver todos os diagramas persistidos, o usuário seleciona o diagrama desejado para a visualização e o mesmo é carregado pela camada de persistência.

Como foi possível constatar no diagrama, foi necessária a implementação de duas buscas no banco (busca id e nome de todos os diagramas e busca diagrama específico com todas as informações) pois um objeto diagrama contém muitas informações fazendo com que não seja performático carregar todos os diagramas com todas as informações em apenas uma consulta.

O diagrama de sequência de cadastro (apresentado na Figura C.5) é iniciado com o usuário solicitando o módulo para modelagem, esta solicitação é atendida pela camada de 


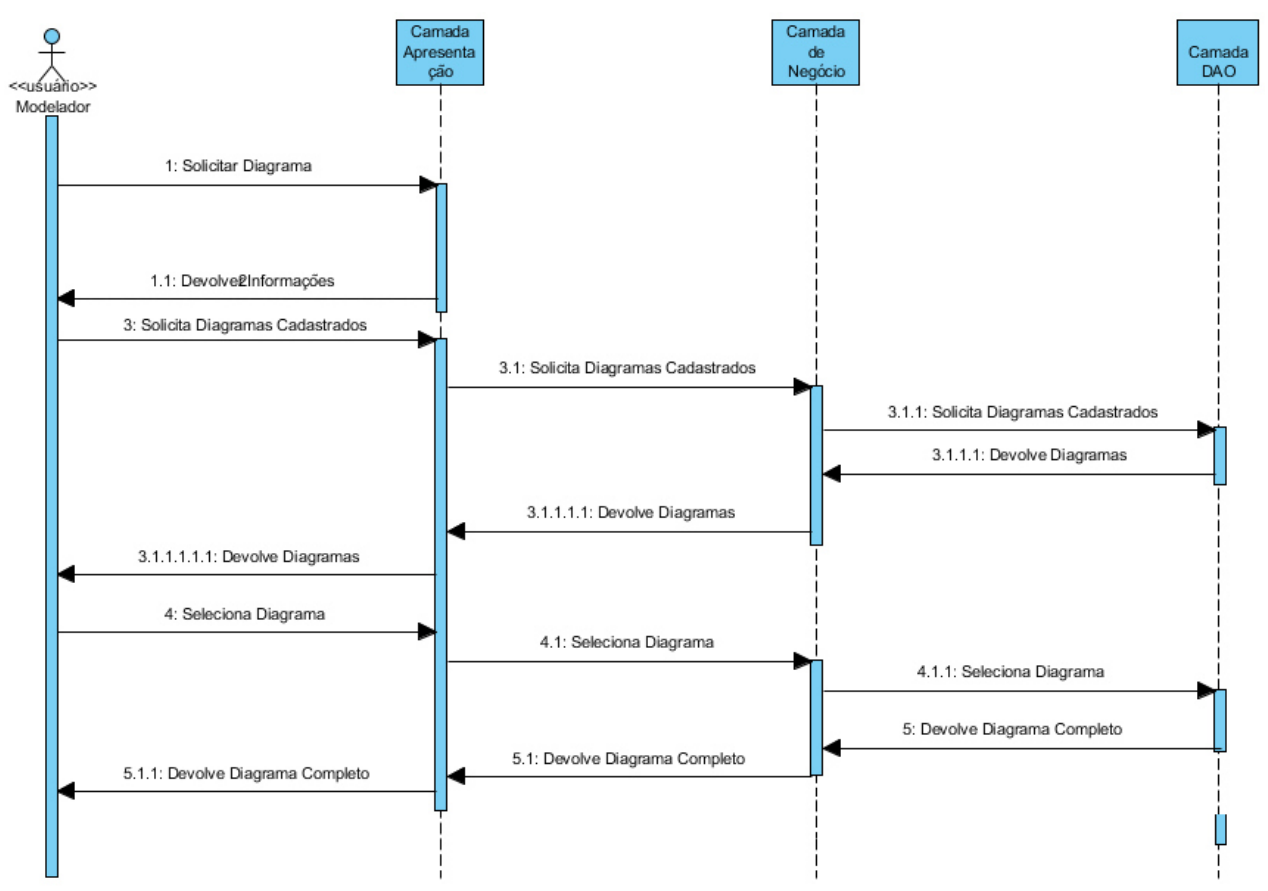

Figura C.4: Diagrama de Sequência - Carregar Diagrama

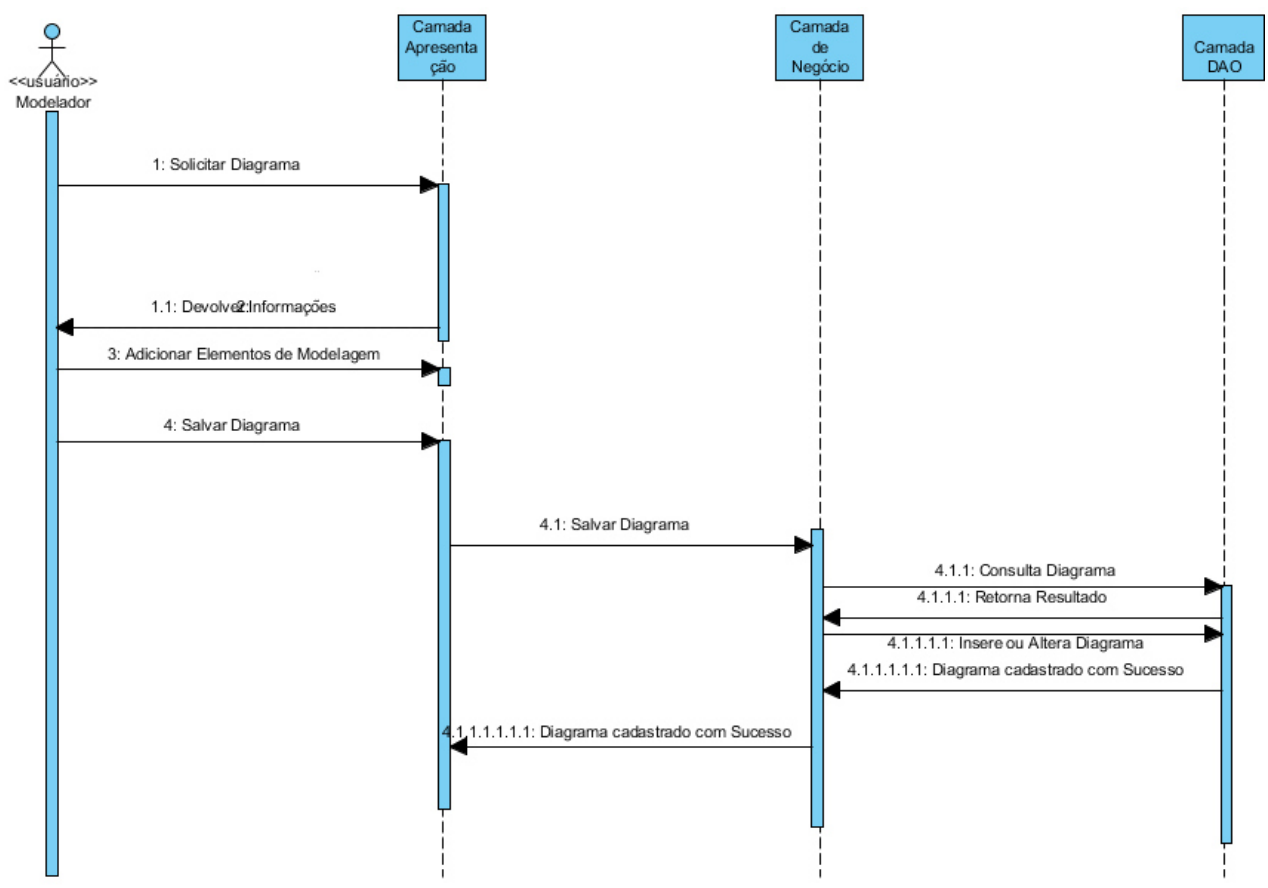

Figura C.5: Diagrama de Sequência - Cadastro

apresentação da aplicação. O usuário realiza a modelagem e seleciona a opção salvar, esta solicitação atravessa as camadas de apresentação, negócio e persistência, onde será feita a busca no banco para validar se o diagrama que está sendo modelado já está persistido. 
Caso seja um diagrama novo a aplicação persiste as informações no banco de dados, caso o diagrama já esteja no banco de dados, a aplicação realiza a alteração das informações do diagrama.

Após persistir o diagrama, uma mensagem de sucesso é apresentada ao usuário.

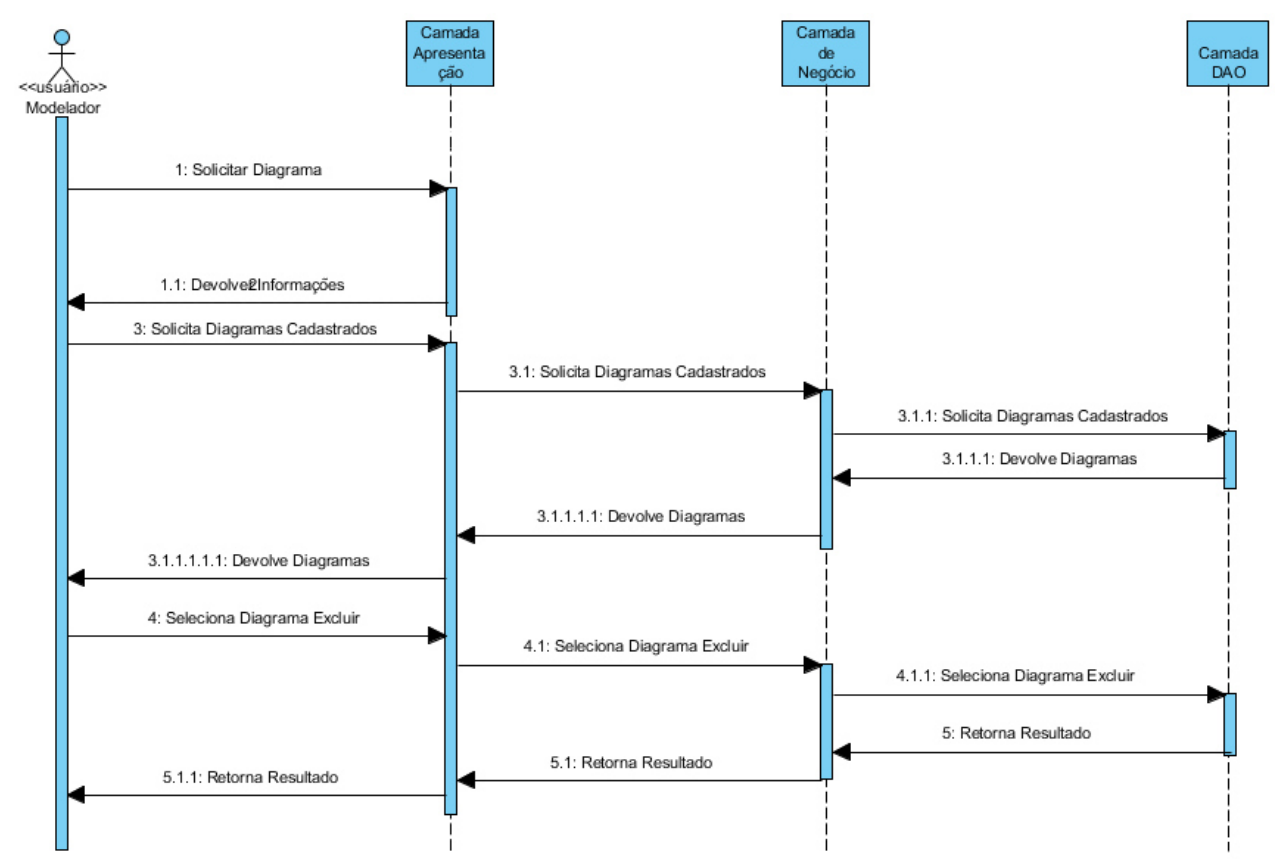

Figura C.6: Diagrama de Sequência - Exclusão

O diagrama de sequência de exclusão (apresentado na Figura C.6)é iniciado com o usuário solicitando o módulo do diagrama, esta solicitação é atendida pela camada de apresentação da aplicação. O usuário solicita a ferramenta todos os diagramas cadastrados, esta solicitação atravessa as camadas de apresentação, negócio e persistência, onde será feita a busca no banco e retornada ao usuário.

Após devolver todos os diagramas persistidos, o usuário seleciona o diagrama desejado para a exclusão e o mesmo é deletado pela camada de persistência. Após a exclusão do diagrama, uma mensagem de sucesso é apresentada ao usuário.

\section{C.2 DER}

O DER (Diagrama Entidade Relacionamento) é um modelo de diagrama que representa o modelo de dados em alto nível de abstração. A Figura C.7 ilustra o DER do projeto. 


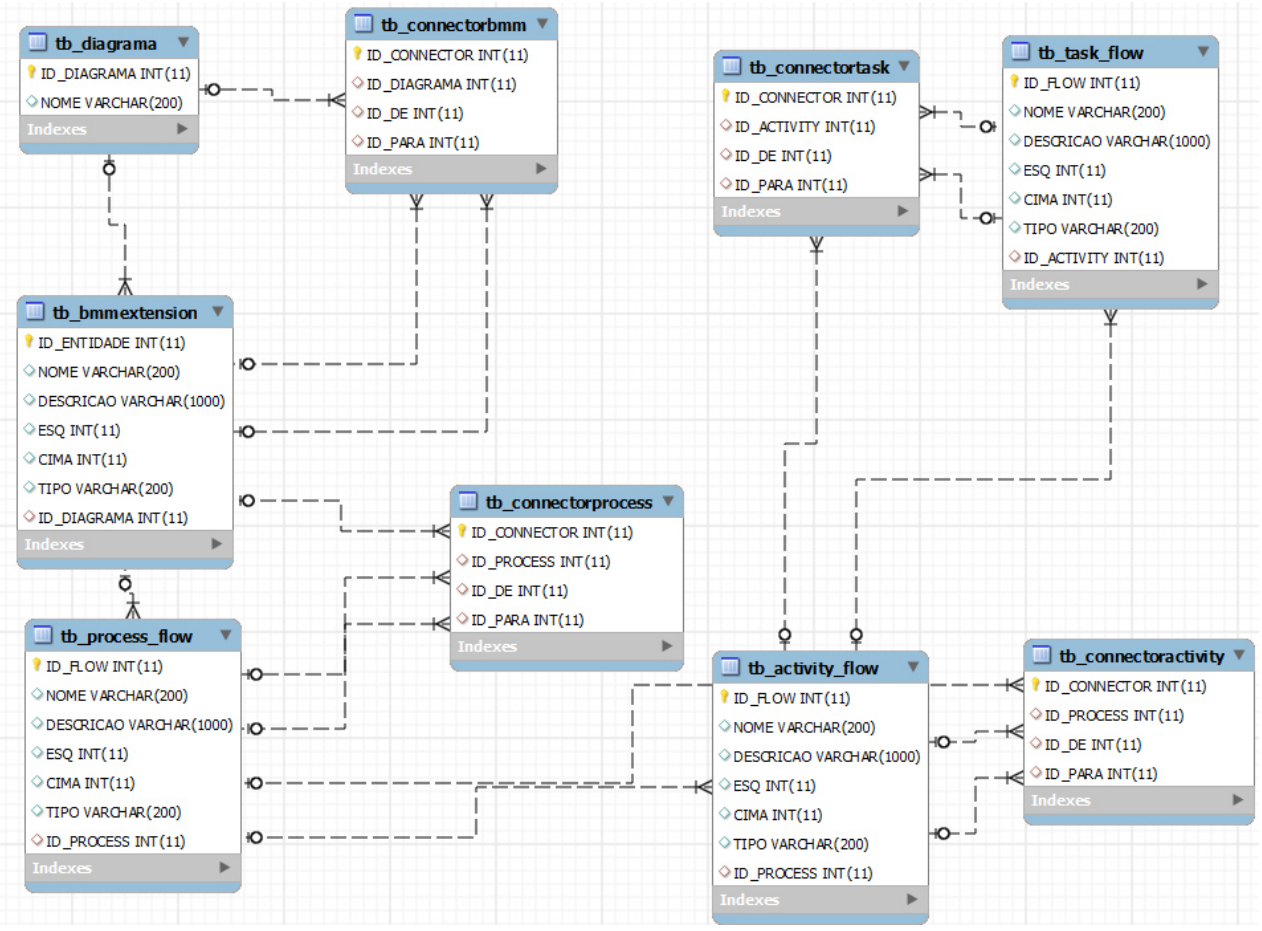

Figura C.7: Diagrama Entidade Relacionamento

\section{C.3 Codificação}

Esta seção possui a finalidade de destacar os pontos importantes da implementação da Ferramenta.

Como dito anteriormente, o GWT converte todo o código cliente desenvolvido em Java para Javascript, após esta conversão, o código é adicionado a uma Div dentro de um arquivo HTML criado pelo próprio projeto. Este arquivo como ilustra a Figura C.8 pode utilizar qualquer recurso HTML, Javascript, CSS entre outros.

Também é possível indicar pelo código fonte a posição ou Div que se deseja adicionar um determinado componente e utilizar um determinado estilo CSS definido no HTML ou em algum arquivo CSS.

Ao criar um projeto GWT, é definido o pacote src (abreviação de Source), no mesmo serão adicionados as classes Java do projeto. O pacote src é dividido em 3 partes, Client, Server e Shared.

Como dito anteriormente, todo o código fonte da camada cliente é convertido para Javascript. O código do pacote Server é executado no Servidor de aplicação. (O Tomcat é o servidor nativo utilizado pelo GWT para desenvolvimento). Por fim, a camada Shared possui a finalidade de criar classes que podem ser vistas em ambos os lados (Cliente e Servidor). 


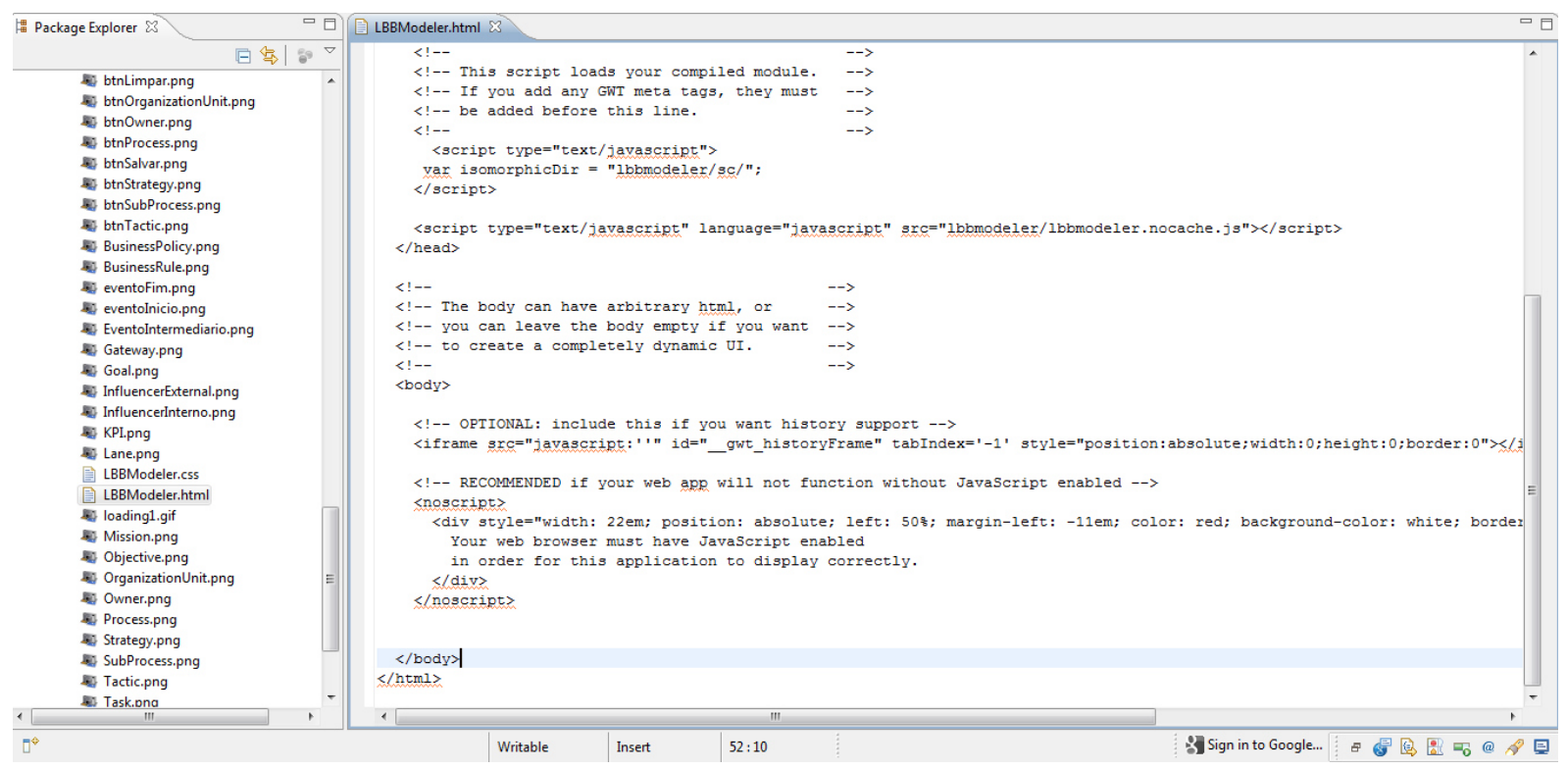

Figura C.8: HTML

O GWT constrói nativamente uma camada para testes unitários (pacote test) para garantir que o retorno dos métodos estejam de acordo com as expectativas. A API possui compatibilidade com o framework de teste unitário JUnit.

Ao gerar o projeto também é criada a pasta war que pode ser utilizada para geração de um arquivo (com extensão war) para a publicação da aplicação em um servidor de aplicação. A pasta war contém todos os HTMLs, CSSs, Códigos Javascript, figuras e qualquer outro tipo de dependência que o projeto precise para executar adequadamente.

O projeto possui também as bibliotecas nativas para a execução do GWT e as bibliotecas adicionadas especificamente para o projeto, como por exemplo o Hibernate. A Figura C.9 ilustra toda a aplicação com seus devidos empacotamentos.

Para iniciar o projeto, o compilador do GWT procura o método nativo onModuleLoad que é responsável pelo início do fluxo da aplicação.

Na Figura C.10 é ilustrada a implementação do método com a criação de um objeto diagramaDTO, criação de componentes de imagem e adição de evento de clique a um componente imagem. Dentro do evento é iniciada a criação de um componente Window(Pop-up) e alguns atributos deste componente são preenchidos.

Para efetuar uma chamada ao Servidor, é necessário implementar uma interface nativa do GWT para chamadas Assíncronas (Figura C.11). Por ser assíncrono, o código cliente não aguarda o processamento da requisição na chamada.

A resposta do servidor pode ser feita de duas formas, Sucesso ou Falha. Caso a chamada seja completada com sucesso, é possível definir um fluxo de atividades a serem desempenhadas após a chamada. Caso ocorra erro na chamada, também é possível efetuar um fluxo de tratamento da exceção lançada pela chamada ao Servidor. 


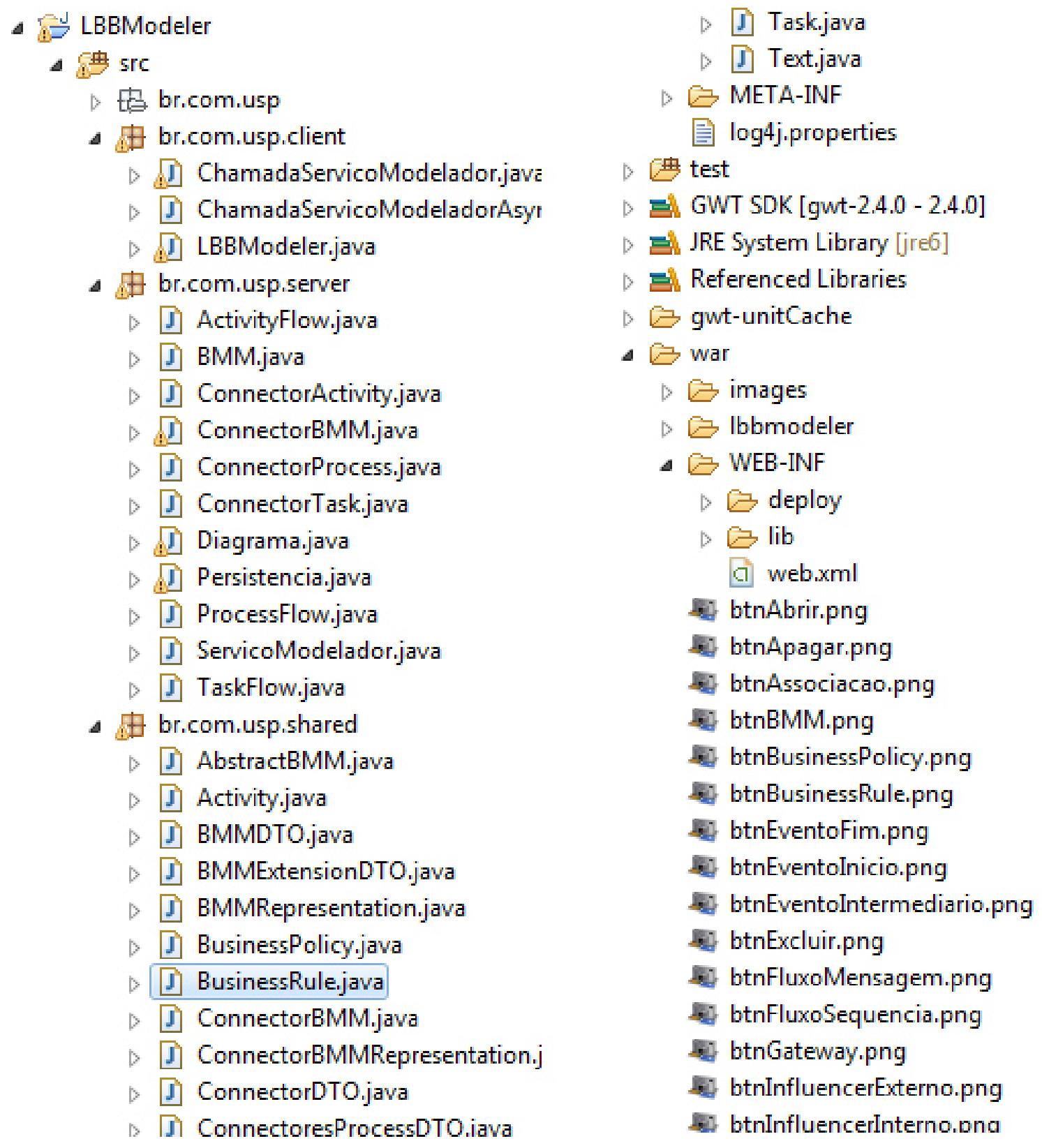

Figura C.9: Empacotamento

A chamada ao servidor ocorre como uma chamada de método convencional, é passado o nome do método e os parâmetros e pode (ou não) haver um objeto de resposta.

Na Figura C.12 ilustra como os Beans do projeto são relacionados com as tabelas no banco de dados (mapeamento objeto relacional em anotação).

Na primeira linha é relacionado com a anotação @Entity a tabela no banco de dados com a classe java implementada. A anotação @Id possui a finalidade de informar que aquele campo é uma chave primária, @GeneratedValue informa ao framework que o banco gera automaticamente o valor e @Column informa o nome da coluna na tabela do banco de dados. 


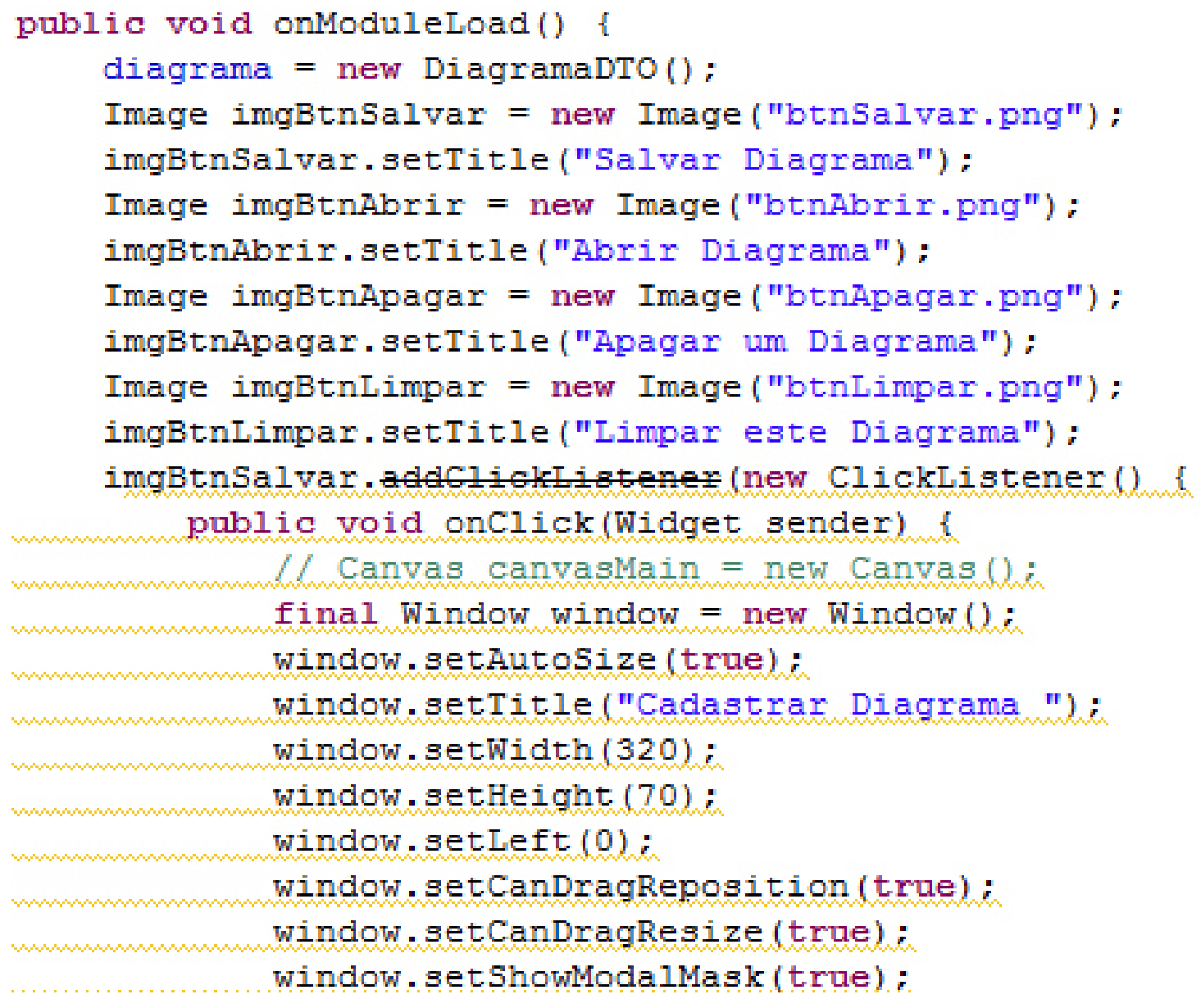

Figura C.10: Fonte Principal

$\oplus$ import java.util.List;

public interface ChamadaServicoModeladorAsync ?

public void salvarModelo (DiagramaDTO diagramaDTO, AsyncCallback<DiagramaDT0> callback) throws IllegalArgumentException:

public void listarDiagramas (AsyncCallback<List<DiagramaDTO>> callback) throws IllegalArgumentException;

public void buscarDiagrama (DiagramaDTo diagramaDTO, AsyncCallback<DiagramaDTO> callback) throws IllegalArgumentExceptio: public void apagarDiagrama (DiagramaDTo diagramaDTO, AsyncCallback<Void> callback) throws IllegalArgumentException;

Figura C.11: Asynchronous Callback

O mapeamento@OneToMany indica que a classe Diagrama possui diversos objetos da classe BMM e ConnectorBMM. 


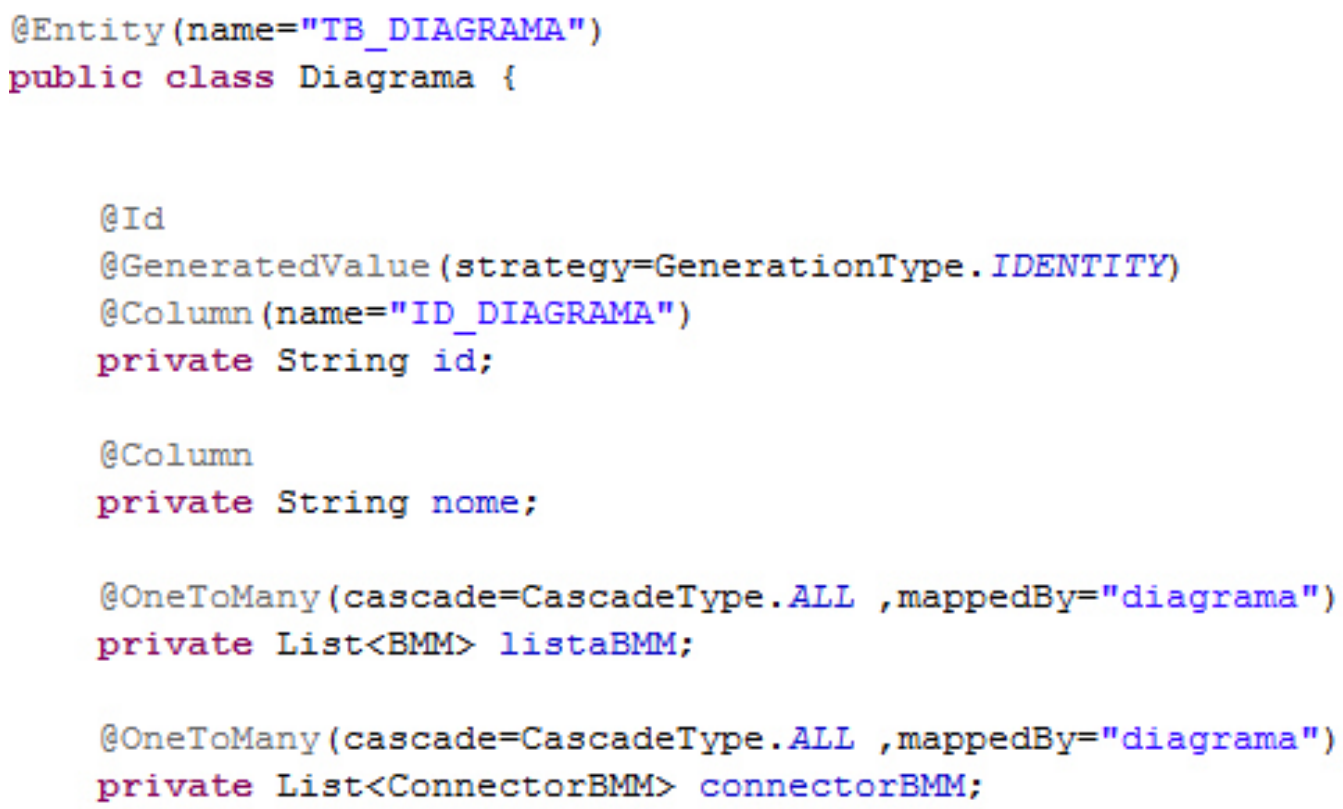

Figura C.12: Annotation 